\title{
Social psychological determinants of health risk behaviors related to cancer and CVD : applications and elaborations of the ASE model
}

Citation for published version (APA):

Lechner, E. H. S. (1998). Social psychological determinants of health risk behaviors related to cancer and CVD : applications and elaborations of the ASE model. [Doctoral Thesis, Maastricht University]. Universiteit Maastricht. https://doi.org/10.26481/dis.19980508el

Document status and date:

Published: 01/01/1998

DOI:

10.26481/dis.19980508el

Document Version:

Publisher's PDF, also known as Version of record

Please check the document version of this publication:

- A submitted manuscript is the version of the article upon submission and before peer-review. There can be important differences between the submitted version and the official published version of record.

People interested in the research are advised to contact the author for the final version of the publication, or visit the DOI to the publisher's website.

- The final author version and the galley proof are versions of the publication after peer review.

- The final published version features the final layout of the paper including the volume, issue and page numbers.

Link to publication

\footnotetext{
General rights rights.

- You may freely distribute the URL identifying the publication in the public portal. please follow below link for the End User Agreement:

www.umlib.nl/taverne-license

Take down policy

If you believe that this document breaches copyright please contact us at:

repository@maastrichtuniversity.nl

providing details and we will investigate your claim.
}

Copyright and moral rights for the publications made accessible in the public portal are retained by the authors and/or other copyright owners and it is a condition of accessing publications that users recognise and abide by the legal requirements associated with these

- Users may download and print one copy of any publication from the public portal for the purpose of private study or research.

- You may not further distribute the material or use it for any profit-making activity or commercial gain

If the publication is distributed under the terms of Article $25 \mathrm{fa}$ of the Dutch Copyright Act, indicated by the "Taverne" license above, 


\section{Social psychological determinants of health risk behaviors related to cancer and CVD}

Applications and elaborations of the ASE model 


\title{
Social psychological determinants of health risk behaviors related to cancer and CVD
}

\author{
Applications and elaborations of the ASE model
}

\author{
Proefschrift
}

ter verkrijging van de graad van doctor

aan de Universiteit Maastricht, op gezag van de Rector Magnificus,

Prof. dr. A.C. Nieuwenhuijzen Kruseman, volgens het besluit van het College van Dekanen, in het openbaar te verdedigen op vrijdag 8 mei 1998 om 14.00 uur

door

Elisabeth Hubertina Sophia Lechner

geboren te Roermond op 4 oktober 1967 


\section{Promotores:}

Prof. dr. H. de Vries

Prof. dr. G.J. Kok

\section{Thesis Committee:}

Prof. dr. ir. P.A. van den Brandt (chairman)

Prof. dr. G. Godin (Laval University, Canada)

Dr. R.A. Knibbe

Prof. dr. F.J.N. Nijhuis

Prof. dr. E. Seydel (University of Twente)

Lechner, Lilian

Social psychological determinants of health risk behaviors related to cancer and CVD: Applications and elaborations of the ASE model

ISBN: 90-5681-033-2

Cover design by Unigraphic, Maastricht

Printed by Unigraphic, Maastricht

The study presented in this thesis was performed at the Maastricht Health Research Institute for Prevention and Care (HEALTH), which participates in the Netherlands School of Primary Care Research ( $\mathrm{CaRe})$, acknowledged in 1995 by the Royal Dutch Academy of Science (KNAW).

All studies were conducted with financial support from the Dutch Cancer Society. The studies described in Chapter 3 and 4 were financially supported by the Netherlands Heart Foundation. The printing of this thesis was financially supported by the Dutch Cancer Society and the Netherlands Heart Foundation. 


\section{Contents}

General introduction

Chapter 1 Analysis of the health problem Cancer, CVD, and their lifestyle related risk behaviors

Chapter 2 Determinants of health risk behaviors: Review of the models

Chapter 3 Starting participation in an employee fitness program: Attitudes, Social Influence and SelfEfficacy

Chapter 4 Maintaining participation in an employee fitness program: Determinants of high adherence, low adherence and dropout

Chapter 5 Attitudes according to the theory of reasoned action: Do we need to include evaluations?

Chapter 6 Misconception of fruit and vegetable consumption: Differences between objective and subjective estimation of intake

Chapter 7 Stages of change for fruit, vegetables and fat intake:

Consequences of misconception

Chapter 8 Participation in a breast cancer screening program: Influence of past behavior and determinants on future screening participation

Chapter 9 Main conclusions and general discussion

References

Summary

Samenvatting

Acknowledgments 


\section{GENERAL INTRODUCTION}

In recent decades, increasingly more emphasis has been placed on primary and secondary prevention of the major health diseases of cancer and cardiovascular diseases (CVD) (Bailar \& Gornik, 1997). This shift from treating patients toward preventing diseases has been caused by an increased knowledge in the last decades of the behavioral causes of several of the major diseases. We now know that several behaviors that people engage in, can be seen as being major contributors of the possible risks for developing diseases such as cancer or CVD (Bailar \& Gornik, 1997; Doll \& Peto, 1981). Behaviors such as smoking, eating too much fat or too few fruit and vegetables, and having too little physical exercise are recognized as being important lifestyle risk behaviors for both cancer and CVD (Doll \& Peto, 1981; Ruwaard \& Kramers, 1997).

However, not with all diseases are the health risk behaviors that cause them that obvious. Moreover, in some diseases health risk behaviors play only a relatively small role in the development of the disease. Other non-behavioral causes are also involved that may influence the origin of certain diseases. For instance, risk factors for the development of breast cancer in women are often of non-behavioral origin, for example, age, hereditary factors or the age of bearing children (Curry \& Emmons, 1994). In diseases where primary prevention proves to be difficult, or with diseases that are highly prevalent in certain risk groups, secondary prevention or early detection has proven to be of major importance (Bailar \& Gornik, 1997). With early detection it is possible to detect a disease at such an early stage that the possible health loss can be minimized, and consequently lives can be saved (Bailar \& Gornik, 1997; Ruwaard \& Kramers, 1997). Although behavioral factors are of less relevance in the cause of breast cancer, behavior does play an important role with the practice of secondary prevention. Breast self-examination and participation in a breast cancer screening program are also health behaviors that women can choose to perform or not. Hence, even though developing breast cancer can hardly be influenced, the behavior of practicing early detection techniques can.

This illustrates that lifestyle behaviors can be important in both primary and 
secondary prevention of diseases. In trying to influence these health behaviors it is important to develop interventions that are based on thorough, systematic research and on theoretical insights into the best ways that behavior can be influenced. Planning models provide a theoretical framework on how to develop, implement and diffuse health education interventions with a systematic approach.

\section{The ABC-planning model}

The ABC planning model (De Vries, 1989; De Vries \& Dijkstra, 1993; De Vries \& Willemsen, 1996) is an integration of several different theoretical insights, such as the planning models of Bracht (1990), Kok (1985), and Rogers (1983). The model distinguishes three phases of importance in the process of successful health education: analysis of the health problem; initiation of behavioral change; and continuation of health education and behavioral change (see Figure 1). The three phases of the $A B C$ planning model do not necessarily succeed each other. In reality, the same emphasis should be placed on all three phases simultaneously, since results from one phase can influence the other phases.

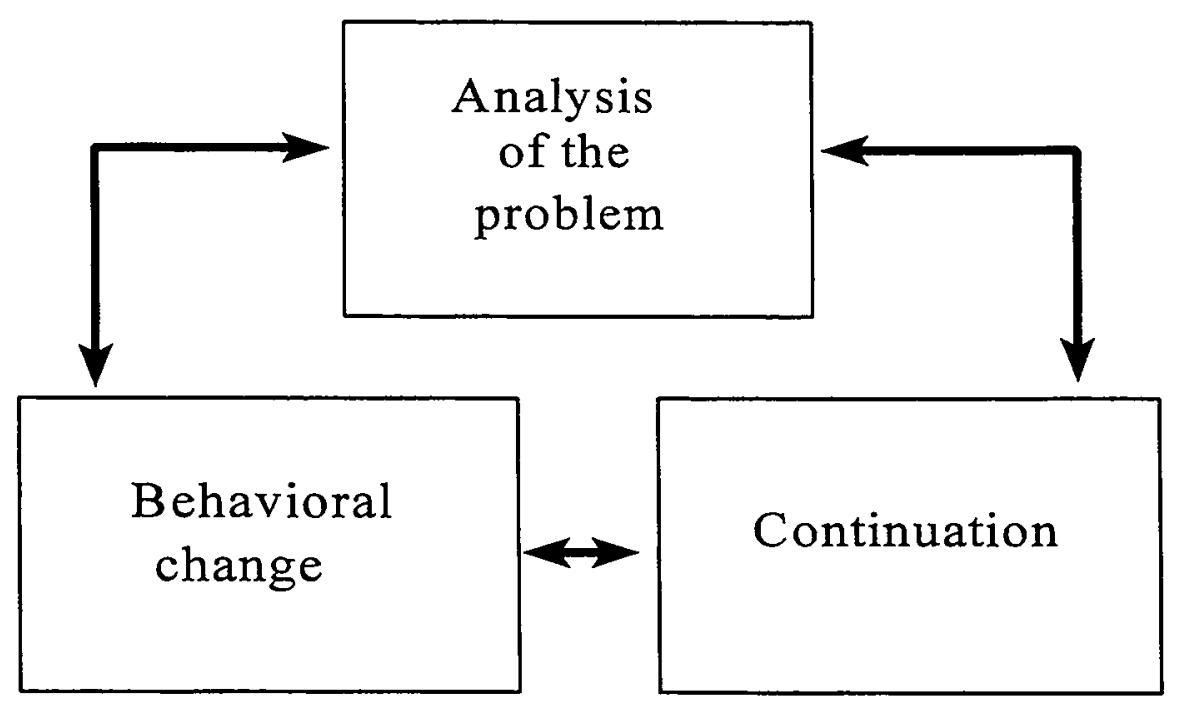

Figure 1: The ABC-planning model (De Vries, 1989) 
The first phase of the ABC-model is based on the PRECEDE-PROCEED model of Green and Kreuter (1991). In this phase, analysis of the health problem is the central issue. This analysis phase can be divided into several steps. First, a diagnosis is made of the existing health problems. These possible problems should be analyzed in a social and epidemiological context. Second, if health problems are identified, there should be a diagnosis of the factors that are related to these health problems and the health promotion actions that can be undertaken to change these factors. Once the relevant behaviors are identified, the next step is to identify certain populations in which the risk behaviors are most prevalent or who have not been targeted before. These populations then become target populations. When both the risk behavior and the target population are known, the next step is to identify possible motivational determinants of the risk behavior in the target population that was chosen in the previous step. This step is essential to find possible indications as to how the risk behavior can be changed. Possible elaborations on this step are the main focus of this thesis. This thesis restricts the determinants that are being studied to motivational or social psychological determinants. Next to these, other determinants (e.g. biological, cultural, environmental) can also influence health risk behaviors (Green \& Kreuter, 1991). However, these determinants are not the focus of this thesis. When the social psychological determinants of the risk behavior have been analyzed a decision is made on which of the determinants can be changed using a health promotion intervention. Following that, an analysis is done to determine the best way in which the target group and possible intermediaries can be reached.

The second phase, behavioral change, can be divided into three different steps. The first step is to set clear objectives for the health promotion intervention. These objectives describe the determinants and risk behavior that the intervention is supposed to change and to what degree these determinants and the risk behavior should be changed. Setting clear and measurable objectives is an essential condition for setting up a solid evaluation design that can measure possible intervention effects. When objectives have been set, the next step is to choose the best theoretical and practical strategies to attain these objectives. During this program development step, pretesting of program components forms an important method to monitor 
the quality of the intervention. Once the intervention has been developed and pretested thoroughly, the program needs to be evaluated on its effects in pilot studies that use experimental or quasi-experimental evaluation designs with control groups.

Once the intervention has proven to be effective, continuation of the intervention on a larger scale should be ensured in the next phase. In this process of continuation and diffusion of a program, several aspects are of importance (Orlandi, Weston et al., 1990; Rogers, 1983). Firstly, it is necessary to get cooperation and collaboration from the different people involved and relevant organizations, such as future user groups and program developers. This is achieved by using the linkage approach (Orlandi, Weston et al., 1990). Secondly, diffusion strategies should be used to diminish possible barriers that can prevent the intervention being implemented on a larger scale. Finally, it is important to use supportive strategies, such as legislation, in order to provide the best possible conditions for continuation of the program.

\section{Outline of the thesis}

This thesis focusses on the first phase of the $\mathrm{ABC}$ planning model, the analysis of the problem. In the first chapter, the diseases cancer and CVD will be analyzed in the context of the different lifestyle risk behaviors involved. This thesis restricts the health behaviors that are being studied to typical lifestyle behaviors (e.g., eating, exercising, smoking, etc.). Health risk behaviors that are less lifestyle related (e.g., working with carcinogenic substances, etc.), are not included in this thesis. In the first chapter, an overview will be given of the most important lifestyle risk behaviors for cancer and CVD. For all these risk behaviors their relation with cancer and CVD will be discussed, followed by the definition or recommendation of when these behaviors are healthy or unhealthy, and the prevalence of these risk behaviors among the general population.

Subsequently, the determinants of some of these health risk behaviors will be the main focus of this thesis. In doing this, the central theory used in this thesis is the Attitude - Social influence - self-Efficacy (ASE) model (De Vries, Dijkstra et al., 1988). In the second chapter, an overview will be given of some of the theories that 
can be used to study behavioral determinants: the Theory of Reasoned Action (Fishbein \& Ajzen, 1975), the Theory of Planned Behavior (Ajzen, 1991), and the ASE model. Recent developments and possible modifications of the models will be reviewed. Other models that can be used to understand behavioral change, such as the stages of change construct of the Transtheoretical Model (TTM) from Prochaska and colleagues (Prochaska \& DiClemente, 1983; Prochaska, Norcross et al., 1994) will also be included in the overview of the second chapter.

For this thesis, several studies were conducted to discover to what extent the ASE model can be elaborated with other theoretical insights when applying it for explaining and understanding health risk behaviors related to cancer and CVD (Table 1).

Table 1: Overview of the studies presented in this thesis, with regard to the design, data collection (w.q. $\approx$ written questionnaire; t.q. = telephone questionnaire), number of subjects, and main objective of the study

\section{Data}

Chapter Design Collection N Main objective of the study

\begin{tabular}{|c|c|c|c|c|}
\hline Ch 3: study 1 & cross-sectional & w.q. & 488 & - testing combination stages/ASE \\
\hline \multirow[t]{2}{*}{ Ch 4: study 2} & longitudinal & w.q. & 236 & - testing combination stages/ASE \\
\hline & & & & - additional self-efficacy measure \\
\hline Ch 5: study 3 & longitudinal & w.q. & 488 & - testing multiplicative function \\
\hline \multirow[t]{2}{*}{ Ch 6: study 4} & cross-sectional & t.q. & 367 & - assessing misconception behavior \\
\hline & & & & - consequences for ASE model \\
\hline \multirow[t]{2}{*}{$\mathrm{Ch} 7:$ study 5} & cross-sectional & t.q. & 402 & - assessing misconceprion behavior \\
\hline & & w.q. & 689 & - consequences for stages of change \\
\hline \multirow[t]{3}{*}{ Ch 8: study 6} & longitudinal & w.q. & 395 & - testing modifications: anticipated \\
\hline & & & & regret, moral obligation, past \\
\hline & & & & behavior \\
\hline
\end{tabular}


The thesis will discuss the consequences of modifying and integrating new aspects in the ASE model (such as the stages of change), and applying this combined model to several health risk behaviors. Furthermore, the thesis will discuss possible expansions or limitations of the model when applied to specific health risk behaviors. The different studies used in this thesis are summarized in Table 1. In Chapter 9, the main findings and conclusions of the different studies will be discussed. 


\section{CHAPTER 1}

\section{Analysis of the health problem \\ Cancer, cvd, and their lifestyle related risk behaviors}

\section{INTRODUCTION}

The chronic diseases of cancer and cardiovascular diseases (CVD) constitute the most important causes of death and illness within the Netherlands (Van der Sanden, Van Barneveld et al., 1994) as well as within most European countries and North America (Kris-Etherthon, Volz-Clarke et al., 1990). In the Netherlands both diseases are accountable for more than $60 \%$ of all mortality (Van der Sanden, Van Barneveld et al., 1994). Therefore, during their life, almost everyone will in some way be involved with one or both of these diseases: directly as a patient or indirectly through having a close relative or friend who is or was a patient.

In the Netherlands, CVD is the main cause of death, responsible for some 40\% of total mortality in 1993 (Van der Sanden, Van Barneveld et al., 1994). Cancer is the second main cause of all mortality in the Netherlands. Around $25 \%$ of total mortality in 1993 was caused by cancer (Van der Sanden, Van Barneveld et al., 1994). Moreover, for the age group 45 to 60 years, cancer is the most important cause of death (Van der Sanden, Van Barneveld et al., 1994). Although relative mortality rates for both CVD and cancer might decrease due to improved medical care, prevention activities and early detection methods, the incidence, prevalence, and total mortality of both diseases are not expected to decline, due to the increasing age of the Dutch population (Dutch Cancer Society, 1997; Ruwaard \& Kramers, 1993).

For both CVD as well as cancer there are several lifestyle behaviors that can play an important role in the prevention and early detection of these diseases. The most important lifestyle behaviors that form possible risk factors for getting CVD or cancer are smoking, lack of exercise, an unhealthy diet, drinking too much 
alcohol and overexposure to UV-radiation. Other lifestyle behaviors can have an influence on detecting a chronic disease such as cancer or CVD at an early time, for example, participating in a cancer screening program or practicing early detection methods. Each of these behaviors is differently related to either CVD or cancer (Table 1.1). Some of these more important risk behaviors and their associations with CVD or cancer will be briefly surveyed. With respect to each risk behavior, information will be reported on three levels. First, the epidemiology of the relation of these behaviors with cancer and CVD will be discussed. Second, a definition or recommendation will be given of what is considered to be healthy or unhealthy with regard to the different behaviors. Third, the prevalence of the risk behaviors in the Netherlands will be reported. A distinction will be made between primary and secondary prevention for each different risk behavior.

Table 1.1: Relation of health risk behavior with cancer and CVD

\begin{tabular}{|c|c|c|}
\hline & Cancer & CVD \\
\hline \multicolumn{3}{|l|}{ primary prevention } \\
\hline smoking & $* * *$ & $x * *$ \\
\hline too much fat consumption & * & $* * * *$ \\
\hline lack of fruit $\&$ vegetable consumption & $* * *$ & $* *$ \\
\hline sedentarism (lack of exercise) & $* *$ & $* * *$ \\
\hline excessive UV-exposure & $* *$ & \\
\hline excessive alcohol consumption & $* *$ & $4 *$ \\
\hline \multicolumn{3}{|l|}{ secondary prevention } \\
\hline early detection & *t; & $* *$ \\
\hline screening participation & $* * *+\infty$ & \\
\hline
\end{tabular}

In this chapter, not all possible behaviors that are related to primary and secondary prevention of cancer and CVD are reviewed. Only the most important 
lifestyle related behaviors are included. Especially the risk behaviors smoking, physical inactivity, consumption of too much (saturated) fat and consumption of too little fruit and vegetables are considered to be strongly related to cancer and CVD (Ruwaard \& Kramers, 1997). Behaviors such as genetic screening or screening for cholesterol levels are not included, since these screenings have not been implemented in national screening programs and are still only of relevance for very specific groups.

\section{PRIMARY PREVENTION}

\section{PHYSICAL ACTIVITY}

\section{Relation with cancer and CVD}

The relation between physical activity and health is of a complex nature. Physical fitness forms an important link between the two. Physical activity is a behavior, while physical fitness can be seen as a consequence of this behavior which can influence health. Therefore, promoting physical activity presents a pathway for preventing health problems. Getting enough physical activity can influence a wide variety of diseases, which can be of a physical or psychological nature. Even though physical activity can be considered as a possible risk factor for getting injuries (Nicholl, Coleman et al., 1995; Van Mechelen, 1992), people who are physical active, have a longer life expectancy than inactive persons (Blair, Kohl et al., 1989). Physical inactivity forms an independent risk factor for getting CVD (Bijnen, Zonderland et al., 1991). The relative risk of coronary heart disease associated with physical inactivity ranges from 1.5 to 2.4 , an increase in risk comparable with that observed for smoking (Centers for Disease control and Prevention, 1993; Powell, Thompson et al., 1987). Furthermore, there is a growing body of evidence to suggest that physical exercise prevents certain forms of cancer (Blair, Kohl et al., 1993; Powell, Caspersen et al., 1989; Shepard, 1996), such as breast cancer (Bernstein, Henderson et al., 1994; Freidenreich \& Rohan, 1995a; 1995b; Hoffman 
\& Husted; 1994; Shepard \& Shek, 1995) and colon cancer (MacFarlane \& Lowenfels, 1994; Shepard \& Shek, 1995; Shepard, 1996). Physical exercise is also related to other determinants of general health and is clearly related to a generally healthy lifestyle. People who are physical active have more control over their bodyweight and their energy intake, smoke less often, and have a lower mean alcohol intake (Bouchard, Shepard et al., 1988).

\section{Definition or recommendation of healthy bebavior}

A consensus seems to be developing with regard to the recommendations on how physical active people should be (Backx, Swinkels et al., 1994). With regard to general health and the prevention of CVD, people are recommended to exercise at least three times a week for about 20 to 30 minutes. This exercise should be at an intensity of around 50 to $80 \%$ of people's individual maximum ability (Astrand, 1992). The intensity should be at a level that one is just able to still have a normal talk. The major muscle groups should be dynamically active (for example, jogging, having a brisk walk, swimming, bicycling) (American College of Sports Medicine, 1990). Adults are considered to be inactive when they are not in adherence with this recommendation (Peeters, Bijnen et al., 1993). When adults are not in adherence with this recommendation they have a higher risk of getting CVD and having a poor general health. However, in recent years it has been recognized and accepted that having only a moderate daily activity level (for example, walking, gardening, etc.) can already have a substantial influence on reducing the health risk for getting CVD or cancer (Peeters, Bijnen et al., 1993; Pate, Pratt et al., 1995). Consequently, the recommendation to exercise at least three times a week for about 20 to 30 minutes per session at an intensity of $50-80 \%$ of people's individual maximum ability, could be considered to be replaced by a less intensive recommendation to participate in a more moderate level of physical activity on a regular base (regular being almost everyday).

\section{Prevalence of risk behavior}

Depending on the operationalization and measurement methods used, we find a large variance in the percentage of inactive subjects in the Netherlands 
(Caspersen, Bloemberg et al., 1991; Verschuur \& Kemper, 1983). This makes a good interpretation of these studies difficult. Physical activity declines continuously as age increases (Caspersen, Pollard et al., 1987; Caspersen \& Merrit, 1992). The average physical activity for both men and women is highest before the fifteenth year and seems to stay below the recommendations afterwards (Backx, Swinkels et al., 1994; De Roos and Oude Vrielink, 1992). De Roos and Oude Vrielink (1992) reported in a Dutch study that the percentage that exercises less than once a week, varies from $28 \%$ in the youngest age group (16-24 years) to $54 \%$ in the oldest age group $(65+)$. This study showed that around one quarter of all adults within the Netherlands report being hardly or not at all physically active, both during work as well as during their leisure time. A health survey in 1990-1991 (Backx, Swinkels et al., 1994) reported that more than one third (34\%) of the adult Dutch population $(16+)$ has a nearly totally inactive lifestyle in their spare time. This percentage of inactivity is lowest in the age group $16-24$ years $(25 \%)$ and rises to $56 \%$ for the age group older than 65 years. Results showed that almost $43 \%$ of all adults are to some extent active in their spare time, but not enough according to the recommendations of exercising three times a week for 20 to 30 minutes. Less then one quarter of Dutch adults (23\%) meet this recommendation (Backx, Swinkels et al., 1994). In all age groups men reported being more physically active than women (Backx, Swinkels et al., 1994). A recent review of Dutch studies with respect to physical activity in the Netherlands reported that between $34 \%$ and $46 \%$ of the Dutch adult population were physically inactive (not engaged in sports or other forms of physical exercise) (Ruwaard \& Kramers, 1997).

The Dutch percentages of inactivity are comparable to other Western countries. The United States reported that $56 \%$ of all men and $62 \%$ of all women were considered to be physically inactive according to the recommendations ( 20 minutes of activity at least three times a week). A considerable part of the population (25\% of all men, $30 \%$ of all women) were nearly totally inactive during their spare time (Caspersen, Christenson et al., 1985). Also, in countries such as Belgium (65\%) and New-Zealand (60\%), large parts of the adult population were insufficiently physically active according to the recommendations (20 minutes of activity at least three times a week) (Bijnen, 1990). 


\section{SMOKING}

\section{Relation with cancer and CVD}

Smoking is the leading cause of preventable morbidity and mortality in the Netherlands. This risk behavior is clearly related to both cancer and CVD, but also to a wide variety of other diseases. In 1994, 59\% of all deaths from the chronic diseases chronic obstructive pulmonary disease, lung cancer, coronary heart disease and stroke were attributed to smoking (Dutch Foundation on Smoking and Health, 1995). In 1994, almost 29,000 deaths from these diseases could be ascribed to people's smoking behavior (Dutch Foundation on Smoking and Health, 1995). Analysis of Dutch national statistics showed that among people from the age group 35 to 69 years, $42 \%$ of all premature deaths were attributed to smoking (Peto, Lopez et al., 1992).

\section{Definition or recommendation of healthy behavior}

Recommendations for the risk behavior smoking are very clear: people should not smoke (Dutch Foundation on Smoking and Health, 1996). Where there seems to be a sliding scale between what is considered to be healthy and unhealthy for behaviors such as nutrition, exercise, or alcohol intake, this difference between healthy and unhealthy behavior is very clear with respect to smoking. Smoking is always unhealthy, even if only a few cigarettes are smoked a day (U.S. Department of Health and Human Services, 1983; 1984).

\section{Prevalence of risk behavior}

Smoking behavior in the Netherlands has a relatively high prevalence. Of all adults in the Netherlands, 35\% smoked in 1995. Men (39\%) smoked more often than women (31\%) (Dutch Foundation on Smoking and Health, 1996). Smoking is highest among the age group 20 to 49 years; in which around $42 \%$ of all men and $37 \%$ of all women smoke (Dutch Foundation on Smoking and Health, 1996). Compared to other European countries, the Netherlands has a relatively high smoking prevalence (Joossens, Naet et al., 1994; Ruwaard \& Kramers, 1993). 


\section{NUTRITION}

\section{Relation with cancer and CVD}

Dietary habits are thought to account for approximately $35 \%$ of all cancer deaths (Doll \& Peto, 1981). Within this diet both fruit and vegetables as well as fat intake play an important role.

A review of the epidemiological evidence on the relation between consuming fruit and vegetables and the prevention of cancer (Block, Patterson et al., 1992) showed that the consumption of fruit and vegetables has a protective effect on cancers at various locations, and especially on cancers of the respiratory and digestive tracts, such as lung cancer and colon cancer (Benito, 1992; Block, 1991). For most of these cancers, persons with low fruit and vegetable intake have about twice the risk of getting cancer, compared to persons who have a high fruit and vegetable intake (Block, Patterson et al., 1992). In recent years, several studies have also suggested a relation with high fruit and vegetable intake and a lowered risk of CVD (Bolton-Smith, Woodward et al., 1991; Hertog, Feskens et al., 1993).

For fat intake, the relation with the risk of getting cancer is less evident. Studies of high fat intake and an increased risk for getting breast cancer have suggested that there might be a relation (Rohan \& Bain, 1987; Van ' $t$ Veer, 1990). However, the results are inconclusive, especially because of the publication of prospective studies that failed to confirm the relation between total fat consumption and a higher cancer risk (Ossendorp, Ypma et al., 1993; Van den Brandt, Van 't Veer et al., 1993; Willet, Hunter et al., 1992). The relation between fat intake and the risk of colon cancer seems clearer: according to a recent literature review, a diet high in meat, fat and protein is important in the etiology of colon cancer (Potter, 1995). The relation between fat intake and the prevention of CVD is much clearer and undisputed: the more (saturated) fat people eat, the higher their risk of getting CVD is (Dutch Nutrition Council, 1986; Mensink, Zock et al., 1994; Shrapnel, Calvert et al., 1992).

\section{Definition or recommendation of bealthy behavior}

Dietary recommendations have been developed for both fruit and vegetable 
intake, as well as for fat intake. For fruit and vegetable intake the Netherlands Food and Nutrition Education Bureau recommends that adults should eat 2 pieces (or more) of fruit each day (approximately 200 grams) and 150 to 200 grams of vegetables each day (Netherlands Food and Nutrition Education Bureau, 1993). For daily fat intake the Dutch Nutrition Council recommends that adults should reduce their daily amount of fat intake to $30-35 \%$ of calories (by especially limiting the amount of saturated fat) (Dutch Nutrition Council, 1986; Hulshof, Löwik et al., 1993).

\section{Prevalence of risk bebavior}

The actual dietary intake of fruit and vegetables in the Netherlands is far below the recommendations for fruit and vegetables, whilst fat intake is above the recommendations. With regard to fruit and vegetables, a recent study reported that the consumption of fruit and vegetables has declined between 1988 and 1993 by some 10\% (Netherlands Food and Nutrition Education Bureau, 1993). This study reported that the average daily consumption for fruit was 114 grams, while the average daily consumption of vegetables was 128 grams (Netherlands Food and Nutrition Education Bureau, 1993). Both amounts suggest that a large proportion of the Dutch population do not meet the recommendations. It was estimated from a national food consumption survey in the Netherlands that $61 \%$ of the adult Dutch population do not consume enough vegetables, while $76 \%$ do not consume enough fruit (Ruwaard \& Kramers, 1997).

The mean average fat intake in the Netherlands is $37 \%$ of calories (Hulshof, Löwik et al., 1994; Netherlands Food and Nutrition Education Bureau, 1993). Although the average fat consumption of the Dutch population has declined somewhat in recent years (Hulshof, Löwik et al., 1993), a large proportion of the Dutch population still eat too much (saturated) fat. A national food consumption survey in the Netherlands estimated that $92 \%$ of the adult Dutch population consume too much (saturated) fat (Ruwaard \& Kramers, 1997). 


\section{UV-EXPOSURE}

\section{Relation with cancer and CVD}

In the Netherlands, there are 19,000 new cases of skin cancer every year. These cancers are mostly the less dangerous basal cell carcinoma, followed by squamous cell carcinoma and then the most dangerous, melanoma (Van der Sanden, Van Barneveld et al., 1994). Annual deaths from melanoma, the most dangerous form of skin cancer, has shown a strong increasing trend in the Netherlands; in 1990, mortality rose to a fivefold of the mortality of 1950 . This increase was apparent in all age groups (Van der Sanden, Van Barneveld et al., 1994). In 1993, 388 people died of melanoma, and 84 people died of other forms of skin cancer in the Netherlands (Visser, Coebergh et al., 1996). Moreover, the incidence of melanoma increased dramatically between 1975 and 1990, for women even more strongly (300\%) than for men (85\%) (Van der Sanden, Van Barneveld et al., 1994). In recent years, melanoma has been one of the three most prevalent cancers among the younger age groups (15-44 years), for both men and women (Van der Sanden, Van Barneveld et al., 1994; Visser, Coebergh et al., 1996).

This increasing incidence and mortality of melanoma in general is being linked to an increase in exposure to ultraviolet (UV-)radiation from sunlight, whereby skin that is usually covered is being exposed to UV-radiation more frequently (Stiggelbout, Leeuwen et al., 1989). In recent years, the relation between excessive exposure to UV-radiation and the origin of skin cancer has become clearer (Marks \& Hill, 1992; McCarthy \& Shaw, 1989). Research has shown that both melanoma and non-melanoma are related to UV-exposure. Melanoma seems related to more incidental excessive recreational UV-exposure, resulting in sunburns (Elwood \& Gallagher, 1993; Evans, Kopf et al., 1988; Marks \& Hill, 1992), while non-melanoma is mostly related to the total amount of absorbed UV-radiation during life time (Keesling \& Friedman, 1987; Elwood \& Gallagher, 1993).

Excessive exposure to UV-radiation is not only a risk in countries with a more (sub-)tropical climate. Also in Western Europe, skin cancer is recognized as a form of cancer that deserves priority within prevention (MacKie, Osterlind et al., 1991; MacKie \& Rycroft, 1982; Osterlind, Tucker et al., 1988). Moreover, recent 
studies show that due to the recent and expected decline in the ozone layer it is expected that the chance of getting overexposed to harmful UV-radiation will increase in the near future (Gezondheidsraad, 1994; Kelder, 1994; RIVM, 1993).

Besides the sun, the use of sunbeds is an important additional source of UVradiation in the Netherlands (Stiggelbout, Leeuwen et al., 1989). Although many of the sunbeds mostly use UV-A radiation instead of the more harmful UV-B radiation, using sunbeds is not without risks. Since large amounts of UV-A radiation are needed to cause pigmentation of the skin, the large amounts of UV-A radiation from sunbeds can also be harmful to the skin (Autier, Dore et al., 1994; Van Loveren, 1994; Schmitz, Garbe et al., 1994; Svenoe, Falks et al., 1995). Recent studies have found clear indications for an increased risk of getting melanoma for people who regularly use sunbeds (Armstrong \& Kricker 1995; Autier, Joarlette et al., 1991; Autier, Dore et al., 1994; Swerdlow, English et al., 1988; Walter, Marret et al., 1990; Westerdahl, Olsson et al., 1994).

\section{Definition or recommendation of bealthy behavior}

The burning of the skin, as a result of excessive exposure to UV-radiation, is an important risk factor for getting skin cancer (Armstrong, 1988; Arthey \& Clarke, 1995; Hill, White et al., 1992). To reduce the risk of getting skin cancer, excessive exposure to UV-radiation, resulting in sunburns of the skin, should be avoided (Hill, White et al., 1992). Several behaviors can decrease this risk of excessive exposure or sunburns. The Dutch Cancer Society (1996) recommends that people should avoid the sun at the peak hours (between 12.00 and 15.00 p.m.); they should not go into the sun for long continuous periods and they should slowly build up their exposure time in the sun, so that the skin can get used to the sun. If people are exposed to the sun for periods longer than 30 minutes, they should use a protective sunscreen (with a high sunblock factor), protective clothing or a hat. Furthermore, when people use sunbeds, they should only use them strictly according to the safety instructions for the sunbed.

\section{Prevalence of risk bebavior}

Dutch research into behaviors related to sun(beds) exposure in the 
Netherlands has shown that almost half of the adult population reports exposing themselves to the sun frequently to as much as possible (Lechner \& De Vries, 1996). People who go into the sun as often as possible are more often women, younger than 35 years, who more often make use of sunbeds and go into the sun at the peak hours (midday). Protective behavior in general is low, and protection is mostly only used when people are intentionally exposing themselves to the sun (e.g., to get a suntan). If people excessively expose themselves to the sun for reasons other than getting a suntan (gardening, bicycling, walking), less than half of them $(47 \%)$ use some form of sun protection (Lechner \& De Vries, 1996; 1997). Moreover, $28 \%$ of the adult population report using sunbeds. Particularly adult women, younger than 35 years, often use sunbeds (48\%) (Lechner \& De Vries, 1997).

\section{ALCOHOL}

Relation with cancer and CVD

Excessive alcohol use (more than 14 glasses of alcohol per week for women and 21 glasses of alcohol per week for men) is causally related to head and neck cancers, such as cancers of the oral cavity, pharynx, and larynx. Furthermore, a causal relation is also apparent for cancer of the esophagus and liver, and probably also for breast cancer (Colsher \& Wallace, 1989; Longnecker, Berlin et al., 1988; Duffy \& Sharples, 1992). Evidence suggests that this association between alcohol consumption and risks for cancers is dose-related: lowest for non-drinkers, higher with increasing alcohol consumption (Colsher \& Wallace; 1989). Furthermore, there is evidence that suggests that the effect of alcohol on cancer risk is synergistic with tobacco use (Colsher \& Wallace, 1989; Doll, 1989).

The relation between alcohol and CVD is less straightforward: although excessive alcohol use is related to a higher risk of CVD, moderate alcohol use ( 2 - 3 alcoholic consumptions per day) seems to be associated to a reduced risk of coronary thrombosis (Colsher \& Wallace, 1989; Doll, 1989; Te Wierik, 1991). This so-called J-shaped curve between the consumption of alcohol and the risk of CVD suggests that the risk in moderate drinkers is lower that the risk of nondrinkers. 
Definition or recommendation of bealthy behavior

Recommendations for the general public with regard to alcohol consumption are given by the Netherlands Bureau for Food and Nutrition. For adults, this organization places the dividing line between moderate and excessive drinking at 14 glasses of alcohol per week for women and 21 glasses of alcohol per week for men (Neve \& Knibbe, 1994). These amounts are in line with the research on excessive drinking of McDonald (1982) and Anderson (1987). In the Netherlands, it is recommended that people should not drink more than these two to three alcoholic consumptions per day. The difference in recommendation between men and women is due to differences in body composition. Since women have lower amounts of water per kilogram body weight, the blood alcohol concentration for women is higher than for men of the same weight with the same amount of alcohol.

\section{Prevalence of risk behavior}

The average alcohol consumption in the Netherlands increased threefold between 1960 and 1980 (Ministry of Welfare, Health and Cultural Affairs, 1993). The Netherlands Institute of Alcohol and Drugs estimated that in 1984 in the Netherlands around 650.000 people had an average consumption of at least eight alcohol consumptions per day (Garretsen, 1986). The prevalence of excessive alcohol use in the Netherlands was reported in several studies. A study of Knibbe and Swinkels (1992) reported an excessive drinking rate ( $>21$ glasses per week) of the general Dutch population in 1989 of $14 \%$ for men and $3 \%$ for women. A study of Van Assema and colleagues (1993) reported a prevalence of $11 \%$ excessive drinkers, consuming at least 22 glasses of alcohol per week, or six or more glasses of alcohol on a single day for at least once a week. A recent study among adults in the Netherlands reported of $13 \%$ of men and $2 \%$ of women that drink at least 22 glasses of alcohol per week (Ruwaard \& Kramers, 1997). Men on average drink more than women, and men more often than women drink more than three consumptions per day (Knibbe \& Swinkels, 1992; Ruwaard \& Kramers, 1997). Unfortunately, the reported studies did not use different norms for men and women. 


\section{SECONDARY PREVENTION}

Unnecessary mortality results from cancers that could have been prevented or could have been successfully treated had they been detected earlier. For many cancer sites detection of the cancer early in the course of the disease, when treatment is more likely to be successful, improves survival (American Cancer Society, 1992). Behaviors related to secondary prevention or early detection of cancer can roughly be divided into two categories:

- self-examination behaviors people perform themselves without interference from others (for example breast self-examination).

- $\quad$ screening for cancers by their G.P. or at a screening facility (for example breast cancer screening).

The most important cancers which can be screened for at an early stage are breast cancer, cervical cancer, prostate cancer, or colorectal cancer. Furthermore, screening for cholesterol can be used as a warning sign for CVD. However, since the Netherlands only has nationally implemented screening programs for breast cancer and cervical cancer, only these two screening behaviors are surveyed in this thesis. The most relevant cancers that can be self-detected by regularly examining oneself are breast cancer for women and testicular cancer for man.

\section{EARIY DETECTION - SCREENING}

\section{Relation with cancer}

Breast cancer is the most prevalent type of cancer amongst women in the Netherlands (Mackenbach, 1988), and most other Western countries (American Cancer Society, 1991; Lipmann, Lichter et al., 1988). Moreover, breast cancer is the highest cause of cancer mortality among women in the Netherlands (Dutch Central Bureau for Statistics, 1995; Visser, Coebergh et al., 1996). In 1993, 9646 new cases of breast cancer were registered in the Netherlands, of which $47 \%$ were from the age group 50 to 70 years (Visser, Coebergh et al., 1996). In 1993, 3532 women died of 
breast cancer in the Netherlands (Visser, Coebergh et al., 1996). By performing regular breast cancer screening on women from the risk age group (50-70 years), possible cancer can be detected at an early stage so that the health loss for these women can be minimized (Shapire, Venet et al., 1982; Tabar, Fagerberg et al., 1985; Vernon, Laville et al., 1990).

Cervical cancer is far less prevalent than breast cancer among women in the Netherlands. In 1993, 705 new cases of cervix cancer were registered in the Netherlands, of which $62 \%$ were from the age group 30 to 60 years (Visser, Coebergh et al., 1996). In 1993, 252 women died of cervical cancer in the Netherlands (Visser, Coebergh et al., 1996). With respect to cervical cancer, evidence suggests that survival rates are better with surgical treatment of early localized lesions. Secondary prevention, through screening of asymptomatic individuals (general public) in the risk age group ( $30-60$ years), may detect cervical cancer at an earlier stage ( $\mathrm{Palm}$, Kant et al., 1993; Van de Graaf, Klinkhamer et al., 1986; Van de Graaf, Vooijs et al., 1988).

\section{Definition or recommendation of bealtby behavior}

Screening programs in the Netherlands are nationally implemented for breast cancer and cervical cancer. In the Netherlands, a national breast screening program was started in 1989 (Van Veen, 1992), and was eventually implemented in all parts of the country. In this national breast cancer screening program, all women in the age group 50 to 75 years receive an invitation and recommendation to attend a breast cancer screening every two years. In the national cervical cancer screening program, as from 1994, women in the age group 30 to 60 years are invited and recommended to get a pap smear every five years.

\section{Prevalence of risk behavior}

Participation is the key factor responsible for the success of a cancer screening program. Research shows that despite high attendance rates in the first screening round of breast cancer screening programs $(72 \%$ to $85 \%$ in the Netherlands), attendance in the following years declines with every new screening round (Baker, 1982; Collette, Rombach et al., 1988; Scaf-Clomp \& Van den Heuvel, 
1990; Vernon, Laville, et al., 1990). Participation in breast cancer screening programs is lower for older women, for women without a spouse and for women with a lower educational background (Tabar, Fagerberg et al., 1985; Scaf-Clomp \& Van den Heuvel, 1990; Vernon, Laville et al., 1990; Hobbs, Smith et al., 1980).

Similar findings were reported with respect to cervical cancer screening programs. Participation rates varied from $40 \%$ to more than $70 \%$, depending on the invitation procedure used (Palm, Kant et al., 1993; Van de Graaf, Klinkhamer et al., 1986; Van de Graaf, Vooijs et al., 1988). Participation in cervical cancer screening programs is lower for older women, for women without a spouse and for women with a lower educational background (Bowling, 1989; Eardley, Elkind et al., 1985; Elkind, Haran et al., 1987; Hayward, Shapiro et al., 1988; King, 1987; Nathoo, 1988).

\section{EARIY DETECTION - SELF-EXAMINATION}

\section{Relation with cancer}

It was estimated that if all breast cancers were discovered in the earliest clinical stage, mortality from breast cancer might be reduced by one third (Strax, 1984). Besides mammography, which alone is not $100 \%$ accurate, breast selfexamination (BSE) forms an important additional method for detecting breast cancer (Bennedict, Williams et al., 1996). Furthermore, as many as $70-80 \%$ of all breast cancer is first discovered by the woman herself (Baines, 1983; Cope, 1992). Although data on efficacy of BSE are not all consistent (Auvinen, Elovanio et al., 1996), the majority of studies indicate that women who practice BSE are diagnosed at an earlier stage of disease and have increased survival rates compared to nonpracticers (Feldman, Carter et al., 1981; Foster \& Costanza, 1984). Foster and Costanza (1984) found that the five-year survival rates of women who performed BSE was $75 \%$ compared to $47 \%$ of women who did not perform BSE, a significant difference even after controlling for age, family history of breast cancer and delay in seeking treatment. 
Although testicular cancer is far less prevalent than breast cancer, within the Netherlands it is the most frequently occurring cancer for men aged 15-44 years (Visser, Coebergh et al., 1996). In 1993, 410 new cases of testicular cancer were registered in the Netherlands, of which $61 \%$ were from the group of adult men younger than 35 years (Visser, Coebergh et al., 1996). In 1993, 35 men died of testicular cancer in the Netherlands (Visser, Coebergh et al., 1996).

\section{Definition or recommendation of bealtby behavior}

The Dutch Cancer Society recommends that BSE for women and testicular self examination (TSE) for men should be performed once every month by certain age risk groups. It is recommended that all women over 18 years of age should examine their breasts monthly at the same time of the month each time (Dutch Cancer Society, 1996; American Cancer Society, 1991). Adult men younger than 35 years of age are considered to be the high-risk age group with respect to testicular cancer. Therefore, it is recommended that adult men younger than 35 years should examine their testicles every month (Dutch Cancer Society, 1996; American Cancer Society, 1991).

\section{Prevalence of risk behavior}

Research shows that most women know of BSE and that the majority of women $(64 \%$ to $90 \%$ ) in the United States report practicing BSE (Auvinen et al., 1996; Friedman, Nelson et al., 1994; Cope, 1992). However, if doing BSE was defined as outlined in the literature, that is monthly, only a small portion of all women would comply. Several studies show that only around $25 \%$ of all women report practicing BSE regularly on a monthly basis (Budden, 1995; Fink, 1991; Friedman, Nelson et al., 1994; Hallal, 1982; Cope, 1992). Moreover, it was estimated that only $20-50 \%$ of the women who practice BSE, do this in a correct way (Pinto \& Fuqua, 1991). Furthermore, women at high risk for breast cancer (because of family history) do not practice BSE more frequently than women at low risk (Alagna, Morokoff et al., 1987; Drossaert, Boer et al., 1996). A recent 
European study (Wardle, Steptoe et al., 1995), regarding the frequency of BSE practice, reported data from 9,181 students aged 17-30 from 20 European countries. The results showed that $54 \%$ of women reported never having practiced BSE. Regular practice (monthly) was reported by only $8 \%$ of the sample, with another $36 \%$ reporting occasional BSE. Significant differences emerged between different countries ranging from $6 \%$ to $15 \%$ reporting regular BSE. In the Netherlands, $65 \%$ of women in the age group 17-30 years reported never performing BSE, while only $6 \%$ of Dutch women reported performing BSE ten times or more per year (Wardle, Steptoe et al., 1995).

Unlike BSE, which is more generally known by women from the Netherlands, TSE knowledge in Europe is reported to range from 0 to $31 \%$ among males in the high-risk age group (adult men younger than 35 years), and TSE performance rates in Europe range from 0\% to 18\% (Best, Davis et al., 1996). In the Netherlands, $93 \%$ of men in the high-risk age group (adult men younger than 35 years) reported never performing TSE, while only $2.5 \%$ of Dutch men reported performing TSE ten times or more per year (Wardle, Steptoe et al., 1994).

\section{CONCLUSION}

The literature review shows that cancer and CVD are clearly related to many risk behaviors, both with respect to primary and secondary prevention. The evidence that was presented suggests that both cancer as well as CVD can possibly be prevented to a significant extent by an active lifestyle, not smoking, having a healthy diet (low in fat, high in fruit and vegetables), and only moderate alcohol consumption. Furthermore, preventing excessive UV-exposure seems an important behavior for preventing skin cancer. With respect to secondary prevention, evidence suggests that some cancers can be detected earlier (with less mortality) if people participate in screening programs and engage in self-detection techniques for cancer warning signs.

The recommendations for some of these behaviors are not always very clear 
or disputable. Even though for some behaviors it is quite obvious when a behavior is healthy (not smoking, participation in a screening program), for other behaviors (exercise, nutrition, alcohol consumption) the dividing line between healthy and unhealthy behavior is less apparent.

Comparison of the recommendations with the actual behavior within the Dutch population, shows that for primary prevention risk behaviors are very prevalent among large portions of the general public (Table 1.2). Studies seem to indicate that around $40 \%$ of the Dutch adult population is physically inactive, $35 \%$ of the adult Dutch population smoke, the large majority of the adult population (over $75 \%$ ) eat too much fat or not enough fruit and vegetables, more than $10 \%$ of the Dutch population has an excessive alcohol intake, and over half of the adult Dutch population is sometimes excessively exposed to UV-radiation without sufficient protection.

Table 1.2: Prevalence of the main lifestyle risk behaviors for the primary prevention of cancer and CVD among adults in the Netherlands

\begin{tabular}{lc}
\hline Risk behavior & Prevalence (\%) \\
\hline inactive lifestyle & $34-46^{2}$ \\
smoking & $35^{\mathrm{b}}$ \\
too much saturated fat & $92^{2}$ \\
too low fruit intake & $76^{2}$ \\
too low vegetables intake & $61^{2^{2}}$ \\
excessive alcohol consumption & $>10^{2, c}$ \\
excessive UV-exposure & $>50^{\mathrm{d}}$ \\
\hline
\end{tabular}

"Ruwaard \& Kramers, 1997

${ }^{b}$ Dutch Foundation on Smoking \& Health, 1996

c Knibbe \& Swinkels, 1992; Van Assema, Pieterse et al., 1993

¿Lechner \& De Vries, 1997

With respect to secondary prevention, it is reported in the literature that participation in cancer screening programs is quite high at the first round (from 60 up to $85 \%$ ), but declines with every new screening round. Furthermore, only few men and women from the target population practice monthly breast selfexamination (less than $20 \%$ ) and testicular self-examination (2.5\%). 


\section{Behavioral determinants}

Having analyzed the health problems with their related health risk behaviors, the next step in the analysis is to study the relevant motivational determinants of these risk behaviors. Insight into the motivational determinants is necessary for the development of effective behavior change interventions. This thesis used the ASE model for studying the behavioral determinants of health risk behaviors. The main focus of this thesis is to study the applications of this model for different health risk behaviors that are related to cancer and CVD.

Not all risk behaviors described in this chapter will be further analyzed with respect to their behavioral determinants. Only some of the reviewed behaviors were chosen, based on several criteria. First, their relevance with respect to cancer and CVD. Second, only those behaviors were included that had not been studied extensively before in the Netherlands. Furthermore, it was hypothesized that applying the ASE model to behaviors that did not have a clear dividing line between healthy and unhealthy behavior (e.g., nutrition behavior, exercise, alcohol consumption) would have consequences for the model. Since the ASE model and the stages of change have been applied extensively to smoking behavior (De Vries \& Backbier, 1994; De Vries, Backbier et al., 1995; De Vries, Dijkstra et al., 1984; Willemsen, De Vries et al., 1996), and since for smoking the difference between healthy and unhealthy behavior is very clear, smoking was not included in the further studies. Furthermore, it was decided to include behaviors with respect to both primary as well as secondary prevention of cancer and CVD, since it was hypothesized that applying the ASE model would be different for more general lifestyle behaviors (primary prevention) versus behaviors that are directly related to chronic diseases (secondary prevention).

Therefore, the following behaviors were included in the further analysis of behavioral determinants (chapters 3 to 8 ): physical activity, the consumption of fruit, vegetables and fat, and participation in a breast cancer screening program. However, before applying the ASE model (with its possible modifications) to the chosen behaviors, first the theoretical and historical background of motivational determinant models, such as the ASE model, will be reviewed in Chapter 2. 


\section{CHAPTER 2}

\section{Determinants of health risk behaviors: Review of the models}

\section{INTRODUCTION}

Several social psychological models and protocols can be of use when analyzing health risk behaviors and finding their determinants. Some models or protocols were developed especially to explain health behaviors or to plan health education interventions, such as the PRECEDE-PROCEED model (Green \& Kreuter, 1991) and the Health Belief Model (Janz \& Becker, 1984). Besides these health specific models, there are more general models for explaining behavior that can also be applied to health behavior. Models that belong to these general behavioral models are, for instance, the Social Cognitive Theory (Bandura, 1986), the Theory of Reasoned Action (TRA) (Fishbein \& Ajzen, 1975; Ajzen \& Fishbein, 1980), and its revised version as described by Ajzen (1988; 1991), the Theory of Planned Behavior (TPB). The Attitude - Social influence - self-Efficacy model or ASE model (De Vries, Dijkstra et al., 1988; De Vries, Backbier et al., 1995) was derived from the TRA and the Social Cognitive Theory.

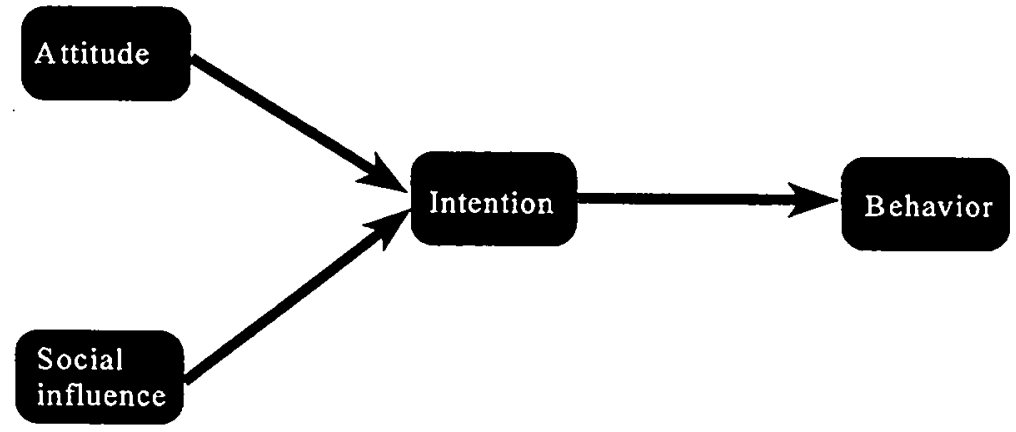

Figure 2.1: The Theory of Reasoned Action (TRA) 
The TRA (see Figure 2.1) was developed more than 20 years ago, derived from several earlier publications on attitudes, intentions and behavior (Ajzen \& Fishbein, 1970; 1972; 1974). The first extensive publication on the TRA took place in 1975 (Fishbein \& Ajzen, 1975); this was followed in 1980 by a second book on the subject (Ajzen \& Fishbein, 1980). The original TRA stated that behavior is determined by the intention to perform the behavior. The intention again is determined by two factors: the attitude and the subjective norm. This TRA proved to be strong in describing behavior in which people were in volitional control. However, for behaviors where people lacked this volitional control, Ajzen proposed his Theory of Planned Behavior (TPB), in which the term Perceived Behavioral Control (PBC) was introduced (Ajzen, 1991). The ASE model (De Vries, Dijkstra et al., 1988) was derived from the TRA and the Social Cognitive Theory, and to some degree resembles the TPB. However, it has evolved as a separate model with several differences, predominantly of a methodological nature. Similar to the TPB, the ASE model suggests that behavior is determined by the intention to perform this behavior (Figure 2.2). This intention is determined by three important factors: attitude, social influence and self-efficacy. In recent years, this model has evolved further, by integrating new theoretical and practical findings in the model (De Vries \& Mudde, 1997).

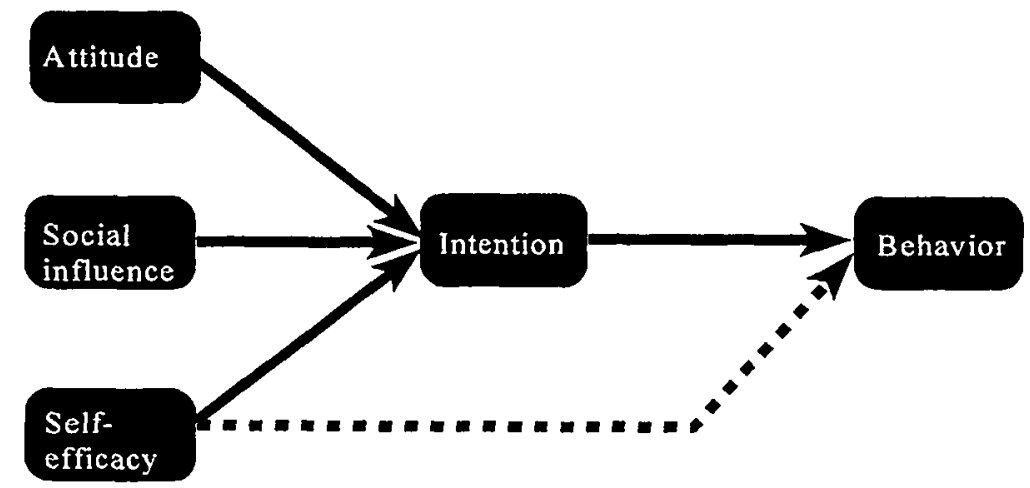

Figure 2.2: Basic concepts of the TPB/ASE model 
This chapter will provide an overview of these basic models (TRA, TPB, ASE), and is divided into two parts. First, the basic constructs of the models (intention, attitude, social influence, self-efficacy) will be described, with respect to different possible operationalizations, relations with other concepts and possible criticisms and new developments. Second, possible new additional modification to these basic concepts of the models will be reviewed. In this second part, emphasis will be placed on aspects such as past behavior, misconception of behavior or lack of awareness, and the stages of change.

\section{CONSTRUCTS OF THE TRA, TPB AND ASE: AN OVERVIEW}

\section{INTENTION}

\section{Definition and operationalization}

For all three models the direct determinant of behavior is behavioral intention. In the literature, there has been a discussion on the best way to assess intention towards behavior (Eagly \& Chaiken, 1993). Some studies suggest that intentions should be measured by asking subjects about their expectancies with respect to the behavior (e.g., bow likely is it that you will do X). The alternative of measuring intentions is by asking subjects whether they plan or intend to perform the behavior (e.g., do you intend to do X). Although Fishbein and Ajzen stated in 1975 that intention should be assessed by measuring expectations, in a later publication (Ajzen \& Fishbein, 1980) they stated that both operationalizations can be used interchangeably. Sheppard and colleagues (1988) found that the superiority of expectations over plans is small for predicting behaviors (eating a piece of fruit) but substantial for predicting the attainment of goals or more complicated behavior (loosing 20 pounds). From this it was concluded that the interchangeability of plans versus expectations in research is generally valid as long as simple, volitional behaviors are predicted rather than the attainment of more remote goals, where major obstacles can prevent the individual's performance of the action or 
attainment of the goal (Fishbein \& Stasson, 1990; Sheppard, Hartwick et al., 1988). If a behavior is truly under an individual's control, a person ordinarily does what he plans to do, and he predicts that he will do what he plans to do. Recent literature review studies of the TRA and TPB (Godin \& Kok, 1996; Randall \& Wolff, 1994; Van den Putte, 1993) suggest that there are no significant differences between intention and behavioral expectation with respect to their correlation to behavior. The only meta-analysis that has tested the intention-behavior relation exclusively on health related behaviors (Godin \& Kok, 1996), found that health behaviors were predicted by intentions $(r=.49)$ at least as well as by expectations $(r=.44)$.

The time interval between the behavioral intention and the behavior seems to have an important influence on the predictive power of intentions. According to Bagozzi (1981), intention has a direct effect on short term behavior, but there is no effect of intention on long term behavior. Similarly, Ajzen $(1988,1991)$ states that for the TRA/TPB, behavior can theoretically be predicted from intention, providing that two conditions are met. First, both behavioral intention and behavior must be measured with the same degree of specificity with respect to target, action, time frame and context of the behavior concerned. Second, there should be limited opportunity for intention to change between the assessment of behavioral intention and the subsequent behavioral measure. This implies that for the purpose of prediction the time interval between the two measures should be kept to a minimum (Ajzen, 1985; Ajzen \& Madden, 1986; Manstead \& Parker, 1995). However, in their review of 98 studies, Randall \& Wolff (1994) found that the intention-behavior correlation coefficient did not significantly decline as the time between intention and behavior increased, and could remain strong over a prediction interval of as long as 15 years. Their study also showed that when selfreport measures of behavior were used, the intention-behavior correlation remained stronger over time than when objective measures of behavior were used. Furthermore, the type of behavior could also influence the strength of the intention-behavior correlation; particularly for alcohol and drug-related activities the intention-behavior relation declined sharply over time (Randall \& Wolff, 1994).

The studies presented in Chapters 4, 5 and 8 of this thesis will study the relation between intention and behavior, and the effect of the time period between 
the assessment of determinants and intention and the assessment of behavior on this relation. The overall discussion of the intention-behavior relation and the timeperiod between the two measures will be described in Chapter 9.

\section{ATTITUDE}

\section{Definition and operationalization}

The first determinant of behavioral intention is formed by the attitude that people have towards a certain behavior. According to Eagly and Chaiken (1993), attitude is a psychological tendency that is expressed by evaluating a particular entity with some degree of favor or disfavor. Psychological tendency refers to a state that is internal to a person, and evaluating refers to all classes of evaluative responding, whether overt or covert, cognitive, affective, or behavioral (Eagly \& Chaiken, 1993).

The overall attitude that people have toward a particular behavior is formed by a combination of several beliefs that people have toward that behavior. These beliefs concerning a certain behavior, can be conceptualized in terms of the advantages and disadvantages of that behavior. In Bandura's Social Cognitive Theory these possible advantages and disadvantages are referred to as outcomes expectations (Bandura, 1986). These possible outcomes can take place directly following the behavior or after a longer period. This is particularly important for many health risk behaviors. Although in the long run health risk behaviors may cause diseases such as cancer or CVD, the short-term outcomes of health risk behaviors might be very positive. Risk behavior might be pleasurable, relaxing and easy. In contrast to the unhealthy behavior, the healthy behavior might have positive outcomes in the long-term (e.g., less risk of cancer and CVD), while the short-term outcomes might not be so positive (e.g., exercise costs time, might leave you with muscle pain; healthier food might not taste nice; screening might cause pain). All these possible outcomes should be taken into account as being important in the process of forming people's attitudes toward a health (risk) behavior.

The TRA/TPB provides clear suggestions on how to assess attitudes. 
Attitudes can be assessed by measuring the beliefs that are associated with a particular behavior (e.g., regular exercise will improve my physical condition), and the evaluations of these beliefs (e.g., improved pbysical condition is very positive for me) (Ajzen \& Fishbein, 1980). This evaluation of a belief can be considered to be the attitude towards the belief or consequence in question (Ajzen \& Fishbein, 1980). To assess the attitude, the different beliefs (b) are multiplied with their evaluations (e), and are then summed together. This makes the attitude a multiplicative function of the beliefs and their evaluations.

$$
\begin{aligned}
\text { attitude } & =\sum b_{\mathrm{i}} e_{\mathrm{i}} \\
& =b_{1} e_{1}+b_{2} e_{2}+b_{3} e_{3}+\ldots+b_{n} e_{n}
\end{aligned}
$$

Reviews and meta-analysis of the TRA/TPB have illustrated the importance of attitude as a predictor of intention and behavior (Godin \& Kok, 1996; Sheppard, Hartwick et al., 1988; Van den Putte, 1993). With respect to health-related behaviors and the TPB, Godin and Kok (1996) reported an overall average correlation between intention and attitude of .46 over 58 applications of the TPB. The correlations between intention and attitude were the lowest for eating behaviors (.34), while the correlations were highest for addictive behaviors (.53), exercising (.51) and screening (.51).

\section{Combining beliefs and evaluations}

Changing attitudes according to the TRA/TPB can be done by either changing people's beliefs or by changing the evaluations of these beliefs. Research that addresses changing attitudes through changing the evaluations of beliefs has, however, hardly been reported. Furthermore, those studies that have tried to change evaluations, have had relatively little effect on these evaluations and on the overall attitudes (Lutz, 1975). Eagly \& Chaiken (1993) suggest that changing evaluations might be so difficult because evaluations of attributes or beliefs are often well-anchored in extensive prior learning. As they have illustrated (Eagly \& Chaiken, 1993, p.237), the perceptions that, for example, it is a good thing that a laptop is light in weight and a bad thing that it is expensive would seem to be 
difficult to alter. A message saying that this particular laptop is lighter and cheaper than other comparable products would be better at convincing potential buyers than saying that lightness is bad or high cost is good. So, changing the beliefs would be a better alternative to changing evaluations. Moreover, since many evaluations of beliefs are so anchored in people's perceptions, not much variance can be expected in people's evaluations of these beliefs (Eagly \& Chaiken, 1993).

Studies suggest that the true magnitude of the correlation of the multiplicative composition to intention is unknown and susceptible to scaling effects (Evans, 1991; Swanborn, 1996; Van den Putte, 1995). Since attitude according to the TRA/TPB is conceived as multiplying and adding up the different beliefs and their evaluations, the correlation between this concept and the intention is difficult to interpret. Moreover, several studies have indicated that correlations of a multiplicative composition with a third variable could vary much, depending on the scaling procedures that are used (Evans 1991; Falbo \& Becker, 1980; Sparks Hedderly et al., 1991; Van den Putte, 1995). Some recent studies have illustrated these possible scaling effects with results from empirical data (Ajzen, 1991; Bagozzi, 1984; Hewstone \& Young, 1988; Mellenbergh, Molendijk et al., 1990; Sparks Hedderly et al., 1991). Ajzen (1991) concluded that the value labels of both beliefs and evaluations should be coded in a bipolar way (e.g., from -3 to +3 for a 7-point scale) instead of in a unipolar way (e.g., from 1 to 7 for a 7-point scale), since bipolar coding resulted in higher correlations with the global attitude measure. Hewstone \& Young (1988) showed that depending on the values that were given to the answering scales of the beliefs and evaluation, the correlation of the product score attitude with the dependent intention variable differed from .30 to .46. Mellenbergh et al. (1990) showed that correlations of an additive product variable with a third external variable could vary from .27 to .50 , depending on the value labels of the product variables. These differences were due to the arbitrary decision by the researchers as to how to score the respondents' answers numerically (Evans, 1991). Therefore, these scaling effects can form a serious threat to the reliability of such additive product terms. Finding a good interpretation of the attitude correlations with other variables thus seems difficult. Moreover, since correlations of attitudes with dependent variables are used to index effect size in meta-analyses, this may 
provide a distortion of presented data (Evans, 1991).

From a statistical point of view, the multiplicative concept of attitude is a combined concept of several interaction terms between the beliefs and the evaluations of these beliefs. However, within a regression analysis an interaction term can only be included if the separate concepts are first entered in the analysis, followed by the interaction term. An interaction term should be included in the analyses only if there is extra explained variance from this term on top of the already included separate terms (Evans, 1991). However, studies in which the attitude itself was treated as an interaction term, have hardly been reported.

Because of these difficulties that arise when using attitude as an additive product term of beliefs and evaluations, some studies, such as the applications of the ASE model, have decided to omit the evaluations from the attitude concept (Brug, Lechner et al., 1995; Van den Putte, Saris et al., 1995; Willemsen, De Vries et al., 1996; Willemsen \& De Vries, 1996). The altered attitude concept is then operationalized by adding up the different belief items. However, hardly any research has been reported that has studied whether omitting the evaluations from the attitude product construct would result in loss of predictive power of attitudes in the explanation of intention. Therefore, Chapter 5 explicitly addresses the issue of the belief $x$ evaluation based attitude versus the belief based attitude. Chapter 5 will describe the consequences of omitting the evaluations from the attitude concept as conceived by the TRA/TPB.

\section{EXTENDING ATTITUDES WITH PERSONAL NORMATIVE BELIEFS: MORAL OBLIGATION, ANTICIPATED REGRET}

As several studies have suggested (Godin \& Kok, 1996; Manstead \& Parker, 1995; Richard, Van der Pligt et al., 1995), the role played by affective factors in determining intentions and behaviors has been underestimated in research using the TRA/TPB. In the TRA/TPB the decision to behave is based primarily on a rational assessment of salient information, and makes no distinction between the feelings one has concerning a behavior and one's evaluation of the costs and 
benefits of performing that behavior (Manstead \& Parker, 1995).

Therefore, it has been suggested that a new factor, called personal norms, should be included in the TRA/TPB. Within personal norms, a distinction can be made between moral norm or moral obligation (an individual's personal beliefs of what ought to be done; the right thing to do) and anticipated regret (anticipated postbehavioral affective reaction such as worry and regret) (Manstead \& Parker, 1995; Parker, Manstead et al., 1995; Richard, Van der Pligt et al., 1995). Similarly, other researchers (Cialdini, Kallgren et al., 1991; Reno, Cialdini et al., 1993) have suggested the existence of what they call injunctive norms as a possible predictor of intention and behavior. Injunctive norms, among others, represent what ought to be done, the moral rules of the group. They also represent personal norms, which guide one's behavior via the perception of whether one would approve/disapprove of one's own conduct.

In a recent review of applications of the TPB to health-related behaviors (Godin \& Kok, 1996), one of the main conclusions was that personal norms or personal normative beliefs should be added to the TPB, since in several healthrelated applications these factors contributed significantly to the explained variance of intention. Ajzen also stated that personal feelings of moral obligation or responsibility to perform a certain behavior can influence intention, parallel with attitudes, social norms and PBC (Ajzen, 1991).

There are several possibilities to place the personal norm concept within the determinant models. Personal norms could be seen as a separate new concept or as a concept within the attitude construct. As Eagly and Chaiken state (1993), personal norms could be subsumed under attitude toward the behavior, because guilt, selfreinforcement, and other outcomes of meeting or violating one's own standards are merely additional consequences of behavior. Therefore, a distinction within attitude between affective consequences of behavior (negative and positive feelings that people anticipate will ensue from engaging in behaviors), and cognitive determinants (costs and benefits) might be a useful modification of the attitude concept.

Several studies have added personal norm as a unique concept in the applications of TRA/TPB. The importance of perceived moral obligation, which 
represents people's personal beliefs about right and wrong (Schwartz \& Tessler, 1972) were tested by Fishbein and Ajzen (1975). They concluded that personal beliefs of what a person thinks he or she should do are so confounded with behavioral intention that they have no additional predictive value with regard to intention. However, several studies have found an additional predictive value (additional $\mathrm{R}^{2}$ of $3-15 \%$ ) of personal norms (personal moral obligation or anticipated regret), over and above the basic concepts of TRA/TPB (Beck \& Ajzen, 1991; Boyd \& Wandersman, 1991; Gorsuch \& Ortberg, 1983; Manstead \& Parker, 1995; Parker, Manstead et al., 1995; Richard, Van der Pligt et al., 1995; Zuckerman \& Reis, 1978).

It can be concluded that these new affective concepts can be of major relevance in socially controversial or emotional situations and for behaviors where some form of moral pressure is apparent. These new variables that are related to the attitude concept will be studied in Chapter 8 . This chapter will study whether these affective variables (anticipated regret, moral obligation) have any predictive value with regard to behavioral intention concerning screening participation. Furthermore, Chapter 8 will study whether these concepts should be placed within the attitude construct or whether they constitute separate new factors within the ASE model.

\section{SOCIAI INFLUENCE}

\section{Definition and operationalization}

A second factor that can influence people's intention to perform a behavior consists of the social influences people are subject to. The TRA/TPB assesses social influence in a similar way to how it assesses attitudes, by using a multiplicative function called subjective or social norm (Ajzen, 1991). The social norm measures the impression people have of how significant others feel, in general, about them performing the behavior. The social norm is assessed by measuring the beliefs subjects have about how a specific important other person feels about them performing the behavior, and weighing these beliefs with the motivation to comply 
with each of these persons. The social norm is formed by multiplying these normative beliefs (nb) by the different motivations to comply (mc), and adding these different product scores into one new variable $\left(\sum n b_{i} m c_{i}\right)$.

Reviews and meta-analyses of the TRA/TPB have illustrated that the social norm as a predictor of intention and behavior is of modest importance (Godin \& Kok, 1996; Sheppard, Hartwick et al., 1988; Van den Putte, 1993), especially when compared to attitudes and Perceived Behavioral Control (PBC). With respect to health-related behaviors and the TPB, Godin and Kok (1996) reported an overall average correlation between social norm and intention of .34 over 58 applications of the TPB. The correlations between intention and social norm were lowest for eating behaviors (.16), while the correlations were higher for addictive behaviors (.32), exercising (.30) and screening (.33). From their review Godin \& Kok (1996) concluded that social influence appears to be less important than attitude and $\mathrm{PBC}$, since social norms were less often significant and had much lower weights than the other two constructs (attitude and $\mathrm{PBC}$ ) in their prediction of intention.

\section{Other measures of social influence}

It has been suggested by several authors, that the consistently low contribution of the social norm might be related to the operationalization of the construct (De Vries \& Kok, 1986; De Vries, Backbier et al., 1995; Godin \& Kok, 1996; Grube, Morgan et al., 1986; Miniard \& Cohen, 1981).

Several authors have suggested other operationalizations of social influence (De Vries, Backbier et al., 1995; Godin \& Kok, 1996; Grube, Morgan et al., 1986). Some studies have found that people might also be encouraged to behave in a particular healthy way if they know that other people are behaving in this healthy way, and are actually rewarded for this in some way (Cialdini, Kallgren et al., 1991; De Vries, Backbier et al., 1995; Grube, Morgan et al., 1986; Reno, Cialdini et al., 1993). This observational learning, which is one of the key concepts within the Social Learning Theory (Bandura, 1986), is also referred to as modeling. Grube and colleagues (1986) found that the inclusion of the perceived behavior factor, in addition to artitudes and social norms, significantly improved the predictive power of the reasoned action model. This finding was replicated for smoking prevention 
(De Vries, Backbier et al., 1995).

Furthermore, some evidence was also found (De Vries, Backbier et al., 1995) for the importance of direct social support or pressure for people to enact in the healthy or unhealthy behavior. People who feel supported by others to perform healthy behaviors are more likely to actually do so.

Other authors have criticized the TRA/TPB operationalization of social influence because it uses a multiplicative composite (Budd, North et al., 1984; Saltzer, 1981; Van den Putte, Saris et al., 1995). As van den Putte and colleagues (1995) state, if the variance of the motivation to comply concept is low due to a large consensus, the construct can be omitted without decreasing the correlation with subjective norm. Budd and colleagues (1984) found that the motivation to comply construct did not significantly add to the predictive power of the model, independent of the scoring of the motivation to comply construct (e.g. uni-polar or bi-polar). Similarly, Saltzer (1981) found that actual practice has indicated that the inclusion of the motivation to comply construct often reduces the relationship of perceived normative beliefs with measures of behavioral intentions, perhaps due to a reactive measurement problem wherein respondents wish to appear autonomous and independent when deciding about potential behaviors.

Furthermore, since the subjective norm has a multiplicative composite $(\Sigma$ $\left.\mathrm{nb}_{\mathrm{i}} \mathrm{mc}_{\mathrm{j}}\right)$, similar to that of attitudes $\left(\sum \mathrm{b}_{\mathrm{i}} \mathrm{e}_{\mathrm{i}}\right)$, scoring problems and interpretation problems can arise (Evans, 1991). Because of these difficulties, some studies have suggested omitting the motivation to comply construct in their applications of the TRA/TPB (Budd, North et al., 1984; Budd, 1986; Greenstein, Miller et al., 1979; Van den Putte, Saris et al., 1995). Applications of the ASE model with regard to social influence, have evolved into placing less emphasis on the subjective norm and more emphasis on modeling and social support aspects of social influence (Brug, Lechner et al., 1995; Lechner \& De Vries, 1997; Willemsen, De Vries et al., 1996; Willemsen \& De Vries, 1996).

In the studies presented in this thesis (Chapters $3-6$, and 8), social influence was operationalized by measuring social support and the influence of modeling. In different chapters, several combinations and measures of social influence are used. In Chapter 9, these different measures and their applications will be discussed. 


\section{SELF-EFFICACY}

\section{Definition and operationalization}

The original TRA, which was restricted to the determinants attitude and social norm, proved to be strong in describing behavior in which people were in volitional control. However, for behaviors where people lacked this volitional control, the predictive value of the theory proved to be far less (Bagozzi \& Warshaw, 1990; Bagozzi, 1992). As Liska (1984) argued, the restriction of the TRA to volitional behavior excluded not only habitual behavior, but also behavior that requires skills, abilities and the cooperation of others. The volitional restriction limits the model to actions that require only motivation on the part of the individual. Behaviors not under volitional control (or only partially under such control) are just as interesting and important than behaviors as those that are.

As a result of this limitation of the TRA, the importance of self-efficacy as a third factor along with attitudes and social influence was acknowledged (Ajzen \& Madden, 1986; De Vries, Dijkstra et al., 1988). The self-efficacy construct is a central element in Bandura's $(1977 ; 1982 ; 1986)$ Social Cognitive Theory. According to Bandura (1986, p.391), perceived self-efficacy is defined as people's judgements of their capabilities to organize and execute courses of action required to attain designated types of performances. Perceived self-efficacy is not concerned with the skills one has but with the judgements one has of what one can do with whatever skills one possesses. According to Bandura (1986), increased self-efficacy will result in improved performance of the behavior.

By including the term Perceived Behavioral Control (PBC), which was derived from the self-efficacy construct of Bandura (1977; 1982), Ajzen and Madden (1986) proposed a new model as the successor of the TRA, the Theory of Planned Behavior (TPB). Similarly, the self-efficacy construct was integrated by De Vries and colleagues (1988) into the Atritude - Social influence - self-Efficacy (ASE) model. In the TPB self-efficacy had both a direct influence on behavior, as well as an indirect influence via the intention to perform the behavior. These adapted models suggest that for behaviors over which people experience a lack of control, this can influence both their intention to perform the behavior as well as directly 
influencing the performance of the behavior.

In the literature, several methods have been suggested to operationalize selfefficacy. The TPB operationalizes self-efficacy by measuring the perceived behavioral control (PBC) that people experience (Ajzen, 1991). According to Ajzen (1991), besides the beliefs people have about outcomes of a behavior (attitudes) and how significant others feel about a behavior (social norm), people also have beliefs that are concerned with the presence or absence of requisite resources and opportunities. These control beliefs may be influenced by past experience with the behavior, but also by information people have about the behavior, and experiences that other people have with the behavior. In concurrence with Bandura (1986), Ajzen (1991) states that the more resources and opportunities individuals believe they possess, and the fewer obstacles or impediments they anticipate, the greater their perceived control over the behavior should be. The PBC in the TPB is measured with the same basic multiplication construct as is used for operationalizing attitudes and social norms. $\mathrm{PBC}$ is operationalized by measuring different control beliefs that people have about the behavior (c), and multiplying these beliefs by the perceived power $(p)$ of the particular control factor to facilitate or inhibit performance of the behavior. The resulting products are then summed together to produce the perception of behavioral control $\left(\sum \mathrm{c}_{\mathrm{P}} \mathrm{P}_{\mathrm{i}}\right)$. PBC beliefs are operationalized by asking either how much control people have over performing the behavior in a certain situation or by asking them how difficult or easy they feel it would be to perform the behavior of interest in a certain situation (Ajzen, 1991; Madden, Ellen et al., 1992).

Several studies have tried to operationalize this PBC concept (Ajzen \& Madden, 1986; Manstead \& Parker, 1995; Parker, Manstead et al., 1995). Two studies (Manstead \& Parker, 1995; Parker, Manstead et al., 1995) operationalized $\mathrm{PBC}$ by asking subjects whether a certain factor (situation) would facilitate or inhibit performance of the behavior (control belief). This belief was then multiplied with the frequency with which subjects encountered the situation (power). Results showed that their PBC operationalization improved the prediction of behavioral intention substantially. However, it was also concluded that there is a clear need for further research into the different measures and methods of combining measures 
into satisfactory indices of $\mathrm{PBC}$. Moreover, similar to the way that attitudes and social norms are operationalized in the TRA/TPB, PBC is also measured by use of a multiplicative function. Again, scoring problems and interpretation problems can arise when analysing a multiplicative function (Evans, 1991; Valois, Desharnais et al., 1993).

\section{Self-efficacy: difficulty versus ability}

Besides assessing self-efficacy by measuring the $\mathrm{PBC}$, alternative operationalizations are often used. Assuming that people want to change their behavior, in general, self-efficacy towards changing that behavior can be operationalized by either asking subjects about perceived difficulty (Do you think it is easy - difficult to ...), or by asking subjects about perceived ability (Do you think you are able to...) of enacting the behavior. There has been some discussion about which operationalization provides the better alternative. According to Bandura (1986), self-efficacy expectations vary along dimensions of magnitude, generality, and strength. As Kok and colleagues have argued (Kok, Den Boer et al., 1992, p.247), these dimensions imply that self-efficacy estimates must be viewed as situation dependent. The perception of a subject's ability to perform a certain behavior is determined, and varies, according to the perceived task difficulty and the situation. Measurement of perceived difficulty does not necessarily imply an estimation of ability. A person can see a behavior in a certain situation as being very difficult, but also as -something that can be done. Measuring ability in relation to situational aspects, however, is likely to include perceived difficulty levels of both situation and behavior. A person asked to rate his confidence of being able to perform a certain behavior in a certain situation, will probably weigh ability against task difficulty and situation difficulty. This leads to the conclusion that instruments to measure perceived ability (Do you think you are able to...) assess both the dimension's strength and magnitude, and should be preferred over perceived difficulty. Including a sample of relevant situations provides an assessment of the dimension generality (Kok, Den Boer et al., 1992).

Applications of the ASE model use this item-based self-efficacy construct in the model, which is operationalized by asking subjects whether they think they are 
able to perform the behavior in several risk situations, and then summing their scores (Brug, Lechner et al., 1995; De Vries, Dijkstra et al., 1988; De Vries \& Backbier, 1994; Willemsen, De Vries et al., 1996; Willemsen \& De Vries, 1996).

\section{Strength of self-efficacy/PBC}

Research over the past decades has stressed the importance of self-efficacy for enacting new healthy behavior in general (Bandura, 1986; Schwarzer, 1992), as well as for several specific health behaviors such as smoking (DiClemente, Prochaska et al., 1985), exercising (Godin, 1993; Marcus, Selby et al., 1992; Sallis, Haskell et al., 1986), eating healthy diets (Shannon, Bagby et al., 1990; Sheeshka, Woolcott et al., 1993), and attending breast cancer screening (Curry \& Emmons, 1994). Several review studies have shown that by including self-efficacy/PBC in the determinant model (TPB/ASE), there is an increase to the explained variance of intention, as well as to the explanation of actual behavior (Ajzen, 1991; Godin \& Kok, 1996; Madden, Ellen et al., 1992; Netemeyer, Burton et al., 1991; Van den Putte, 1993), especially for behaviors that present some problem with respect to control. With respect to health-related behaviors and the TPB, Godin and Kok (1996) reported an overall average correlation between intention and $\mathrm{PBC}$ of .46. The correlations between intention and $\mathrm{PBC}$ were the lowest for eating behaviors (.32), while the correlations were relatively high for addictive behaviors (.49), exercising (.50) and screening (.46). Furthermore, their review found an overall correlation of .39 between PBC and behavior. Nevertheless, intention (.46) proved to be a more important predictor of behavior than PBC. From this it was concluded that, in general, health-related behaviors are largely performed according to one's personal motivation (Godin \& Kok, 1996).

In this thesis, self-efficacy was assessed by asking about people's ability to enact the healthy behavior in different problem or high-risk situations. This situation based self-efficacy measure was used in all determinant studies to see if they proved relevant predictors of intention, behavior or behavioral stages of change with respect to different health behaviors. Furthermore, in Chapter 4 an alternative measure of self-efficacy was assessed to study whether an additional factor existed within the self-efficacy construct. In Chapter 9 the overall merit of the self-efficacy 
measures used will be discussed.

\section{FURTHER MODIFICATIONS}

One of the basic assumptions of the TPB/ASE models is that the influence of other variables is mediated by the three determinant concepts. This means that the influence of other variables (external variables) on intention and behavior will be mediated by either attitude, social norm or self-efficacy. Although the TPB performs quite well with respect to explaining intention and behavior (Ajzen, 1991; Godin \& Kok, 1996; Madden, Ellen et al., 1992; Netemeyer, Burton et al., 1991; Van den Putte, 1993), many researcher have suggested that the model could be extended. One of these alterations has been the change from the TRA to the TPB and the ASE model, by including PBC or self-efficacy in the models. However, other modifications have also been suggested. The most important are discussed below.

\section{DISTAL FACTORS - PAST BEHAVIOR}

One of the concepts that has been added by various researchers is past behavior, in terms of experience with the behavior, habit or previous behavior (Eagly \& Chaiken, 1993). Many studies have shown that the inclusion of past behavior can improve the prediction of intention or behavior (Bagozzi, 1981; Bagozzi, Baumgarter et al., 1992; Bentler \& Speckart, 1979; Bentler \& Speckart, 1981; Budd, North et al., 1984; De Vries, Backbier et al., 1995; Fredricks \& Dosset, 1983; Willemsen, De Vries et al., 1996).

Bentlar and Speckart $(1979,1981)$ were among the first to include past behavior in the determinant model. They suggested a new model with an extension of past behavior. Their model suggested a direct influence of past behavior and attitude on both intention and subsequent behavior. Based on their results they concluded that past behavior and subsequent behavior may not be completely 
explicable through past behavior's impact on attitudes and intention (Bentler $\&$ Speckart, 1979). Budd and colleagues (1984) tested the modified model of Bentlar and Speckart and concluded that the extended model with past behavior could significantly improve the model's predictive power of behavioral intentions.

Bagozzi and colleagues (Bagozzi, 1981; Bagozzi, Baumgarter et al., 1992) also concluded that past behavior is an important determinant of behavioral intention. Furthermore, their results showed that past behavior tends to lessen the impact of intention on behavior. In these results, Bagozzi (1981) saw a confirmation of Triandis' theory. According to Triandis $(1977,1980)$, the role of the habits that people have with respect to behaviors is of major importance. Habit implies that a behavior has become so routinized through repetition that a person has ceased to make any conscious decision to act yet still behaves in the accustomed way. Triandis suggests that as habit increases, the performance of the behavior becomes less one of rational evaluation of the consequences of the act and more one of a learned response. Similarly, Fredricks and Dosset (1983) conclude that prior behavior has a direct causal influence on both subsequent behavior and intention. They found that once prior behavior is included in the model, the effects of intention become non-significant, that is, unnecessary for the prediction of subsequent behavior. From this they conclude that when a study encompasses behavior that tends to be habitual and/or low in arousal quality, the prior and target behaviors are reflections of highly similar constructs. Under these conditions, cognitive mediation (i.e. intention) is perhaps reduced or even eliminated.

Ajzen (1991) denied a direct influence of past behavior or experience on future behavior. As Ajzen (1991) stated, a model that is sufficient contains all important variables in the set of determinants. If all determinants are measured sufficiently, past behavior will not add to the prediction of intention and future behavior. Including past behavior in the model can be used to test whether any model designed to predict future behavior is sufficient. If past behavior is found to have a significant residual effect beyond the predictor variables contained in the model, it would suggest the presence of other factors that have not been accounted for. Ajzen (1991) concluded that past behavior is best treated not as a measure of habit, but as a reflection of all factors that determine the behavior of interest but 
are missing in the measurements. Furthermore, measures of past and later behavior may have common method variance not shared by measures of the other variables in the model (different measure method, observed versus self-reported) (Ajzen, 1991). However, in some studies the introduction of past behavior has produced an improvement in explained variance of intention and behavior that is probably too large to be attributable to only method variance (Ajzen, 1991; Budd \& Spencer, 1985; De Vries, Backbier et al., 1995; Fredricks \& Dosset, 1983; Willemsen, De Vries et al., 1996). Furthermore, Ajzen (1991) suggested that past behavior only had additional explained variance for applications of the TRA, when self-efficacy was not yet included. Since past behavior is the most important source of information for self-efficacy or behavioral control (Bandura, 1986), Ajzen expected that the influence of past behavior would be mediated by the self-efficacy (PBC) construct (Ajzen, 1991). However, several studies, including the study of Ajzen (1991), have demonstrated that even after the inclusion of self-efficacy, past behavior still resulted in a significant improvement in explained variance of intention and behavior (Ajzen, 1991; De Vries, Backbier et al., 1995; Willemsen, De Vries et al., 1996).

In this thesis, the role of past behavior will be studied in Chapter 4 and Chapter 8 . Furthermore, Chapter 8 will study possible interactions between the basic determinants (attitude, social influence, self-efficacy) and past behavior with respect to screening participation. The relevance and the possible consequences of including past behavior will be discussed in Chapter 8 and in the general discussion of the thesis in Chapter 9.

\section{STAGES OF CHANGE}

One of the criticisms of models such as the TRA/TPB/ASE has been the absence of any detailed consideration of how people plan and change their actions (Eagly \& Chaiken, 1993). Therefore, besides the models described (TRA/TPB/ ASE), several other theories can be used for understanding behavioral change in general (Glanz \& Eriksen, 1993; Glanz \& Mullis, 1988). 
One of the theoretical frameworks that has become very popular as a framework to understand the process of behavior changes, is the TransTheoretical Model (TTM) of Prochaska and colleagues (Prochaska \& DiClemente, 1983; Prochaska, Velicer et al., 1991). In the TTM, different theoretical insights are used to explain how people change their behavior over time. An important concept in the model is the so-called Stages of Change. This Stages of Change concept suggests that people do not change their behavior in a dichotomous step from unhealthy to healthy behavior, but that the dynamic process of behavioral change can be divided into different stages. In order to change their behavior, people can move from precontemplation (not interested in change) via contemplation (thinking about change) to preparation (actively planning to change within a short period). Subsequently, people can move to the action stage (actually enacting the new behavior) and finally, to maintenance (sustaining the new behavior). In their movement through the stages, people can relapse and fall back to earlier stages. Moreover, movement through the stages often involves a cycling and recycling process (Prochaska \& DiClemente, 1983; Prochaska, Velicer et al., 1991).

The Stages of Change concept, which has its origin in research on addictive behaviors, has been applied extensively to smoking cessation behavior (Prochaska \& DiClemente, 1983; Prochaska et al., 1991). One of the implications of the concept is that people in different behavioral stages need different information, tailored to their specific stage, to motivate them to proceed through the change process to action and maintenance. The stages of change have also been similarly applied to numerous other behaviors, such as exercise (Marcus, Banspach et al., 1992; Marcus, Selby et al., 1992), nutrition (Brug, Glanz et al., 1997; Brug, Hospers et al., 1997), and to other behaviors such as participation in mammography screening, sunscreen use, weight control and condom use (Prochaska, Velicer et al., 1994).

The Stages of Change construct of the TTM and the determinant models (TRA/TPB/ASE) can be integrated into a new model in which the intention and the behavior concepts can be replaced by the different stages of behavioral change (see Figure 2.3). In this integrated model, there is a direct influence of attitudes, social influence and self-efficacy on the different stages of intentional and behavioral 
change. By combining both models, the influence of determinants on each separate behavioral stage can be studied in detail. Applications in which ASE determinants were combined with the stages of change have recently been reported for several behaviors, such as smoking (De Vries \& Backbier, 1994) and fat consumption (Brug, Glanz et al., 1997; Brug, Hospers et al., 1997).

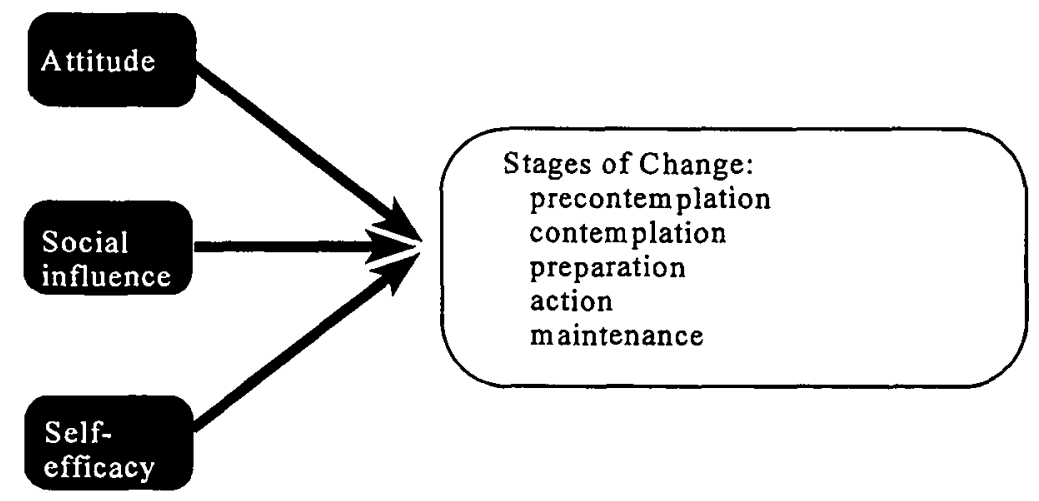

Figure 2.3: The ASE model integrated with the Stages of Change concept of the TTM

One of the important research goals of this thesis is to test whether this integrated ASE-stages model can be applied to new health risk behaviors. Applications and possible consequences of the integrated ASE-stages model will be tested in Chapters 3 and 4 with respect to exercise and in Chapters 6 and 7 with respect to nutrition.

\section{AWARENESS AND MISCONCEPTION OF BEHAVIOR}

An important issue in changing health risk behavior seems to be people's awareness of their own behavior. Weinstein proposed that awareness of risk behavior is one of the key issues in motivating people to move from 
precontemplation to further stages of behavior change (Weinstein, 1988; Weinstein \& Sandman, 1992). The precaution adoption process distinguishes several stages of awareness with respect to a certain issue, with special emphasis on the role played by perceptions of personal vulnerability (Weinstein, 1988; Weinstein \& Sandman, 1992). Applied to health risk behavior, the model suggests that people are initially simply not aware of the fact that a behavior is unhealthy. At the first level of awareness, they become aware that a certain behavior is unhealthy (eating too little fruit and vegetables is related to getting cancer). At the second level, people are aware that many other people act unhealthy, but they do not apply this knowledge to themselves (I know that many other people eat too little fruit and vegetables, but my eating pattern is o.k.). Following that, at the third level of awareness people know about the health risk behavior and realize that they themselves are acting unhealthily (my fruit and vegetable consumption is too low, which is unbealtby). As Weinstein states, as long as people are not aware of the fact that their behavior is unhealthy, they are not likely to consider changing their risk behavior (Weinstein, 1988; Weinstein \& Sandman, 1992).

The prevalence of lack of awareness of unhealthy behavior was recently demonstrated for fat consumption in the Netherlands (Brug, Van Assema et al., 1994). This study reported large differences between the objective assessment of dietary fat intake and the self-rated, subjective fat intake. Also, in the same study almost all psychosocial determinants (atritude, social influence, self-efficacy) had significantly higher correlations with the subjectively measured fat-intake than with the objectively measured fat-intake. Furthermore, a study by Bowen et al. (Bowen, Fries et al., 1994) found that those subjects with the highest fat intake, consistently underestimate the amount of fat in their diets. Similarly, with respect to sun protective behavior in the Netherlands (Lechner \& De Vries, 1997), results showed that many people are unaware of the fact that their sun-protective behavior is unhealthy. Consequently, the attitude, social influence and self-efficacy were more related to their own estimation of their sun protective behavior, than with their actual sun protective behavior.

It seems that this lack of awareness could have consequences for the relation of determinants and behavioral intention to actual behavior. Furthermore, if we 
combine the determinant model with the stages of change, the lack of awareness might have consequences for the application of the Stages of Change concept to behaviors where subjects do not have an accurate perception of their actual behavior. Therefore, Chapters 6 and 7 of this thesis will study the prevalence of the misconceptions that people have with regard to their fruit, vegetable and fat consumption. Moreover, these chapters will study the consequences of misconceptions for the application of the ASE model and for the application of the Stages of Change concept.

\section{CONCLUSION}

Although models such as the TPB or the ASE model are undoubtedly very useful for predicting and understanding social behavior, there is a potential for further development of these models (Manstead \& Parker, 1995). This chapter has illustrated that several alterations to these models are possible. Table 2.1 shows which alterations and modifications will be applied and tested in this thesis.

The operationalizations of the basic concepts of attitude, social norm, and perceived behavioral control are open to some discussion. As the overview has shown, the basic multiplicative constructions of the three concepts, according to the TRA/TPB, can be criticized with regard to possible scaling and statistical problems. Alternatives to the multiplicative construct have been suggested and will be studied in this thesis. Extension of the attitude construct with personal norms (anticipated regret, moral obligation) have also been suggested and will be tested in Chapter 8. Furthermore, alternative operationalizations as regards the operationalizations of social influence (modeling, social support) and perceived behavioral control (self-efficacy) will be applied in this thesis. Moreover, a second alternative measure of self-efficacy will be tested in Chapter 4. 
Table 2.1: The chapters in which the different concepts are applied and tested

\begin{tabular}{ll}
\hline Research question & Chapter \\
\hline Basic construct & \\
Attitude & $3,4,5$ \\
Multiplicative construct & 5 \\
Testing multiplicative construct & $5,6,8$ \\
Additive construct & 8 \\
Extending with anticipated regret, moral obligation & \\
Social influence & $3,4,5,6,8$ \\
Social support & $5,6,8$ \\
Modeling & $3,4,5,6,8$ \\
Self-efficacy & 4 \\
Situation based measure of ability & \\
Additional measure & 4,8 \\
\hline Further modifications & $3,4,6,7$ \\
Past behavior & 6,7 \\
Stages of change & \\
Awareness & \\
\hline
\end{tabular}

By integrating new additional concepts in the model, such as past behavior, it might be possible to improve the predictive power of the model substantially and make it more applicable to a broad range of health behaviors and health risk behaviors. Furthermore, recent new developments from the fields of health education and promotion, such as the Stages of Change concept and the finding that there is a large prevalence of lack of awareness concerning certain health risk behaviors, might also have a place in a new integrated determinant model. Different chapters of this thesis will discuss the application of some of these findings. 


\title{
CHAPTER 3
}

\section{Starting participation in an employee fitness program: Attitudes, Social Influence and Self-Efficacy ${ }^{1}$}

\begin{abstract}
Background. This article presents a study about the determinants of starting participation in an employee fitness program. Information from 488 employees, recruited from 2 worksites, was obtained. From these employees the determinants of participation were studied.

Methods. A questionnaire was used, based on two theoretical models. The 'stages of change' model was used to measure the bealth behavior, consisting of precontemplation (no intention to participate), contemplation (considering participation), preparation (intending to participate within a short period) and action (participating at fitness). The possible determinants were measured according to the ASE model, including the attitude towards an employee fitness program, social influence and self-efficacy expectations.

Results. Subjects in action stage were most convinced of the benefits of participation at the employee fitness program and of their owm skills to participate at a fitness program. Subjects in precontemplation stage were least convinced of the advantages of participation and had the lowest selfefficacy scores. Subjects in action stage experienced the most social support to participate in the employee fitness program.

Conclusions. Health education for employees within industrial fitness programs can be tailored toward their motivational stage. Promotional activities for industrial fitness programs should concentrate on persons in the precontemplation and contemplation stages, since people in these stages are insufficiently convinced of the advantages of a fitness program and expect many problems with regard to their ability to participate in the program.
\end{abstract}

\footnotetext{
1 Published as:
}

Lechner, L., \& De Vries, H. (1995). Starting participation in an employee fitness program: Attitudes, social influence and self-efficacy. Preventive Medicine, 24, 637-633. 


\section{INTRODUCTION}

Increasing the levels of participation in regular physical activity has become a major health concern in developed countries (Owen \& Lee, 1989). Despite the fact that more evidence is needed from controlled research (Powell, Thompson et al., 1987), it seems that the benefits of exercise influence a wide variety of diseases and conditions affecting both physical and mental health. Regular exercise can help prevent and treat coronary heart disease, osteoporosis, diabetes, hypertension, depression, and some forms of cancer (Bouchard, Shepard et al., 1988; Harris, Caspersen et al., 1989).

Exercise is a process that is influenced by physiological, psychological, social, and behavioral parameters (Dishman, 1988; Sallis, Hovell et al., 1989). Motivating people to exercise and to maintain this behavior is a complex behavioral process. It is therefore important to analyze the factors that determine behavior in general and exercise behavior in particular.

Social psychological models suggest that behavior in general is determined by three important factors. The first factor is the attitude, consisting of the advantages and disadvantages of a particular behavior. These are also referred to as outcome expectations in Bandura's Social Learning Theory (Bandura, 1986). The Theory of Reasoned Action provides clear suggestions on how to assess attitudes. Attitudes can be assessed by measuring the beliefs that are associated with a particular behavior, and the evaluations of these beliefs (Ajzen \& Fishbein, 1980).

The second factor consists of the social influences individuals encounter, such as social norms (Ajzen \& Fishbein, 1980). Social norms are determined by the normative beliefs of important referent persons about a behavior, and the individual's motivation to comply with these persons. The predictive power of the model for exercise behavior has been demonstrated in several studies (Godin \& Shepard, 1990; Godin, 1993). Perception of behaviors of others is another factor, which is also an important social determinant. Observational learning is a key concept within the Social Learning Theory and is also referred to as modeling. Grube and colleagues (1986) found that the inclusion of the perceived behavior factor, in addition to attitudes and social norms, significantly improved the 
predictive power of the reasoned action model. This finding was replicated for smoking prevention, while evidence was also found for an additional social factor measuring the impact of direct social support or pressure (De Vries, Backbier et al., 1995).

The third factor consists of self-efficacy expectations, which are beliefs of a person about his abilities to perform a particular behavior (Bandura, 1986). Increased self-efficacy will result in improved performance of this behavior. Research over the past decades has stressed the importance of self-efficacy expectations for moving people to action in general (Bandura, 1986; Schwarzer, 1992), as well as for exercise behavior in particular (Godin \& Shepard, 1990; Marcus, Banspach et al., 1992; Marcus, Selby et al., 1992; McAuley, 1993). Recently the concept of self-efficacy has been added to the model of reasoned action by several researchers, although Ajzen refers to the concept as perceived behavioral control. The renewed model is referred to as the model on planned behavior (Ajzen, 1991) or the ASE model (Attitude - Social influence - self-Efficacy) (De Vries, Dijkstra et al., 1988; De Vries \& Backbier, 1994).

Prochaska and colleagues suggest in their Transtheoretical Model that the process of behavioral change can be divided into several stages $(1983 ; 1991)$. People can move from precontemplation via contemplation to action, and then to maintenance or relapse. Moreover, movement through the stages involves a cycling and recycling process. Recent applications of the model to exercise behaviors are reported by Prochaska et al. (1994), Marcus et al. (Marcus \& Owen, 1992; Marcus, Selby et al., 1992), and Booth et al. (1993).

The present study aims to analyze the determinants of exercise among workers, utilizing an integration of the above-mentioned model. Until now, with respect to starting exercise participation, applications of such an integrated model (ASE model with the Stages of Change) have not been reported. Previous results from this integrative model on smoking suggested that subjects in precontemplation stage were not convinced of the advantages and had low selfefficacy expectations (De Vries \& Backbier, 1994). Subjects in contemplation stage were found to be convinced of the advantages but still had low self-efficacy expectations. Subjects in action stage, however, had both positive attitudinal and 
self-efficacy beliefs. Perceived social support appeared to increase with a linear pattern from precontemplation to action.

\section{METHODS}

\section{Respondents and procedures}

In January 1992, the Dutch National Police (Rijkspolitie) started an industrial health program for the district of Den Bosch. Within the framework of this program, employees could participate in a physical exercise program, allowing them to do supervised fitness exercises twice a week (once in their spare time, once during working hours). The fitness program consisted of several components: warming up, stretching, workout, cooling down and stretching. The exercise facilities that were used for the program were not located at the worksite itself, but at existing exercise schools located outside the workplace. Questionnaires were distributed among both participants and nonparticipants in the Den Bosch district fitness program. In addition, questionnaires were distributed in another police district, which served as a comparison group. At the time of the assessment the fitness program had just started. The questionnaires were distributed by the fitness instructors and contact persons within the police force. The determinant study was part of an extensive process and effect evaluation of the industrial health program.

\section{Questionnaire}

The questionnaire included questions about attitude, social influence, selfefficacy expectations, intention, and demographic variables. The items on attitude, social influence and self-efficacy were based on results of both qualitative and quantitative studies concerning determinants of participation in industrial fitness programs (Poppe, 1991; Peeters, Oostveen et al., 1991).

Attitude was measured with the procedure described by Ajzen and Fishbein (1980), using 8 items on beliefs (b) about industrial fitness programs and the corresponding evaluations (e). The beliefs were assessed by 4 -point scales, while the evaluations were measured by 5-point scales ranging from important to 
unimportant. Attitude scores were calculated by multiplying the beliefs by the corresponding evaluations $\left(\sum b^{*}\right.$ ). The eight attitude scores (see Table 3.3) were added to form a scale (Cronbach's alpha $=0.83$ ).

Social influence was measured by means of three questions on the support or opposition of superiors, colleagues, or partners with regard to participation in the industrial fitness program. A 7-point scale was used, with answers ranging from much support to much opposition ( $\alpha=0.75$, see Table 3.4).

Self-efficacy was measured by proposing six different problem situations and asking the respondents whether they would feel able to participate in an industrial fitness program under these circumstances $(\alpha=0.76$, see Table 3.5). A 7-point scale was used, with answers ranging from certainly to certainly not.

In addition to attitude, social influence and self-efficacy, questions were asked about age, gender, and the type of work in which the respondent was engaged. Furthermore, two questions were used to measure the intention to participate in an industrial fitness program. A 6-point scale was used for the question whether the respondents intended to participate in the fitness program, and a 5-point scale was used for the question how frequently they intended to participate. The intention to perform the behavior and the actual behavior (whether or not they actually participated) were used to categorize the respondents into behavioral stages.

\section{Classification into Stages of Change}

At the moment of the questionnaire the maximum number of subjects were participating in the program, so at that time there were no vacancies in the program. Because of this situation the experimental and the comparison company were very comparable: for both groups there was, at the time of the questionnaire, no practical possibility of participating in the fitness program. In measuring the intention the subjects were asked to indicate if they intended to participate in an employee fitness program at once if there was a vacancy. Subjects who responded they would certainly start at once in the program, if a program was available to them, were placed in preparation stage. Almost all of the subjects in the preparation stage from the experimental worksite had already placed themselves on a waiting list to fill in a new place if a vacancy would occur, so they were already taking steps 
to change. Subjects in preparation stage in the comparison worksite did not have this possibility. Subjects were placed in contemplation stage if they responded they probably would like to start in the program if a program was available to them. These subjects were not yet certain if they wanted to start. Subjects were placed in precontemplation if they responded they had no intention to start in the program if a program was available to them. Subjects were placed into the action stage if they were enlisted in the exercise program and had actually started participating in the program. Since the program had only just started at the time the questionnaires were distributed, there were as yet no subjects in maintenance or relapse.

\section{RESULTS}

The study group

A total of 685 questionnaires was distributed among the personnel, 488 of which were returned. Total response was $71 \%$. The questionnaires were stratified and distributed over three groups: participants and nonparticipants at the fitness program from the experimental worksite and subjects from the comparison worksite. Among the group of participants in the fitness program at the experimental worksite all 240 questionnaires that were distributed were completed and returned, making the response in the action stage $100 \%$. Among the nonparticipants from the experimental worksite and among the comparison worksite a total of 445 questionnaires was distributed, of which 248 questionnaires were returned. This made the total response for the stages precontemplation, contemplation, and preparation $56 \%$. The group of nonparticipants from the experimental worksite received 265 questionnaires, of which $44 \%$ was returned. Of the 180 questionnaires distributed in the comparison worksite, $73 \%$ was returned. Total response in the experimental worksite, both participants and nonparticipants, was $71 \%$.

The average age of the respondents was $36(\mathrm{SD}=6.9)$, ranging from 20 to 55 . Of the respondents, $86 \%$ were engaged in active police work, while $14 \%$ had supportive or administrative tasks. The group of respondents consisted of $87 \%$ men 
and $13 \%$ women.

Within the experimental and the comparison groups, no differences were found between the precontemplation, contemplation, and preparation groups with regard to variables such as age, gender, the proportion of active police work versus supportive/administrative tasks, attitude, self-efficacy, social influence or intention. Hence, the precontemplation, contemplation and preparation stage groups from the district of Den Bosch and from the comparison district of Eindhoven were combined. This resulted in 48 respondents in the precontemplation stage (10\%), 105 respondents in the contemplation stage (22\%), 92 respondents in the preparation stage (19\%), and 240 respondents in the action stage (49\%).

\section{Relations between variables}

The correlations between the various components of the ASE model show that self-efficacy correlated most strongly with the stages of behavioral change $(r=0.51)$, followed by attitude $(r=0.37)$ and social influence $(r=0.30)$. All correlations were statistically significant $(p<0.001)$.

A stepwise multiple regression analysis of the ASE components showed that self-efficacy explained $27 \%$ of the variance in the stages of behavioral change. The significant unique contributions of attitude $(5 \%)$ and social influence $(1 \%)$ were relatively small (see Table 3.1). The total explained variance of the ASE components was $33 \%$. After the ASE components the demographics and other external variables (like type of work) did not have any significant contribution to the explained variance of the stages of change.

Table 3.1: Stepwise multiple regression analysis $(n=488)$, prediction of stage of behavioral change

\begin{tabular}{lccccccc} 
Step & Variable & $R$ & $R^{2}$ & $R^{2}$-change & $p<$ & $r$ & $\beta$ \\
\hline & & & & & & & \\
Prediction of stage of behavioral change: & & & & & \\
1. & Self-efficacy & 0.52 & 0.27 & 0.27 & 0.001 & 0.51 & 0.43 \\
2. & Attitude & 0.56 & 0.32 & 0.05 & 0.001 & 0.37 & 0.17 \\
3. & Social support & 0.58 & 0.33 & 0.01 & 0.001 & 0.30 & 0.14 \\
\hline
\end{tabular}


Differences between the precontemplation, contemplation, preparation and action stages

One-way analyses of variance using Scheffe's multicomparison test were used to determine any significant differences between the respondents in the four stages of behavioral change with regard to attitude, social influence, and self-efficacy.

Respondents in the action and preparation stages showed a significantly more positive attitude toward the fitness program than respondents in the precontemplation and contemplation stages (see Table 3.2). Respondents in the precontemplation stage had a significantly less positive attitude than those in the contemplation stage. No significant differences in encountered social support were found among those in precontemplation, contemplation, and preparation stage. Respondents in the action stage, however, experienced significantly more social support than those in the other stages.

Table 3.2: Mean values and significant differences in ASE scores between the four stages of behavioral change; precontemplation $(P)$, contemplation (C), preparation (PR) and action (A)

\begin{tabular}{|c|c|c|c|c|c|}
\hline Score & $\begin{array}{l}\mathrm{P} \\
\mathrm{n}=48\end{array}$ & $\begin{array}{l}C \\
n=105\end{array}$ & $\begin{array}{l}\mathrm{PR} \\
\mathrm{n}=92\end{array}$ & $\begin{array}{l}\text { A } \\
n=240\end{array}$ & $\begin{array}{l}\text { Oneway Scheffé } \\
p<0.05\end{array}$ \\
\hline Attitude & 0.60 & 1.20 & 1.76 & 1.85 & $\mathrm{P}<\mathrm{C} ; \mathrm{P}, \mathrm{C}<\mathrm{PR} ; \mathrm{P}, \mathrm{C}<\mathrm{A}$ \\
\hline Social support & 1.35 & 1.36 & 1.35 & 1.95 & $\mathrm{P}, \mathrm{C}, \mathrm{PR}<\mathrm{A}$ \\
\hline Self-efficacy & 0.27 & 0.93 & 1.55 & 1.77 & $\mathrm{P}<\mathrm{C} ; \mathrm{P}, \mathrm{C}<\mathrm{PR} ; \mathrm{P}, \mathrm{C}<\mathrm{A}$ \\
\hline
\end{tabular}

$(P<C$ : the mean value of $P$ is significantly less than the mean value of $C$ in a oneway analysis using Scheffé's multicomparison test) (attitude ranges from -6 to +6 ; social support from -3 to +3 ; selfefficacy from -3 to +3 )

Self-efficacy levels of those in action stage were significantly higher than those of subjects in precontemplation and contemplation stage. Self-efficacy levels of those in contemplation stage were significantly higher than those of subjects in precontemplation stage. The data from Table 3.2 have been visualized in Figure 3.1. 


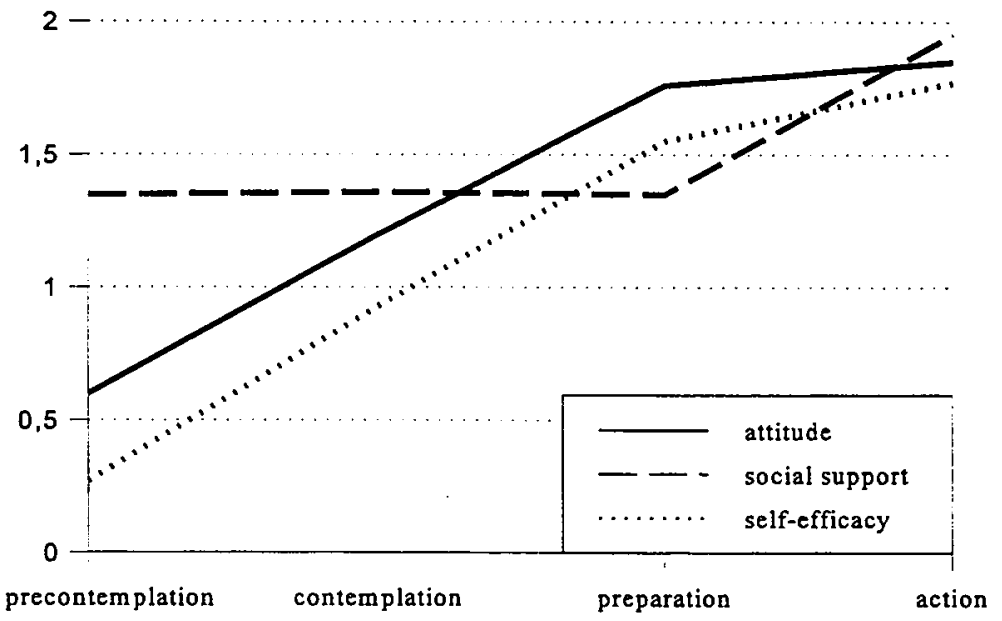

Figure 3.1: Mean scores per stage of behavioral change

Differences in attitude between the stages of behavioral change

The significantly greater positive attitude for those in preparation and action stages resulted from greater endorsement of the importance of the advantages of fitness training, such as improved physical condition, reduced risk of cardiovascular diseases, weight reduction, improved well-being, good supervision during fitness training, stress relief, better contacts with colleagues, and improved productivity at work (Table 3.3).

Table 3.3: Mean values and significant differences in attitude scores between the four stages of behavioral change; precontemplation ( $P$ ), contemplation (C), preparation (PR) and action (A)

\begin{tabular}{|c|c|c|c|c|c|}
\hline Irem & $\begin{array}{l}\mathrm{P} \\
\mathrm{n}=48\end{array}$ & $\begin{array}{l}\mathrm{C} \\
\mathrm{n}=105\end{array}$ & $\begin{array}{l}\mathrm{PR} \\
\mathrm{n}=92\end{array}$ & $\begin{array}{c}\mathrm{A} \\
\mathrm{n}=240\end{array}$ & $\begin{array}{l}\text { Oneway Scheffé } \\
p<.05\end{array}$ \\
\hline Improved physical condition & 0.81 & 1.38 & 2.01 & 2.38 & $\mathrm{P}, \mathrm{C}<\mathrm{PR} ; \mathrm{P}, \mathrm{C}<\mathrm{A}$ \\
\hline Reduced risk of CVD & 1.08 & 1.65 & 2.12 & 2.41 & $\mathrm{P}<\mathrm{PR} ; \mathrm{P}, \mathrm{C}<\mathrm{A}$ \\
\hline Weight reduction & 0.60 & 1.01 & 1.70 & 1.86 & $\mathrm{P}, \mathrm{C}<\mathrm{PR} ; \mathrm{P}, \mathrm{C}<\mathrm{A}$ \\
\hline Improved well-being & 0.88 & 1.65 & 2.27 & 2.77 & $\mathrm{P}<\mathrm{PR} ; \mathrm{P}, \mathrm{C}<\mathrm{A}$ \\
\hline Sufficient supervision & 0.35 & 1.01 & 1.28 & 2.13 & $\mathrm{P}<\mathrm{PR} ; \mathrm{P}, \mathrm{C}, \mathrm{PR}<\mathrm{A}$ \\
\hline Stress relief & 0.44 & 1.04 & 1.67 & 1.72 & $\mathrm{P}, \mathrm{C}<\mathrm{PR} ; \mathrm{P}, \mathrm{C}<\mathrm{A}$ \\
\hline Improved social contacts & 0.29 & 0.96 & 1.27 & 1.04 & $\mathrm{P}<\mathrm{C} ; \mathrm{P}<\mathrm{PR} ; \mathrm{P}<\mathrm{A}$ \\
\hline Improved productivity & 0.06 & 0.47 & 1.00 & 0.60 & $\mathrm{P}, \mathrm{C}<\mathrm{PR} ; \mathrm{P}<\mathrm{A}$ \\
\hline
\end{tabular}

$(P<C$ : the mean value of $P$ is significantly less than the mean value of $C$ in a oneway analysis using Scheffé's multicomparison test) $(-6=$ negative attitude; $+6=$ positive attitude) 
Differences in social influence between the stages of behavioral change

Respondents in the action stage perceived greater support for participation in the fitness program than those in the preparation, contemplation, and precontemplation stages, both from their superiors and from their colleagues and partners (see Table 3.4). A striking finding is that respondents in both the precontemplation and the contemplation stages experienced significantly more support from their superiors than did those in the preparation stage. Respondents in the precontemplation, contemplation, and preparation stages did not differ significantly in the support for participation received from colleagues and partners.

Table 3.4: Mean values and significant differences in perceived social support scores between the four stages of behavioral change; precontemplation $(P)$, contemplation (C), preparation (PR) and action (A)

\begin{tabular}{llllll}
\hline Item & $\mathrm{P}$ & $\mathrm{C}$ & $\mathrm{PR}$ & $\mathrm{A}$ & Oneway Scheffé \\
& $\mathrm{n}=48$ & $\mathrm{n}=105$ & $\mathrm{n}=92$ & $\mathrm{n}=240$ & $\mathrm{P}<.05$ \\
\hline
\end{tabular}

\begin{tabular}{llllll} 
Support from superiors & 1.25 & 1.12 & 0.68 & 1.75 & $\mathrm{PR}<\mathrm{P}, \mathrm{C} ; \mathrm{P}, \mathrm{C}, \mathrm{PR}<\mathrm{A}$ \\
Support from colleagues & 1.13 & 1.31 & 1.27 & 1.81 & $\mathrm{P}, \mathrm{C}, \mathrm{PR}<\mathrm{A}$ \\
Support from partner & 1.50 & 1.61 & 1.88 & 2.31 & $\mathrm{P}, \mathrm{C}, \mathrm{PR}<\mathrm{A}$ \\
\hline
\end{tabular}
$(\mathrm{P}<\mathrm{C}$ : the mean value of $\mathrm{P}$ is significantly less than the mean value of $\mathrm{C}$ in a oneway analysis using Scheffé's multicomparison test $)(-3=$ much opposition; $+3=$ much support $)$

Differences in self-efficacy between the stages of behavioral change

There were two general patterns in the differences in self-efficacy between the various stages of behavioral change (see Table 3.5). First, those in action and preparation stage found it significantly easier than those in contemplation and precontemplation stage to participate in the exercise program if their superiors were against participation, if colleagues disapproved of it, if they had insufficient time, if they were on standby duty, if they were doing night shifts, and if they had sore muscles (see Table 3.5). Second, subjects in action and preparation stage found it easier to participate than subjects in precontemplation stage if they had insufficient time or if they had sore muscles. 
Table 3.5: Mean values and significant differences in self-efficacy scores between the four stages of behavioral change; precontemplation $(P)$, contemplation (C), preparation (PR) and action (A)

\begin{tabular}{llllll}
\hline Item & $\mathrm{P}$ & $\mathrm{C}$ & $\mathrm{PR}$ & $\mathrm{A}$ & Oneway Scheffé \\
& $\mathrm{n}=48$ & $\mathrm{n}=105$ & $\mathrm{n}=92$ & $\mathrm{n}=240$ & $\mathrm{P}<.05$ \\
\hline
\end{tabular}

$\begin{array}{lrrrrl}\text { Superior disagrees } & 0.69 & 1.19 & 1.49 & 2.02 & \mathrm{P}<\mathrm{PR} ; \mathrm{P}, \mathrm{C}, \mathrm{PR}<\mathrm{A} \\ \text { Colleagues disagree } & 1.00 & 1.39 & 1.76 & 2.17 & \mathrm{P}<\mathrm{PR} \text { P,C,PR }<\mathrm{A} \\ \text { Insufficient time } & -0.77 & 0.11 & 1.35 & 1.67 & \mathrm{P}<\mathrm{C} \text {; }, \mathrm{C}<\mathrm{PR}, \mathrm{A} \\ \text { Stand-by duty } & 0.46 & 1.54 & 2.21 & 2.04 & \mathrm{P}, \mathrm{C}<\mathrm{PR}, \mathrm{A} \\ \text { Night shift } & -0.31 & 0.28 & 0.70 & 1.08 & \mathrm{P}<\mathrm{PR} ; \mathrm{P}, \mathrm{C}<\mathrm{A} \\ \text { Sore muscles } & 0.46 & 1.54 & 2.21 & 2.04 & \mathrm{P}<\mathrm{C} ; \mathrm{P}, \mathrm{C}<\mathrm{PR}, \mathrm{A}\end{array}$

$(\mathrm{P}<\mathrm{C}$ : the mean value of $\mathrm{P}$ is significantly less than the mean value of $\mathrm{C}$ in a oneway analysis using Scheffé's multicomparison test) $(-3=$ low self-efficacy; $+3=$ high self-efficacy)

\section{DISCUSSION}

The findings of the present study suggest that the ASE components show a clear pattern in the various stages of behavioral change (see Figure 3.1). Both attitude and self-efficacy showed a gradual, constant rise from the precontemplation stage to the preparation stage. The increase between the preparation and action stages was smaller. Social support showed a different pattern. The perceived social support was nearly identical in the precontemplation, contemplation, and preparation stages, while it was considerably larger in the action stage.

Self-efficacy was the best predictor of the stages of behavioral change. A possible explanation is that the work situation was such that it included many circumstances that complicate participation in a fitness program. Many of the selfefficacy items were clearly related to possible barriers to participation. This means that self-efficacy must be rather high if one is to participate under such circumstances. Because of the type of work ( $86 \%$ were engaged in active police work) the situations described in the self-efficacy items (being on standby duty, lack of time, variable shifts) largely determined the participation in the fitness program. After self-efficacy, attitude had the highest predictive value. Although respondents in all stages of behavioral change regarded participation in fitness programs as 
advantageous, there were significant differences between the stages. Respondents in the precontemplation and contemplation stages were significantly less convinced of the advantages of more and regular exercise. The contribution of social support over and above those of self-efficacy and attitude was very small, which might be partly explained by the fairly strong correlation between social support and attitude $(r=0.41)$. The importance of self-efficacy for exercise behavior was found in several other studies (Marcus \& Owen, 1992; Marcus, Selby et al., 1992; McAuley, 1993).

The attitude patterns found in the present study correspond with those found in earlier studies of smoking cessation programs. Respondents in the precontemplation and contemplation stages were least convinced of the advantages, while those who were seriously considering participation in the program (the preparation stage) did not differ significantly in their conviction from the actual participants. Other studies by Marcus and Owen (1992) and Prochaska et al. (1994) of behavior with respect to exercise gave similar results with regard to the advantages of more and regular exercise. A study of Godin et al. (1995) showed a different pattern in the attitude scores between different stages of the process of exercise adherence. This study resulted in the highest attitude scores for respondents in the second stage of exercise adherence (comparable to a combined contemplation and preparation stage) (Godin, Desharnais et al., 1995). These different results may be caused by the use of a different definition of the stages and the desired behavior (exercising in general versus participation in an employee fitness program), or by a different operationalization of the attitude concept.

Self-efficacy and social support showed patterns slightly different from those in previous research on smoking cessation (De Vries \& Backbier, 1994). Whereas in the present study the self-efficacy was found to be higher in the contemplation stage than in the precontemplation stage, previous research on smoking behavior found that self-efficacy was equally low in both stages. On the other hand, recent research on fitness programs also found a gradual rise in self-efficacy (Marcus \& Owen, 1992; Marcus, Selby et al., 1992). A possibly important difference between studies of smoking cessation and studies of fitness programs might be that those who want to stop smoking have usually already made several attempts at doing so. This would mean that smokers in the contemplation stage are relapsers, while the respondents 
who were contemplating participation in the fitness program in the present study were confronted with a new behavior. It is conceivable that people in the contemplation stage are more optimistic about their self-efficacy when starting a new behavior. Further research will be needed to show whether such high expectations of efficacy are also found among those people in the contemplation stage who have attempted to participate in fitness programs before, but have dropped out.

The social support factor also showed a different pattern from that found in the study of smoking cessation (De Vries \& Backbier, 1994). The encountered (slightly) positive social support was nearly identical for the precontemplation, contemplation, and preparation stages, while respondents in the action stage experienced significantly more social support. This is remarkable, since the social environment partly consists of the same people, superiors and colleagues. One explanation for this could be the decision to engage in an exercise program is not related to social support. Another explanation could be that the experience of social support becomes more salient when respondents are actually participating in the exercise program. Perceived social support in smoking cessation (De Vries \& Backbier, 1994) showed a different pattern, involving a gradual rise from the precontemplation to the action stage. A possible explanation for this difference is that participation in fitness programs is a completely new and relatively invisible behavior (much of the exercise training took place during lunch breaks or in the participants' spare time and exercise facilities that were used for the program were not located at the worksite itself, but in existing exercise schools located outside the workplace), while the behavior of smokers is usually very visible to their environment (smoking is still allowed at some parts of the worksite), as a result of which they may experience more clearly what the social environment thinks about that behavior.

A number of critical remarks have to be made about the present study. Although the total responses in the experimental and comparison worksites were much alike, there was a relatively higher response in the comparison worksite for the stages precontemplation, contemplation, and preparation (73\%), compared with the response within these stages in the experimental worksite (44\%). This selective 
response resulted in a distortion of the proportions between the various stages of behavioral change. These proportions can therefore not be regarded as representative for the entire police force. Some subjects in the preparation stage from the comparison worksite were probably very motivated to start but could not yet participate in a fitness program. Although the subjects in preparation stage from the experimental worksite had the same problem (being in the waiting group), this fact was probably more prevalent in the comparison worksite, which may have resulted in a higher response rate. However, since all subjects in the preparation stage (experimental and comparison worksite) were in the same waiting condition, and since subjects in preparation stage from the experimental worksite did not differ significantly from the comparison worksite on any of the determinants and demographics, it is not likely that the different response rates between the experimental and comparison worksite had a detrimental effect concerning the internal validity.

An important restriction of the study was its cross-sectional nature. This implies that it is not clear whether changes in the determinants lead to behavioral changes or whether behavioral changes lead to changes in the determinants. A longitudinal or cohort study over time could provide a better understanding of these relationships.

Since the fitness program was still in its initial stage, maintenance of the behavior and relapse could not be examined in the present study. Marcus and Owen (1992) found that self-efficacy and a positive attitude regarding the advantages of fitness training continued to rise among long-term participants. At the time of the present study, no participants had dropped out yet. Previous research, however, has shown dropout percentages of $50 \%$ over the first 3 to 6 months (Dishman, 1988). It is therefore recommended to analyze the determinants of drop-out more in detail, in order to be able to tailor information toward the specific needs of potential relapsers (Desharnais, Bouillon et al., 1986; Marcus \& Owen, 1992; Marcus, Selby et al., 1992).

The first step in designing promotional campaigns for industrial fitness programs is analyzing the advantages and disadvantages as perceived by employees and employers, the management's expectations, and the problems which may be 
anticipated. The present study suggests that promotional activities for industrial fitness programs should concentrate on persons in the precontemplation and contemplation stages, since people in these stages are insufficiently convinced of the advantages of a fitness program. These advantages, in terms of physical condition, weight reduction, sense of physical well-being, stress relief, and increased productivity, will have to be made more explicit. In addition, people in this stage expect many problems with regard to their ability to participate in the program. It is therefore of vital importance in designing a good promotional campaign to analyze the practical problems which could be expected to occur. For example, the promotional campaign in a company will have to be very clear about the possibilities for taking time off from work to engage in the fitness training, where and when the training sessions are held, how participants can deal with (or prevent) sore muscles, and, finally, how to deal with the opinions of one's superiors and colleagues. The present study showed that respondents in the action stage experienced significantly more social support. Perhaps the respondents in the other stages were insufficiently aware of the opinions of their superiors and colleagues. The opinions of the management and supervising staff will have to be clear. It is also conceivable that not all supervising staff are sufficiently convinced of the usefulness and feasibility of fitness programs, in which case they will have to be convinced first.

Recent studies suggest that promotion can generally be more effective if it is tailored to the specific behavioral stage of the receiver, an approach that has also been advocated for smoking cessation programs (De Vries \& Backbier, 1994). In the case of industrial fitness programs this may imply that people in the precontemplation stage are initially given more information on the advantages of the program, while those in the contemplation stage are given more information about its feasibility. It would also be possible to provide relapsers with information tailored to their specific needs. Before a stage-specific intervention can be designed, however, further research will be required, since the group of relapsers was not available in the present study. Further research will also be required to find out whether the patterns found in the present study can be replicated in other industrial situations. 


\title{
CHAPTER 4
}

\section{Maintaining participation in an employee fitness program: Determinants of high adherence, low adherence and dropout ${ }^{1}$}

\begin{abstract}
Background. This article presents the results of a study of the determinants of adherence level in an employee fitness program. Of all 236 employees who started participating in the program the determi. nants of level of participation during the program were studied by means of a pretest and posttest design.

Methods. The questionnaire was based on different theoretical concepts. The determinants measured included the attitude towards an employee fitness program, self-efficacy expectation and social support. Self-efficacy was assessed using two different measures. Level of participation was operationalized as bigh adherence, low adherence or dropouts.

Results. The results show that there were no differences in determinants between the groups at the start of the program. During the second measurement the high and low adberence groups were most convinced of the benefits of participation at the program. The low adherence group and the dropouts were least convinced of their own skills to participate at a fitness program.

Conclusions. Theoretical and practical implications are discussed. Both self-efficacy measures used, had a unique contribution to the explanation of exercise adherence. The differences in determinants between different adberence levels can be used to improve exercise adberence levels and prevent future dropout.
\end{abstract}

1 Published as:

Lechner, L., \& De Vries, H. (1995). Participation in an employee fitness program: determinants of high adherence, low adherence, and dropour. Joumal of Occupational and Environmental Medicine, $37,429-436$. 


\section{INTRODUCTION}

Getting enough physical activity can influence a wide variety of diseases, which can be of a physical or psychological nature. People who are physical active, have a longer life expectation time than inactive persons (Blair, Kohl et al., 1989). Physical activity forms an independent risk factor for getting CVD (Bijnen, Zonderland et al., 1991; Centers for Disease control and Prevention, 1993; Powell, Thompson et al., 1987). Furthermore, there is a growing body of evidence to suggest that physical exercise prevents getting certain forms of cancer (Blair, Kohl et al., 1993; Powell, Caspersen et al., 1989; Shepard, 1996; Shepard \& Shek, 1995). Furthermore, results of several studies suggest additional effects for exercise programs, when they are placed within the worksite, such as reduced health care costs, reduced absenteeism, and less employee turnover (Tsai, Braun et al., 1987; Bowne, Russel et al., 1984; Lynch, Golaszewski et al., 1990).

Exercise behavior is influenced by physiological, psychological, social, and behavioral determinants (Dishman, 1988; Sallis, Hovell et al., 1989). Motivating people to exercise and especially to maintain this behavior is a complex behavioral process. Results from several studies show that about $30 \%$ of employees within an organization will actually start participating when a program is offered to them (Oldridge, 1989). Furthermore, studies show that three to six months after the start, only 50 to $60 \%$ of the original participants are still participating in the program (Dishman, 1988; Marcus, Banspach et al., 1992; Oldridge, 1984). It is therefore important to analyze the factors that determine the maintenance of behavior in general and exercise behavior in particular.

Social psychological models suggest that behavior in general is determined by three important factors. The first factor is the attitude, consisting of the advantages and disadvantages of a particular behavior. These are also referred to as outcome expectations in Bandura's Social Learning Theory (Bandura, 1986). Attitudes can be assessed by measuring the beliefs that are associated with a particular behavior, and the evaluations of these beliefs (Ajzen \& Fishbein, 1980). The second factor consists of the social influences individuals encounter, such as social norms (Ajzen \& Fishbein, 1980). Social norms are determined by the normative beliefs of important 
referent persons about a behavior, and the individual's motivation to comply with these persons. The predictive power of the model for exercise behavior has been demonstrated in several studies (Godin \& Shepard, 1990; Godin, 1993), and evidence was found for a social factor measuring the impact of direct social support or pressure (Grube, Morgan et al., 1986; Lechner \& De Vries, 1995a). The third factor consists of self-efficacy expectations, which are beliefs of a person about his abilities to perform a particular behavior (Bandura, 1986). Increased self-efficacy will result in improved performance of this behavior. Research over the last few decades has stressed the importance of self-efficacy expectations to the initiation of action in general (Bandura, 1986; Schwarzer, 1992), as well as for exercise behavior in particular (Lechner \& De Vries, 1995a; Marcus \& Owen, 1992; McCauley, 1993). Recently the concept of self-efficacy has been added to the model of reasoned action by several researchers, although Ajzen (1991) refers to the concept as perceived behavioral control. The revised model is referred to as the model of planned behavior (Ajzen, 1991), or the ASE model (Attitude - Social influence - Efficacy model) (De Vries, Dijkstra et al., 1988; De Vries \& Backbier, 1994).

Prochaska and colleagues suggest in their transtheoretical model that the process of behavioral change can be divided into several stages (Prochaska \& DiClemente, 1983; Prochaska, Velicer et al., 1991). People can move from precontemplation via contemplation to action, and then to maintenance or relapse. Moreover, movement through the stages involves a cycling and recycling process. Recent applications of the model to exercise behaviors are reported by Marcus et al. (Marcus, Banspach et al., 1992; Marcus, Selby et al., 1992), and Booth et al (1993). However, relatively little information is available about the movement from action to either maintenance, which can be divided into high adherence and low adherence, or relapse or dropout from the program (Oldridge, 1984).

The present study aims to analyze the determinants of adherence (high, low, dropout) for participants who started participating in an employee fitness program, utilizing an integration of the above mentioned models. The goal of this study is to describe first the extent to which exercise adherence can be explained on the basis of the determinants self-efficacy, attitude, and social support. Second, this chapter will describe the differences in self-efficacy, attitude, and social support between a 
group of participants who started in an employee fitness program and who exhibit high adherence or low adherence to or drop out of the fitness program. Differences before the start and 10 months after the start of the program are described.

\section{METHODS}

\section{Respondents and procedures}

In January 1992, the Dutch National Police started a worksite health program for the District of Den Bosch. Within the framework of this program, employees could participare in a physical exercise program, performing supervised fitness exercises twice a week (once in their spare time, once during working hours). The program was evaluated using a pretest-posttest design among all participants who started in the program. Questionnaires for the first measurement were distributed among all employees who intended to participate in the program. They had to answer the first questionnaire before the start of the fitness program. Questionnaires for the second measurement were distributed among the same employees 10 months after the start of the project. The questionnaires were distributed by the fitness instructors and contact persons within the police force. This study was part of an extensive process and effect evaluation of the worksite health program.

\section{Classification into bigh adherence, low adberence, and dropouts}

During the program the exercise level of all participants was recorded, based upon the average exercise frequency per week in the program. Participants who had stopped exercising during the study period were classified as dropouts with an average exercise frequency of 0 . Participants who were still exercising in the program at the end of the study period were divided into high or low adherence groups. High adherence was defined as having an average exercise frequency of at least once a week during the study period, while low adherence was defined as having an average exercise frequency of less than once a week. 


\section{Questionnaire}

The questionnaire included questions about attitude, social influence, selfefficacy expectations, and demographic variables. The questionnaire was partly based on the results of an earlier study (Lechner \& De Vries, 1995a) of the determinants of participation in industrial fitness programs.

Attitude was measured following the procedure described by Ajzen and Fishbein (Ajzen \& Fishbein, 1980), using eight items on beliefs (b) about industrial fitness programs and the corresponding evaluations (e). The beliefs were assessed by 4-point scales $(+1$ to +4$)$, and the evaluations were measured by 5 -point scales ranging from important $(+2)$ to unimportant $(-2)$. Attitude scores were calculated by multiplying the beliefs by the corresponding evaluations $\left(\sum b^{*} e\right)$. The eight attitude scores were added to form a scale (Cronbach's alpha $=.79$ ).

Social influence was measured by three questions on the support or opposition by superiors, colleagues, and partners with regard to participation in the industrial fitness program. A 7-point scale was used, with answers ranging from much support $(+3)$ to much opposition $(-3)(\alpha=.63)$.

Self-efficacy was measured indirectly by proposing six different problem situations and asking the respondents whether they would feel able to participate in an industrial fitness program under these circumstances $(\alpha=.77)$. A 7-point scale was used, with answers ranging from certainly $(+3)$ to certainly not $(-3)$. Selfefficacy was also measured directly by asking in one item how often people were placed in situations in which they would not feel able to participate in the fitness program. A 5-point scale was used, ranging from very often (+1) to never (+5).

In addition to attitude, social influence and self-efficacy, questions were asked about age, sex, and the type of work the respondent was engaged in. Furthermore, to measure exercise behavior before the start of the program, the average sports frequency was measured by asking how many times the respondents usually exercised each week, for a duration of at least 20 minutes.

Data analyses included basic descriptive statistics of the different groups. Statistical differences $(p<.05)$ between the groups at the first and second measurement were evaluated using ANOVA with Tukey HSD contrast, or chisquare $\left(\chi^{2}\right)$ tests for categorical variables. Differences in determinants within the 
groups between the first and second measurement were analyzed with MANOVA repeated measurements. Regression analyses were used to assess the predictive value of the determinants toward the average weekly exercise frequency in the program.

\section{RESULTS}

\section{The study group}

At the end of the study period the 236 participants who had started the program could be divided into three groups: high adherence $(n=58)$, low adherence $(n=78)$ and dropouts $(n=100)$. In the first measurement a total of 236 questionnaires were distributed among all participants in the program, all of them were fully completed and returned. In the second measurement 159 of 236 questionnaires $(67 \%)$ were fully completed and returned. Total response differed among the groups: $95 \%$ of high adherence respondents returned the second questionnaire $(n=55)$, compared to $83 \%$ of the low adherence group $(n=65)$ and $39 \%$ of the dropouts of the exercise program $(n=39)$. No significant differences on demographic characteristics (age, sex, type of work) were found between response and nonresponse at the second questionnaire. Furthermore, no significant differences were found in mean scores and item scores of attitude, social support, and self-efficacy in the first measurement between the response and nonresponse at the second questionnaire.

The average age of the respondents who participated in both questionnaires was 36.7 years $(S D=7.0)$, ranging from 21 to 53 years. Of all the respondents, $83 \%$ were engaged in active police work, while $17 \%$ had supportive or administrative tasks. The group of respondents included $90 \%$ men and $10 \%$ women. No significant differences on these variables were found between the three groups high adherence, low adherence, and dropout groups.

\section{Relations between variables}

The components of the ASE model during the first measurement showed no significant correlations with the average exercise frequency or the adherence level 
during the program (high adherence, low adherence or dropout). The correlations between the components of the ASE model during the second measurement showed that the indirectly measured self-efficacy score correlated most strongly with the average exercise frequency $(r=.50)$, followed by the directly measured selfefficacy $(r=.43)$ and the attitude $(r=.31)$. All of these correlations were statistically significant $(p<.001)$. The correlation of the social support was not as strong $(r=.18$; $\mathrm{p}<.05)$

A stepwise multiple regression analysis of the ASE components at the second measurement showed that the indirectly measured self-efficacy explained $25 \%$ of the variance in the weekly average exercise frequency in the program (from 0 to 2 times), followed by significant unique contributions of the directly measured selfefficacy (10\%) and attitude (4\%) (Table 4.1). Social support showed no extra significant unique contribution, nor did any interaction terms of self-efficacy, attitude, and social support. The total explained variance of the ASE components at the second measurement was $39 \%$. None of the demographic characteristics made a unique contribution to the regression.

Table 4.1: Stepwise multiple regression analysis $(n=159)$, prediction of average exercise frequency at the second measurement

\begin{tabular}{llllllll} 
Step & Variable & $\mathrm{R}$ & $\mathrm{R}^{2}$ & $\mathrm{R}$-change & $\mathrm{P}<$ & $\mathrm{r}$ & $\beta$ \\
\hline & & & & & & & \\
Prediction of average exercise frequency: & & & & & & \\
1. & Self-efficacy, indirectly & 0.50 & 0.25 & 0.25 & 0.001 & 0.50 & 0.37 \\
2. & Self-efficacy, directly & 0.59 & 0.35 & 0.10 & 0.001 & 0.43 & 0.33 \\
3. & Atritude & 0.62 & 0.39 & 0.04 & 0.005 & 0.31 & 0.19 \\
\hline
\end{tabular}

\section{Differences between groups before the start of the program}

To analyze the determinants of exercise behavior further the participants were classified into high adherence, low adherence, and dropouts. At pretest there were very few significant differences between the three groups in mean scores and item scores of attitude, social support, and self-efficacy. Only one item showed a significant difference between the groups: the high adherence and low adherence 
groups were more convinced that participation would lead to improved productivity than the respondents who would drop out during the program.

Before the start of the program the high adherence group had a significantly higher average sports frequency per week than the dropouts $(p<.05)$. Average sports frequencies per week of high and low adherence groups and dropouts were $1.6,1.2$, and 1.0 times respectively. No significant differences on demographic characteristics (age, sex, type of work) were found between the high adherence, low adherence and dropout groups.

\section{Differences between groups at posttest}

Differences between the groups in mean scores and item scores of attitude, social support, and self-efficacy were much more explicit at the posttest (Table 4.2). The overall attitude for the high and low adherence groups was significantly higher than the overall attitude for the dropouts. This difference in overall attitude was caused by several attitude items. The high and low adherence groups were more convinced than the dropouts that participation in the fitness program was under sufficient supervision, and that it resulted in an improved condition, in a reduced risk for cardiovascular disease (CVD), in improved well-being, and in stress relief. Furthermore, the high adherence group was significantly more convinced than the dropouts that participation in the fitness program would improve their productivity at work.

The three groups encountered no differences with respect to the overall amount of social support. However, the low adherence group experienced significantly more social support from their superiors than did the dropouts.

Overall self-efficacy was significantly greater for the high adherence group than for the low adherence group; the dropout group had a significantly lower score than the high and low adherence groups. The differences in overall score were caused by differences in several self-efficacy items. The high adherence group found it significantly easier than the low adherence group to participate in the exercise program if there was insufficient time and if they were on stand-by duty. Furthermore, the high adherence group found it significantly easier than the dropouts to participate in the exercise program if colleagues disagreed with their 
participation, if there was insufficient time, if they were on stand-by duty, if they were doing night shifts, or if they had sore muscles. Finally, the low adherence group found it significantly easier than the dropouts to participate if colleagues disagreed with their participation, if there was insufficient time, if they were on stand-by duty, or if they had sore muscles. The directly measured self-efficacy score showed that the high adherence group was placed significantly less often than the low adherence and dropout groups in situations in which they did not feel able to participate in the fitness program.

Table 4.2: Mean values and significant differences in ASE scores between the three groups high adherence (HA), low adherence (LA) and dropouts (DO) at the second measurement

\begin{tabular}{|c|c|c|c|c|}
\hline Variable & $\begin{array}{l}\mathrm{HA} \\
\mathrm{n}=55\end{array}$ & $\begin{array}{l}\mathrm{LA} \\
\mathrm{n}=65\end{array}$ & $\begin{array}{l}\mathrm{DO} \\
\mathrm{n}=39\end{array}$ & $\begin{array}{l}\text { Tukey HSD } \\
(p<0.05)\end{array}$ \\
\hline Attitude total & 2.35 & 2.27 & 1.45 & $\mathrm{HA}, \mathrm{LA}>\mathrm{DO}$ \\
\hline improved condition & 2.40 & 2.47 & 1.62 & $\mathrm{HA}, \mathrm{LA}>\mathrm{DO}$ \\
\hline reduced risk CVD & 3.02 & 3.08 & 2.05 & $\mathrm{HA}, \mathrm{LA}>\mathrm{DO}$ \\
\hline weight reduction & 1.86 & 1.59 & 1.37 & \\
\hline improved well-being & 3.18 & 2.88 & 1.87 & $\mathrm{HA}, \mathrm{LA}>\mathrm{DO}$ \\
\hline sufficient supervision & 3.11 & 3.20 & 1.74 & $\mathrm{HA}, \mathrm{LA}>\mathrm{DO}$ \\
\hline stress relief & 2.53 & 2.33 & 1.36 & $\mathrm{HA}, \mathrm{LA}>\mathrm{DO}$ \\
\hline improved social contacts & 1.67 & 1.69 & 1.21 & n.s. \\
\hline improved productivity & 1.04 & 0.85 & 0.41 & $\mathrm{HA}>\mathrm{DO}$ \\
\hline Social support total & 1.81 & 1.80 & 1.48 & n.s. \\
\hline support superiors & 1.58 & 1.78 & 1.10 & $\mathrm{LA}>\mathrm{DO}$ \\
\hline support colleagues & 1.58 & 1.52 & 1.42 & n.s. \\
\hline support partner & 2.26 & 2.08 & 1.87 & n.s. \\
\hline Self-efficacy total & 1.96 & 1.51 & 0.83 & $\mathrm{HA}>\mathrm{LA}>\mathrm{DO}$ \\
\hline superior disagrees & 2.23 & 1.77 & 1.69 & \\
\hline colleagues disagree & 2.49 & 1.97 & 1.62 & $\mathrm{HA}, \mathrm{LA}>\mathrm{DO}$ \\
\hline insufficient time & 1.95 & 1.34 & -.15 & $\mathrm{HA}>\mathrm{LA}>\mathrm{DO}$ \\
\hline stand-by duty & 1.93 & 1.37 & 0.51 & $\mathrm{HA}>\mathrm{LA}>\mathrm{DO}$ \\
\hline night shift & 1.13 & 0.56 & -.16 & $\mathrm{HA}>\mathrm{DO}$ \\
\hline sore muscles & 2.36 & 2.08 & 1.41 & $\mathrm{HA}, \mathrm{LA}>\mathrm{DO}$ \\
\hline Self-efficacy direct & 3.93 & 3.24 & 2.74 & $\mathrm{HA}>\mathrm{LA}, \mathrm{DO}$ \\
\hline
\end{tabular}


Improvement between first and second measurement

Next to looking at the absolute scores, differences between the first and second measurements were analyzed using MANOVA (repeated measurements) (Table 4.3).

Table 4.3: Mean changes in ASE scores between the three groups high adherence (HA), low adherence (LA) and dropouts (DO) at the second measurement

\begin{tabular}{|c|c|c|c|c|}
\hline Variable & $\begin{array}{l}\mathrm{HA} \\
\mathrm{n}=55\end{array}$ & $\begin{array}{l}\mathrm{LA} \\
\mathrm{n}=65\end{array}$ & $\begin{array}{l}\mathrm{DO} \\
\mathrm{n}=39\end{array}$ & $\begin{array}{l}\text { Manova repeated } \\
\text { measures }(p<0.05)\end{array}$ \\
\hline $\begin{array}{l}\text { Artitude total } \\
\text { improved condition } \\
\text { reduced risk CVD } \\
\text { weight reduction } \\
\text { improved well-being } \\
\text { sufficient supervision } \\
\text { stress relief } \\
\text { improved social contacts } \\
\text { improved productivity }\end{array}$ & $\begin{array}{l}0.27 \\
0.32 \\
0.46 \\
0.21 \\
0.02 \\
0.46 \\
0.42 \\
0.25 \\
0.15\end{array}$ & $\begin{array}{r}0.47 \\
0.14 \\
0.81 \\
-0.55 \\
0.30 \\
0.94 \\
0.80 \\
0.78 \\
0.39\end{array}$ & $\begin{array}{l}-0.45 \\
-0.59 \\
-0.64 \\
-0.24 \\
-0.56 \\
-0.16 \\
-0.05 \\
0.18 \\
0.13\end{array}$ & $\begin{array}{l}\mathrm{HA}, \mathrm{LA}>\mathrm{DO} \\
\mathrm{HA}, \mathrm{LA}>\mathrm{DO} \\
\mathrm{HA}, \mathrm{LA}>\mathrm{DO} \\
\mathrm{HA}>\mathrm{LA} \\
\mathrm{LA}>\mathrm{DO} \\
\mathrm{LA}>\mathrm{DO} \\
\mathrm{LA}>\mathrm{DO} \\
\text { n.s. } \\
\text { n.s. }\end{array}$ \\
\hline $\begin{array}{l}\text { Social support total } \\
\text { support superiors } \\
\text { support colleagues } \\
\text { support partner }\end{array}$ & $\begin{array}{r}-0.01 \\
-0.13 \\
0.07 \\
0.02\end{array}$ & $\begin{array}{r}-0.19 \\
0.13 \\
-0.27 \\
-0.27\end{array}$ & $\begin{array}{l}-0.52 \\
-0.82 \\
-0.42 \\
-0.39\end{array}$ & $\begin{array}{l}\mathrm{HA}>\mathrm{DO} \\
\mathrm{HA}, \mathrm{LA}>\mathrm{DO} \\
\mathrm{HA}>\mathrm{LA}, \mathrm{DO} \\
\mathrm{HA}>\mathrm{LA}, \mathrm{DO}\end{array}$ \\
\hline $\begin{array}{l}\text { Self-efficacy total } \\
\text { superior disagrees } \\
\text { colleagues disagree } \\
\text { insufficient time } \\
\text { stand-by dury } \\
\text { night shift } \\
\text { sore muscles }\end{array}$ & $\begin{array}{r}0.10 \\
0.17 \\
0.23 \\
0.24 \\
0.08 \\
-0.30 \\
0.20\end{array}$ & $\begin{array}{r}-0.24 \\
-0.15 \\
-0.06 \\
-0.42 \\
-0.19 \\
-0.71 \\
0.13\end{array}$ & $\begin{array}{l}-1.06 \\
-0.64 \\
-0.71 \\
-1.84 \\
-1.15 \\
-1.37 \\
-0.74\end{array}$ & $\begin{array}{l}\mathrm{HA}>\mathrm{LA}>\mathrm{DO} \\
\mathrm{HA}>\mathrm{DO} \\
\mathrm{HA}, \mathrm{LA}>\mathrm{DO} \\
\mathrm{HA}>\mathrm{LA}>\mathrm{DO} \\
\mathrm{HA}, \mathrm{LA}>\mathrm{DO} \\
\mathrm{HA}, \mathrm{LA}>\mathrm{DO} \\
\mathrm{HA}, \mathrm{LA}>\mathrm{DO}\end{array}$ \\
\hline $\begin{array}{l}\text { Self-efficacy direct } \\
\text { (HA }>\text { DO indicates that } \\
\text { than the mean change of } D\end{array}$ & $\frac{-0.23}{\text { mean }}$ & $\frac{-0.63}{\mathrm{HA} i}$ & $\frac{-1.44}{\text { antly } \mathrm{m}}$ & $\begin{array}{l}\mathrm{HA}>\mathrm{LA}>\mathrm{DO} \\
\text { ive (or less negative) } \\
\text { nts) }\end{array}$ \\
\hline
\end{tabular}

The attitude toward participation among high and low adherence participants had become more positive, and the attitude of the dropouts had fallen. This effect in overall attitude was caused by differences in several attitude items. Since the first measurement the high adherence group had increased significantly 
more than the dropouts their conviction that participation in the fitness program would lead to an improved condition and to a reduced risk of CVD. The high adherence group had become significantly more convinced than the low adherence group that participation would lead to weight reduction. The low adherence group had become more convinced than the dropouts that participation at the fitness program would be guided by sufficient supervision, that participation would lead to an improved condition, to a reduced risk of CVD, to improved well-being, and to stress relief.

Results also show that the high adherence group encountered significantly less decline in their experienced social support than did the dropouts. The effect in this differential change in social support was caused by differences in several social support items. Since the first measurement the high adherence group experienced significantly more support from their colleagues and partner than did the low adherence group and the dropouts. Furthermore, the dropouts experienced a greater decline in the social support from their superiors than did the high and low adherence groups.

The high adherence group reported higher increases of their overall selfefficacy than the low adherence group and the dropouts, and dropouts experienced a decline in their overall self-efficacy. These differences were caused by various selfefficacy items. The dropouts had a significantly greater decline than the high and low adherence groups in their expectations that they would be able to participate in the program if colleagues disagreed, if they were on stand-by duty, if they were working in the night shift, or if they had sore muscles. The high adherence group had greater expectations than the dropouts that they would be able to participate in the program if superiors disagreed and if they had insufficient time. Furthermore, the low adherence group experienced a significantly lower decline in their expectations than the dropouts that they would be able to participate if they had insufficient time.

The decline in the directly measured self-efficacy score was significantly less for the high adherence group than for the low adherence group and the dropouts; the dropout group had a significantly greater decline in their direct self-efficacy than the high and low adherence groups. The dropouts had the greatest increase in 
the times they were in situations in which they did not feel able to participate at the fitness program.

\section{DISCUSSION}

The indirectly measured self-efficacy at the second measurement was the best predictor of average exercise frequency, followed by the directly measured selfefficacy and attitude. The self-efficacy scores, both directly and indirectly measured, showed clear patterns. Before the start of the program self-efficacy was equally positive for all groups, but after the start of the project different developments occurred. The high adherence group did not change much in self-efficacy between the first and second measurements, but self-efficacy fell significantly for the low adherence group. The dropout group showed the greatest decline in self-efficacy scores, significantly more than the low adherence group. The self-efficacy scores at the second measurements, both directly and indirectly measured, were the best predictors of average exercise frequency. The importance of self-efficacy for exercise adherence was also found in several other studies (Desharnais, Bouillon et al., 1986; Marcus \& Owen, 1992; Marcus, Selby et al., 1992; McAuley, 1993).

A possible explanation for the importance of self-efficacy in this study is that the work situation was such that it included many circumstances that complicated participation in a fitness program. Many of the self-efficacy items were clearly related to possible barriers to participation, regarding types of situations and how often difficult situations did occur. Consequently, self-efficacy must be rather high if one is to participate under such circumstances. After the indirectly measured selfefficacy, the directly measured self-efficacy had the highest predictive value of the average exercise frequency. The correlation between the two self-efficacy factors was not very high $(r=.22)$. Both concepts seem to measure different aspects of selfefficacy. The scale of six items measured how difficult it is to participate in certain situations (indirect), and the direct self-efficacy questions measured how often difficult situations occur. The two aspects of self-efficacy seem to be complementary to each other. 
After self-efficacy, attitude had the highest predictive value of the average exercise frequency at the second measurement. The importance of attitude for exercise adherence was also found in several other studies (Desharnais, Bouillon et al., 1986; Marcus, Rakowski et al., 1992). The overall attitude toward participation was positive for the high and low adherence groups and the dropouts, in both the first and second measurements. Between the first and second measurements the attitude toward participation became more positive for the high and low adherence groups, and it became significantly less positive for the dropouts.

Social support did not make a unique contribution at the second measurement. This might be partly explained by the correlation with attitude $(r=.47)$ and the overall self-efficacy $(r=.27)$. The experienced social support before the start of the program was very positive for all groups, but there was a difference in development between the first and second measurements: for the high and low adherence groups there were no differences, whereas the social support reported by the dropouts had declined. It is possible that the social support influences the adherence level more indirectly, through attitude and self-efficacy.

At the second measurement differences were found with respect to motivational stages. Respondents with the highest motivation to participate, the high adherence group, differed from the low adherence group and the dropouts on self-efficacy. The high adherence group had the highest self-efficacy, the low adherence had an intermediate position, and the dropouts had the lowest selfefficacy. No differences were found on the attitude between high and low adherence, but these two groups had a significantly more positive attitude than the dropouts. The three motivational groups did not differ in general on encountered social support. These results partly support the $\varnothing$-pattern reported by $D e$ Vries and Backbier (1994) suggesting a relative importance of attitudes and self-efficacy for different motivational stages in smoking. This may suggest a more general pattern indicating that people unmotivated to adopt a particular behavior may be characterized by a lack of positive attitude and low self-efficacy, whereas motivated people are characterized by a positive attitude, but still lack self-efficacy. Individuals who are highly motivated to adopt a new behavior may be characterized by a positive attitude and high self-efficacy. 
This chapter analyzed determinants of adherence both before as well as 10 months after the start, using ANOVA Tukey HSD. Additionally changes in determinants during the research period were measured, using MANOVA repeated measurements. Measuring differences at the posttest is therefore different from measuring differences in change between pretest and posttest. The two analytical techniques seem to be complementary to each other. Consequently, the analytical techniques show different results on two of four total scales (social support, direct self-efficacy) and on 11 of 17 item scales (Tables 4.2 and 4.3).

This study had several limitations. Response at the second measurement differed per group: $95 \%, 83 \%$ and $39 \%$ for high and low adherence and dropout groups respectively. The results for the dropouts therefore cannot simply be generalized to all dropouts from the program. During the research period, people either kept participating with a low or high average exercise frequency, or they dropped out of the program. Although the cohort study included two measurements, it is unclear whether changes in the determinants at posttest led to either high or low participation or dropout, or whether the participation level (high, low, or dropout) led to changes in the determinants of exercise. A longitudinal or cohort study with more frequent measurements within the study period could provide a better understanding of these relationships.

\section{Implications}

Respondents who were still participating at the end of the study period showed different participation levels. Both the absolute attitude score at posttest as well as difference scores indicate that the high and low adherence groups do not differ greatly on the perceived (positive) outcomes of exercise. A similar conclusion can be made with respect to social support, although the low adherence group seems to experience a relatively greater drop in support than the high adherence group. Grcater differences between the groups emerged with respect to self-efficacy. Consequently, messages focusing on improving adherence should focus on how to overcome the barriers (although some reinforcements about attitudinal and social outcomes may be needed as well). Hence, stimulating the low adherence group to participate more implies enhancing their self-efficacy expectations. The low 
adherence group was significantly less convinced that they would be able to participate in the program under different circumstances. It is difficult to determine whether this lack of confidence was caused by objective concrete barriers or by subjective estimations of their ability to overcome these barriers. Because no differences were found between the high and low adherence groups for age, sex, and type of work (active police work or supportive and administrative work), the latter explanation may be more plausible. Hence, practical information about how to overcome certain practical barriers and how to participate in the fitness program despite these barriers seems necessary for the low adherence group.

There were differences between respondents who were still participating at the end of the research period (high and low adherence) and the dropouts. People who dropped out of the program were less convinced of the advantages of the program in comparison with their conviction before the start of the program, whereas people who still participated were even more convinced of the advantages than they were before the start. It is unclear whether the decline in attitude preceded dropping out of the program or the reverse was the case. However, it seems very important to keep the motivation for participating high. By monitoring motivational level regularly, lapses in motivation to participate could be prevented or detected early, thus facilitating actions to remotivate the participant in time.

Another explanation for dropping out is that the dropouts had unrealistic expectations of the advantages and disadvantages of fitness before they started, possibly because of lack of experience. This explanation is in accordance with the significantly lower rate of participation in sports they had before the start of the program. This lack of experience could also be one of the reasons why self-efficacy scores declined substantially for the dropouts. Process evaluation showed that many dropouts reported difficulty combining fitness with work and free time as reasons for quitting. Hence, participants with only little exercise experience (low average sports frequency before the start of the program) need to receive well-balanced and realistic information before entering into a fitness program about the advantages and disadvantages of exercising as well as factors that facilitate or discourage participation in such a program. This may result in a situation in which they are better prepared for setbacks and difficulties they will experience while trying to 
Chapter 4

maintain their new behavior. 


\title{
CHAPTER 5
}

\section{Attitudes according to the Theory of Reasoned Action: Do we need to include evaluations?}

\begin{abstract}
Background. Measuring attitudes according to the theory of reasoned action bas been criticized in recent years. It has been suggested that the structure of the attitude, which is formed by adding up the different product scores of the beliefs and their evaluations, causes both practical and theoretical problems. This study was done to test these objections to empirical data and to see if there are possible alternatives to the traditional way of measuring attitudes.

Methods. Theoretical questions were tested using empirical data from a longitudinal study that assessed intention and determinants (such as beliefs and evaluations) of participation in an employee fitness program on two occasions. Regression analyses tested whether the multiplicative attitudes concept could explain additional variance in intention, besides beliefs and evaluations, both on item - and concept level. Moreover, in multiple regression analyses the explained variance of attitudes was compared to that of the separate belief and evaluation concepts.

Results. Correlations showed that attitudes were very similar to the beliefs from which they were derived. The multiplicative attitude concept could not explain any additional variance in intention over and above the belief and evaluation concepts. On item level, the extra explained variance of attitude items was minimal. Further multiple regression analyses showed that the total explained variance of attitudes and other determinants on intention remained similar if attitudes were replaced by beliefs.

Conclusions. It was concluded that the traditional measurement of attitudes bas possible weaknesses and is not statistically necessary. When beliefs concerning a bebavior are clearly formulated as either positive or negative outcomes, assessing attitudes by only measuring beliefs seems to form a useful and relevant alternative.
\end{abstract}

1 Submitted for publicarion as:

Lechner, L., De Vries, H., \& Kok, G. Atritudes according to the Theory of Reasoned Action: Do we need to include evaluations? 


\section{INTRODUCTION}

The importance of social psychological models in understanding behavior is well recognized. In recent decades, some of these models have suggested that behavior is determined by the intention to perform this behavior. This intention, in general, is determined by several factors: attitude, social influence and, in more recent years, self-efficacy. These factors have been integrated in models such as the Theory of Reasoned Action (TRA) (Fishbein \& Ajzen, 1975; Ajzen \& Fishbein, 1980), its successor the Theory of Planned Behavior (Ajzen, 1991) or the ASE-model (Attitude - Social influence - self-Efficacy) (De Vries, Dijkstra et al., 1988; Lechner \& De Vries, 1995a; 1995b), which was derived from the Model of Reasoned Action and the Social Learning Theory (Bandura, 1986).

The TRA, which was developed over 20 years ago, was derived from several publications on attitudes, intentions and behavior (Ajzen \& Fishbein, 1970; 1972; 1974). The first publications on the TRA were reported in 1975 and 1980 (Fishbein \& Ajzen, 1975; Ajzen \& Fishbein, 1980). The original TRA stated that behavior is determined by the intention to perform this behavior. The intention, in turn, is determined by two factors. The first factor is the attitude, consisting of the advantages and disadvantages of a particular behavior. These are also referred to as outcome expectations in Bandura's Social Learning Theory (Bandura, 1986). The Theory of Reasoned Action provides clear suggestions on how to assess attitudes. Attitudes can be assessed by measuring the beliefs that are associated with a particular behavior (exercise will improve my physical condition), and the evaluations of these beliefs (improved physical condition is very positive for me) (Ajzen \& Fishbein, 1980). To assess the attitude, the different beliefs are multiplied with their evaluations. This makes the attitude a multiplicative function of the beliefs and their evaluations.

A second factor that can influence people's intention to perform a behavior consists of the social influences people are subject to. The TRA assesses social influence in a similar way to how it assesses attitudes, by using a multiplicative function called subjective or social norm. The social norm measures the impression people have of how significant others feel, in general, about them performing the 
behavior. However, several authors have suggested other operationalizations of social influence, like observational learning or modeling (Cialdini, Kallgren et al., 1991; De Vries, Backbier et al., 1995; Grube, Morgan et al., 1986; Reno, Cialdini et al., 1993), and direct social support or pressure for people to enact in the healthy or unhealthy behavior (De Vries, Backbier et al., 1995).

In recent years, the Attitude - Social influence - self-Efficacy (ASE) model and the Theory of Planned Behavior (TPB) have also included a third factor in their models. This factor consists of self-efficacy expectations, which are a person's beliefs about his or her abilities to perform a particular behavior (Bandura, 1986). In the Theory of Planned Behavior, Ajzen refers to the concept as perceived behavioral control (Ajzen, 1991). Increased self-efficacy results in improved performance of this behavior. Research over the last decades has stressed the importance of self-efficacy expectations for getting people to change their behavior in general (Bandura, 1986; Schwarzer, 1992), as well as for exercise behavior in particular (Godin \& Shepard, 1990; Marcus, Selby et al., 1992; Lechner \& De Vries, 1995a; 1995b).

These determinants - intention - behavior models have been widely used in recent years. Several review studies illustrated the importance of these models for applications to various behaviors like addictions, automobile use, eating, exercise and HIV/AIDS prevention (Godin \& Kok, 1996; Sheppard, Hartwick et al., 1988; Van den Putte, 1993).

\section{The attitude intention relation}

Measuring attitudes (and social norms) according to the traditional method of the TRA has been criticized in recent years for various reasons (Evans, 1991; Van den Putte, Saris et al., 1995; Valiquette, Valois et al., 1988). These criticisms have focused on different aspects of the attitude concept. However, some of these criticisms are a result of the same basic construction of the attitude concept, in that it is a combination of two other concepts (beliefs and evaluations). To assess the attitude, the different beliefs (b) are multiplied with their evaluations (e), and are then summed together. This makes the attitude a multiplicative function of the beliefs and their evaluations. 
attitude $=\sum b_{i} e_{i}$

$$
=b_{1} e_{1}+b_{2} e_{2}+b_{3} e_{3}+\ldots+b_{n} e_{n}
$$

Since attitude according to the TRA/TPB is conceived as multiplying and adding up the different beliefs and their evaluations, the correlation between this concept and the intention is difficult to interpret. The true magnitude of the correlation of the multiplicative composition to intention is unknown and susceptible to scaling effects (Evans, 1991; Swanborn, 1996; Valiquette, Valois et al., 1988; Van den Putte, Saris et al., 1995). Several studies have indicated that correlations of a multiplicative composition with a third variable could vary a lot, depending on the scaling (Evans 1991; Falbo \& Becker, 1980; Sparks, Hedderly et al., 1991; Van den Putte, Saris et al., 1995). Some recent studies have illustrated these possible scaling effects with results from empirical data (Ajzen, 1991; Bagozzi, 1984; Hewstone \& Young, 1988; Mellenbergh, Molendijk et al., 1990; Sparks, Hedderly et al., 1991). Ajzen (1991) concluded that the value labels of both beliefs and evaluations should be coded bipolar (e.g., from -3 to +3 for a 7-point scale) instead of unipolar (e.g., from 1 to 7 for a 7-point scale), since bipolar coding resulted in higher correlations with the global attitude measure. Hewstone and Young (1988) showed that depending on the values that were given to the answering scales of the beliefs and evaluation, the correlation of the product score attitude with the dependent intention variable differed from .30 to .46. Mellenbergh et al. (1990) showed that correlations of an additive product variable with a third external variable could vary from .27 to .50 , depending on the value labels of the product variables. These differences were due to the arbitrary decision by the researchers as to how to score the respondents' answers numerically (Evans, 1991). Therefore, these scaling effects form a serious threat to the reliability of such additive product terms. Furthermore, since both beliefs and evaluations are recommended to be scaled on a bipolar scale (e.g., from -3 to +3) (Ajzen, 1991), an additional interpretation problem arises when two negative scores are multiplied, resulting in a meaningless positive score (Valiquette, Valois et al., 1988). Finding a good interpretation of the attitude correlations with other variables thus seems difficult. Moreover, since correlation of attitudes with dependent variables are used to index effect size in meta-analyses, this may provide a distortion of presented data 
(Evans, 1991).

From a statistical point of view, the multiplicative concept of attitude is a combined concept of several interaction terms between the beliefs and the evaluations of these beliefs. However, within a regression analysis an interaction term can only be included if the separate concepts are first entered in the analysis, followed by the interaction term. An interaction term should be included in the analyses only if there is extra explained variance from this term on top of the already included separate terms. However, studies where the attitude itself was treated as an interaction term, have hardly been reported. Evans (1991) gives clear suggestions on the way to appropriately test whether this multiplicative function is justified. In his study, he suggests that the multiplicative function can be checked on item level or on concept level, using a three step regression analysis. In the first and second step the separate items or concepts (beliefs, evaluations) are first entered in the analysis, followed by the interaction term (beliefs * evaluations). The increase in explained variance $\left(R^{2}\right)$ going from step 2 to step 3 indicates whether the multiplicative version is better than the additive model (Evans, 1991).

Because of these difficulties that arise when using attitude as an additive product term of beliefs and evaluations, some studies, like the applications of the ASE model, have decided to omit the evaluations from the attitude concept (Brug, Lechner et al., 1995; Lechner, De Vries et al., 1997; Van den Putte, Saris et al., 1995; Willemsen, De Vries et al., 1996; Willemsen \& De Vries, 1996). The altered attitude concept is then operationalized by adding up the different belief items. However, there has not been research reported that studied whether omitting the evaluations from the attitude construct would result in loss of predictive power of attitudes in the explanation of intention.

Therefore, this study will test whether the combination of beliefs and evaluations is of enough relevance to assess attitude according to the TRA. Furthermore, this study will look for possible alternatives for the traditional assessment of attitudes. The theoretical questions of this study will be answered by using existing empirical data bases in which the different concepts were assessed in accordance with the theory (Lechner \& De Vries; 1995a; 1995b). 


\section{METHODS}

\section{Respondents and procedure}

In January 1992, the Dutch National Police started an industrial health program for the District of Den Bosch. Within the framework of this program, employees could participate in a physical exercise program, allowing them to do supervised fitness exercises twice a week. On two occasions, determinants and intention to exercise in a fitness program were assessed: at the start of the program (T1), and ten months after the start of the program (T2) (Lechner \& De Vries, 1995a; 1995b). Written questionnaires were distributed among both participants and nonparticipants of the Den Bosch district fitness program. At the first measurement 685 questionnaires were distributed, of which 488 were returned (response $71 \%$ ). All subjects who had returned the first questionnaire received a second questionnaire 10 months later. Of these, 299 questionnaires were returned at the second measurement (response 61\%). More details on the respondents are published elsewhere (Lechner \& De Vries, 1995a; 1995b).

\section{Questionnaire}

The questionnaire included questions about beliefs, evaluations and intention. Besides these concepts, social influence and self-efficacy expectations were assessed. However, for the purpose of this study these latter two concepts are only described briefly. The items on attitude, social influence and self-efficacy were based on results of both qualitative and quantitative studies concerning determinants of participation in industrial fitness programs (Peeters, Oostveen et al., 1991; Poppe, 1991).

Attitude was measured similar to the procedure described by Ajzen \& Fishbein (Ajzen \& Fishbein, 1980), using 8 items on beliefs (b) about industrial fitness programs ("If I participate in an employee fitness program, my physical condition will improve very much (4) to not at all (1)") and the corresponding evaluations (e) (" $A n$ improved physical condition is very important (+2) to very unimportant $(-2)$ to me"). The beliefs (Table 5.1) were all related to positive consequences of behavior. Possible negative consequences of behavior were all processed within the different self-efficacy items. The beliefs were assessed by 4-point scales, while the evaluations 
were measured by 5-point scales ranging from very important to very unimportant. The following method was used to assess the attitude:

attitude $\quad=\sum b_{\mathrm{i}} \mathrm{e}_{\mathrm{i}}$

$$
=b_{1} e_{1}+b_{2} e_{2}+b_{3} e_{3}+\ldots+b_{n} e_{n}
$$

Attitude scores were calculated by multiplying the beliefs by the corresponding evaluations. The 8 attitude scores were added to form a scale (Cronbach's alpha: $\mathrm{T} 1=.83 ; \mathrm{T} 2=.79$ ). Since all beliefs concerned positive consequences of exercising, no beliefs or evaluations needed to be recoded. The 8 beliefs were also added in a separate beliefs scale (Cronbach's alpha: $\mathrm{T} 1=.84 ; \mathrm{T} 2=.86$ ), while the 8 evaluations were added in a separate evaluation scale (Cronbach's alpha: $\mathrm{T} 1=.73 ; \mathrm{T} 2=.77$ ).

Social influence was measured by means of 3 questions on the support or opposition of superiors, colleagues or partners with regard to participation in the industrial fitness program. A 7-point scale was used, with answers ranging from much support to much opposition ( $\alpha: \mathrm{T} 1=.75 ; \mathrm{T} 2=.63)$.

Self-efficacy was measured by proposing six different problem situations and asking the respondents whether they would feel able to participate in an industrial fitness program under these circumstances $(\alpha: \mathrm{T} 1=.76 ; \mathrm{T} 2=.77$ ). A 7-point scale was used, with answers ranging from certainly to certainly not.

At both measurements, the intention to participate in an industrial fitness program was assessed using a 7-point scale, with answers ranging from certainly to certainly not.

\section{Statistical methods}

Data analyses included correlations and several multiple regression analyses. Several methods were used for the multiple regression analyses. First, as was suggested by Evans (1991), the concepts of beliefs and evaluation were entered in the regression, to test whether the multiplicative attitude concept could explain any additional variance after beliefs and evaluations. These regressions were done both on item level as well as on concept level.

Second, additional regression analyses were done to compare the predictive power of the attitude concept versus the beliefs and evaluation concepts, using a stepwise approach together with social influence and self-efficacy. 
All correlations and regression analyses were analyzed with three combinations of variables, resulting in three different studies:

Study 1 The degree to which determinants assessed at $\mathrm{T} 1$ were associated with the intention at $\mathrm{T} 1$ (cross-sectional; $\mathrm{n}=488$ )

Study 2 The degree to which determinants assessed at $\mathrm{T} 1$ were associated with the intention at $\mathrm{T} 2$ (longitudinal; $\mathrm{n}=299$ )

Study 3 The degree to which determinants assessed at T2 were associated with the intention at T2 (cross-sectional; $\mathrm{n}=299$ )

The assumptions necessary for the stepwise multiple regression analyses to be applicable were satisfied: the residuals of the intentions at T1 and T2 were approximately normally distributed, there were no outliers or influential cases, and examination of scatter plots showed that intention was linearly related to the independent variables. All analyses were performed using the SPSS-X statistical program (SPSS Inc., 1988) (significant differences for $\mathrm{p}<.05$ ).

\section{RESULTS}

\section{Correlations of beliefs, evaluations and attitudes}

Table 5.1 shows the correlations of all the different items of beliefs, evaluations and the combined attitudes assessed at $\mathrm{T} 1$ or $\mathrm{T} 2$, with the intention to participate in an employee fitness program both at $\mathrm{T} 1$ and $\mathrm{T} 2$ (study 1 to 3 ). The table also shows the correlation of the combined scales with the intentions for all three studies.

The results show that from the 24 combinations of each of the three types of items ( $\left.b, e, b^{*} e\right)$, the beliefs are most often the ones with the highest correlations (16 times). The evaluation items generally showed the lowest correlations with the intentions, for seven of the evaluation items the correlations with the intentions were not significant. The correlations of the attitude-items showed the most resemblance with the correlations of the belief-items. For the total additive scales, the correlations of the belief and attitude scales were almost the same in all three studies. The correlation of the additive total evaluation scale was much lower for all three studies. This resemblance between the attitude and belief concepts was also 
reflected in the correlations between the three concepts. The correlations between the attitude and belief concepts (correlation $\mathrm{T} 1=.91 ; \mathrm{T} 2=.90$ ) were much higher than the correlations with the attitude and evaluation concepts (correlation $\mathrm{T} 1=.56$; $\mathrm{T} 2=60$ ). Furthermore, the variance within the additive belief scales (variance $\mathrm{T} 1=.44 ; \mathrm{T} 2=.41)$ was much higher than the variance within the additive evaluation scales (variance $\mathrm{T} 1=.14 ; \mathrm{T} 2=.14$ ).

Table 5.1: Correlations of the different belief-items (b), evaluation-items (e) and attitude- items (b*e) (assessed at $\mathrm{T} 1$ and $\mathrm{T} 2$ ) with the behavioral intention at $T 1$ and $T 2$

\begin{tabular}{|c|c|c|c|c|c|c|c|c|c|}
\hline \multirow[b]{2}{*}{ item } & \multicolumn{3}{|c|}{$\begin{array}{l}\text { STUDY } 1 \\
\text { determinants (T1) with } \\
\text { intention at } \mathrm{T} 1\end{array}$} & \multicolumn{3}{|c|}{$\begin{array}{l}\text { STUDY } 2 \\
\text { determinants }(\mathrm{T} 1) \text { with } \\
\text { intention at } \mathrm{T} 2\end{array}$} & \multicolumn{3}{|c|}{$\begin{array}{l}\text { STUDY } 3 \\
\text { determinants (T2) with } \\
\text { intention at } \mathrm{T} 2\end{array}$} \\
\hline & $\mathrm{b}$ & e & $b^{*} e$ & $\mathrm{~b}$ & e & $b^{*} e$ & $\mathrm{~b}$ & e & $\mathrm{b}^{*} \mathrm{e}$ \\
\hline improved condition & $.33^{2 * *}$ & $.28^{22+25}$ & $.34^{\text {*** }}$ & $.16^{* *}$ & $.24^{* *}$ & $.24^{* * *}$ & $.35^{* *}$ & $.34^{* * *}$ & $.41^{* *}$ \\
\hline reduced risk of CVD & $.22^{* * *}$ & $.10^{*}$ & $.21^{* *}$ & .08 & .03 & .09 & $.33^{* *}$ & $.23^{* *}$ & $.32^{* *}$ \\
\hline weight reduction & $.32^{2 * *}$ & $.14^{* 3 *}$ & $.26^{* *}$ & $.20^{* *}$ & $.15^{*}$ & $.20^{* * *}$ & $.25^{* *}$ & $.14^{*}$ & $.18^{* *}$ \\
\hline improved well-being & $.37^{x-*}$ & $.18^{* 3+}$ & $.34^{* *}$ & $.27^{* *}$ & $.19^{* *}$ & $.29^{* *}$ & $.43^{* * *}$ & $.20^{*+*}$ & $.41^{3 * *}$ \\
\hline sufficient supervision & $.22^{2+2 k}$ & $.34^{2+*}$ & $.28^{2+25}$ & $.19^{* * *}$ & $.19^{* * *}$ & $.21^{* 2 *}$ & $.31^{* * 4}$ & $.27^{* *}$ & $.40^{* * *}$ \\
\hline stress relief & $.31^{* *}$ & .09 & $.28^{* *}$ & $.27^{* *}$ & .07 & $.25^{* *}$ & $.39 * *$ & $.18^{* *}$ & $.38^{* *}$ \\
\hline improved social contacts & $.20^{* *}$ & .01 & $.15^{* *}$ & $.21^{* * *}$ & .01 & $.13^{*}$ & $.30^{* * *}$ & $.17^{* *}$ & $.25^{x-26}$ \\
\hline improved productivity & $.22^{* *}$ & -.01 & $.16^{* * 4}$ & $.24^{* * *}$ & .08 & $.21^{* *}$ & $.32^{* *}$ & $.14^{*}$ & $.31^{x-4 t}$ \\
\hline combined total scale & $.39^{* 2 *}$ & $.23^{x-4}$ & $.38^{* 4}$ & $.30 * 3$ & $.20^{2+2 k}$ & $.30^{* *}$ & $.47^{* *}$ & $.33 * *$ & $.49 *+4$ \\
\hline
\end{tabular}

\section{Attitude as an interaction term}

To test whether the use of the interaction term of attitude has additional value, regression analyses were used to test this multiplicative function both on concept level as well as on item level, using the method as was suggested by Evans (1991). From a statistical point of view, an interaction term should only be included in the 
analysis if there is extra explained variance from this term on top of the already included separate terms.

To test a possible interaction effect of attitude on intentions on concept level a multiple regression was done involving three steps (Table 5.2). In the first step, the belief concept was entered in the regression resulting in $9 \%$ (study 2) to $22 \%$ (study 3) explained variance. In the second step, the evaluation concept was entered in the regression, resulting in $2 \%$ (study 1 and 2) to $4 \%$ (study 3) extra explained variance. Total explained variance from beliefs and evaluations varied from $11 \%$ to $26 \%$. In the third step, the attitude concept was entered in the regression, resulting in no further change in explained variance in either of the three studies $(p>.05)$.

Table 5.2: Prediction of intention to participate in an employee fitness program: regression analyses using a 3-step method (beliefs entered in step 1, evaluations entered in step 2, attitudes entered in step 3) to see if attitudes account for extra explained variance after beliefs and evaluations

\begin{tabular}{|c|c|c|c|c|c|c|c|c|c|c|}
\hline \multirow[b]{2}{*}{ step } & \multirow[b]{2}{*}{ variable } & \multicolumn{3}{|c|}{$\begin{array}{l}\text { STUDY } 1 \\
\text { determinants (T1) } \\
\text { with intention at T1 }\end{array}$} & \multicolumn{3}{|c|}{$\begin{array}{l}\text { STUDY } 2 \\
\text { determinants (T1) with } \\
\text { intention at } T 2\end{array}$} & \multicolumn{3}{|c|}{$\begin{array}{l}\text { STUDY } 3 \\
\text { determinants (T2) with } \\
\text { intention at } T 2\end{array}$} \\
\hline & & $\mathrm{R}$ & $\mathrm{R}^{2}$ & $\beta$ & $\mathrm{R}$ & $\mathrm{R}^{2}$ & $\beta$ & $\mathrm{R}$ & $\mathrm{R}^{2}$ & $\beta$ \\
\hline 1 & beliefs (b) & .39 & .15 & .43 & .29 & .09 & .37 & .47 & .22 & .36 \\
\hline 2 & evaluations (e) & .41 & .17 & .16 & .33 & .11 & .18 & .51 & .26 & .20 \\
\hline 3 & attitude (b"e) & .41 & .17 & -.10 & .33 & .11 & -.12 & .51 & .26 & .04 \\
\hline
\end{tabular}

Besides a regression on concept level, the interaction effect of attitude was also tested on item level. The different attitude items are all interactions of the beliefs and their evaluations. In all three studies (determinants at T1 to intention at $\mathrm{T} 1$ and at T2; determinants at T2 towards intention at T2), there were 8 attitude items which were interactions of 8 beliefs and their evaluations. In three regressions, we analyzed if there was indeed an interaction effect of the different attitude items for each study. This was done by regressions for each study where first all belief-items were entered, followed in a second step by all evaluation items. In a third step, it was tested whether the interaction items (belief * evaluation) could explain any 
additional variance in the intention. In total we tested if there was an additional explained variance for 24 interaction terms, since three regression analyses were done, with each 8 beliefs and 8 evaluations. Of all 24 interaction items, only two attitude items showed extra explained variance of the intentions. The other 22 interaction terms displayed no extra interaction effects of attitude above the belief and its evaluation. So, the multiplication of both terms had no additional value for $92 \%$ of all attitude items used.

\section{Attitudes, beliefs and evaluations among other determinants of exercise intention}

To analyze the difference in predictive power between the attitude concept and the separate beliefs and evaluation concepts, several stepwise regression analyses were performed (Table 5.3 and 5.4). For all three studies two different regression analyses were done. In the traditional regression analysis, a stepwise regression analysis was done with the attitude $\left(b^{*} e\right)$ concept, the social influence concept and the self-efficacy concept as possible predictors of the intentions (Table 5.3).

Table 5.3: Prediction of intention to participate in an employee fitness program: stepwise regression analyses with the predictors attitude (multiplicative concept), social influence and self-efficacy

\begin{tabular}{llllllllllllll}
\hline & $\begin{array}{l}\text { STUDY 1 } \\
\text { determinants (T1) with } \\
\text { intention at T1 }\end{array}$ & & $\begin{array}{l}\text { STUDY 2 } \\
\text { determinants (T1) with } \\
\text { intention at T2 }\end{array}$ & \multicolumn{4}{l}{$\begin{array}{l}\text { STUDY 3 } \\
\text { determinants (T2) with } \\
\text { intention at T2 }\end{array}$} \\
step variable & $\mathrm{R}$ & $\mathrm{R}^{2}$ & $\beta$ & variable & $\mathrm{R}$ & $\mathrm{R}^{2}$ & $\beta$ & variable & $\mathrm{R}$ & $\mathrm{R}^{2}$ & $\beta$ \\
\hline 1 & self-efficacy & .53 & .28 & .42 & $\sum \mathrm{b}^{*} \mathrm{e}$ & .30 & .09 & .30 & $\sum \mathrm{b}^{*} \mathrm{e}$ & .51 & .26 & .38 \\
2 & $\sum \mathrm{b}^{*} \mathrm{e}$ & .58 & .34 & .25 & & & & & self-efficacy & .58 & .34 & .29 \\
\hline
\end{tabular}

In the alternative regression analysis the attitude concept was replaced with separate belief and evaluation concepts (Table 5.4). All three studies showed that the separate belief and evaluation concepts were better predictors of the intention, resulting in higher explained variance than the regressions with the attitude concept. After the beliefs concepts were included in the regression analyses, the evaluation concepts had a small but significant additional predictive value of the intention in 
two of the three studies (both $1 \%$ extra explained variance).

When the regression analyses, as presented in Table 5.4, were done without including the evaluation concepts, the regressions that included the attitude concept were almost equal to the regressions that only included the belief concept (without evaluations), with regard to the total explained variance of the models. For study 1 , the explained variance of the belief-included regression was $1 \%$ higher than the attitude-included regression. For the second and third study the explained variance was the same for both the attitude- and the belief-included regressions.

Table 5.4: Prediction of intention to participate in an employee fitness program: multiple stepwise regression analyses with the predictors beliefs, evaluations (as separate concepts), social influence and self-efficacy

\begin{tabular}{|c|c|c|c|c|c|c|c|c|c|c|c|c|}
\hline \multicolumn{5}{|c|}{$\begin{array}{l}\text { STUDY } 1 \\
\text { determinants (T1) with } \\
\text { intention at } T 1\end{array}$} & \multicolumn{4}{|c|}{$\begin{array}{l}\text { STUDY } 2 \\
\text { determinants (T1) with } \\
\text { intention at } T 2\end{array}$} & \multicolumn{4}{|c|}{$\begin{array}{l}\text { STUDY } 3 \\
\text { determinants (T2) with } \\
\text { intention at T2 }\end{array}$} \\
\hline step & variable & $\mathrm{R}$ & $\mathrm{R}^{2}$ & $\beta$ & variable & $\mathrm{R}$ & $\mathrm{R}^{2}$ & $\beta$ & variable & $\mathrm{R}$ & $\mathrm{R}^{2}$ & $\beta$ \\
\hline 1 & self-efficacy & .53 & .28 & .41 & $\sum$ beliefs & .30 & .09 & .27 & $\sum$ beliefs & .48 & .23 & .32 \\
\hline 2 & $\sum$ beliefs & .58 & .34 & .27 & Eevaluations & .32 & .10 & .13 & self-efficacy & .57 & .33 & .28 \\
\hline 3 & & & & & & & & & Eevaluations & .59 & .35 & .15 \\
\hline
\end{tabular}

\section{DISCUSSION}

The results from this study on empirical data suggest that statistically there is no reason for using the attitude interaction term. Regression analyses, based on suggestions from earlier studies (Evans, 1991; Swanborn, 1996) show that the extra additional explained variance of attitudes over and above the beliefs and their evaluations are of no significant relevance. In this study we found that on item level only 2 out of 24 attitude interaction items (8\%) showed any additional explained variance after the belief and evaluation items were already included in the regression. On concept level, in all three studies the attitude concept did not result 
in any additional explained variance of behavioral intention, after the belief and evaluation concepts were already included. So, the multiplication of the attitude concept did not seem necessary in this study.

Several studies showed that the somewhat arbitrary scaling of the product terms can heavily influence the interpretation of the attitude score (Valiquette, Valois et al., 1988) and the correlation of the attitude with the intention (Ajzen, 1991; Bagozzi, 1984; Hewstone \& Young, 1988; Mellenbergh, Molendijk et al., 1990). These scaling problems, combined with the finding from this study that the multiplicative attitude concept did not result in any additional explained variance of behavioral intention, makes it worthwhile to consider an alternative measurement for this additive product term. The results from this study give some suggestions for such an alternative assessment of attitude. The empirical data of this study clearly show that the product term attitude is mostly connected to the belief concept and much less to the evaluation concept. Moreover, the belief and attitude concepts were highly correlated to each other $(r=90)$. The similarity between beliefs and attitudes was also reflected in the regression analyses that were performed to see to what degree attitude, social influence and self-efficacy could explain the variance in intention to participate in the fitness program. Total explained variance was similar for the belief and attitude concepts. The evaluation concepts contributed only slightly in two of the three studies.

The fact that attitudes were mostly similar to the beliefs in this study and that evaluations did not seem to strengthen the relation of beliefs to intention, suggests that the evaluation is partly already imbedded in the beliefs assessment. If respondents think that weight loss is totally unimportant for them, they will probably not connect weight loss very strongly to participation in a fitness program. Since this outcome is less salient for them, their belief concerning this specific outcome will probably be less strong. As a result, they are less likely to answer with the highest answering scale ("If I participate in an employee fitness program I will loose a lot of weight $t^{n}$ ).

The beliefs that were used in this study were all possible positive outcomes or pros of participating in an exercise program. In many recent studies attitudes are operationalized according to the decisional balance (Marcus, Rakowski et al., 1992; 
Prochaska, Velicer et al., 1994; Velicer, DiClemente et al., 1985), based on the theoretical model of decision making by Janis and Mann (1977). This decisional balance is operationalized by asking subjects for possible pros and cons as outcomes of a behavior (Marcus, Rakowski et al., 1992; Prochaska, Velicer et al., 1994). When beliefs are clearly operationalized as either positive or negative outcomes of a behavior, evaluations of these beliefs are not expected to vary a lot, and therefore can probably be omitted. As Eagly \& Chaiken (1993) state, evaluations of attributes or beliefs are often well anchored in extensive prior learning. People will not easily evaluate positive outcomes as bad, or negative outcomes as good. Moreover, since many evaluations of beliefs are so anchored in people's perception, not much variance can be expected in people's evaluations of beliefs, especially if beliefs clearly represent a positive or negative outcome. Results from this study confirm this supposition, since the variance within the additive evaluation scales ( $T 1=.14$; $\mathrm{T} 2=.14)$ was much lower than the variance within the additive beliefs scales $(\mathrm{T} 1=.44 ; \mathrm{T} 2=.41)$.

Findings of this study suggest that for assessing attitudes it may be sufficient to measure only beliefs or behavioral outcomes, providing that the beliefs that are measured are clearly positive or negative outcomes of a behavior. Altering the traditional way of assessing attitudes has been suggested in other studies (Evans, 1991, Swanborn, 1996; Van de Putte, Saris et al., 1995). Also, some of the recent studies have indeed only assessed behavioral outcomes which they address as attitudes (Brug, Lechner et al., 1995; Lechner, De Vries et al., 1997; Willemsen, De Vries et al., 1996; Willemsen \& De Vries, 1996). However, studies that have tried to support this alteration empirically have hardly been reported (Peay, 1980).

It can be expected that for beliefs that are less clearly positive or negative ("by participating in an employee fitness program, I see my colleagues outside of work"), the variance in the evaluation concept will be more apparent. If such is the case, then the evaluation term has an important additional value and indeed should be included as a concept of the attitude. In other words, if preliminary studies suggest that variance in the evaluations of beliefs are not very apparent, then the evaluation part could be omitted form the attitude construct. By clearly formulating beliefs as either positive (pros) or negative (cons), this variance in evaluations will probably be 
minimal.

According to Ajzen (1991), the optimal scaling for both beliefs and evaluations should be on a bipolar scale (e.g., from -2 to +2 for a 5-point scale). In this study only the evaluations were scaled bipolar, while the beliefs were scaled unipolar (e.g., from 1 to 4). Since this study used only positive outcomes (pros), in accordance with the decisional balance, a bipolar scaling of the beliefs would not have been logical. Furthermore, when both beliefs and evaluations are scaled bipolar, an additional interpretation problem arises when two negative scores are multiplied, resulting in a meaningless positive score (Valiquette, Valois et al., 1988). However, the fact that the beliefs were scaled unipolar instead of bipolar, might have influenced the results presented. In future research it is recommended to test both unipolar and bipolar scaled beliefs with respect to the additional value of product scores over and above the separate beliefs and evaluation scales. Furthermore, Ajzen (1991) suggests that the belief-based attitude cannot be used to predict intention if it does not correspond to the global measure of attitude. In the present study, the global attitude was not assessed. Therefore, we have no insight into the relation between global attitude and belief-based attitude. It is therefore recommended that in future research into the relation between beliefs, evaluations and intentions, a measure of the global attitude is included.

For the other element of the TRA, the social norm, several authors have criticized the TRA/TPB operationalization of social influence because it uses a multiplicative composite (Ajzen \& Fishbein, 1970; 1972; Budd, 1986; Budd, North et al., 1984; Saltzer, 1981; Van den Putte, Saris et al., 1995). As van den Putte and colleagues (1995) state, if due to a large consensus, the variance of the motivation to comply concept is low, the construct can be omitted without decreasing the correlation with subjective norm. Budd and colleagues (1984) found that the motivation to comply construct did not significantly add to the predictive power of the model, independent of the scoring of the motivation to comply construct (e.g. unipolar or bipolar). Similarly, Saltzer (1981) found that the inclusion of the motivation to comply construct often reduces the relationship of perceived normative beliefs with measures of behavioral intentions, perhaps due to a reactive measurement problem wherein respondents wish to appear autonomous and 
independent when deciding about potential behaviors.

The study presented here empirically strengthens the suggestion that the evaluation term can also be omitted from the attitude in certain situations. However, replications of the findings are needed to form a more solid base for the given conclusions, especially when modifications to the attitude concept are being applied to other than the presented behaviors and beliefs.

The current use of both beliefs and evaluation also provides some major practical disadvantages. By assessing both beliefs and evaluation of these beliefs, subjects are burdened with a large number of questions. Also, the repetition of questions which appear very similar to the subject (first the beliefs, followed with the evaluation of the same beliefs), could irritate the respondents. This extra load of partly similar questions might enlarge the non-response of subjects to the questionnaires. Since the loss of information seems minimal when evaluations are not included, the possible gain in response may provide an additional argument for not including evaluations in questionnaires.

We conclude that beliefs or outcome expectations that are clearly either positive or negative, could provide a good assessment of the attitudes subjects have towards health behaviors. By excluding evaluations from the attitude concept, the different problems that occur when applying the traditional multiplicative attitude term can be avoided with a minimum loss of information. 


\title{
CHAPTER 6
}

\section{Misconception of fruit and vegetable consumption: Differences between objective and subjective estimation of intake ${ }^{1}$}

\begin{abstract}
Background. This study reports the discrepancy between two metbods to assess fruit and vegetable consumption in a Dutch adult population $(N=367)$.

Metbods. The consumption of fruit and vegetables was assessed by telephone interviews in two ways: it was estimated objectively by using a food frequency method (the number of grams of fruit and vegetables that subjects ate every day), and it was estimated subjectively by assessing the self-rated fruit and vegetable intake of subjects. Besides behavior, intention was measured in two ways: the intention to eat fruit and vegetables each day and the intention to eat more fruit and vegetables. Also, determinants were measured using a theoretical model including the attitude toward fruit and vegetable consumption, self-efficacy expectation, and the social influence to eat fruit and vegetables.

Results. There were large differences between the self-rated and estimated objective consumption of fruit and vegetables. Subjects rated their own intake as much bigher than their estimated objective intake. Furthermore, multiple regression analyses show that the determinants predicted the self-rated consumption much better than the estimated objective consumption. Subjects who rated their own consumption as high bad more positive beliefs concerning fruit and vegetable consumption, experienced more positive social influence to eat fruit and vegetables, and had higher self-efficacy expectations of being able to eat fruit and vegetables than subjects who rated their own consumption as low.

Conclusions. It is concluded that nutrition education aimed at stimulating fruit and vegetable consumption should especially focus on making people aware of their own fruit and vegetable intake, in addition to changing attitudes and self-efficacy expectations.
\end{abstract}

${ }^{1}$ Published as:

Lechner, L., Brug, J., \& De Vries, H. (1997). Misconceptions of fruit and vegetable consumption: Differences between objective and subjective estimation of intake. Joumal of Nutrition Education, $29,313-320$. 


\section{INTRODUCTION}

In recent years, knowledge about the relationship between fruit and vegetable consumption and the prevention of several diseases has increased substantially. Population groups that consume moderate to high amounts of fruit and vegetables have a lower risk of several kinds of cancer, coronary heart disease, hypertension, and stroke (Block, Patterson et al., 1992; Gerster, 1991; Hertog, Feskens et al., 1993; Weisburger, 1991). The underlying mechanisms by which fruit and vegetable intake may influence these risks are still largely unknown (Anderson, Hunt et al., 1994).

Because of these positive effects, many countries give guidelines for daily fruit and vegetable intake. The U.S. Dietary Guidelines and the Food Guide Pyramid both recommend eating five or more servings of fruit and vegetables each day (U.S. Department of Agriculture, 1990; 1992). In many European countries, including the Netherlands, the recommendation to increase the consumption of fruit and vegetables is part of dietary guidelines (Benito, 1992; Dutch Nutrition Council, 1986). The Netherlands Bureau for Food and Nutrition recommends that adults eat three to four serving spoons (approximately 150-200 grams) of vegetables and two pieces of fruit per day (Netherlands Bureau for Food and Nutrition Education, 1993).

These guidelines are in strong contrast with the actual nationwide food consumption, which is lower than recommended both in the U.S. and in the Netherlands (Hulshof, Löwik et al., 1994; Patterson, Block et al., 1990). These discrepancies have led to several public health campaigns to increase fruit and vegetable consumption among the general public, such as the " 5 a day" projects in the U.S. (Havas, Heimendinger et al., 1994) and the 1994 European Week against Cancer (European Community Commission, 1990; Lechner, De Vries et al., 1994). Motivating people to eat more fruit and vegetables is a complex process. Therefore, the psychosocial factors important in stimulating the consumption of fruit and vegetables were the subject of investigation in a number of studies conducted by our research group. First, a qualitative study, using focus group interviews, was conducted to study a number of issues and beliefs important in relation to fruit and 
vegetable consumption (Brug, Debie et al., 1995). These focus group interviews left the impression that subjects were unaware of what, from a health perspective, desirable levels of fruit and vegetable consumption were. Partly based on this research, a survey was conducted to study the determinants of fruit and vegetable consumption quantitatively (Brug, Lechner et al., 1995; Lechner, De Vries et al., 1994). Only a few other studies have actually studied the psychosocial determinants of fruit and vegetable consumption (Baranowski, Domel, et al. 1993; Glanz, Patterson et al., 1994). In this chapter, the role of awareness in motivating individuals to increase fruit and vegetable consumption is further investigated.

Prochaska et al. suggest in their transtheoretical model that the process of behavioral change can be divided into several stages (Prochaska \& DiClemente, 1983; Prochaska, Velicer et al., 1991). In changing their behavior, people can move from precontemplation via contemplation and preparation to action, and then to either maintenance or relapse. Moreover, movement through the stages involves a cycling and recycling process (Prochaska \& DiClemente, 1983; Prochaska, Velicer et al., 1991). Recent applications of the model to fruit and vegetable consumption are reported (Glanz, Patterson et al., 1994).

An important issue in dietary behavior could be people's awareness of their own behavior. Weinstein proposed that awareness of risk behavior is one of the key issues in motivating people to move from precontemplation to further stages of preventive behavioral change (Weinstein, 1988). This has been demonstrated for dietary behavior in a study on fat consumption reduction (Brug, Van Assema et al., 1994). This study reported large differences between the objective assessment of dietary fat intake and the self-rated, subjective fat intake. Also, in the same study, almost all psychosocial determinants had significantly higher correlations with the subjectively measured fat intake than with the objectively measured fat intake.

Social psychological models suggest that behavior in general is determined by behavioral intention (Ajzen \& Fishbein, 1980). Behavioral intention is determined by three important factors. The first factor is the attitude, consisting of the advantages and disadvantages of a particular behavior. These are also referred to as outcome expectations in Bandura's social learning theory (Bandura, 1986). The second factor consists of the social influences that individuals encounter, which are 
a result of social norms relevant to the behavior, support from others to perform the behavior and the perception of behavior from others (modeling) (De Vries, Backbier et al., 1995). The third factor concerns self-efficacy expectations, which are beliefs of a person about his or her abilities to perform a particular behavior (Bandura, 1986). The corresponding models using these concepts, such as the Attitude - Social influence- self-Efficacy (ASE) model (De Vries, Dijkstra et al., 1988; Lechner \& De Vries, 1995a) and the Planned Behavior Model (Ajzen, 1991), have been used to predict various health behaviors, as well as dietary behavior in particular (Brug, Lechner et al., 1995; Stafleu, De Graaf et al., 1991; Van Assema, Pieterse et al., 1993).

Until now, no research has been conducted into whether the differences between how people rate their own consumption and their actual consumption are also present with fruit and vegetable consumption. The present study aims to assess the prevalence of misconception, and especially overestimation, of fruit and vegetable intake among a random sample of the Dutch population. Furthermore, the consequences of inconsistent estimation of fruit and vegetable intake will be studied and the practical implications for nutrition education will be discussed.

\section{METHODS}

\section{Subjects}

Data collection was done by means of telephone questionnaires. Since over $96 \%$ of all Dutch households have telephones, the telephone proves to be a sufficient tool to obtain representative data of the general Dutch population (KPN, 1996). A random sample of 598 address-telephone number combinations was obtained through the Dutch national telephone company. The general administration procedure is described elsewhere (Brug, Lechner et al., 1995). Respondents had to be older than 17 years (adult) to participate. Of the original sample of 598 telephone numbers, 367 subjects participated in the study. Since 56 respondents were excluded from the original sample because they could not be reached after several attempts or did not meet the inclusion criteria, a response rate 
of $68 \%$ was reached.

\section{Questionnaire}

Administration of the telephone questionnaire took about 15 minutes per person. The questionnaire included questions about behavior (consumption of fruit and vegetables), intention, attitude, social influence, self-efficacy expectations, and demographic variables. Within the behavior fruit and vegetable consumption, three separate behaviors were distinguished: consumption of raw vegetables eaten as salads (salads), consumption of boiled or otherwise heated vegetables (processed vegetables), and the consumption of fruit. The distinction between salads and processed vegetables was made as a result of different focus group interviews (Brug, Debie et al., 1995), in which people had different opinions on both types of vegetables.

Consumption of fruit, salads, and processed vegetables was assessed using two methods. First, intake was estimated objectively by means of a food frequency method (estimated objective intake) in which respondents were asked to indicate the frequency and portion size in which they consumed salads, processed vegetables, and fruit during the last month. Portion size for boiled vegetables and salads could be answered either in serving spoons or in grams but were coded as grams (1 serving spoon $=50$ grams, according to the Netherlands Bureau of Food and Nutrition Education instructions). The food frequency method was tested in a small-scale study $(\mathrm{N}=47)$ in which the reproducibility (test-retest correlation was 0.77 between first and second administration) and the relative validity in classifying subjects according to intake levels were assessed in relation to a validated comprehensive Dutch food frequency questionnaire (Cohen's $K$ value $=0.59$ ) (Goldbohm, Van de Brandt, 1994). The food frequency questionnaire was applied in several studies (Brug, Lechner et al., 1995; Brug, Steenhuis et al., 1996).

Consumption of fruit, salads, and processed vegetables was also assessed subjectively by asking subjects to rate their own consumption of fruit, salads, and processed vegetables (self-rated intake). They could rate their own consumption on a 5-point scale from very low to very high.

Intention was measured in two ways. First, intention was measured with one 
item in which respondents were asked to indicate on a 5-point scale whether they intended to eat the groups of food products every day. Also, respondents were asked if they intended to increase their fruit and vegetable consumption within the coming month and within the coming 6 months.

Table 6.1: Description of the different assessed determinant-constructs, with the number of items, Cronbach's alphas and mean scores $(n=367)$

\begin{tabular}{lllll}
\hline Consumption of & Determinant (range) & $\begin{array}{l}\text { How many } \\
\text { items }\end{array}$ & $\begin{array}{l}\text { Cronbach's } \\
\text { alpha }\end{array}$ & Mean score (SD) \\
\hline salads & $\begin{array}{l}\text { attitude }(-2,2) \\
\text { social influence }(0,4)\end{array}$ & 11 & 0.62 & $0.58(0.34)$ \\
& self-efficacy $(-2,2)$ & 5 & 0.70 & $2.08(0.92)$ \\
& & & 0.70 & $0.50(1.01)$ \\
processed & attitude $(-2,2)$ & 11 & 0.54 & $0.63(0.29)$ \\
vegetables & social influence $(0,4)$ & 2 & 0.58 & $2.35(0.77)$ \\
& self-efficacy $(-2,2)$ & 5 & 0.64 & $1.21(0.82)$ \\
fruit & & & & \\
& attitude $(-2,2)$ & 12 & 0.62 & $0.78(0.31)$ \\
& social influence $(0,4)$ & 2 & 0.61 & $2.18(0.88)$ \\
& self-efficacy $(-2,2)$ & 4 & 0.79 & $1.38(1.35)$ \\
\hline
\end{tabular}

The items on attitude and self-efficacy beliefs were based on results of qualitative research (Brug, Debie et al., 1995). Items on attitude, social influence, and self-efficacy were separately measured for all three behaviors (Brug, Lechner et al., 1995). Table 6.1 shows the number of items for each determinant-construct, as well as the Cronbach's alpha and the mean score of the construct. Attitude was measured by asking the respondents to evaluate several beliefs or outcome expectations concerning the three behaviors on 5-point scales (e.g. health consequences, taste, price, etc.). Social influence was measured by combining two items. One item asked respondents how much social support they perceived from important others (spouse, family, friends) to eat fruit, salads and processed vegetables, rated on a 5-point scale. The second item asked respondents to assess how much fruit, salads, and processed vegetables important others consumed, also on a 5-point scale. Both items were scaled together forming the social influence 
scale. Self-efficacy was measured by proposing different problem situations and asking the respondents whether they would feel able to eat salads, processed vegetables, and fruit in these situations (e.g. when eating alone, in the weekends, when in a hurry, etc.). The self-efficacy items were measured on 5-point scales, with answers ranging from certainly to certainly not.

The last part of the questionnaire consisted of sociodemographic variables such as gender, age, educational level, and marital status.

\section{Statistical analysis}

Data analyses included basic descriptive statistics for the different behaviors (statistical differences for $\mathrm{p}<.05$ ). Pearson correlations were computed between the estimated objective intake and self-rated intake of fruit, processed vegetables, and salads.

Subjects were labeled as sufficient consumers if their estimated objective fruit and vegetable intake (as was assessed with the food frequency method) was in keeping with Dutch dietary guidelines. If the estimated objective fruit and vegetable intake was below the Dutch guidelines, subjects were labeled as insufficient consumers. Misclassification of fruit and vegetable intake was assessed by comparing these sufficient and insufficient consumers (according to the guidelines) with their subjective, self-rated consumption. Sufficient consumers who rated themselves as eating ample fruit and vegetables and insufficient consumers who rated themselves as eating few fruit and vegetables were considered to have a correct or consistent classification of their fruit and vegetable intake. Insufficient consumers who rated their consumption as being sufficient or (very) high and sufficient consumers who rated their consumption as (very) low were considered to have misclassified their fruit and vegetable intake.

Also, to assess misclassification between the estimated objective and self-rated behaviors in a statistical way, Cohen's $\mathrm{K}$ values (Fleiss, 1981) were computed. For these analyses, both behavior assessments were divided in tertiles.

Stages of change were operationalized in this study into the precontemplation stage (subjects who rated themselves as low consumers and had no intention of increasing their consumption), contemplation stage (subjects who 
rated themselves as low consumers and had the intention to increase their consumption within 6 months), preparation stage (subjects who rated themselves as low consumers and had the intention to increase their consumption within 1 month), and action/maintenance stage (subjects who rated themselves as high consumers).

Multiple regression analyses, using forced entry, were used to assess the predictive value of the determinants and the intention toward the estimated objective and self-rated consumption of salads, processed vegetables, and fruit. All analyses were performed using the SPSS-X statistical program (SPSS Inc, 1988).

\section{RESULTS}

The study group

Of the 367 subjects, 162 (44\%) were male and 205 (56\%) were female. The average age was 46 years $(S D=17)$, ranging from 18 to 91 years. Most respondents (68\%; $N=249$ ) had a spouse. Twenty-four percent $(n=86)$ had a high level of education (higher vocational school or university), $30 \%(n=111)$ a medium level (secondary vocational school or high school), and $46 \%(n=169)$ a low level of education (primary or basic vocational school). Of all respondents, $78 \%(n=286)$ reported doing the cooking regularly.

\section{Self-rated and estimated objective bebavior}

For measuring the more subjective consumption, people were asked to rate their own fruit and vegetable consumption (Table 6.2). Most respondents rated their consumption as being (very) high or sufficient. Only $6 \%$ of all respondents rated their consumption of processed vegetables as (very) low, $21 \%$ rated their fruit consumption (very) low, and $31 \%$ rated their consumption of raw vegetables as (very) low. 
Table 6.2: Self-rated behavior: how respondents rate their own consumption of raw vegetables (salads), processed vegetables and fruit $(n=367)$

\begin{tabular}{lcccccc}
\hline $\begin{array}{l}\text { self-rated } \\
\text { consumption }\end{array}$ & salads & \multicolumn{3}{c}{$\begin{array}{c}\text { processed } \\
\text { vegetables }\end{array}$} & \multicolumn{2}{c}{ fruit } \\
& $\%$ & $\mathrm{n}$ & $\%$ & $\mathrm{n}$ & $\%$ & $\mathrm{n}$ \\
\hline very high & $7 \%$ & 24 & $9 \%$ & 35 & $10 \%$ & 35 \\
high & $31 \%$ & 110 & $56 \%$ & 206 & $42 \%$ & 155 \\
sufficient (not high/not low) & $32 \%$ & 120 & $29 \%$ & 105 & $27 \%$ & 99 \\
low & $25 \%$ & 89 & $5 \%$ & 17 & $19 \%$ & 68 \\
very low & $6 \%$ & 22 & $1 \%$ & 4 & $2 \%$ & 9 \\
\hline
\end{tabular}

The average estimated objective consumption of salads and processed vegetables was $68(S D=60)$ and $140(S D=76)$ grams per day. The average estimated objective daily consumption of fruit was $2.0(\mathrm{SD}=1.9)$ pieces per day. If we collate these amounts with the guidelines from The Netherlands Bureau for Food and Nutrition, we find that total vegetable consumption was too low for $32 \%(n=112)$ of all respondents (less than 150 grams per day) and the fruit consumption was too low for $56 \%(n=205)$ of all respondents (less than 2 pieces per day). There were no significant differences in estimated objective and self-rated consumption with regard to age, gender, or education.

Comparison of the sufficient or insufficient consumers (estimated to be above or below the national guideline) with the self-rated consumption shows that $30 \%$ made an inconsistent estimation of their total vegetable consumption, while $38 \%$ made an inconsistent estimation of their own fruit consumption (Table 6.3). These inconsistent estimations were mostly overestimation of intake for both vegetables ( $94 \%$ overestimation; $n=99$ ) and fruit ( $96 \%$ overestimation; $n=134)$. The percentage of respondents who made an inconsistent estimation of their own consumption was particularly high for the consumers who, according to the guidelines, did not consume sufficient amounts of fruit and vegetables (Table 6.3): $88 \%$ of the respondents who, according to the guideline, did not eat enough vegetables rated themselves as eating enough vegetables, while $65 \%$ of the subjects who were too low in fruit intake rated themselves as eating enough fruit. 
Table 6.3: Comparison of self-rated with estimated objective consumption of vegetables and fruit: inconsistency in estimating personal consumption $(n=367)$

\begin{tabular}{llll}
\hline estimation for all respondents & vegetables & fruit \\
\hline inconsistent estimation & $30 \% \quad(n=105)$ & $38 \% \quad(n=140)$ \\
consistent estimation & $70 \% \quad(n=245)$ & $62 \% \quad(n=225)$ \\
\hline $\begin{array}{llll}\text { estimation for respondents who } \\
\text { consume less than the guideline }\end{array}$ & \multicolumn{1}{l}{ vegetables } & fruit & \\
\hline inconsistent estimation & $88 \% \quad(n=99)$ & $65 \% \quad(n=134)$ \\
consistent estimation & $12 \% \quad(n=13)$ & $35 \% \quad(n=71)$ \\
\hline
\end{tabular}

Besides the inconsistency of self-rated intake when compared to the national guidelines, the relation between the estimated objective and self-rated intake was also studied statistically. The misclassifications between both methods were in accordance with the correlations between the self-rated and estimated objective behavior: both the correlation and the $\mathrm{k}$ values were highest for salads (Pearson $r=0.55, \quad k=0.38$ ), followed by fruit (Pearson $r=0.44, k=0.32$ ) and processed vegetables (Pearson $r=0.37, \kappa=0.12$ ). According to Fleiss (Fleiss, 1981), all three $\kappa$ values are considered to be low, showing little similarity in classification according to estimated objective and self-rated behavior.

\section{Application to stages of change}

Application of the stages of change (based on self-rated intake) for both the consumers who were estimated objectively to be below or above the dietary guidelines are presented in Table 6.4. The intention to eat more fruit and vegetables in the coming month or even in the coming half year was very low for both groups and for both fruit and vegetables. Translation of these numbers into stages of change would result in almost no subjects in the contemplation stage (intend to increase consumption within half a year) and only a few subjects in preparation stage (intend to increase consumption within 1 month). Most subjects in both groups consider themselves as being in the action/maintenance stage for their fruit and vegetable intake, even if their estimated objective intake is below the guidelines. 
Of the subjects with an estimated insufficient intake, 54\% thought they were in action with respect to their salad intake, 55\% thought they were in action with respect to their fruit intake, and $80 \%$ thought they were in action with respect to their processed vegetables intake.

Table 6.4: The stages of change of fruit and vegetable consumption, applied for subjects who consume less than the guideline (insufficient intake) or according to the dietary guidelines (sufficient intake)

\begin{tabular}{|c|c|c|c|c|c|c|}
\hline \multirow[t]{2}{*}{ consumption of } & \multicolumn{2}{|l|}{ salads } & \multicolumn{2}{|c|}{ processed vegetables } & \multicolumn{2}{|l|}{ fruit } \\
\hline & $\begin{array}{l}\text { sufficient } \\
\text { intake }\end{array}$ & $\begin{array}{l}\text { insufficient } \\
\text { intake }\end{array}$ & $\begin{array}{l}\text { sufficient } \\
\text { intake }\end{array}$ & $\begin{array}{l}\text { insufficient } \\
\text { intake }\end{array}$ & $\begin{array}{l}\text { sufficient } \\
\text { intake }\end{array}$ & $\begin{array}{l}\text { insufficient } \\
\text { intake }\end{array}$ \\
\hline $\begin{array}{l}\text { Stages of change } \\
\text { precontemplation }\end{array}$ & $22 \%(52)$ & $41 \%(64)$ & $2 \%(6)$ & $12 \%(13)$ & $3 \%(5)$ & $29 \%(59)$ \\
\hline contemplation & $0 \%(1)$ & $1 \%(1)$ & $0 \%(0)$ & $0 \%(0)$ & $1 \%(1)$ & $1 \%(1)$ \\
\hline preparation & $7 \%(17)$ & $4 \%(5)$ & $12 \%(28)$ & $8 \%(10)$ & $9 \%(14)$ & $15 \%(32)$ \\
\hline action/maintenance & $71 \%(168)$ & $54 \%(60)$ & $86 \%(204)$ & $80 \%(89)$ & $87 \%(141)$ & $55 \%(113)$ \\
\hline
\end{tabular}

\section{Determinants of bebavior}

The differences between the estimated objective intake and the self-rated intake of vegetables and fruit may have consequences for the way in which the determinants can explain the behaviors. Multiple regression analyses, using forced entry, were used to assess the differences in explained variance of the determinants attitude, social influence, self-efficacy, and the intention (to eat the products on a daily basis) toward the estimated objective consumption, as was reported elsewhere (Brug, Lechner, et al., 1995), and toward the self-rated consumption of salads, processed vegetables, and fruit (Table 6.5). 
Table 6.5: Multiple regression analyses, the determinants to explain the estimated objective consumption (food frequency method) and the self-rated consumption of salads, processed vegetables and fruit

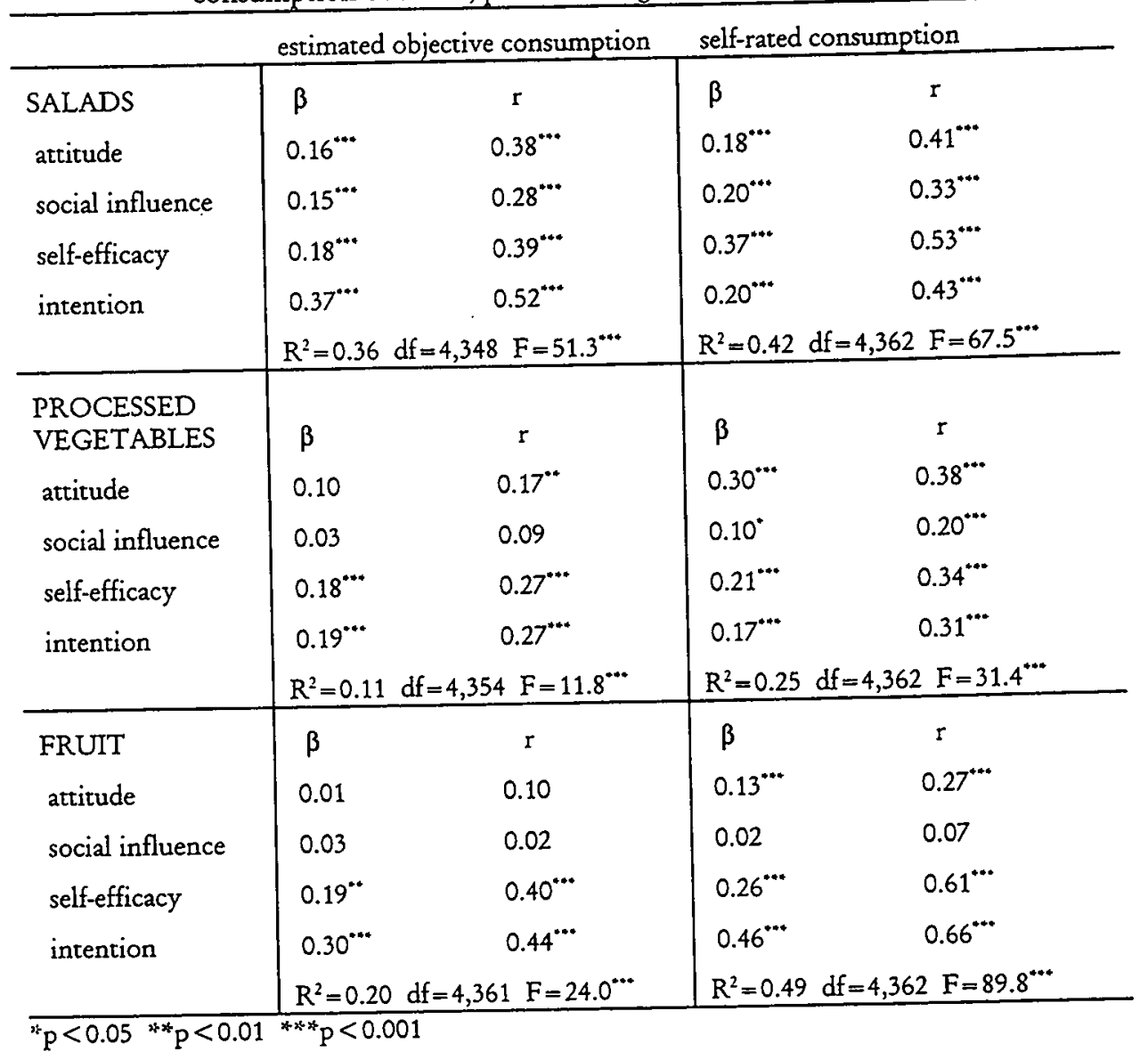

The intention and the determinants were more highly related to the selfrated behavior than to the estimated objective behavior, especially for the consumption of processed vegetables and fruit. The intention and all three determinants were significantly related to both the estimated objective and the selfrated consumption of salads. Respondents with higher estimated objective salad consumption and respondents who rated themselves as high salad eaters were more positive in their beliefs about eating salads, experienced more support from 
significant others toward eating salads, and were more convinced that they were able to eat salads in difficult situations (e.g. having little time, when eating alone, when preparation is difficult, etc.). The intention, together with the determinants, explained the self-rated consumption $\left(R^{2}=0.42\right)$ better than they explained the estimated objective consumption $\left(R^{2}=0.36\right)$ of salads.

The intention and all three determinants were significantly related to the self-rated consumption of processed vegetables, making the total of explained variance $25 \%$ (see Table 6.5). Respondents who rated themselves as high processed vegetable eaters had more positive attitudes toward processed vegetables, experienced more positive social influence for eating processed vegetables, and were more convinced that they were able to eat processed vegetables in difficult situations. The explained variance of the estimated objective consumption of processed vegetables was low (11\%), with only the intention and self-efficacy significantly related to the estimated objective behavior.

Intention, self-efficacy, and attitude were significantly related to the self-rated consumption of fruit, making the total of explained variance $49 \%$ (see Table 6.5). Respondents who rated themselves as high fruit eaters had a more positive attitude toward fruit and were more convinced that they were able to eat fruit in difficult situations. The explained variance of the estimated objective consumption of fruit was, as with processed vegetables, lower $(20 \%)$, with only intention and self-efficacy significantly related to the estimated objective behavior.

\section{DISCUSSION}

This study estimated that, according to Dutch nutrition guidelines, $32 \%$ of the study group did not eat enough vegetables, while $56 \%$ did not eat enough fruit. If we compare these findings with other Dutch research, we find similar results (Netherlands Bureau for Food and Nutrition Education, 1993; Hulshof, Löwik et 
al., 1994), although the average estimated objective consumption of fruit and vegetables in our study was somewhat higher. This difference might be caused by a difference in methodology used in measuring food consumption. In a recent nationwide survey, a 2-day record was used (Netherlands Bureau for Food and Nutrition Education, 1993). Furthermore, our study was conducted in late summer, when the supply of fresh fruit and vegetables is very large.

This study used a food frequency questionnaire to estimate the objective consumption of fruit and vegetables (Brug, Lechner et al., 1995). This means that we could only give an approximation of the objective fruit and vegetable intake. Since data were gathered by use of telephone surveys, it was not possible to use more extensive methods, such as diaries, in order to get a more precise estimation of actual intake. Since overestimation was so prevalent among subjects, it is conceivable that subjects even overestimated the more objectively measured intake of fruit and vegetables. This would mean that the discrepancies between actual and perceived consumption in reality could even be greater.

This group of people, who, according to the guidelines, do not eat enough fruit and vegetables, forms an important target group for nutrition education. The number of respondents who overestimated their own vegetable and fruit consumption was very high in this target group: $88 \%$ of the respondents who consumed less vegetables than the guideline did not rate their own vegetable intake as low, while similarly $65 \%$ of those who consumed less fruit than the guideline did not rate their own fruit consumption as low. These data indicate that overestimation of fruit and vegetable consumption is highly prevalent in the Dutch population. Lack of awareness of their own behavior seems to be a major concern for respondents consuming too few fruit and vegetables. A recent study showed that around $30 \%$ of the whole Dutch population did not know the dietary guideline with respect to fruit consumption, while around $50 \%$ did not know the dietary guideline concerning vegetable consumption (Van Assema, Brug et al, 1996). This is in accordance with the level of misconception of subjects' own intake, which is 
higher for subjects who are too low in their vegetable intake than for subjects who are too low in their fruit intake. It seems that knowing the guidelines has some relation to misconceptions of people's own intake. If people do not know how much, from a health perspective, they should eat, they are more likely to underestimate their intake. Making people more aware of the dietary guidelines might provide an important step in making them aware of their own low intake.

The differences between the estimated objective and self-rated behavior were highest for the consumption of processed vegetables and fruit. For eating salads, the difference was smaller: Pearson correlation was high $(r=0.55)$ and Cohen's $k$ had the highest value (0.38), which is, however, still low (Fleiss, 1981). People seem to be more aware of their salad intake than of their processed vegetables and fruit intake. Results show that respondents eat about twice the amount of processed vegetables compared to salads. Dutch society may not be as accustomed to consuming raw vegetables as to consuming processed vegetables, thus making people more aware of their consumption of raw vegetables.

Only a few subjects intended to increase their consumption of fruit and vegetables within half a year. This is probably due to the high self-rated consumption of subjects. If respondents think they are already eating enough fruit and vegetables, they hardly have reasons to increase their consumption. Lack of awareness of personal consumption seems to be very important here.

In this study, we tried to translate the self-rated behavior of subjects into behavioral stages of change, as was done in a recent study (Glanz, Patterson et al., 1994). It seems questionable, however, to apply the stage algorithm to dietary behavior when subjects do not have an accurate perception of their estimated objective behavior. In the present study, many of the subjects who did not meet the dietary guidelines thought that they ate enough salads (54\%), fruit (55\%), and processed vegetables $(80 \%)$. Consequently, they did not feel an urge to change their behavior. So, according to the stages of change, they would be in the maintenance stage with their fruit and vegetable consumption, and nutrition education should 
focus on maintaining the behavior. However, when considering the estimated objective consumption, these subjects should be placed in the precontemplation stage since they did not consume enough fruit and vegetables and did not consider changing their behavior. Hence, the lack of congruence between estimated objective and self-rated behavior appears to seriously lower the internal validity of the stage algorithm. A stage algorithm combining estimated objective consumption and subjective self-rated consumption as well as subjects' intention toward dietary behavior in the future seems to be worthwhile considering.

In the current study, psychosocial determinants of fruit and vegetable consumption were assessed using the ASE model. Results showed that the estimated objective consumption of fruit, salads, and processed vegetables could be explained partly by the psychosocial determinants and the intention to consume the three food groups each day. The explained variance ranged from $11 \%$ for the consumption of processed vegetables to $36 \%$ for salad consumption (Brug, Lechner er al., 1995). These results are comparable with findings in other studies on psychosocial determinants and diet (Stafleu, De Graaf et al., 1991; Van Assema, Pieterse et al., 1993). The explained variance of subjects' self-rated consumption by the psychosocial determinants was higher, ranging from $25 \%$ for processed vegetables to $49 \%$ explained variance for fruit. These percentages of explained variance are higher than those found in other studies of psychosocial factors and estimated objective diet (Glanz, Patterson et al., 1994; Godin \& Kok, 1996). The psychosocial determinants as assessed in this study appeared to reflect people's selfrated consumption better than their estimated objective consumption of fruit and vegetables.

Although the internal consistency of the attitude, social influence, and selfefficacy concepts were all higher than 0.5 , which is considered to be sufficient for summation of items to form overall determinants scores (Nunnally, 1967), some of the alphas were not very high (see Table 6.1). If the reliability of the constructs had been higher, the correlation and the explained variance in the regression analyses to 
predict self-rated and estimated objective behavior might also have been higher. Therefore, future research should try to improve the reliability of the determinant constructs.

The self-rated consumption of salads, processed vegetables, and fruit were not explained equally by the determinants and the intention. As was to be expected, intention was highly related to all of the behaviors. Attitude was also significantly related to all three behaviors, although it was more important for the self-rated consumption of processed vegetables and salads than for fruit. Social influence was significantly related to the self-rated consumption of salads and, to a smaller degree, processed vegetables. It was, however, not related to the self-rated consumption of fruit. Self-efficacy was highly related to all three self-rated and estimated objective behaviors, although it seemed especially important for the self-rated consumption of fruit. These differences between the three behaviors are in accordance with results from qualitative research (Brug, Debie et al., 1995), confirming that beliefs differ considerably between the three behaviors.

\section{Implications for researchers and practitioners}

The findings in this study have implications both for nutrition education and for the way in which nutrition behavior should be assessed. With respect to nutrition behavior regarding the consumption of fruit and vegetables, there seems to be a major discrepancy between the self-rated subjective consumption and the estimated objective consumption. Furthermore, psychosocial determinants are associated better with self-rated assessments of dietary behavior than with the estimated objective assessments. Researchers should take note that, in measuring nutrition behavior, the researcher might have a different association with the concept of nutrition consumption than subjects do. As a result, it is possible that differences that occur between objective and subjective estimated consumption of fruit and vegetable intake could lead to faulty assumptions of nutrition educators. This might negatively impact the appropriateness of a resulting nutrition education 
message.

Nutrition education aimed at increasing fruit and vegetable consumption might not be effective as long as subjects misjudge, and especially overestimate, their level of consumption of these foods. If these people get attitude information, they are not likely to change since they think that they are already behaving healthily. Therefore, before changing attitudes and increasing self-efficacy (Brug, Lechner et al., 1995), increasing awareness of the (lack of) adequacy of personal fruit and vegetable consumption should be an important first intervention target. This could be done by making them aware of the guidelines, since many people do not know the guidelines (Van Assema, Brug et al., 1996). Furthermore, the education message can be made more concrete by visualizing how much 150-200 grams of vegetables and two pieces of fruit really is (so that people can compare this with their own intake). For this, it could be important that consumers are taught how to visualize their consumption more accurately. This can be further personalized by giving people personal feedback on their own intake, using messages tailored to the individual situation of the subjects (Brug, Steenhuis et al., 1996). As soon as people know how little they eat, further steps can be made toward changing behavior. 


\title{
CHAPTER 7
}

\section{Stages of change for fruit, vegetable and fat intake: Consequences of misconception ${ }^{1}$}

\begin{abstract}
Background. In order to study whether the Stages of Change concept of the Transtheoretical Model is applicable to fruit, vegetable, and fat intake, data on two different study populations were analyzed.

Methods. Two methods of classifying stages of change were compared in both study populations. The first, more traditional, classification method was based on intentions and self-rated intake. In the second classification method, estimated level of consumption (using a food frequency questionnaire) of fruit, vegetables, and fat was included.

Results. Differences between both classification methods in distributions of respondents over stages of change were large, especially for vegetable and fat intake. Many subjects who were in maintenance based on the traditional classification method, were classified in precontemplation stage if the alternative classification method was used, since these subjects were unaware of their unfavorable dietary intake.

Conclusions. Nutrition education that uses the Stages of Change as a base for developing educational messages should not provide these subjects with information aimed at sustaining the present behavior but with information that creates awareness of personal dietary behavior. Considerations should be given to including more objective behavioral assessment methods in Stages of Change classification methods when the Transtheoretical Model is applied to nutrition research.
\end{abstract}

${ }^{1}$ Will be published as:

Lechner, L., Brug, J., De Vries, H., Van Assema, P., \& Mudde, A. (1998). Stages of change for fruit, vegetable and fat intake: Consequences of misconception. Health Education Research (in press). 


\section{INTRODUCTION}

The relationship between the consumption of fruit, vegetables, and fat and the prevention of numerous diseases has become more explicit in recent years. Many studies have shown that people with moderate to high consumption of fruit and vegetables have a lower risk of several kinds of cancer, cardiovascular diseases, hypertension, and stroke (Block, Patterson et al., 1992; Gerster, 1991; Hertog, Feskens et al., 1993; Weisburger, 1991). Consumption of high fat diets, especially diets high in saturated fats, is considered a risk factor for a number of chronic diseases like cardiovascular diseases, various kinds of cancer, diabetes mellitus, and obesity (Dutch Nutrition Council, 1986; 1991; National Research Council, 1989; Surgeon General, 1988).

Increased knowledge of the health effects of fruit, vegetable, and fat intake has led to the development of guidelines for daily intake. The Netherlands Bureau for Food and Nutrition recommends adults eat three to four serving spoons (approximately 150-200 grams) of vegetables and two pieces of fruit (approximately 200 grams) per day (Netherlands Bureau for Food and Nutrition Education, 1993). Also, the Dutch Nutrition Council recommends adults reduce their dietary fat intake to $35 \%$ or less of total calories, especially by reducing intake of saturated fat (Dutch Nutrition Council, 1986; 1991). Only a small proportion of the Dutch population eat according to these guidelines (Hulshof, Löwik et al., 1994). Health education interventions aimed at increasing fruit and vegetable consumption, and decreasing fat intake are therefore necessary.

Health education interventions aimed at changing people's dietary behavior will be more effective if they are based on insights into how people change their behavior (Glanz, Patterson et al., 1994). Several theories can be used for understanding behavioral change in general, and change in dietary behavior in particular (Glanz \& Eriksen, 1993; Glanz \& Mullis, 1988). One of the theoretical frameworks that is very popular nowadays as a framework to understand the process of behavior changes, is the transtheoretical model of Prochaska and colleagues (Prochaska $\&$ DiClemente, 1983; Prochaska, Velicer et al., 1991). In this model different theoretical insights are used to explain how people change their behavior over time. An 
important concept in the model is the so-called Stages of Change. This Stages of Change model suggests that people do not change their behavior in a dichotomous step from unhealthy to healthy behavior, but that the dynamic process of behavioral change can be divided into different stages. In order to change their behavior, people can move from precontemplation (not interested in change) via contemplation (thinking about change) to preparation (actively planning to change within a short period). Subsequently, people can move to the action stage (actually enacting the new behavior) and finally, to maintenance (sustaining the new behavior). In their movement through the stages, people can relapse and fall back to earlier stages. Moreover, movement through the stages often involves a cycling and recycling process (Prochaska \& DiClemente, 1983; Prochaska, Velicer et al., 1991).

The Stages of Change model, which has its origin in research on addictive behaviors, has been applied extensively on smoking cessation behavior (Prochaska \& DiClemente, 1983; Prochaska, Velicer et al., 1991). One of the implications of the model is that people in different behavioral stages need different information, tailored to their specific stage, to motivate them to proceed in the change process to action and maintenance. The stages of change were also similarly applied to numerous other behaviors, such as exercise (Lechner \& De Vries, 1995a; 1995b; Marcus, Banspach et al., 1992; Marcus, Selby et al., 1992), and to other behaviors, such as participation in mammography screening, using sunscreen protection, weight control, and condom use by Prochaska et al. (1994). The usual way to divide subjects into the different stages is based on self-reported behavior and intentions. Subjects are asked whether they intend to change their behavior within the next 6 months (contemplation), whether they plan to do this within the next 30 days (preparation), whether they have already changed their behavior recently (action), and whether they have sustained the healthy behavioral change for a significant amount of time, often operationalized as over 6 months (maintenance) (Prochaska \& DiClemente, 1983; Prochaska, Velicer et al., 1991).

Applications of the stages of change model to nutrition behavior were reported recently in some studies (Curry, Kristal et al., 1992; Glanz, Patterson et al., 1994; Greene, Rossi et al., 1994; Kramisch-Campbell, De Vellis et al., 1994). All of these studies applied the stages of change model to fat reduction. Only one 
application to fibre consumption was reported (Glanz, Patterson et al., 1994). These studies based their classification of subjects in stages on the subjects' self-reports of intention and behavior. If subjects thought they were on a healthy diet, they were placed in the action or maintenance stages. This resulted in similar distribution patterns over the different studies: a relatively high proportion of the subjects were in action or maintenance, while relatively few respondents were in the precontemplation, contemplation, or preparation stages (Curry, Kristal et al., 1992; Glanz, Patterson et al., 1994; Greene, Rossi et al., 1994).

An important issue in changing dietary behavior seems to be people's awareness of their own behavior. Weinstein proposed that awareness of risk behavior is one of the key issues in motivating people to move from precontemplation to further stages of behavior change (Weinstein, 1988). The prevalence of lack of awareness of dietary behavior was demonstrated in two studies in The Netherlands (Brug, Van Assema et al., 1994; Lechner, Brug et al., 1997), in which large differences were found between the objective assessment of dietary fat, fruit and vegetable intake and the self-rated, subjective intake of fat, fruit, and vegetables. Furthermore, a study by Bowen et al. (Bowen, Fries et al., 1994) found that those subjects with the highest fat intake, consistently underestimate the amount of fat in their diet.

This lack of awareness could have consequences for the application of the stages of change to dietary behavior. It seems questionable to apply the Stages of Change model based on subjective, self-rated intake to dietary behavior, when subjects do not have an accurate perception of their actual behavior. In the studies on stages of change in fat reduction, it was found that fat consumption levels declined from precontemplation to maintenance (Curry, Kristal et al., 1992; Greene, Rossi et al., 1994; Kramisch-Campbell, DeVellis et al., 1994), and it was argued that this association between stages and fat consumption could be seen as an indication for the validity of the way subjects were divided in the different stages. At the same time, Greene et al. (1994) showed that among subjects eating more fat than the U.S. recommendation, $40 \%$ were classified as maintainers based on their self-reports. Curry et al., (1992) showed similar results: among male maintainers the average fat intake was more than $35 \%$ of total energy intake. Glanz et al. (1994) 
reported an average fat consumption among maintainers of $32 \%$ of calories, which indicates that at least a substantial proportion of maintainers consumed more fat than is recommended. This study also reported, with respect to fruit and vegetable consumption, an average daily amount of 2.15 servings of fruit and vegetables for subjects in action, and 3.11 servings of fruit and vegetables for subjects in maintenance with regard to fibre intake (Glanz, Patterson et al., 1994). Both scores are below the recommended five servings of fruit and vegetables per day. This difference between actual behavior and subjective perceptions of behavior creates a serious threat to the internal validity of a stage algorithm that is only based on subjective perceptions of behavior. Therefore, it has been argued that subjects who are unaware of the fact that they do not meet the dietary guidelines, and who might therefore consider themselves as actors or maintainers, might better be considered as precontemplators (Brug, Hospers et al., 1997; Lechner, Brug et al., 1997). Hence, a stage classification method that validates subjective estimation of dietary intake with a more accurate assessment of consumption seems recommendable. Until now, with respect to fruit, vegetable, and fat consumption, alternative classification methods of the stages of change model, which are based on a combination of both subjective estimation of consumption and estimated actual consumption, have not been reported.

The present study aims to apply both the traditional staging classification method (which is based on intention and subjects' self-rated intake), and an alternative classification method (which combines estimated actual consumption, intention, and self-rated consumption) to fruit, vegetable, and fat intake. It was hypothesized that a large number of subjects who are classified as being in maintenance by means of the traditional method, will be in precontemplation under the alternative classification method. The differences, the consequences and the practical implications for nutrition education of both staging classification methods are studied, using two different samples. 


\section{METHODS}

\section{Respondents and procedures}

Study 1

Data collection among two study populations were analyzed. The data concerning fruit and vegetables were collected by means of a telephone survey among 670 adults from the Dutch general public. A total of 402 subjects completed the survey (response rate $=60 \%$ ). Fifty percent were male; the mean age of the respondents was 43 years $(S D=16)$; most of the respondents had a spouse $(73 \%)$. Thirty-five percent of the respondents had a high level of education (higher vocational school or university), $36 \%$ a medium level (secondary vocational school or high school), and $29 \%$ a low level of education (primary or basic vocational school). Thirty-six percent had a higher income than the Dutch average. The distribution of demographics such as age, gender, and educational level was comparable to the general Dutch adult population (Dutch Central Bureau for Statistics, 1994).

\section{Study 2}

The data concerning fat intake were obtained from a random sample of 689 employees of a major oil company in The Netherlands, by means of written questionnaires. A total of 507 completed questionnaires were returned (response rate $=74 \%)$. The mean age of the respondents was 39 years $(S D=7.7) ; 83 \%$ of the respondents were male; most of the respondents had a spouse (88\%). Thirty-four percent of the respondents had a high level of education (higher vocational school or university), 59\% a medium level (secondary vocational school or high school), and $7 \%$ a low level of education (primary or basic vocational school).

\section{Questionnaire}

The questionnaires included questions about consumption of fruit, vegetables (study 1) and fat (study 2), intentions, and demographic variables.

\section{Study 1}

The distinction between fruit and vegetables was made since earlier research 
indicated that people have different motivations for consumption of these food groups (Brug, Debie et al., 1995; Brug, Lechner et al., 1995; Lechner, De Vries et al., 1994; Lechner, Brug et al., 1997). Self-rated intake, consumption levels, and intentions were assessed in relation to fruit consumption and vegetable consumption. Self-rated intake was assessed by asking the respondents to indicate their intake levels of fruit and vegetables on a 5-point scale, ranging from very low to very high. Consumption levels were assessed with a food frequency questionnaire (estimated consumption level). The consumption levels of fruit and vegetables were assessed by asking respondents to indicate the frequency and portion size in which they ate vegetables and fruit during the last month. Portion size for vegetables could be given either in serving spoons or in grams, but were coded as grams ( 1 serving spoon $=50$ grams, according to the Netherlands Bureau of Food and Nutrition Education instructions). The food frequency questionnaire was tested in a small scale study $(N=47)$ in which the reproducibility (test-retest correlation was 0.77 between first and second administration), and the relative validity in classifying subjects according to intake levels were assessed in relation to a validated comprehensive Dutch food frequency questionnaire (Pearson correlation $=0.58$ ) (Goldbohm, Van den Brandt et al., 1994). The food frequency questionnaire was applied in several studies (Brug, Lechner et al,. 1995; Brug, Steenhuis et al., 1996; Lechner, Brug et al., 1997). Intention to increase fruit and vegetable intake was assessed by asking the respondents whether they intended to increase their intake of fruit and vegetables within 6 months and within 1 month.

\section{Study 2}

Self-rated intake, consumption levels, and intentions were assessed in relation to consumption of fat. Self-rated intake was assessed by asking the respondents to indicate their intake level of fat on a 5-point scale, ranging from very low to very high. The estimated consumption level of fat was assessed with a 25 -item validated food frequency questionnaire from which a fat score, ranging from 12 to 60 can be calculated (Van Assema, Brug et al., 1992). Fat scores of 22 for women and 25 for men correspond with the approximated upper levels of recommended dietary fat intake in The Netherlands (test-retest correlation was 0.71 ; validation in compari- 
son to a 7-day dietary record: $r=0.59$ ). This questionnaire was used in several studies before (Brug, Hospers et al., 1997; Brug, Steenhuis et al., 1996; Van Assema, Steenbakkers et al., 1994). Intention to decrease fat intake was assessed by asking the respondents whether they intended to decrease their fat intake within 6 months and within 1 month.

\section{Classification into stages of change}

Two methods were used to classify subjects into stages of change, separately for fruit and vegetable intake (study 1), and for fat intake (study 2). Figure 7.1 shows these two classification methods graphically. The figure describes the classification methods applied to consuming more vegetables (study 1), but the methods are basically the same for the consumption of more fruit (study 1) or less fat (study 2).

\section{Study 1}

The traditional method of classifying stages of change (Figure 7.1), which is in accordance with earlier research on stages of change in dietary behavior, is based on intentions and subjects' self-rated intake (Curry, Kristal et al., 1992; Glanz, Patterson et al., 1994; Greene, Rossi et al, 1994; Kramisch-Campbell, DeVellis et al., 1994). In the traditional method of classifying stages of change for fruit and vegetables, subjects were classified in the combined action/maintenance stage if they rated their fruit and vegetable consumption as sufficient or high. In this study, for fruit and vegetables no further division was made between action and maintenance, since earlier research indicated that hardly any subjects regard themselves as being in action, but rather in maintenance regarding their fruit and vegetable intake (Lechner, Brug et al., 1997). Respondents were classified in preparation when they reported an intention to change their dietary behavior (increase fruit and vegetable intake) within 30 days and in contemplation when they intended to make the dietary change within 6 months but not within 30 days. Respondents were in precontemplation when they did not consider themselves as eating a high fruit and vegetable diet, were not in the process of changing their dietary behavior, and had no intention to change their diet with respect to vegetables or fruit. 


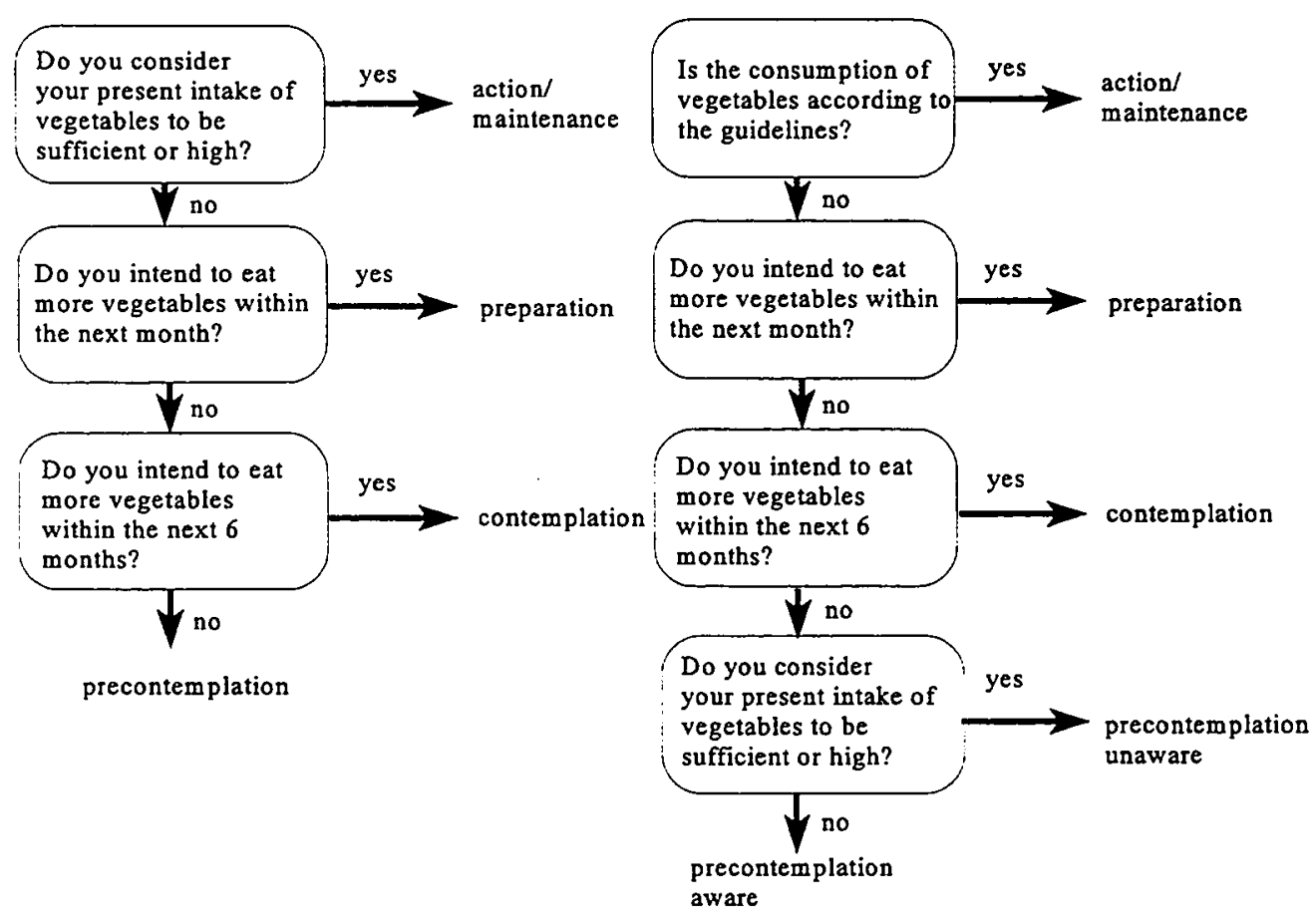

Figure 7.1: The traditional method and the alternative method of classifying the stages of change, applied to vegetable consumption

In the alternative method of classifying stages of change, the stages classification was additionally linked to the consumption levels of fruit or vegetables, as assessed by the food frequency questionnaire (Figure 7.1). For fruit and vegetables respondents were placed in the combined action/maintenance stage if their estimated consumption levels of fruit and vegetables were according to the Dutch dietary guidelines (over 150 grams of vegetables per day and at least 2 pieces of fruit per day). Respondents with diets low in fruit or vegetables were divided into the other stages of change similar to the traditional classification method, but a distinction was made between precontemplators who were aware, and those who were unaware of their low fruit and vegetable intake. 


\section{Study 2}

In the traditional method of classifying stages of change for fat intake, respondents were classified as being in action when they reported they were presently trying to eat less fat, and were classed in maintenance when they reported they were eating a low fat diet and were not presently trying to lower their fat intake. Respondents were classified in preparation when they reported an intention to reduce their fat intake within 30 days, and in contemplation when they intended to make the dietary change within 6 months but not within 30 days. Respondents were in precontemplation when they did not consider they ate a low fat diet, were not in the process of changing their fat intake, and had no intention to reduce their fat intake.

In the alternative method of classifying stages of change, the stages classification was additionally linked to the estimated consumption levels of fat, as assessed with a food frequency questionnaire (Figure 7.1). Respondents were only classified as being in action or maintenance when they had low consumption levels of fat. When these respondents with low consumption levels of fat reported they were presently trying to reduce their fat consumption, they were classified as being in action. Respondents with low fat consumption levels, who were not in the process of reducing their fat intake, were classified as being in maintenance. Respondents with high fat diets were divided into the other stages of change similar to the traditional staging classification method, but a distinction was made between precontemplators who were aware, and those who were unaware of their high fat intake.

\section{Statistical analysis}

To calculate the level of agreement in classification between the traditional and alternative classification method, Cohen's $\mathrm{K}$ values (Fleiss, 1981) were computed for each stage separately. For these analyses subjects were divided into the precontemplation, contemplation, preparation, action, and maintenance stages, according to both classification methods. Differences in mean fruit, vegetable, and fat intake between the stages were assessed using analysis of variance with Scheffé's multi comparison test (significant differences for $\mathrm{p}<0.05$ ). 


\section{RESULTS}

\section{Study 1}

According to the traditional classification method, most respondents were in the action/maintenance stage with respect to their consumption of vegetables (89\%), and fruit (71\%) (Table 7.1). Only a small percentage of the respondents were in precontemplation based on the traditional classification method with regard to vegetables and fruit intake. However, a high proportion of the respondents who were placed in the action or maintenance stage based on the traditional classification method did not meet the dietary guidelines. Therefore, the alternative classification method (which included estimated consumption levels) displays a substantially different distribution (Table 7.1), revealing that the majority of respondents were in precontemplation with regard to vegetable (59\%), and fruit intake (35\%). Most of these subjects in precontemplation were unaware of their unfavorable consumption patterns. For fruit and vegetables, in both the traditional and the alternative classification methods few respondents were classified in the contemplation or preparation stage.

Table 7.1: Distribution of respondents over stages of change for fruit and vegetable intake, using two classification methods (study 1)

\begin{tabular}{lllll}
\hline & \multicolumn{2}{c}{ VEGETABLES $(\mathrm{n}=402)$} & \multicolumn{2}{c}{ FRUIT $(\mathrm{n}=402)$} \\
\cline { 2 - 5 } Stage & $\begin{array}{l}\text { traditional } \\
\text { method }\end{array}$ & $\begin{array}{l}\text { alternative } \\
\text { method }\end{array}$ & $\begin{array}{l}\text { traditional } \\
\text { method }\end{array}$ & $\begin{array}{l}\text { alternative* } \\
\text { method }\end{array}$ \\
\hline precontemplation & $8 \%$ & $59 \%\left(51 \%^{2}, 8 \%^{\mathrm{b}}\right)$ & $18 \%$ & $35 \%\left(18 \%^{2}, 17 \%^{\mathrm{b}}\right)$ \\
contemplation & $1 \%$ & $2 \%$ & $5 \%$ & $5 \%$ \\
preparation & $2 \%$ & $2 \%$ & $6 \%$ & $8 \%$ \\
action/maintenance & $89 \%$ & $37 \%$ & $71 \%$ & $52 \%$ \\
"The alternative method of classifying stages & of change distinguishes between unaware \\
precontemplators and aware precontemplators &
\end{tabular}

For vegetable consumption, Cohen's $\kappa$ values were very low for the agreement in the precontemplation stages (.10) and the action/maintenance stages (.10). 
For fruit consumption, Cohen's $\mathrm{k}$ values between the precontemplation stages (.51) and between the action/maintenance stages (.55) were higher than for vegetable intake, showing a stronger but still not more than moderate similarity in classification between both classification methods. Agreement within the contemplation stages (vegetables $=.49$; fruit $=.94$ ) and within the preparation stages (vegetables $=.66$; fruit $=.84$ ) was relatively high between both classification methods, especially for fruit intake.

The average daily consumption of fruit and vegetables for the different stages of change is presented in Table 7.2. Since the alternative classification is partly based on estimated consumption levels, consumption for fruit and vegetables in action/maintenance are according to the guidelines by definition for this classification. Therefore, the differences between the earlier stages and action/maintenance were less often statistically significant in the traditional classification method, compared to the alternative classification method.

Table 7.2: The average daily consumption level of vegetables (in grams) and fruit (in pieces) for the different stages of change, based on two methods of classifying the stages of change (study 1)

\begin{tabular}{|c|c|c|c|c|}
\hline \multirow[b]{2}{*}{ Stage } & \multicolumn{2}{|c|}{ VEGETABLES $(n=402)$} & \multicolumn{2}{|c|}{ FRUIT $(n=402)$} \\
\hline & $\begin{array}{l}\text { traditional } \\
\text { method }\end{array}$ & $\begin{array}{l}\text { alternative } \\
\text { method }\end{array}$ & $\begin{array}{l}\text { traditional } \\
\text { method }\end{array}$ & $\begin{array}{l}\text { alternative } \\
\text { method }\end{array}$ \\
\hline precontemplation unaware (PU) & & 111 & & 1.02 \\
\hline precontemplation aware (PA) & 68 & 65 & 0.52 & 0.38 \\
\hline contemplation (C) & 90 & 54 & 0.38 & 0.44 \\
\hline preparation (Pr) & 81 & 72 & 0.47 & 0.50 \\
\hline action/maintenance (A/M) & 160 & 236 & 2.43 & 3.00 \\
\hline $\begin{array}{l}\text { Significant differences: Scheffé's } \\
\text { multicomparison test }(p<.05)\end{array}$ & $\mathrm{PA}<\mathrm{A} / \mathrm{M}$ & $\begin{array}{l}\mathrm{PU}, \mathrm{PA}, \mathrm{C}, \mathrm{Pr}<\mathrm{A} / \mathrm{M} \\
\mathrm{PU}>\mathrm{PA}\end{array}$ & $\mathrm{PA}, \mathrm{C}, \operatorname{Pr}<\mathrm{A} / \mathrm{M}$ & $\begin{array}{l}\mathrm{PU}, \mathrm{PA}, \mathrm{C}, \mathrm{Pr}<\mathrm{A} / \mathrm{M} \\
\mathrm{PU}>\mathrm{PA}\end{array}$ \\
\hline
\end{tabular}

For both fruit and vegetable consumption, analyses of the alternative classification method showed that subjects in the action/maintenance stages had a 
significantly higher fruit and vegetable intake than subjects in the precontemplation (aware and unaware), contemplation, and preparation stages. For both fruit and vegetable consumption in the alternative classification method, respondents who were unaware of their insufficient consumption had a significantly higher daily intake than respondents who were aware of their insufficient consumption.

\section{Study 2}

According to the traditional classification method, most respondents were in the action and maintenance stages with respect to their consumption of fat (52\%), with only a small percentage of respondents in precontemplation (14\%) (Table 7.3). The alternative classification method displays a different distribution (Table 7.3), revealing that the majority of respondents were in precontemplation with regard to their fat intake (55\%), most of whom were unaware of their high fat intake. With respect to fat intake, the proportion of respondents in preparation was relatively high in both classifications.

Table 7.3: Distribution of respondents over stages of change for fat intake using two classification methods (study 2)

\begin{tabular}{lcc}
\hline & \multicolumn{1}{c}{ FAT (n=507) } \\
\cline { 2 - 3 } Stage & $\begin{array}{l}\text { traditional } \\
\text { method }\end{array}$ & $\begin{array}{l}\text { alternative* } \\
\text { method }\end{array}$ \\
\hline precontemplation & $14 \%$ & $55 \%\left(42 \%^{2}, 13 \%{ }^{b}\right)$ \\
contemplation & $8 \%$ & $7 \%$ \\
preparation & $26 \%$ & $21 \%$ \\
action & $12 \%$ & $8 \%$ \\
maintenance & $40 \%$ & $9 \%$ \\
"The alternative method of classifying stages of change distinguishes between unaware \\
precontemplators and aware precontemplators
\end{tabular}

For fat intake, Cohen's $\kappa$ values between the precontemplation stages (.17), and between the action (.20) and maintenance stages (.16) were very low and comparable with the $K$ values for vegetables intake. Agreement within the contem- 
plation stages (.94), and within the preparation stages (.87) was high between both classification methods for fat intake.

The average daily fat intake for the different stages of change is presented in Table 7.4. Since the alternative classification is partly based on the estimated consumption level, fat scores in action and maintenance are by definition according to the guidelines for this classification. Therefore, the differences between the earlier stages and action and maintenance were less often statistically significant in the traditional classification method, compared to the alternative method. Analyses of the alternative classification method showed that subjects in the action/maintenance stages had a significantly lower fat intake than subjects in precontemplation (aware and unaware), contemplation, and preparation. Respondents in precontemplation had a significantly higher average fat score as compared to respondents in preparation in both the traditional and alternative classification methods.

Table 7.4: The average daily consumption level of fat (mean fat consumption score) for the different stages of change, based on two methods of classifying stages of change (study 2)

\begin{tabular}{lll}
\hline & \multicolumn{2}{c}{ FAT $(\mathrm{N}=507)$} \\
\cline { 2 - 3 } Stage & $\begin{array}{l}\text { traditional } \\
\text { method }\end{array}$ & $\begin{array}{l}\text { alternative } \\
\text { method }\end{array}$ \\
\hline precontemplation unaware (PU) & & 30.0 \\
precontemplation aware (PA) & 30.6 & 31.7 \\
contemplation (C) & 28.7 & 29.2 \\
preparation (Pr) & 27.7 & 29.0 \\
action (A) & 27.1 & 21.2 \\
maintenance $(\mathrm{M})$ & 28.9 & 22.1 \\
\hline Significant differences in Scheffé's & $\mathrm{PA}>\mathrm{Pr}, \mathrm{A}$ & $\mathrm{PA}, \mathrm{PU}, \mathrm{C}, \mathrm{Pr}>\mathrm{A}, \mathrm{M}$ \\
multicomparison test $(\mathrm{P}<.05)$ & & $\mathrm{PA}>\mathrm{Pr}$ \\
\hline
\end{tabular}




\section{DISCUSSION}

In this research, two methods were used to classify subjects of two study populations into stages of change, regarding their fruit and vegetable intake (study 1), and their fat intake (study 2). Besides a more traditional classification method, which is based on subjective, self-rated intake and intention to change, an alternative classification method of stages was used, where a more objective assessment of consumption was included in the classification method. There were some clear differences in classification between both methods, evident in both studies. The distributions over the different stages in both studies showed that many subjects who were in action or maintenance according to the traditional classification method were classified in the precontemplation stage according to the alternative classification method, because they did not meet the dietary guidelines, and had no intention to change their behavior. Since misconception of fruit intake (study 1) was less frequent than misconception of vegetable intake (study 1), and fat intake (study 2), differences in distribution over the stages between both classification methods were less substantial for fruit consumption. Comparison of the alternative classification method presented in this research with other dietary studies, which used the stages of change classification method based on self-rated behavior (Curry, Kristal et al., 1992; Glanz, Patterson et al., 1994; Greene, Rossi et al., 1994), shows that the alternative classification method resulted in a higher proportion of subjects in precontemplation instead of maintenance.

The differences between both classification methods were also confirmed by the calculated Cohen's $k$ values between the different stages of both methods. For the precontemplation stages and the action/maintenance stages, the level of agreement in classification between both methods was very low for vegetable and fat intake (Fleiss, 1981), and only moderately high for fruit intake. For all three behaviors, the level of agreement was rather high between the contemplation stages and between the preparation stages, indicating that people who are (actively) considering changing their diet are more aware of their actual intake.

In the first study, only small proportions of subjects intended to increase their consumption of fruit and vegetables. The low percentages may result from the 
fact that most respondents believed that they already ate enough fruit and vegetables. Self-rated dietary behavior has been identified as a significant predictor of intention to change dietary behavior (Brug, Van Assema et al., 1994). Comparable proportions of subjects in contemplation and preparation stages were found in another Dutch study on fruit and vegetable consumption (Lechner, Brug et al., 1997). Studies in the U.S. showed higher proportions of subjects in contemplation or preparation stages (Glanz, Patterson et al., 1994; Kramisch-Campbell, DeVellis et al., 1994). Although no research was done to explain these differences, they may be due to a higher awareness of nutrition in the U.S., compared to The Netherlands.

The alternative classification method in the first study shows a clear difference in consumption of fruit and vegetables between respondents who were aware and those who were not aware of their low consumption. The first group had a lower fruit and vegetable intake than the second. In view of these consumption patterns, one might expect these respondents to have increased their consumption in the past, and therefore consider themselves to be in maintenance. It is not likely that these persons are contemplating change if they feel that they are currently meeting the recommendations. However, as they have not reached the dietary recommendation levels yet, they should be stimulated to contemplate further changes.

The two studies used food frequency questionnaires to assess objective or actual levels of consumption of fruit and vegetables (study 1), and fat (study 2). This means that we could only give an approximation of the actual fruit, vegetable, and fat intake. Since data were gathered by use of telephone surveys (study 1) and relatively short written questionnaires (study 2), it was not possible to use more extensive methods, such as multiple day food records or multiple 24-hour recalls, in order to get a more precise estimation of actual consumption level. However, despite the fact that this research used two different methods of collecting data (telephone versus written questionnaire), two different study populations (general public versus predominately male worksite employees), and different dietary behaviors (high fruit and vegetable diet versus low fat diet), the findings in both studies are quite comparable. These similar findings strengthen the importance of attending to the problems that arise when using a stage classification method based 
only on subjects' self-rated intake for dietary behavior.

One of the most important implications of the Transtheoretical model is that subjects in different stages of change use different processes of change in order to proceed in the behavioral change process (Prochaska \& DiClemente, 1983). This implicates that health education messages should be tailored to the stage of change subjects are in (Brug, Hospers et al., 1997; Lechner \& De Vries, 1995a). Subjects in maintenance should be encouraged to sustain their present behavior. However, it seems unjustifiable to stimulate subjects who wrongly think they are in maintenance to sustain their present diet. Since this group does not yet meet the dietary guidelines, nutrition education should focus on making them aware of their misconception and of the need to make further changes. Health educators should take into account that the group of consumers who are unaware of their undesirable dietary behavior may need to be treated as a separate group with different educational targets.

We conclude that altering the method for classifying subjects to stages of change for dietary behaviors, by using a combination of the subjects' self-rated answers on traditional staging questions, and objective assessments of dietary behavior is useful for research into motivational factors for changing dietary behavior, and for identifying stage-tailored nutrition education goals. 


\title{
CHAPTER 8
}

\section{Participation in a breast cancer screening program: Influence of past behavior and determinants on future screening participation $^{1}$}

\begin{abstract}
Background. This study analyzed the relationship between past screening bebavior, determinants, intention, and future screening participation in the Dutch national breast cancer screening program.

Metbods. Participation at the first and second screening rounds was monitored. Furthermore, between the first and the second screening rounds, women received a questionnaire (response 58\%, $n=395$ ). The questionnaire was based on the ASE model, including attitude (consequences, anticipated regret, and moral obligation), social influence (support and modeling), and self-efficacy. Other distal variables assessed were previous screening behavior, evaluation of screening characteristics, and demographics.
\end{abstract}

Results. Participants at the second screening differed from nonparticipants on all ASE determinants. Stepwise multiple regression analyses showed that for previous participants and nonparticipants different ASE determinants and distal variables explained the variance in intention to participate in the next screening ( 30 to $45 \%$ ). Logistic regression analyses showed that past behavior and intention (which mediated the effects of the ASE variables) were significant predictors of participation in the second screening.

Conclusions. Differences between previous participants and nonparticipants in determinants of intention and future screening behavior can be used to improve participation and adberence to breast cancer screening.

${ }^{1}$ Published as:

Lechner, L., De Vries, H., \& Offermans, N. (1997). Participation in a breast cancer screening program: Influence of past behavior and determinants on future screening participation. Preventive Medicine, 26, 473-482. 


\section{INTRODUCTION}

Breast cancer is the most prevalent type of cancer among women in the Netherlands (Mackenbach, 1988), and most other Western countries (American Cancer Society, 1991; Lipmann, Lichter et al., 1988). Since there is still limited insight into the behaviors related to developing breast cancer (Kelsey, 1988; McDermott, 1991), primary prevention of breast cancer proves to be very difficult. However, early detection does provide an important tool for implementing secondary prevention. By performing regular breast cancer screening on women from the high-risk age groups, possible cancer can be detected at an early stage so that the health loss for these women can be minimized (Shapiro, Venet et al., 1982; Tabar, Fagerberg et al., 1985).

In The Netherlands, a national breast screening program was started in 1989 (Van Veen, 1992), and eventually was implemented in all parts of the country. In this national screening program, all women in the age group 50 to 70 years receive an invitation to attend a breast cancer screening in a specially designed screening unit every 2 years. However, research shows that despite high attendance rates in the first screening round, attendance in the following years declines with every new screening round (Baker, 1982; Collette, Rombach et al., 1988; Howe, 1992; ScafKlomp \& Van den Heuvel, 1990; Vernon, Laville et al., 1990). Therefore, it seems highly relevant to gain insight into the reasons why women attend the screening, and why this attendance declines with time.

\section{Theoretical framework and research questions}

Social psychological models suggest that behavior is determined by the intention to perform this behavior. This intention, in general, is determined by three important factors: attitude, social influence, and self-efficacy. These factors can be integrated in models such as the Theory of Planned Behavior (Ajzen, 1991) or the ASE model (Attitude - Social influence - self-Efficacy) (De Vries, Dijkstra et al., 1988; Lechner \& De Vries, 1995a), which was used in the present study.

According to the ASE model, the first possible determinant of behavioral intention is the attitude, which consists of the advantages and disadvantages of a 
particular behavior. These expected outcomes (Bandura, 1986) can take place directly following the behavior or after a longer period. With respect to breast cancer screening, this time period between behavior and possible outcome seems particularly important: although long-term outcomes of screening might be very positive (participating in the screening could lengthen a healthy life), the short term benefits of screening may not be so obvious, since screening might cause pain and may result in fear of the results.

Another possible determinant of participating in the screening could be the personal norm women experience. One aspect of the personal norm is anticipated regret (Van der Pligt \& Richard, 1993). Women might think that not attending the screening would leave them with feelings of regret if at a later date breast cancer were detected. Research has shown that the more regret women anticipate if they do not attend the screening, the more likely they are to participate in the screening (Scaf-Klomp \& Van den Heuvel, 1990). In addition to regret that women may anticipate, women may feel they are fulfilling a moral obligation by participating in the screening: "by participating in the screening you show res̀ponsibility toward yourself and others." Compliance to the felt obligation could be considered an outcome of the desired behavior and therefore can be placed within the attitude concept. There are several possibilities to place the personal norm concept (anticipated regret, moral obligation) within the ASE determinant model. Personal norms could be seen as a separate new concept or as a concept within the attitude construct. As Eagly and Chaiken state (1993), personal norms could be subsumed under attitude toward the behavior, because guilt, self-reinforcement, and other outcomes of meeting or violating one's own standards are merely additional consequences of behavior. Therefore, a distinction within attitude between affective consequences of behavior (negative and positive feelings that people anticipare will ensue from engaging in behaviors), and cognitive determinants (costs and benefits) might be a useful modification of the attitude concept.

A second factor, next to attitude, consists of the social influences people encounter. This social influence can manifest itself in several ways (De Vries, Backbier et al., 1995; Grube, Morgan et al., 1986; Reno, Cialdini et al., 1993). Some evidence was found for the importance of direct social support or pressure for 
participating in a screening. Women who feel encouraged to participate in a screening by their spouses, family, friends, or physician are more likely to attend to the screening (Baines, To et al., 1990; Baumann, Brown et al., 1993; Calnan, 1984; Curry \& Emmons, 1994; Howe, 1992; Maclean, Sinfield et al., 1984; Rimer, Trock et al., 1991; Skinner, Strecher et al., 1994). In addition to direct support, the knowledge that other women participate in the screening might also encourage women to attend the screening (modeling) (Lechner, 1991).

The third factor consists of self-efficacy expectations, which are a person's beliefs in his or her abilities to perform a particular behavior. Increased self-efficacy will result in improved performance of the healthy behavior. Research over the past decades has stressed the importance of self-efficacy for enacting new healthy behaviors in general (Bandura, 1986; Schwarzer, 1992), as well as for attending breast cancer screening in particular (Maclean, Sinfield et al., 1984; Boer, Taal et al., 1990; Eardley \& Elkind, 1990).

The impact of these three proximal factors is assumed to be influenced by four types of distal, predisposing factors (Flay \& Petraitis, 1994). One of these factors is behavioral (e.g. previous experience with the same and related behaviors). With respect to breast cancer screening it has been found that women who have already attended an earlier breast cancer screening are more likely to attend future screening rounds (Baumann, Brown et al., 1993; Calnan, 1984; Curry \& Emmons, 1994; Lechner, 1991; Rimer, Kasper et al., 1989; Rimer, Trock et al., 1991; Sutton, Bickler et al., 1994). This past behavior could influence intention directly or indirectly through the three proximal predictors of intention. Ajzen (1991) suggested that past behavior would not have a great unique contribution in predicting behavior after controlling for attitude, social influence, self-efficacy, and intention. However, several studies have shown that the effects of past behavior were sometimes not fully accounted for by the model (Ajzen, 1991; Bagozzi, 1992; De Vries, Backbier et al., 1995; Fredricks \& Dosset, 1983; Grube, Morgan et al., 1986).

Other distal predisposing factors that might influence women's intention to participate are psychological factors (e.g., attributions, vicarious learning processes), biological factors (e.g., age, hereditary variables), and social and cultural factors 
(e.g., social climate, socioeconomic status) (Flay \& Petraitis, 1994; De Vries, 1993; Glanz, Resch et al., 1996). Participation in breast cancer screening programs is lower for older women, for women without a spouse, and for women with a lower educational background (Hobbs, Smith et al., 1980; Scaf-Klomp \& Van den Heuvel, 1990; Tabar, Fagerberg et al., 1985; Vernon, Laville et al., 1990). The proximal cognitions of an individual about the behavior can also be changed by an intervention, which may be elaborate but can sometimes also serve as a very salient "cue to action" (Janz \& Becker, 1984). Therefore, the characteristics of the screening intervention (e.g, personal invitation to the screening, screening unit near home) can facilitate or enable participation at the screening. If characteristics of the screening itself are evaluated positively, women are able to participate more easily and are more likely to participate (Bryant \& Mah, 1992; Eardley \& Elkind, 1990; Rimer, Trock et al., 1991, Rimer, 1994; Rutledge, Hartman et al., 1988). However, little is known about the way these intervention factors may influence attitudes, social influences, and self-efficacy expectations with respect to breast cancer screening.

The present study aims to analyze the way in which the ASE determinants, together with the intention and distal variables (past behavior, screening characteristics, demographics), can describe and predict the differences in participation in the second screening round. Moreover, since it is expected that intention will be an important predictor of second round participation, the predictive power of the ASE determinants, together with distal factors for the intention to participate in the next screening, will be assessed. Since it is also expected that women who have participated in the previous screening round will have more experience with screening, resulting in a stronger association between ASE determinants and (intention of) participation in the second screening round, possible interaction effects between the ASE determinants and past behavior will be analyzed in additional regression analyses. This study is the first to systematically apply the ASE model to breast cancer screening behavior, with the inclusion of both distal and proximal variables. Furthermore, new concepts were included in the model, like anticipated regret and screening characteristics. The strengths of the study include using a longitudinal design, analyzing possible interactions between 
distal factors (past behavior) and ASE determinants, and performing separate analyses for previous participants and nonparticipants.

\section{METHODS}

\section{Respondents and procedures}

During the research period, measurements were taken at three times. The participation in the first screening round (past behavior) was assessed by monitoring the participation in the screening as it was registered between May and July 1993 at the screening units (T1). The determinants and intentions of future screening behavior were assessed between April and May 1994, by means of a written questionnaire (T2). The third measurement consisted of monitoring the participation of the second screening round, which took place between March and July 1995 (T3).

The national breast cancer screening program was implemented in 1993 in Kerkrade, a small Dutch town in the south of The Netherlands. The screening is free of charge for all women. A stratified random sample was selected from all women who had received an invitation to attend the first screening round (T1). Earlier research indicated a high prevalence of selective response to questionnaires among participants and nonparticipants of breast cancer screening and an overrepresentation of participants compared with nonparticipants in the first screening round (Lechner, 1991). Therefore, the sample was stratified and oversampled with women who did not attend the first screening round. Consequently, 345 questionnaires were sent to women who participated in the first screening and 453 to women who did not participate. In total 798 women received a written questionnaire between their first and second screening round (T2). Questionnaires were distributed in April 1994, together with an introductory letter and a return envelope. Two weeks later women received the first reminder, followed 2 weeks later by another reminder together with a new questionnaire. 


\section{Questionnaire}

The questionnaire was based on earlier research (Lechner, 1991), qualitative interviews, and a small pilot study among women from the target group $(\mathrm{N}=15)$ (Offermans, 1994).

Attitude was measured using several concepts:

- Perceived consequences or outcomes of the screening behavior were assessed via 11 items on 4point scales (Cronbach's $\alpha=.74$ ). Seven items consisted of positive consequences (pros), while 4 items consisted of negative consequences (cons).

- The moral obligation women experience to participate in a national breast cancer screening program was assessed via 2 items on 4-point scales (Pearson $r=.53$ ). For example: "I feel that by participating in the screening program, I fulfil a very great (3) to no obligation (0) to myself."

- Anticipated regret of not participating in the screening was assessed with 2 items on 4-point scales $(r=.74)$. For example: "If I did not participate in the screening, afterward I would feel very much regret (3) to no regret at all (0)."

Social influence was assessed by two concepts:

- Social support from significant others was assessed with 4 items on 4-point scales $(\alpha=.77)$.

- Modeling was assessed with 2 items of which 1 used a 4-point scale (modeling 1): "How many women do you know who have received an invitation to the screening?" Another item used a 5-point scale (modeling 2): "Of the women you know who also received an invitation, how many actually participated in the screening?" Both items were analyzed separately since their scaling differed.

Self-efficacy was assessed using 7 items on 7-point scales $(\alpha=.90)$. All items proposed different situations in which respondents were asked if they would feel able to participate under these circumstances.

Intention was assessed by asking the women if they intended to participate in the next screening round, using a 7-point scale.

In addition to the ASE determinants, the intention, and past behavior, questions were asked about age, educational level, and marital status. Also, several facilitating characteristics of the screening were evaluated via 4 items on 7-point scales $(\alpha=.79)$. 
Response

As was expected, a difference in response to the questionnaire occurred between women who had participated in the first screening round and women who had not participated. Of the 345 questionnaires that were distributed among participants in the first screening, 259 were returned (75\%), while 229 of the 453 questionnaires of nonparticipants were returned (51\%). Twenty-three women were excluded from the original sample because of ongoing treatment for breast cancer (4), language problems (9), change of address (2), or being deceased (8). Of the 488 respondents to the questionnaire, 93 respondents were excluded from further analyses, since participation at the second screening round could not be monitored (46 respondents had turned 70 or older at $\mathrm{T} 3 ; 19$ respondents were excluded because of ongoing rreatment for (breast) cancer, change of address, or being deceased at T3; 28 respondents could not be monitored because of missing data at T3). This resulted in 395 respondents for further analyses (response 58\%), of whom $219(55 \%)$ had participated and 176 (45\%) had not participated in the previous screening.

\section{Statistical Analysis}

Data analyses included basic descriptive statistics of the respondents. Statistical differences between participants and nonparticipants at the second screening round were analyzed using $t$ tests. Logistic regression was used to assess the predictive value of the intention together with the determinants and the distal variables (past behavior, screening characteristics) for the participation in the second screening round. Regression analyses were used to assess the predictive value of the determinants together with the distal variables (past behavior, screening characteristics) for the intention to participate in the next screening round. The assumptions for regression analysis to be applicable were satisfied: none of the independent variables showed high colinearity, the residuals of intention were approximately normally distributed, there were no outliers or influential cases, and examination of scatterplots showed that intention was linearly related to the independent variables. All analyses were performed using the SPSS-X statistical program (SPSS Inc, 1988) (differences were significant for $p<.05$ ). 


\section{RESULTS}

\section{Respondents}

The average age of the respondents was 59 years, ranging from 50 to 69 years. Of the respondents $75 \%$ had a spouse, $14 \%$ were widowed, and $11 \%$ were single. Of the respondents $4 \%$ had a high level of education (higher vocational school or university), $22 \%$ had a medium level of education (secondary vocational school or high school), and $74 \%$ had a lower educational level (primary or basic vocational school).

Correlations of distal variables, ASE determinants, intention, and behavior

Table 8.1 presents the correlations between the different concepts of the ASE model. All ASE concepts correlated significantly with future screening intention and behavior.

Table 8.1: Correlations between the different ASE determinants, distal variables, intention and behavior

\begin{tabular}{|c|c|c|c|c|c|c|c|c|c|c|}
\hline & I & $\mathrm{AR}$ & $\mathrm{CO}$ & $\mathrm{MO}$ & SS & M1 & M2 & $\mathrm{SE}$ & PB & SC \\
\hline intention (I) & - & & & & & & & & & \\
\hline anticipated regret (AR) & .58 & - & & & & & & & & \\
\hline consequences $(\mathrm{CO})$ & .49 & .47 & - & & & & & & & \\
\hline moral obligation (MO) & .36 & .48 & .48 & - & & & & & & \\
\hline social support (SS) & .33 & .35 & .34 & .38 & - & & & & & \\
\hline modeling 1 (M1) & .28 & .26 & .16 & .21 & .30 & - & & & & \\
\hline modeling 2 (M2) & .29 & .27 & .19 & .30 & .30 & .41 & - & & & \\
\hline self-efficacy (SE) & .54 & .56 & .41 & .37 & .30 & .36 & .28 & - & & \\
\hline past behavior $(\mathrm{PB})$ & .45 & .46 & .28 & .18 & .23 & .30 & .23 & 46 & - & \\
\hline screening characteristics (SC) & .41 & .44 & .42 & .44 & .26 & .15 & .18 & .40 & .36 & - \\
\hline screening round 2 (B2) & .56 & .36 & .28 & $.12^{\circ}$ & .20 & .24 & .20 & .30 & .56 & .23 \\
\hline
\end{tabular}


The different attitude concepts had high intercorrelations, ranging from .47 to .48 , showing that the different concepts were related to each other. This was also true for three social influence concepts, intercorrelations ranging from .30 to .41 . The distal variable characteristics of the screening intervention showed high correlations with the different attitude concepts (at least .42) and with the selfefficacy variable (.40). Past behavior showed high correlations with anticipated regret (.45) and self-efficacy (.46). Screening behavior at the second round showed the highest correlations with past behavior and the intention to participate at the second screening.

\section{Differences between participants and nonparticipants at the second screening}

In order to analyze whether differences in participation at the second screening (T3) could be described on the basis of already existing differences in motivational determinants (as assessed at T2), potential differences in scores on various determinants are presented in Table 8.2. There were no differences between both groups concerning level of education, age, or marital status. However, participants had significantly more positive scores than nonparticipants on all ASE determinants and on the intention to participate in the next screening round. Women who participated in the second screening round at T3 were at T2 (a year earlier) already more convinced of the positive consequences of participation and less of the negative consequences, they felt more morally obliged to participate, and they anticipated more regret if they did not participate in the screening. With regard to social influence, women who had participated in the second screening round at $\mathrm{T} 3$, reported at $\mathrm{T} 2$ more support from significant others for participating, knew more women who had received invitations to the first screening, and knew more women who had actually participated in the first screening round. Moreover, women who had participated in the second screening round were at T2 more convinced of their ability to participate in the screening if they were placed in difficult situations (like being tense for the screening).

Analyses of the distal variables showed that women who had participated in the second screening (T3) had more positive evaluations regarding various characteristics of the intervention at T2 than did women who had not participated 
in the second screening. Finally, there was a difference in past behavior indicating that of the respondents who participated in the second screening round (T3), 74\% had also participated in the first screening round (T1), while from the respondents who had not participated in the second screening round, only $13 \%$ had participated in the previous screening $\left(\chi^{2}=126.5 ; \mathrm{df}=1 ; \mathrm{p}<.0001\right)$.

Table 8.2: Differences between participants and nonparticipants at the second screening round

\begin{tabular}{|c|c|c|}
\hline & Participants & Nonparticipants \\
\hline Intention & 2.39 & $0.48^{* * *}$ \\
\hline $\begin{array}{l}\text { Attitude concepts } \\
\text { - anticipated regret }\end{array}$ & 2.43 & $1.67^{* * *}$ \\
\hline - consequences total & 2.12 & $1.84^{* * *}$ \\
\hline - moral obligation & 1.83 & $1.57^{\star}$ \\
\hline $\begin{array}{l}\text { Social influence } \\
\text { - modeling } 1\end{array}$ & 1.47 & $1.10 * * *$ \\
\hline - modeling 2 & 2.24 & $1.28 * * *$ \\
\hline - social support & 1.61 & $1.16^{* *}$ \\
\hline Self-efficacy & 1.91 & $0.97^{* 2 * *}$ \\
\hline $\begin{array}{l}\text { Distal variables } \\
\text { - screening characteristics }\end{array}$ & 2.41 & $1.97^{* * *}$ \\
\hline - participation first screening & $74 \%$ & $13 \% * * *$ \\
\hline
\end{tabular}
consequences screening, moral obligation, modeling 1 from 0 to 3 ; modeling 2 from 0 to 4)

' differences in participation in the previous screening was analyzed using a chi-square test, all other tests were t-tests

* $p<.05 * * p .01 * * * p<.001$

\section{Determinants of future screening bebavior}

A stepwise logistic regression was used to assess the predictive value of the intention together with the proximal ASE determinants and the distal variables (past behavior, screening characteristics, demographics) for the participation in the second screening round (Table 8.3). 
Table 8.3: Multivariate analyses of predictors of participation at the second screening round, using stepwise logistic regression

\begin{tabular}{|c|c|c|c|c|c|c|}
\hline Variable & $\begin{array}{l}\text { Step } 1 \\
\text { O.R. }\end{array}$ & $(95 \% \mathrm{Cl})$ & $\begin{array}{l}\text { Step } 2 \\
\text { O.R. }\end{array}$ & $(95 \% \mathrm{CI})$ & $\begin{array}{l}\text { Step } 3 \\
\text { O.R. }\end{array}$ & $(95 \% \mathrm{CI})$ \\
\hline att. consequences & $2.78^{*}$ & $(1.21-6.39)$ & n.s. & & n.s. & \\
\hline anticipated regret & $1.79^{* * *}$ & $(1.22-2.64)$ & n.s. & & n.s. & \\
\hline modeling 2 & $1.22^{*}$ & $(1.02-1.46)$ & n.s. & & n.s. & \\
\hline intention & & & $2.20^{* * * *}$ & $(1.53-3.08)$ & $2.23^{* * *}$ & $(1.48-3.35)$ \\
\hline past behavior & & & & & $8.17^{* * * *}$ & $(4.06-20.09)$ \\
\hline
\end{tabular}

To test the ASE model different steps were taken in the analyses. In the first step all attitude, social influence, and self-efficacy constructs were entered in the model. Three concepts proved to be significant predictors of participation: consequences of the screening, anticipated regret, and how many women they knew who had participated in the previous screening (modeling 2). In a second step the intention to participate was entered in the analyses, resulting in a significantly higher prediction of participation (Table 8.3). In agreement with the ASE model, all ASE variables were now fully mediated by the intention to participate. In a third step, background variables were entered. Two significant predictors of secondround participation remained in the model: the intention to participate and past behavior.

\section{Determinants of future screening intention}

Since intention to participate in the next screening proved to be such an important predictor of second-round participation, it was decided to analyze to what extent the different determinants could predict the intention to participate in the next screening. A stepwise multiple regression analysis was conducted, involving three steps. First, all mediating ASE variables were entered, resulting in $45 \%$ explained variance of the intention to participate in the next screening round. The attitude concept anticipated regret explained $33 \%$ of the variance in intention, followed by significant unique contributions of self-efficacy $(8 \%)$ and the attitude 
concept consequences (4\%). In the second step, the distal variables were entered stepwise in the regression analyses, showing that past behavior made a significant contribution (3\%) to the prediction of intention. Additionally, the screening characteristics made a small but significant contribution (1\%) to the prediction of the intention. Total explained variance of the ASE determinants together with the distal variables was $49 \%$.

In the third step, possible relevant interaction terms of the determinants and past behavior were entered. Since the interaction of previous behavior with the attitude concept consequences showed a small but significant unique contribution $\left(\mathrm{R}^{2}\right.$ changed to .51$)$, multiple regression analyses were performed separately for participants and nonparticipants at the previous screening round (Table 8.4).

Table 8.4: Stepwise multiple regression analysis, prediction of intention to participate in the next breast cancer screening round, separate for participants and nonparticipants at the first screening

\begin{tabular}{|c|c|c|c|c|c|c|}
\hline Step & $\begin{array}{l}\text { Participants round } 1 \\
\text { Variable }\end{array}$ & $\mathrm{R}$ & $\mathrm{R}^{2}$ & $\beta$ & $p<$ & $\mathbf{r}$ \\
\hline 1 & self-efficacy & 0.42 & 0.18 & 0.37 & 0.001 & 0.42 \\
\hline 2 & attitude, moral obligation & 0.47 & 0.22 & 0.07 & 0.01 & 0.28 \\
\hline 3 & attitude, anticipated regret & 0.49 & 0.24 & 0.10 & 0.05 & 0.31 \\
\hline 4 & screening characteristics & 0.55 & 0.30 & 0.27 & 0.001 & 0.34 \\
\hline
\end{tabular}

\begin{tabular}{lllllll} 
Step & $\begin{array}{l}\text { Nonparticipants round } 1 \\
\text { Variable }\end{array}$ & $\mathrm{R}$ & $\mathrm{R}^{2}$ & $\beta$ & $\mathrm{P}<$ & $\mathrm{r}$ \\
\hline 1 & attitude, anticipated regret & 0.60 & 0.36 & 0.41 & 0.001 & 0.60 \\
2 & attitude, consequences & 0.67 & 0.45 & 0.36 & 0.001 & 0.58 \\
\hline
\end{tabular}

Among participants at the first round, the model was predictive of intention $\left(F=21.14 ; \mathrm{p}<.0001 ; \mathrm{R}^{2}=.30\right)$. Four predictors remained in the model for previous participants: self-efficacy was the strongest predictor, followed by moral obligation, anticipated regret, and screening characteristics. Among nonparticipants in the previous screening round, the model was also highly predictive of intention 
$\left(F=40.80 ; p<.0001 ; R^{2}=.45\right)$. Two predictors of intention remained in the model for previous nonparticipants: anticipated regret was the most important predictor with an explained variance of $36 \%$, followed by consequences of the screening, which added another $9 \%$ to the explained variance.

\section{DISCUSSION}

This study analyzed the influence of the determinants attitude, social influence, and self-efficacy together with the past behavior and the screening characteristics on the intention to participate and on the actual participation in the second round of the Dutch national breast cancer screening. In addition, the study tried to analyze the way in which past behavior (participation in the first screening round) was related to determinants of participation in the next round of the national breast cancer screening. The results showed that past breast cancer screening participation was strongly associated with positive determinants toward future screening participation, with the positive intention to participate in the next screening, and with the actual repeated participation in the second screening.

Although the participation at the first screening occurred long before the measurement of the determinants, it is difficult to get an insight into the causality of the relationship between past behavior and the determinants. This relationship may have been directed both ways. Determinants of women who participated in the first screening round were probably already positive before entering the first screening round, since otherwise they would not have participated. On the other hand, experiences women had with participating in the first screening round will have influenced, reinforced or enfeebled, the existing determinants of future screening behavior. For a further insight into the interactions of behavior and determinants it is of great importance to obtain longitudinal data on screening behavior and their determinants over several rounds of the screening program.

By oversampling the nonparticipants of the previous screening round, it was possible to get a substantial number of previous nonparticipants in the study, despite the lower response among previous nonparticipants. Studying the 
determinants of nonparticipants especially provides an important tool for trying to motivate women to start participating. However, this difference in response rates between previous participants and nonparticipants should not be forgotten. Caution should be taken when generalizing the nonparticipants findings toward all nonparticipants of breast cancer screening programs.

In this research, the women that were studied came from a relatively small town and were predominately white with no relevant minority groups. These women were specially invited to participate and did not have to pay for their screening. These factors make it somewhat difficult to generalize the findings to communities with other characteristics and different health care systems. Recent studies show that ethnic groups differ in their screening behavior (Glanz, Resch et al., 1996; Rakowski, Rimer et al., 1993) and have different beliefs concerning cancer screening (Howe, 1992; Glanz, Resch et al., 1996). Therefore, it is of great importance to further study if relatively new concepts, like anticipated regret, are also of relevance in other communities.

The importance of the intention in predicting screening behavior, which was also found in other studies (Calnan, 1984; Rakowski, Dube, et al., 1992; Rakowski, Fulton et al., 1993; Sutton, Bickler et al., 1994), confirms the theoretical basis of the ASE model, which suggests that intention is the best predictor of behavior. These results also confirm the theoretical basis of the ASE model, which suggests that the influence of the ASE determinants on behavior is mediated through the intention. However, past behavior was not fully mediated by the ASE determinants or the intention to participate, showing that there also seems to be a direct influence of past screening behavior on future screening behavior. This finding is in line with other studies applied to smoking cessation, showing that after ASE determinants past behavior has some small but significant additional predictive power toward explaining (intention of) quitting smoking (De Vries, Backbier et al., 1995; Willemsen, De Vries et al., 1996). The present findings, therefore, suggest the inclusion of a direct relationship between past behavior and the intention and behavior in the ASE model, supporting similar conclusions reached by others (Bagozzi, 1992; Fredricks \& Dosset, 1983). However, it may also be that the direct effect of past behavior on future behavior may occur not at the level of the 
underlying theoretical constructs, but at the level of the assessments of those constructs. If two subjects profess high intentions to act, one subject may mean this much more than the other. Thus, it may be the inability to assess cognitive states (like intention or determinants) with enough precision that allows past behavior to have an incremental effect over and above the cognitive constructs.

As Eagly and Chaiken state (1993), personal norms (anticipated regret, moral obligation) could be subsumed under attitude toward the behavior, because guilt, self-reinforcement, and other outcomes of meeting or violating one's own standards are merely additional consequences of behavior. The great impact of anticipated regret on the prediction of the intention to participate in the next screening $\left(\mathrm{R}^{2}=.33\right)$ stresses the importance of addressing this concept as a separate concept within attitude, instead of integrating it into one overall attitude score. Although correlations between the different attitude concepts (anticipated regret, consequences, and moral obligation) were high (at least .47), using the concepts separately in the analyses provides relevant additional information for motivational campaigns. The need for different attitude concepts was also illustrated by the results of the separate regression analyses for participants and nonparticipants of the previous screening. Anticipated regret proved to be an important predictor of intention for both groups, but mostly for nonparticipants at the first screening. The consequences of screening were only a significant predictor of intention for nonparticipants, while moral obligation was only a significant predictor of intention for previous participants.

There were clear differences between previous participants and nonparticipants in predictors of intention to participate at the second screening. For previous participants self-efficacy proved to be the best predictor of the intention to participate again. These previous participants might already have experienced some difficulties during their first screening, which might have had a negative influence on their self-efficacy. For these women situations like being tense and being afraid of possible pain during the screening were situations in which they thought it was difficult to participate. For these women, health education should focus on preparing them thoroughly for the following screening rounds and giving them clear and easy information to alleviate feelings of tension (for example, giving 
them relaxation exercises). Furthermore, laboratory workers should be instructed to be very careful during the actual screening to minimize possible pain, in order to prevent future dropout. Possible barriers that can diminish women's self-confidence of being able to participate in future screening rounds should be reduced as much as possible.

For previous nonparticipants anticipated regret proved to be the best predictor of the intention to participate at the second screening. Since it is difficult to get an insight into the causality between the relation of anticipated regret with intention and participation in screening rounds, different explanations of these findings are possible. For example, it might be possible that the women who reported high anticipated regret were partly those who wanted to participate in the first screening round, but were unable to. Naturally, such women would be especially likely to participate in the second round. It might also be that anticipating more regret could actually influence intention and future behavior. If the latter is true, this anticipated regret concept may provide relevant additional information for motivational campaigns. Health education directed toward nonparticipants could explicitly appeal to the possible feelings of regret women might feel if they decide not to participate at the screening. This message could be further personalized by letting a woman from the target group tell from her own experience how sorry she expects to be if she did not participate and a possible lump was not detected. However, further research into the causality of the different concepts needs to be done first.

The predictive power of the evaluation of intervention characteristics on the intention to participate in the second screening stresses the importance of providing good basic facilities (sending invitations, screening by special appointment in a screening unit near home) to guarantee as few barriers as possible to women's participation. In accordance with the theoretical model the influence of this concept on intention was highly mediated by the ASE determinants, which was reflected in high correlations of the characteristics evaluation with the attitude and self-efficacy concepts.

An important objective of applying theoretically based models, such as the ASE model that was used in this study, is trying to gain more insight into the 
determinants of breast cancer screening behavior and the maintenance of this behavior. In the application of the ASE model toward breast cancer screening, some choices were made in the constructs that were assessed. Since the model presented in this study was a very broad model, not all concepts of the model were fully assessed. The choice of concepts that were assessed was based on previous (qualitative) research (Lechner, 1991; Offermans, 1994) and on findings from other studies. Moreover, some aspects of the screening were confidential medical information (result of the first screening), to which this study had no access. The findings suggest that even with these limitations, the application of the model was of substantial relevance. The results prove that besides the more often applied Health Belief Model (Aiken, West et al., 1994; Calnan, 1984; Champion, 1994; Curry \& Emmons, 1994; Fishera \& Frank, 1994; Rimer, Trock et al., 1991; Rutledge, Hartman et al., 1988), other more general models on determinants of behavior, such as the ASE model, may facilitate the understanding of mammography behavior. Total explained variance of the intention by the attitude, social influence, and self-efficacy concepts was rather high (45\%). Separate regression analyses of intention for participants and nonparticipants showed similar or higher explained variances, compared with other studies (Curry \& Emmons, 1994; Jepson \& Rimer, 1993). The application of the different concepts of the ASE model, and the differentiation in subfactors within these concepts, provides important additional information that can be used to motivate women to start participating in the national screening program and furthermore, to maintain their participation in the following screening rounds. 


\section{CHAPTER 9}

\section{Main conclusions and general discussion}

\section{INTRODUCTION}

The main goal of this thesis was to study recent developments and possible modifications of the Atritude - Social influence - self-Efficacy (ASE) model (De Vries, Dijkstra et al., 1988). Findings and theories that were used in the different studies will be integrated in this chapter. This integration will result in conclusions being drawn, which have both practical as well as theoretical consequences. This thesis focused on the first phase of the ABC-planning model, the analysis of the health problem (De Vries, 1989; De Vries \& Willemsen, 1996). Several steps can be distinguished within this analysis of the health problem. These steps will be described in this chapter. First, the health problems of cancer and CVD and their related lifestyle risk behaviors will be shortly discussed. Second, the determinants of some of these lifestyle risk behaviors will be studied. The analysis of the social psychological determinants of risk behaviors was done by using the Attitude Social influence - self-Efficacy (ASE) model (De Vries, Dijkstra et al., 1988), which was derived from the Theory of Reasoned Action (TRA) (Fishbein \& Ajzen, 1975; Ajzen \& Fishbein, 1980) and the Social Cognitive Theory (Bandura, 1986). The premises of the rest of this chapter will be based on the ASE model with its different concepts and possible modifications. The findings of the different studies will be discussed according to the different concepts of the theoretical model. First, conclusions with respect to the basic constructs (intention, attitude, social influence, self-efficacy) will be discussed, followed with a discussion of possible alterations (past behavior, awareness, stages of change). 


\section{HEALTH PROBLEM ANALYSIS FOR CANCER AND CVD}

As the overview in Chapter 1 showed, cancer and CVD together are responsible for approximately $60 \%$ of all mortality within the Netherlands (Van der Sanden, Van Barneveld et al., 1994). Within primary and secondary prevention there are several lifestyle health behaviors that can contribute to preventing getting cancer or CVD or that can contribute to detecting these diseases at an earlier stage. The most important lifestyle behaviors related to cancer and CVD are smoking, exercise, nutrition, alcohol consumption and UV-exposure for primary prevention, and participating in cancer screening programs or practicing self-detection techniques (such as breast and testis self-examination) for secondary prevention.

The literature review in Chapter 1 showed that around 40\% of the Dutch adult population is physically inactive, $35 \%$ of the Dutch adult population smoke, the large majority (over $70 \%$ ) of the adult population eat too much fat or not enough fruit and vegetables, more than $10 \%$ of the Dutch population has an excessive alcohol intake, and over half of the Dutch adult population is sometimes excessively exposed to UV-radiation without sufficient protection. Moreover, selfdetection techniques for cancer are either not practiced by many people (less than $20 \%$ ), or are not practiced according to the guidelines, and participation in cancer screening programs declines with every new screening round. This large prevalence of risk behaviors provides many challenges for health education and promotion interventions. However, for these interventions to be successful, they have to be well-planned and based on a thorough insight in the important determinants of these risk behaviors.

In this thesis, some of the lifestyle health behaviors were further studied in order to find relations with possible motivational determinants, and to look at new concepts such as the application of the stages of change, the role of awareness or the role of personal norms or past behavior. The behaviors that were the focus of this thesis were physical exercise, nutrition behavior (eating fruit, vegetables and fat) and participating in a breast cancer screening program. The rest of this chapter will be based on the ASE model with its different concepts and possible modifications. The findings of the different studies will be discussed according to the different 
concepts of the theoretical model.

\section{INTENTION}

Of the six studies presented in this thesis, three studies used the traditional way of measuring intentions. The other three studies replaced the traditional intention and behavior by the stages of change concept.

In the breast cancer screening study (Chapter 8), the time between the measurement of intention and screening participation was approximately a year. According to some studies the time interval between the behavioral intention and behavior has an important influence on the predictive power of intentions. The longer this time interval, the more the relation between intention and behavior will decline (Bagozzi, 1981; Manstead \& Parker, 1995). However, Randall \& Wolff (1994) found that the intention-behavior correlation coefficient can remain strong over a prediction interval of as long as 15 years, mainly influenced by the type of behavior. In a recent meta analysis (Godin \& Kok, 1996), the predictive value of intention for explaining behavior for clinical and screening behavior was rather low $\left(\mathrm{R}^{2}=.16\right)$. In the screening study presented in this thesis, the correlation between intention and behavior was quite high, even with this relatively long time period $\left(r=.56 ; R^{2}=.31\right)$. The reason for the difference between this study and the metaanalysis might be the organization of the screening program in the Netherlands: women receive invitations, screening is free of charge and near home. This means that there are less barriers that can obstruct women from actually participating in the screening program. Furthermore, within this time period of one year between intention and behavior, women were not exposed to any interventions or new experiences with respect to breast cancer screening, which could change their perception of the screening program. In sum, the high correlation between intention and actual screening behavior suggests that the time interval between intention and behavior may not necessarily affect the predictive value of intentions.

For both nutrition behavior as well as for exercise behavior, the determinants, intention and behavior were measured at the same time for most 
analyses. The predictive value of determinants with regard to explaining intention and of intention with regard to explaining behavior was quite high. However, with respect to exercise participation it was found that if determinants and intention or behavior were not assessed at the same moment, the relation between motivational determinants and intention and between intention and behavior was rather poor. Chapter 4 showed that the motivational determinants which were measured before the start of the fitness program could not explain the level of adherence to the program after 10 months. As Chapter 5 showed, the determinants could hardly predict the intention that was assessed 10 months later. This suggests that either determinants or intention, or both, may not be very stable in time with respect to predicting adherence to a fitness program. With respect to our exercise study, it is reasonable to assume that the intervention (fitness program) between the first and second measurement influenced both the subjects' determinants as well as their intention to exercise. Since subjects had no experience with the employee fitness program at the first measurement of determinants and intention, their estimate of determinants and intention was purely based on expectations. However, during the second measurement 10 months later, their estimate of determinants and intention was now not only based on expectations of exercising, but to a large degree on actual experience of the exercise program. Hence, their estimate of determinants and intention at the second measurement was based on an integration of their past experiences and their future expectations, resulting in a change in the frame of reference in participants of the fitness program.

In conclusion, the relation between intention and behavior can stay strong over a longer time interval, providing that there is limited opportunity for determinants or intention to change between the measurements of (determinants and) intention and behavior (Manstead \& Parker, 1995). If (determinants and) intention are likely to change because of new experiences or information, or if there are many possible barriers between intention and behavior, then the determinants and intentions form poor predictors for subsequent behavior. 


\section{ATTITUDES}

\section{Beliefs with or without evaluations}

Attitudes proved to be important predictors of intention and stages of change in all the studies presented. Throughout this thesis, attitudes were measured in different ways. With regard to exercise participation, attitude was measured by adding several multiplications of beliefs concerning exercise to their evaluations. This multiplicative term proved to be an important predictor of stages of change, both for starting to exercise as well as for predicting the level of adherence or maintenance to exercise, which was used as the operationalization of the transference from action to either maintenance or dropout. These results for exercise concur with other studies that have applied the TRA or the TPB to exercise promotion (Godin, 1993, Godin \& Kok, 1996).

However, several studies showed that scaling and statistical difficulties arise when the attitude concept is operationalized as a multiplicative term of beliefs and evaluations (Evans, 1991; Van den Putte, Saris et al., 1995; Swanborn, 1996). Chapter 5 showed that the predictive value of attitudes was just as strong when it was operationalized as an additive term, which was formed by omitting the evaluations. Moreover, evaluations did not seem to strengthen the relation of beliefs to intention, suggesting that the evaluation is already partly imbedded in the beliefs assessment.

The beliefs that were used in the fitness studies were all possible positive outcomes or pros of participating in an exercise program. In some recent studies, attitudes have been operationalized according to the decisional balance (Marcus, Rakowski et al., 1992; Prochaska, Velicer et al., 1994; Velicer, DiClemente et al., 1985), based on the theoretical model of decision making by Janis and Mann (1977). This decisional balance is operationalized by asking subjects for possible pros and cons as outcomes of a behavior (Marcus, Rakowski et al., 1992; Prochaska, Velicer et al., 1994). As Eagly \& Chaiken (1993) state, evaluations of attributes or beliefs are often well-anchored in extensive prior learning. People will not easily evaluate positive outcomes as bad, or negative outcomes as good. Moreover, since many evaluations of beliefs are so anchored in people's perceptions, not much variance 
can be expected in people's evaluations of beliefs, especially if beliefs clearly represent a positive or negative outcome. Results from Chapter 5 confirm that indeed the variance in the addirive evaluation scales were very low (variance .14 and .14), especially when compared to the variance in the additive beliefs scales (variance .41 and .44 ).

In Chapter 6, the attitudes toward eating fruit, salads and processed vegetables, were operationalized by measuring and adding beliefs about eating these food groups, without measuring evaluations. Again, the possible outcomes were clearly positive (eating fruit is bealtby) or negative (eating fruit is expensive), so that the evaluations of these beliefs (bealth is good, expense is bad) would probably have had little or no added value.

In Chapter 8, the attitude toward breast cancer screening was operationalized by measuring and adding up possible positive or negative outcomes of the screening behavior. These consequences of screening were formed by seven pros and four cons of screening participation. This additive belief term without evaluations was strongly correlated with intention $(r=.49)$. In the meta-analysis on the TPB by Godin \& Kok (1996) the attitude-intention correlation for cancer screening varied from .36 to .47 , illustrating that the unipolar additive attitude term from our screening study forms a good replacement substitute to the additive product term of the TPB.

In conclusion, the studies from this thesis suggest that if possible outcomes or beliefs are clearly operationalized as either positive or negative outcomes, the evaluation concept may be omitted from the attitude concept without loosing vital information. Nonetheless, the precise consequences of this procedure will need further investigation.

\section{PERSONAL NORM: ANTICIPATED REGRET, MORAL OBLIGATION}

Several researchers have criticized cognitive motivational determinant models because of their emphasis on cognitive determinants and their underestimation of affective factors as determinants of behavior (Beck \& Ajzen, 
1991; Godin \& Kok, 1996; Gorsuch \& Ortberg, 1983; Manstead \& Parker, 1995; Richard, Van der Pligt et al., 1995; Zuckerman \& Reis, 1978). Personal beliefs about the inherent rightness or wrongness of behaving in a certain way, founded on more abstract principles than short-term advantages or disadvantages or immediate approval or disapproval, may not be adequately represented in models such as TRA/TPB or the ASE model. Therefore, it has been suggested that a new factor called personal norms should be included in the determinant models. (Manstead \& Parker, 1995; Parker et al., 1995; Richard et al., 1995).

With regard to the breast cancer screening behavior in Chapter 8 , the personal norms of women were assessed as part of the attitude construct. Personal norms were operationalized using two concepts: the moral obligation that women experience toward participating in the screening, and the (anticipated) feelings of regret that women anticipate feeling if they do not participate in the screening. Both concepts proved to be among the strongest predictors of intention to participate in the next screening round $(r=.58$ for anticipated regret, and $r=.38$ for moral obligation with intention).

These two aspects of the personal norms were not placed as new separate concepts in the ASE model, along with attitude, social influence, and self-efficacy. Instead, they were placed as separate concepts within the attitude construct, because attitudes may be products of both affective consequences of behavior (negative and positive feelings that people anticipate will ensue from engaging in behaviors), as well as cognitive responses to attitude objects (costs and benefits) (Eagly \& Chaiken, 1993).

The results from Chapter 8 support this positioning of personal norms within the attitude concept, although additional research is required to further confirm this positioning. The inter-correlations between the different attitude concepts (consequences, anticipated regret, moral obligation) were high (at least .47), showing that the concepts were indeed related to the same basic construct. It may be argued that moral obligation is more related to social influence, since the moral norm of how to behave probably originated from external sources. However, the correlations of moral obligation with the social influence concepts ( $r$ between .21 and .38 ) were much lower than the correlations with the two attitude 
concepts (both $\mathrm{r}=.48$ ). The results indicate that the moral obligation concept represents some kind of internalized social norm, making it no longer an influence from outside the person, but an internal aspect of the attitude.

Even though the three attitude concepts (consequences, anticipated regret, moral obligation) are obviously related to each other, the results of the screening study stress the importance of addressing the three concepts as separate concepts within the attitude, instead of integrating them into one overall attitude score. Using the concepts separately in the analyses provides relevant additional information for motivational campaigns. The need for separate attitude concepts was illustrated by the results of the separate regression analyses for participants and nonparticipants of the previous screening. Anticipated regret proved to be an important predictor of intention for both groups, but mostly for nonparticipants at the previous screening. The consequences of screening were only a significant predictor of intention for nonparticipants, while moral obligation was only a significant predictor of intention for previous participants at the screening.

According to the literature, concepts such as moral obligation are mainly important determinants for intention or behavior in the case of morally tensed situations (Beck \& Ajzen, 1991; Boyd \& Wandersman, 1991; Gorsuch \& Ortberg, 1983; Manstead \& Parker, 1995; Parker et al., 1995; Zuckerman \& Reis, 1978). Health related behaviors and especially health risk behaviors may be seen as morally fraught behaviors. For breast cancer screening, this moral tension might be particularly obvious. Screening is very directly related to the possibility of having breast cancer, which can be an emotionally fraught subject for women. Furthermore, the whole breast cancer screening program was developed specifically to give women the chance to get screened, with as few barriers as possible (women get personal invitations, screening is free of charge, near their home). Because of all these factors women are likely to feel morally obliged to participate (women might think: "All this work was done so that I can get a screening, not participating would therefore be very irresponsible").

Similarly, a study in which anticipated regret proved to be an important determinant for condom use among adolescents (Richard, Van der Pligt et al., 1995), illustrated that for behaviors that are emotionally fraught, anticipated regret 
forms an important determinant of intention and subsequent behavior.

The importance of moral obligation and anticipated regret is probably less evident. for health risk behaviors that are not directly related to major health problems, for behaviors that are not heavily influenced by emotions, or for behaviors that are less related to moral standards (Gorsuch \& Ortberg, 1983; Parker, Manstead et al., 1995; Richard, Van der Pligt et al., 1995). For risk behaviors such as eating too little fruit, moral obligation or anticipated regret are not expected to be major determinants of behavioral intention.

It can be concluded that anticipated regret and moral obligation can be of major relevance in determining behavioral intention and subsequent behavior. By using these concepts in addition to the standard attitudinal constructs, relevant additional information for understanding intentions and behavior can be gained. These additional affective concepts seem specially important for health risk behaviors that are directly related to major health problems, and for health risk behaviors that are emotionally loaded or morally fraught. Even though anticipated regret and moral obligation have a separate unique contribution to the model, results from this thesis support a theoretical positioning of the concepts within the attitude construct in the ASE model, next to the more cognitive based outcome expectations (pros and cons). Although additional research is necessary, the results support the existence of an extended attitude construct that represent both the cognitive as well as the affective consequences of a behavior.

\section{SOCIAL INFLUENCE}

Reviews and meta-analyses of the TRA/TPB have illustrated that the social norm as a predictor of intention and behavior is of modest importance (Godin \& Kok, 1996; Shepard, Heartsick et al., 1988; Van den Putte, 1993), especially when compared to attitudes and self-efficacy/PBC. It has been suggested by several authors, that the consistently modest contribution of the social norm is related to the operationalization of the construct (Godin \& Kok, 1996; Grube, Morgan et al., 1986; Miniard \& Cohen, 1981). Several authors have suggested other 
operationalizations of social influence, such as observational learning or modeling (Cialdini, Kallgren et al., 1991; De Vries, Backbier et al., 1995; Grube, Morgan et al., 1986; Reno, Cialdini et al., 1993), and direct social support or pressure for people to enact the healthy or unhealthy behavior (De Vries, Backbier et al., 1995). In this thesis social influence was operationalized by either measuring direct social support or by measuring the influence of observational learning or modeling.

From a theoretical perspective one might argue that the social norm might be the result of both modeling and direct support or opposition. When people have to estimate how significant others feel about them performing a behavior (social norm), this estimation is probably to a great extent based on two aspects: what these people see of how those significant others behave (modeling) or how those significant others actually react toward them with respect to this behavior (are they supportive or encouraging or are they discouraging to the behavior).

As the exercise studies in Chapter 3 and 4 showed, social support proved to be important for exercise at the moment people actually started exercising, that is, the transfer from preparation to the action stage. The correlations between social support and intention or stages of behavioral change were similar to the correlations between social norm and intention as presented in the literature with regard to exercise (Godin, 1993; Godin \& Kok, 1996). In sum, there was no indication from our studies that the social support measured was a better or worse predictor of exercise participation than the social norm according to the TRA/TPB.

For eating fruit and vegetables (Chapter 6), social influence was measured by combining a social support item with a modeling item. The combination of these two items assessed the social influence people felt with regard to their fruit and vegetable consumption. This social influence measure proved to be a significant predictor of intention to consume salads (Brug, Lechner et al., 1995). Furthermore, Chapter 6 showed that social influence was a significant predictor of self-rated consumption of salads and processed vegetables, but was not related to the actual consumption of fruit. It is difficult to compare these result to other studies, since studies that apply motivational determinant models (TPB/ASE) to fruit and vegetables consumption have hardly been reported. In a recent study (Krebs-Smit, 
Heimendinger et al., 1995), the perceived influence of friends and families was not significantly associated with fruit and vegetable consumption. With regard to fat consumption, social norms have been found to be of minor importance in predicting intentions (Stafleu, De Graaf et al., 1991). In sum, our studies suggest that the social influence measured proves to be only of moderate importance in explaining intention and behavior with respect to fruit and vegetable consumption.

Chapter 8 showed that for participation in a breast cancer screening program correlations between intention and social support $(r=.33)$ or modeling $(r=.28$ and .29) were highly significant. These correlations are comparable to the correlations in the meta analysis between the social norm and behavioral intention with regard to screening participation (Godin \& Kok, 1996). Although the correlations between social influence and intention in Chapter 8 were all significant, they, together with other determinants, had only a limited predictive value with regard to intention.

Several explanations are possible for this limited predictive power of the social influence measured. First, it could be that the social influence measured is indeed only a determinant of limited importance with respect to people's intentions and behavior. The limited predictive power of social influence to intentions could also be influenced by the health behaviors chosen in this thesis. It may well be that for certain behaviors social influence is a more important predictor of intention than for other behaviors. The meta-analyses of Godin and Kok (1996) illustrate that social influence is a more important predictor of intention for behaviors such as safe driving and oral hygiene, compared to behaviors such as nutrition intake.

Inter-correlations between social influence and attitudes or self-efficacy suggest that some of the predictive power of social influence is already imbedded in the other determinants, attitude and self-efficacy. These intercorrelations could also suggest that the relation between social influence and intention or behavioral stage might be partly mediated by the attitude and self-efficacy construct. This would imply that social influence may be more indirectly related to intention, and that in the ASE model, social influence could be placed as a more distal factor, before attitude and self-efficacy.

Another possible explanation for the limited predictive power of social influence to intentions, might be the method for assessing social influence. The 
studies in this thesis used written or telephone questionnaires in which people selfrated the social influence they encountered. It is possible that people are reluctant to admit that they are influenced by others, and that their choices and behavior may not be as individual and self made as they would wish them to be. This would plead for other, more objective ways to assess social influence.

It can be concluded that the alternatives of assessing social influence (modeling and social support) are significantly related to behavioral intentions and behavioral stages of change. It seems that the strength of the social support and modeling concepts are quite comparable to the strength of the social norms according to TRA/TPB, with respect to their relation to intention. Therefore, it seems that the social influence experienced and modeling can be used as alternatives to the additive multiplication construct of social norm. However, in comparison to attitudes and self-efficacy, social support and modeling are still only of limited importance in predicting intentions or stages of change.

\section{SELF-EFFICACY}

In all the studies presented in this thesis, self-efficacy was assessed by asking subjects to estimate whether they were able to perform the health behavior in several problem or high risk situations. Several review studies have shown that including self-efficacy/Perceived Behavioral Control (PBC) in the model results in an increase in the explained variance of intention (Ajzen, 1991; Godin \& Kok, 1996; Madden, Ellen et al., 1992; Netemeyer, Burton et al., 1991; Van den Putte, 1993) as well as in the explained variance of actual behavior (Ajzen, 1991; Godin \& Kok, 1996; Madden, Ellen et al., 1992; Netemeyer, Burton et al., 1991; Van den Putte, 1993). In all the determinant studies presented in this thesis, self-efficacy proved to be among the strongest determinants of intentions, behavior, and stages of change, independent of the type of behavior (exercise, fruit and vegetable consumption, breast cancer screening).

With respect to health-related behaviors and the TPB, Godin and Kok (1996) reported an overall average correlation between intention and self-efficacy/PBC of 
.46. A comparison of the results in this thesis to the meta-analysis of Godin and Kok (1996) shows similar or higher correlations of self-efficacy with behavioral intention or behavior. In the meta-analysis (Godin \& Kok, 1996), the average correlation between intention and self-efficacy/PBC was .32 for eating behaviors (compared to correlations between .34 to .69 in Chapter 6), .50 for exercising (compared to .53 in Chapter 5), and .46 for screening behavior (compared to .54 in Chapter 8). Similarly, in the meta-analysis the correlation between selfefficacy/PBC and behavior was .41 for exercising (compared to .51 in Chapter 4), and .29 for screening behavior (compared to .30 in Chapter 8).

In Chapter 4, besides assessing self-efficacy in different problem situations, another aspect of self-efficacy was operationalized by asking subjects how often they encountered problem situations in which exercising was difficult. This more direct measure of self-efficacy only used one item. To some degree this measure is comparable to the power concept of the PBC construct (Ajzen, 1991). According to Ajzen (1991), PBC is operationalized by measuring different control beliefs (about the performance of the behavior in high risk situations) that people have about the behavior, and multiplying these beliefs by the perceived power of the particular control factor to facilitate or inhibit performance of the behavior. The resulting products are then summed together to produce the perception of behavioral control. Several studies have tried to operationalize this power concept by asking for the frequency with which subjects encountered the different high risk situations (Manstead \& Parker, 1995; Parker et al., 1995).

However, the additional self-efficacy measure in Chapter 4 used only one, more general item to assess the frequency with which high risk situations occur. Furthermore, in Chapter 4 both measures of self-efficacy were placed as separate concepts in the model, instead of combining the two measures in a multiplicative construct. As the results of Chapter 4 showed, this direct measure of self-efficacy improved the predictive value of the behavior substantially, by $10 \%(p<.001)$. The correlation between the two self-efficacy factors was not very high $(r=.22)$, indicating that both concepts measured a different aspect of self-efficacy. Together with the situation-based measure of self-efficacy, both measures of self-efficacy could explain $35 \%$ of the variance in behavior $(R=.59)$. 
In conclusion, the operationalization of self-efficacy expectations (by asking the ability to perform the behavior in different situations) forms a good alternative to measuring $\mathrm{PBC}$ according to the TPB. When assessing self-efficacy, the use of a multiplication construct is not necessary. This results in shorter questionnaires for assessing self-efficacy, that can have predictive values similar to PBC. However, a relevant addition to the situational self-efficacy concept seems to be a short direct measure of the frequency with which problem situations occur. This addition forms a relevant extra self-efficacy concept that has a potentially high predictive power with regard to intention, behavior and stages of change.

\section{PAST BEHAVIOR}

One of the concepts that has been suggested to add to the motivational determinant models by various researchers is past behavior, in terms of experience with the behavior, habit or previous behavior (Eagly \& Chaiken, 1993). Ajzen (1991) denied a direct influence of past behavior or experience on future behavior. As Ajzen (1991) stated, if all determinants are measured sufficiently, past behavior will not add to the prediction of intention and future behavior. However, many studies have shown that the inclusion of past behavior can improve the prediction of intention or behavior (Bagozzi, 1981; Bagozzi, Baumgarter et al., 1992; Bentler \& Speckart, 1979; Bentler \& Speckart, 1981; Budd, North et al., 1984; De Vries, Backbier et al., 1995; Fredricks \& Dosset, 1983; Willemsen, De Vries et al., 1996).

Past or previous behavior can have a relation with intention and future behavior as a result of experience that people have with the healthy behavior, or as a result of a behavior being a habit that has become so routinized that a person behaves in an accustomed way without making a conscious decision to act (Triandis, 1977; 1980). In this thesis, the influence of past or previous behavior was analyzed in two longitudinal studies (Chapter 4 and 8). In both chapters past behavior refers mostly to past experience with the healthy behavior, and much less to the behavior as being a habit.

In Chapter 4, the exercise activity of subjects previous to the start of the 
employee fitness program proved to be related to the level of adherence to and dropout from the fitness program. Subjects who dropped out of the program were the ones who exercised the least prior to the start of the program. These people had the least experience with exercising. However, after the ASE determinants were entered in the regression analyses, past behavior did not add significantly to the predictive value of the model toward explaining level of adherence or maintenance.

In Chapter 8, past behavior for breast cancer screening was assessed by measuring whether women had participated in the previous screening round. The results showed that previous screening behavior was one of the most important determinants of behavioral intention and of participation in the second breast cancer screening round. Furthermore, in explaining behavioral intention there was an interaction effect between past behavior and one of the attitude concepts.

It can be argued that past behavior should not be included in the determinant models, because past behavior is not changeable, and is therefore not relevant from a health promotion perspective. Furthermore, although past behavior can significantly improve the model's predictive power with regard to behavioral intentions, the inclusion of past behavior in the analyses also results in a decline of the explained variance of other (changeable) determinants (Bagozzi, 1981; Bagozzi, Baumgarter et al., 1992; Fredricks \& Dosset, 1983). However, by not including past behavior some relevant information can be missed as well. As Chapter 8 showed, there was an interaction effect of past behavior with an attitude concept, indicating that determinants for behavioral intention were different between women who had participated in the previous screening and women who had not. Past behavior then becomes an instrument to further divide the target population into relevant segments, so that possible health education interventions can be designed to better match determinants of specific target groups within the population. Using past behavior then may become an important instrument for target group segmentation.

It can be concluded that past behavior is potentially an important determinant of behavioral intention and subsequent behavior. Although past behavior is a factor that cannot be changed by health promotion interventions, past behavior does become very important if there are possible interaction effects with other, changeable determinants. If past behavior or experience results in people 
having different determinants of intention or behavior, past behavior can be used as an important instrument for target group segmentation. Therefore, past behavior could be included in the model as a check to find out whether interaction effects of past behavior with other determinants do exist.

\section{AWARENESS AND MISCONCEPTION OF BEHAVIOR}

An important issue in changing health risk behavior seems to be people's awareness of their own behavior. Weinstein proposed that awareness of risk behavior is one of the key issues in motivating people to start thinking about behavioral change (Weinstein, 1988). If people are not aware of the fact that their behavior is unhealthy, they are not likely to consider changing their risk behavior (Weinstein, 1988; Weinstein \& Sandman, 1992).

In this thesis, two chapters addressed the problem of awareness. In Chapter 6 , the prevalence of lack of awareness or misconception of people's own behavior was assessed with regard to fruit and vegetable consumption. Results showed that over $80 \%$ of respondents who do not eat enough vegetables, believe that their vegetable intake is sufficient or high. Similarly, over $60 \%$ of respondents who do not eat enough fruit, believe that their fruit intake is sufficient or high. The results were replicated in another study of the Dutch population (Chapter 7). These data indicate that lack of awareness of people's own behavior seems to be a major concern for respondents consuming too little fruit and vegetables. This lack of awareness is also prevalent for other health risk behaviors, as was demonstrated for fat consumption in The Netherlands (Brug, Van Assema et al., 1994; Lechner, Brug et al., 1997). These studies reported large differences between the objective assessment of dietary fat intake and the self-rated, subjective fat intake. Furthermore, an American study (Bowen, Fries et al., 1994) found that those subjects with the highest fat intake, consistently underestimated the amount of fat in their diet. Similarly, with respect to sun protective behavior in The Netherlands, results showed that many people were unaware of the fact that their sun-bathing behavior is unhealthy (Lechner \& De Vries, 1997). 
A misconception of one's own behavior is much more prevalent for some behaviors, than for others. Lack of awareness seems to be a problem for behaviors in which the dividing line between healthy and unhealthy behavior is not very clear. For very clear healthy or unhealthy behaviors, awareness is no problem; since people know whether they do or do not smoke or whether they do or do not participate in a screening program. However, it is much more difficult to know whether one's food intake or one's exercise pattern is healthy enough. For behaviors where the guidelines are unknown and for behaviors where it is difficult to exactly assess one's own behavior (e.g., average fat intake), misconception or lack of awareness of behavior often seems to be prevalent.

As Weinstein (1988) states in his precaution adoption process, knowledge of the precise relation between a behavior and a health risk is one of the first stages of awareness. Only if people have the knowledge about when a behavior is healthy or when it becomes unhealthy, can they start to apply this knowledge to themselves. A recent study confirmed the prevalence of lack of knowledge of the guidelines for fruit and vegetable consumption. This study showed that around $30 \%$ of the total Dutch population did not know the dietary guideline for fruit consumption, while around $50 \%$ did not know the dietary guideline for vegetable consumption (Van Assema, Brug et al., 1996).

Chapter 6 showed that this misconception of behavior had several consequences for the application of the ASE model. The results showed that intention, attitude, social influence, and self-efficacy could predict the subjective self-rated behavior much better than the objective actual behavior. Differences in explained variance between self-rated and objective intake were relatively small for eating salads ( $\mathrm{R}^{2}=.36$ (objective) versus .42 (subjective)), but much higher for eating processed vegetables $\left(\mathrm{R}^{2}=.11\right.$ (objective) versus .25 (subjective)), and for eating fruit $\left(\mathrm{R}^{2}=.20\right.$ (objective) versus .49 (subjective)). Similar results were found for other behaviors. With regard to fat consumption almost all psychosocial determinants (attitude, social influence, self-efficacy) had significantly higher correlations with the subjectively measured far-intake than with the objectively measured fat-intake (Brug, Van Assema et al., 1994). Also, with respect to sun protective behavior in the Netherlands (Lechner \& De Vries, 1997), results showed that attitude, social 
influence and self-efficacy were more related to people's own estimation of their sun protective behavior, than with their actual sun protective behavior.

The results indicate that it is very difficult to assess motivational determinants, when misconception of behavior is highly prevalent. One way of correctly assessing motivational determinants for behaviors with much misconception could be by linking the determinants directly to the desired, healthy behavior. Instead of asking determinants of more general behaviors (e.g., eating fruit), the determinants should be linked to very specific behaviors (e.g., eating two pieces of fruit every day). This would have consequences for assessing attitude beliefs (e.g., "Eating fruit is healthy" should be "Eating two pieces of fruit every day is healthy"), for assessing social influence (e.g., "Does your spouse stimulate you to eat fruit?" should be "Does your spouse stimulate you to eat two pieces of fruit every day?"), and for assessing self-efficacy (e.g., "Do you think you are able to eat fruit when there is little time?" should be "Do you think you are able to eat two pieces of fruit every day when there is little time?"). However, even though for fruit consumption this alteration in behavior can be done easily, for complex behaviors like fat consumption, linking the exact healthy behavior to the measured determinants proves to be much more difficult.

In conclusion, it seems that lack of awareness has important consequences for the relation of determinants and behavioral intention toward actual behavior. Researchers should note that in measuring certain behaviors the researcher might have a different association with the concept of healthy behavior than subjects do. Health education aimed at changing people's risk behaviors might not be effective as long as subjects misjudge, and especially overestimate, their health behavior. If these people receive information aimed at creating a positive attitude, feelings of social support and high self-efficacy toward a particular health behavior, they are not likely to change since they think they are already behaving healthily. Therefore, before changing attitudes and increasing self-efficacy (Brug, Lechner et al., 1995), increasing awareness of the personal health risk behavior should be an important first intervention target. This could be done by making people aware of the guidelines for healthy behavior, and teaching them how to apply these guidelines to themselves. As soon as people know exactly how unhealthy they 
themselves behave, further steps can be made toward changing behavior. For the ASE-model, this would mean that for behaviors where misconception is prevalent an extra basic step should be built in to make people aware before trying to change determinants.

\section{STAGES OF CHANGE}

The Stages of Change concept (Prochaska \& DiClemente, 1983; Prochaska, Velicer et al., 1991) suggests that people do not change their behavior in a dichotomous step from unhealthy to healthy behavior, but that the dynamic process of behavioral change can be divided into different stages. In order to change their behavior, people can move from precontemplation (not interested in change) via contemplation (thinking about change) to preparation (actively planning to change within a short period). Subsequently, people can move to the action stage (actually enacting the new behavior) and finally, to maintenance (sustaining the new behavior). In their movement through the stages, people can relapse and fall back to earlier stages (Prochaska \& DiClemente, 1983; Prochaska, Velicer et al., 1991).

The stages of change construct and the motivational determinant models (TRA/TPB/ASE) can be integrated into a new model in which intention, past behavior and current behavior can be integrated into the different stages of behavioral change. In this integrated model there is a direct influence of the determinants on the different stages of behavioral change. Applications in which ASE determinants were combined with the stages of change have recently been reported for several behaviors, such as smoking (De Vries \& Backbier, 1994) and nutrition (Brug, Glanz et al., 1998; Brug, Hospers et al., 1997).

In Chapters 3 and 4 , the stages of change concept was applied to participation in an employee fitness program. The application of stages toward starting to exercise showed that subjects in different stages of change differed substantially in their determinant scores. The results of attitudes and self-efficacy scores per stage were comparable to other studies that applied the decisional balance 
or self-efficacy toward stages of change for exercise (Marcus, Rakowski et al., 1992; Marcus, Selby et al., 1992; Prochaska, Velicer et al., 1996). Chapter 4 studied the transition of subjects from action to either maintenance or dropout with regard to their exercise behavior. The findings illustrated that in reality it was difficult to operationalize maintenance of exercising in an employee fitness program. In Chapter 4, maintenance was divided into two levels of adherence, high (exercise frequency in the program of at least once a week), and low adherence (exercising less than once a week). However, one may question whether subjects who only exercise very sporadically, should be considered to be in maintenance or action with their behavior.

In Chapters 6 and 7, the stages of change concept was applied to behaviors where lack of awareness is prevalent. By combining the determinant-model with the stages of change concept, the lack of awareness had serious consequences for the application of the stages of change concept. Since the stages of change concept was originally developed for addictive behaviors such as smoking (Prochaska \& DiClemente, 1983; Prochaska, Velicer et al., 1991), where lack of awareness is not an issue, the classification in stages was based on self-rating of subjects. However, as Chapters 6 and 7 showed, for behaviors where misconception is very prevalent, this stage classification based on self-rating of behavior resulted in many people classifying themselves as being in action or maintenance, while in reality they were in precontemplation (not meeting the guidelines and no intention to change). Both studies showed that out of the people who rated themselves as being in action or maintenance, a large portion did not meet the dietary guidelines for their fruit, vegetable and fat intake. Since one of the implications of the stages of change concept is that people in different stages obtain information that is tailored to their specific stage, this would result in people who are incorrectly in maintenance getting information on how to sustain their current behavior. However, in reality these subjects should receive information on raising awareness and changing their behavior. The classification into stages of change must be based on a validated algorithm. If one of the variables defining the algorithm is behavior, a valid measure must be used. Thus, self-rated behavior will only be an appropriate method, if validated. Therefore, an alternative stage algorithm was suggested (Chapter 7), in 
which, besides self-rated consumption, a measure of objective consumption was included. This resulted in a new stage algorithm, in which the precontemplation stage distinguishes between people who are aware of their unhealthy behavior and people who are not aware of their behavior. Consequently, both groups should receive different information. Unaware precontemplators should get information that raises awareness of unhealthy behavior (to go from unaware to aware precontemplation), while aware precontemplators should get information that will cause them to consider changing their behavior (to go from precontemplation to contemplation).

Participation in a two yearly screening program (Chapter 8) was not translated into stages of change because of problems that arose when applying the stages of change concept. Since the traditional stages of change concept uses the intention to change in combination with a certain time period in which people want to change, it seems impossible to use it for a behavior that takes place only once every 2 years. With respect to a two yearly screening program, intending to participate in the screening program within a month would be useless. This makes it difficult to distinguish between contemplation and preparation with respect to breast cancer screening. Further-more, the difference between the action stage (having changed the behavior for less than 6 months) and the maintenance stage (having changed for more than 6 months) seems impossible to use with a two yearly participation in a cancer screening program. Rakowski and colleagues (1992; 1993 ; 1996) suggested an adaptation of the stages of change for mammography in which future screening intention, together with past screening behavior over several previous screening rounds played an important role. In their studies, data of participation over several past screening rounds were used. However, since the screening study of this thesis only had information on one previous screening round, translating the data to their suggested stages algorithm did not have any additional value over and above the traditional use of behavioral intention, behavior and past behavior.

In conclusion, the integrated ASE-stages model is useful as an instrument for target group segmentation and for translating determinant differences between stages into specific health education targets. One of the major gains of applying the 
stages of change concept is that current behavior, intention and to some degree past behavior are combined into a new measure of behavioral stage. This means that the potentially large influence of past behavior on intentions and subsequent behavior is now partly embedded into the new behavioral measure (e.g., the difference between action and maintenance is based on past behavior). For explicit behavior such as smoking, the combinations provide relevant information (De Vries \& Backbier, 1994). However, in the studies presented in this thesis, this integrated ASE-stages model was applied to behaviors other than smoking, which the stages of change concept was originally developed for. When the integrated model is applied to new behaviors several problems can arise. First, the exact stage definitions should be clear with respect to the new behaviors. It should be very obvious where the cutoff point is between healthy and unhealthy behavior. Furthermore, for behaviors where lack of awareness is prevalent, the stage which people are in should be objectively validated. Subjects who misclassify their own risk behavior, should be placed in a separate stage, that can be placed as a segment within the precontemplation stage. The traditional self-rated stages of change can only be correctly applied to subjects who are aware of their current risk behavior. Finally, applying the combined ASE-stages model is difficult for periodical behavior such as a two yearly screening. In order to classify such periodical behavior into stages of change, the stage algorithm and inclusion criteria have to be adapted considerably for each separate stage. Only if enough data on past behavior are available, can such a combined ASE-stages model have additional value to the more traditional determinant-intention models that use intention and behavior as separate measures.

\section{METHODOLOGICAL CONSIDERATIONS AND SUGGESTIONS FOR FURTHER RESEARCH}

Because of the reciprocal nature of the relationship between the different ASE determinants, intention, and behavior, demonstration of causality through correlation studies is extremely difficult. In correlational studies with synchronous measures of determinants and behavior, as opposed to experimental studies in 
which manipulation of one of the variables is possible, it is equally valid to attribute the behavior to the determinants as vice versa. In field studies, where manipulation of one of the variables is not possible, causality can be demonstrated only to the extent that asynchronous, over-time measures of determinants and behavior are available. Of the five determinants studies presented in this thesis, two were exclusively cross-sectional studies, while three studies contained longitudinal measures. However, even for these longitudinal studies it proved to be very difficult to prove causality between variables that were measured differently in time. Therefore, within the conclusions that were drawn based on the presented studies, there should be room for suggesting alternative explanations for relations that were presented.

The conclusions of this thesis were based on only a few studies. It is evident that the results found in this thesis need to be replicated for different behaviors and different populations. As the thesis shows, different results and findings emerge when applying the extended ASE model to different behaviors. For each behavior, the application of the model has its own consequences with respect to personal norms, past behavior, (lack of) awareness or stages of change. The applications and findings of the studies reported in this thesis are, because of their diversity, more or less illustrative of applications and consequences that can occur. Replications of the findings are needed to create a more solid foundation for the conclusions presented, especially if modifications to the determinant models are applied to behaviors other than those presented. For future research, further in depth analysis is required with regard to several aspects of the ASE model:

Further research into possible new factors within the attitude construct. Besides personal norms, the differences between pros and cons within the attitude construct needs further attention. Furthermore, since personal norms proved to be a factor of major relevance, this implies a need for further research into possible ways of influencing this construct, in order to find clues for health promotion interventions.

- The role of perceived social influences within different health behaviors needs further research. More insight is needed in ways to assess perceived social influence, and to find out whether social influence is mostly behavior 
dependent. Furthermore, more insight is needed into the way that the social influence construct is related to the other constructs of the ASE model.

- Further research is needed into the different dimensions or factors within the self-efficacy construct. More insight is needed into the difference between measuring ability versus difficulty, and into the extra value of assessing the rate of occurrence of problem situations.

More research is needed into possible methods of assessing awareness of different health behaviors. The method that is used for assessing misconception of nutrition intake should be adapted and tested for other behaviors.

- More research is needed into possible alternative staging algorithms to prevent problems of misconceptions of behavior and the consequences of these misconceptions for the stages of change.

Finally, research is necessary to find the differential relevance of the different factors of the ASE model in the prediction of stage transitions with regard to the stages of change concept.

\section{MAIN CONCLUSIONS}

Several modification to the determinant models (TPB/ASE) were suggested in this thesis. The main conclusions of this thesis are either related to the basic concepts of the model (attitude, social influence, self-efficacy), or are related to new additional modifications of the model.

With respect to the basic concepts of the model, we can conclude that several operationalizations may be possible to assess attitude, social influence and selfefficacy, without using a multiplicative function. Although further research is necessary, this thesis provides no indications that vital information is lost when using alternatives to the multiplicative concepts.

Furthermore, with regard to attitude, the results indicate that besides to the more cognitive-based outcome expectations, the more affective based personal norm (anticipated regret, moral obligation) has a potentially important and relevant 
place within the attitude construct. However, the inclusion of anticipated regret and moral obligation into the attitude construct needs to be supported by additional research. Particularly for emotional or morally fraught behaviors, these affective personal norm concepts seem to have a high predictive value toward intention and behavior.

In measuring social influence, the alternatives presented in this thesis (modeling, social support) seem to be comparable to the more traditional social norm of the TPB, with regard to their predictive value toward intention. The predicting value of social influence toward intention is, compared to attitude and self-efficacy, of minor importance. The question that remains is how to assess social influence in a more objective way.

With regard to self-efficacy, it is concluded that the predictive power of the situation-based construct (that measures ability to perform the behavior in several situations) is quite valuable and comparable to that of the PBC. An additional measure of self-efficacy, in which the frequency of occurrence of problem situations with regard to performance of the behavior was assessed, proved to be a valuable addition to the situation-based assessment of self-efficacy, with a unique contribution to the explanation of intention, behavior, or stages of change.

Furthermore, several new modifications to the basic model were studied. Past behavior or experience with the healthy behavior proved to be an important additional factor to explain intention and behavior with respect to breast cancer screening. Although in itself past behavior is of less relevance because it represents a factor that cannot be changed, past behavior does become very important if there are possible interaction effects with other, changeable determinants. If past behavior or experience results in people having different determinants of intention or behavior, including past behavior in the model becomes an important instrument for target group segmentation.

Misconception of people's own behavior proved to be highly prevalent with respect to nutrition behavior. This lack of awareness has important consequences for the relation of determinants and behavioral intention toward actual behavior or behavioral stages of change. For behaviors where misconception is prevalent, increasing awareness of the personal health risk behavior should be an important 
first intervention target. This could be done by making people aware of the guidelines for healthy behavior, and teaching them how to apply these guidelines to themselves. For the ASE model this would mean that for behaviors where misconception is prevalent an extra basic step should be built in to make people aware before trying to change determinants. The traditional basic ASE model can only be correctly applied, if awareness of people's own behavior is realized.

The integration of the stages of change concept within the ASE model is useful as an instrument for target group segmentation and for translating determinant differences between stages into specific health education targets. One of the major gains of applying the stages of change concept is that the potentially large influence of past behavior on intentions and subsequent behavior is now embedded into the new behavioral measure. However, several problems can arise when the integrated model is applied to different behaviors. The traditional selfrated stages of change can only be correctly applied to subjects who are aware of their current risk behavior. For behaviors where lack of awareness is prevalent, the stage in which people are in should be validated by including a measure of people's actual behavior. Subjects who misclassify their own risk behavior and have no intention to change their behavior, should be placed in a separate stage, located as a separate sub-stage within precontemplation. Furthermore, in order to apply the combined ASE-stages model to periodical behavior such as two yearly screening, the stage algorithm and inclusion criteria have to be adapted considerably for each different stage. 


\section{References}

Aiken, L.S., West, S.G., Woodward, C.K., \& Reno, R.R. (1994). Health beliefs and compliance with mammography-screening recommendations in asymptomatic women. Health Psychology, 13, 122-129.

Ajzen, I., \& Fishbein, M. (1970). The prediction of behavior from attitudinal and normative variables. Joumal of Experimental and Social Psychology, 6, 466-487.

Ajzen, I., \& Fishbein, M. (1972). Attitudes and normative beliefs as factors influencing behavioral intentions. Joumal of Personality and Social Psycbology, 21, 1-9.

Ajzen, I., \& Fishbein, M. (1974). Factors influencing intentions and the intention-behavior relation. Human Relations, 27, 1-15.

Ajzen, I., \& Fishbein, M. (1980). Understanding attitudes and predicting social behavior. Englewood Cliffs NJ: Prentice Hall.

Ajzen, I. (1985). From intentions to actions: A theory of planned behavior. In J. Kuhl \& J. Beckman (eds.), Action control: From cognition to behavior (pp. 11-39). Berlin: Springer.

Ajzen, I. (1988). Attitudes, personality, and behavior. Milton Keys: Open University Press.

Ajzen, I., \& Madden, T.J. (1986). Prediction of goal-directed behavior: Artitudes, intention, and perceived behavioral control. Journal of Experimental Social Psychology, 22, 453-473.

Ajzen, I. (1991). The theory of planned behavior. Organizational Behavior Human Decision Processes, 50, 179-211.

Alagna, S.W., Morokoff, J.M., Bevett J.M., \& Reddy, D.M. (1987). Performance of breast selfexamination by women at high risk for breast cancer. Women and Health, 12, 29-46.

American Cancer Society (1991). Cancer statistics (1991). CA Cancer Journal of Clinicians, 41, 1936.

American Cancer Society (1992). Cancer facts and figures (1992). American Cancer Society, Inc.

American College of Sports Medicine (1990). The recommended quantity and quality of exercise for developing and maintaining cardiorespiratory and muscular fitness in healthy adults. Medicine and Science in Sports and Exercise, 22, 265-274.

Anderson, A.S., Hunt, K., Ford, G., \& Finnigan, F. (1994). One apple a day? Fnuit and vegetable intake in the West of Scotland. Health Education Research, 9, 297-305.

Anderson, P. (1987). What is a safe level of alcohol consumption? Stress Medicine, 2, 99-101.

Armstrong, B.K. (1988). Epidemiology of malignant melanoma: Intermittent or total accumulated exposure to the sun? Journal of Dermatologic Surgery and Oncology, 14, 835-849.

Armstrong, B.K., \& Kricker, A. (1995). Skin cancer. Dermatology Clinitics, 13, 583-594.

Arthey, S., \& Clarke, V.A. (1995). Suntanning and sun protection: A review of the psychological literature. Social Science and Medicine, 40, 265-274.

Astrand, P.O. (1992). Why exercise? Medicine and Science in Sports and Exercise, 24, 153-162.

Autier, P., Dore, J.F., \& Lejeune, F. (1994). Cutaneous malignant melanoma and exposure to sunlamps or sumbeds: an EORTC multicenter case-control study in Belgium, France and Germany. International Joumal of Cancer, 58, 809-813.

Autier, P., Joarlette, M., \& Lejeune, F., (1991). Cutaneous malignant melanoma and exposure to sunlamps and sunbeds: a descriptive study in Belgium. Melanoma Research, 1, 69-74.

Auvinen, A., Elovanio, L., \& Hakama, M. (1996). Breast self-examination and survival from breast cancer: A prospective follow-up study. Breast Cancer Research and Treatment, 38, 161-168.

Backx, F.J.G., Swinkels, H., \& Bol, E. (1994). Hoe lichamelijk (in)actief zijn Nederlandse volwassenen in hun vrije tijd? Maandbericht Gezondheidsstatistiek (CBS), 3, 4-11.

Bader, J.P. (1986). Screening for colectoral cancer. Digestive Disease Science, 31 (Supplement), 43-56.

Bagozzi, R.P. (1981). Attitudes, intentions, and behavior: A test of some key hypotheses. Journal of Personality and Social Psychology, 41, 607-627.

Bagozzi, R.P. (1984). Expectancy-value attitude models: An analyses of critical measurement issues. 
International Joumal of Research in Marketing, 1, 295-310.

Bagozzi, R.P. (1986). Attitude formation under the theory of reasoned action and a purposeful behaviour reformulation. Britisch Joumal of Social Psychology, 25, 95-107.

Bagozzi, R.P. (1992). The self-regulation of atitudes, intentions, and behavior. Social Psychology Quarterly, 55, 178-204.

Bagozzi, R.P., Baumgarter, H., \& Youjae, Y. (1992). State versus action orientation and the theory of reasoned action: An application to coupon usage. Journal of Consumer Research, 18, 505 517.

Bagozzi, R.P., \& Warshaw, P.R. (1990). Trying to consume. Journal of Consumer Research, 17, 127 140.

Bailar, J.C., \& Gornik, H.L. (1997). Cancer undefeated. The New England Joumal of Medicine, 336, 1569-1574.

Baines, C.J. (1983). Some thoughts on why women don't do breast self-examination. Canadian Medical Association Journal, 128, 225-226.

Baines, C.J., To, T., \& Wall, C. (1990). Women's attitudes to screening after participation in the national breast screening study. Cancer, 65, 1663-1669.

Baker, L. (1982). Breast Cancer Detection Demonstration Project: Five-year summary report. CA Cancer Journal of Clinicians, 32, 194-225.

Bandura, A. (1977). Social Learning Theory. Engelwood Cliffs, NJ: Prentice Hall.

Bandura, A. (1982). Self-efficacy mechanism in human agency. American Psychologist, 37, 122-147.

Bandura, A. (1986). Social foundations of thought and action. Englewood Cliffs, NJ: Prentice Hall.

Baranowski, T., Domel, S., Gould, R., Baranowski, J., Leonard, S., Treiber, F., \& Mullis, R. (1993). Increasing fruit and vegetable consumption among 4th and 5th grade students: Results from focus groups using reciprocal determinism. Journal of Nutrion Education, 25, 114-120.

Baumann, L.J., Brown, R.I., Fontana, S.A., \& Cameron, L. (1993). Testing a model of mammography intention. Journal of Applied Psychology, 23, 1733-1756.

Beck, L., \& Ajzen, I. (1991). Predicting dishonest actions using the theory of planned behavior. Journal of Research in Personality, 25, 285-301.

Benedict, S., Williams, R.D., \& Hoomani, J. (1996). Method of discovery of breast cancer. Cancer Practitioner, 4, 147-155.

Benito, E. (1992). Overview of dietary recommendations on diet and cancer. In E. Benito, A. Giascosa, \& M.J. Hil (eds.), Public Education on Diet and Cancer. Dordrecht: Kluwer Academic Publishers.

Bentler, P.M., \& Speckart, G. (1979). Models of attitude-behavior relations. Psychological Reviere, 86, $452-464$.

Bentler, P.M., \& Speckart, G. (1981). Attitudes "cause" behaviors: A structural equation analysis. Journal of Personality and Social Psychology, 40, 226-238.

Bernstein, L., Henderson, B.E., Hanisch, R., Sullivan-Halley, J., \& Ross, R.K. (1994). Physical exercise and reduced risk of breast cancer in young women. Joumal of the National Cancer Institute, 86, 1403-1408.

Best, D.L., Davis, S.W., Vaz, R.M., \& Kaiser, M. (1996). Testicular cancer education: A comparison of teaching methods. American Joumal of Health Bebavior, 20, 229-241.

Bijnen, F.C.H. (1990). Lichamelijke inactiviteit. Risicofactor voor bart- en vaatziekten. Den Haag: Nederlandse Hartstichting.

Bijnen, F.C.H., Zonderland, M.L., Van Ernst, G.C., \& Mosterd, W.L. (1991). Bewegen, fitheid en gezondheid. Themanummer Bewegen en Gezondheid. Geneeskunde en Sport, 24, 163-168.

Blair, S.M., Kohl, H.W., Paffenbarger, R.S., Clark, D.G., \& Cooper, K.H. (1989). Physical fitness and all-cause mortality. A prospective study of healthy men and women. Joumal of the American Medical Association, 262, 2395-2401.

Block, G. (1991). Vitamin $C$ and cancer prevention: The epedimiologic evidence. American Journal 
of Clinical Nutrition, 53, 270s-282s.

Block, G., Patterson, B., \& Subar, A. (1992). Fruit, vegetables, and cancer prevention: A review of the epidemiological evidence. Nutrition and Cancer, 18, 1-29.

Boer, H., Taal, E., \& Seydel, E. (1990). Voorlichting over het bevolkingsonderzoek naar borstkanker [Education about the national breast cancer screening program]. Enschede: Technical University of Twente.

Bolton-Smith, C., Woodward, M., \& Tunsall-Pedoe, H. (1991). The Scottish heart health study: Dietary intake by food frequency questionnaire and odds ratios for coronary heart disease risk. II. The antioxidant vitamins and fibre. European Joumal of Clinical Nutrition, 46, 8593.

Booth, M.L., Macaskill, P., Owen, N., Oldenburg, B., Marcus, B.H., \& Bauman, A. (1993). Population prevalence and correlates of stages of change in physical activity. Health Education Quarterly, 20, 431-440.

Bouchard, C., Shephard, R.J., Stephens, T., Sutton, J.R., \& McPherson, B.D. (1988). Exercise, fitness and bealth, a consensus of current knowledge. Champaign Illinois: Human Kinetics Books.

Bowen, D.J., Fries, E., \& Hopp, H.P. (1994). Effects of dietary fat feedback on behavioral and psychological variables. Journal of Bebavioral Medicine, 17, 589-604.

Bowling, A. (1989). Implications of preventive health behaviour for cervical and breast cancer screening programmes: A review. Family Practice, 6, 224-231.

Bowne, D.W., Russel, M.L., Morgan, M.A., Optenberg, S., \& Clarke, A. (1984). Reduced disability and health care costs in an industrial fitness program. Joumal of Occupational Medicine, 26, 809-816.

Boyd, B., \& Wandersman, A. (1991). Predicting undergraduate condom use with the Fishbein and Ajzen and Triandis attitude-behavior models: Implications for public health interventions. Journal of Applied Social Psychology, 21, 1810-1830.

Brug, J., Debie, S., Van Assema, A., \& Weijts, W. (1995). Psychosocial determinants of fruit and vegetable consumption among adults: Results of focus group interviews. Food Quality and Preference, 6, 99-107.

Brug, J., Glanz, K., \& Kok, G. (1998). Do eating practices and psychosocial factors differ across stages of change for fruit and vegetable intake? (submitted for publication).

Brug, J., Hospers, H.J., \& Kok, G.J. (1997) Differences in psychosocial factors and fat consumption between stages of change for fat reduction. Psychology and Health, 12, 719. 727.

Brug, J., Lechner, L., \& De Vries, H. (1995). Psychosocial determinants of fruit and vegetable consumption. Appetite, 25, 285-296.

Brug, J., Steenhuis, I., Van Assema, P., \& De Vries, H. (1996). The impact of a computer-tailored nutrition intervention. Preventive Medicine, 25, 236-242.

Brug, J., Van Assema, P., Kok, G.J., Lenderink, T., \& Glanz, K. (1994) Self-rated dietary fat intake: Association with objective assessment of fat, psychosocial factors, and intention to change. Joumal of Nutrition Education, 26, 218-223.

Bryant, H., \& Mah, Z. (1992). Breast cancer screening attitudes and behaviors of rural and urban women. Preventive Medicine, 21, 405-418.

Budd, R.J. (1986). Predicting cigarette use: The need to incorporate measures of salience in the theory of reasoned action. Joumal of Applied Social Psychology, 16, 663-685.

Budd, R.J., North, D., \& Spencer, C. (1984). Understanding sear-belt use: A test of Bentler and Speckart's extension of the theory of reasoned action. European Journal of Socal Psychology, 14, 69-78.

Budd, R.J., \& Spencer, C. (1985). Exploring the role of personal normative beliefs in the theory of reasoned action: The problem of discriminating between alternative path models. European Journal of Social Psychology, 15, 299-313. 
Budden, L. (1995). Young women's breast self-examination knowledge and practice. Joumal of Community Healtb Nursing, 12, 23-32.

Calnan, M. (1984). The Health Belief Model and participation in programmes for the early detection of breast cancer: A comparative analysis. Social Science and Medicine, 19, 823-830.

Caspersen, C.J., Bloemberg, B.P.M., Saris, W.H.M., Merrit, R.K., \& Kromhout, D. (1991). The prevalence of selected physical activities and their relation with chronic coronary heart disease risk factors in elderly man: The Zutphen Study, 1985. American Joumal of Epidemiology, 133, 1078-1092.

Caspersen, C.J., Christenson, G.M., \& Pollard, R.A. (1985). Status of the 1990 physical fitness and exercise objectives-evidence from NHIS 1985. Public Health Reports, 17, $200-213$.

Caspersen, C.J., \& Merritt, R.K. (1992). Trends in physical activity patterns among older adults: the behavioral risk factor surveillance system, 1986-1990. Medicine and Science in Sports and Exercise, 24 (Supplement), S26.

Casperson, C.J., Pollard, R.A., \& Pratt, S.O. (1987). Scoring physical activity data with special consideration for elderly population. In Proceedings of the 21th National meeting of the public bealth conference on records and statistics: Data for an aging popluation. Washington DC: Public Health Service; July 13-15, 1987: 30-34. DHHS publication PHS 88-1214.

Centers for Disease Control and Prevention. (1993). Public Health focus: Physical activity and the prevention of coronary heart disease. Morbidity Mortality Weekly Report, 42, 669-672.

Champion, V.L. (1994). Strategies to increase mammography utilization. Medical Care, 32, 118-129.

Cialdini, R.B., Kallgren, C.A., \& Reno, R.R. (1991). A focus theory of normative conduct: A theoretical refinement and reevaluation of the role of norms in human behavior. Advances in Experimental Social Psychology, 24, 201-234.

Cohen, J., \& Cohen, P. (1975). Applied multiple regression/correlation analyses for the behavioral sciences. Hillsdale, NJ: Erlbaum.

Collette, H., Rombach, J.J., De Waard, F., \& Collette, C. (1988). An update of the DOM Project for early detection of breast cancer. In N. Day $8 x$ A. Miller (eds.), Screening for breast cancer. Toronto.

Colsher, P.L., \& Wallace, R.B. (1989). Is modest alcohol consumption better than none at all: An epidemiologic assessment. Annual Reviere of Public Health, 10, 203-219.

Cope, D.G. (1992). Self-esteem and the practice of breast self-examination. Western Joumal of Nursing Research, 14, 618-631.

Curry, S.J., \& Emmons, K.M. (1994). Theoretical models for predicting and improving compliance with breast cancer screening. Annuals of Behavioral Medicine, 16, 302-316.

Curry, S.J., Kristal, A.R., \& Bowen, D.J. (1992). An application of the stage model of behavior change to dietary fat reduction. Health Education Research, 7, 97-105.

De Roos, F., \& Oude Vrielink, H.A.M. (1992). Wetenschappelijke evaluatie KRO TV serie Je zult bet zien. Utrecht: Janus Jongbloed Research Centrum.

Desharnais, R., Bouillon, J., \& Godin, G. (1986). Self-efficacy and outcome expectations as determinants of exercise adherence. Psychological Reports, 59, 155-1159.

De Vries, H. (1989). Prevention of cancer: Towards a national ABC framework. European Journal of Cancer and Clinical Oncology, 25, 1025-1033.

De Vries, H. (1993). Determinanten van gedrag [Determinants of behavior]. In V. Damoiseaux, H.T. Van (der Molen, \& G.J. Kok, (eds.), Gezondheidvoorlichting en gedragsverandering [Health education and behavioral change]. Assen: Van Gorcum, 109-132.

De Vries H., \& Backbier E. (1994). Self-efficacy as an important determinant of quitting among smoking pregnant women: The $\varnothing$-pattern. Preventive Medicine, 23, 167-174.

De Vries, H., Backbier, E., Kok. G.J., \& Dijkstra, M. (1995). Measuring the impact of social influences on smoking onset in a longitudinal study: An integration of social psychological approaches. Joumal of Applied Social Psychology, 25, 237-257.

De Vries, H., Dijkstra, M., \& Kuhlman, P. (1988). Self-efficacy: The third factor besides attitude 
and subjective norm as a predictor of behavioral intentions. Health Education Research, 3, 273-282.

De Vries, H., \& Kok, G.J. (1986). From determinants of smoking behavior to the implications for a prevention programme. Health Education Research, 1, 85-94.

De Vries, H., \& Mudde, A. (1998). Forward and backward stage transitions in the smoking cessation process: A longitudinal report on differences in attitudes, social support and selfefficacy expectations using the ASE-model. Psychology and Health, (in press).

De Vries, H., \& Willemsen, M.C. (1996). Planmatige gezondheidsvoorlichting in de arbeidsituatie [systematic health education in worksites]. In P. Baart, G. Roerink, \& M. Selie (eds.), Gezondbeidsbevordering op de werkplek [Helath promotion in worksites]. Amsterdam: NIA.

DiClemente, C.C., Prochaska, J.O., Fairhurst, S., Velicer, W.F., Velasquez, M., \& Rossi, J.S. (1991). The process of smoking cessation: An analysis of precontemplation, contemplation and preparation stages of change. Joumal of Consulting Clinical Psychology, 59, 295-304.

DiClemente, C.C., Prochaska, J.O., \& Gibertini, M. (1985). Self-efficacy and the stages of selfchange of smoking. Cognitive Tberapy and Research, 9, 181-200.

Dishman, R.K. (1988). Exercise adherence research: Future directions. American Joumal of Health Promotion, 3, 52-56.

Doll, R. (1989). The prevention of cancer: Opportunities and challenges. In T. Heller, B. Davey, \& L. Bailey (eds.), Reducing the risk of cancers (pp. 14-25). London: Hodder \& Stoughton.

Doll, R., \& Peto, R. (1981). The causes of cancer: Quantitative estimate of avoidable risks of cancer in the United States today. Joumal of the National Cancer Institute, 66, 1191-1308.

Duffy, S.W., \& Sharples, L.D. (1992). Alcohol and cancer risk. In J. Duffy (ed.), Alcohol and illness, the epidemiological viewpoint (pp. 64-127). Edinburgh: University Press.

Dutch Cancer Society (1996). Vroege ontdekking van kanker... wat u zelf kan doen [Early detection of cancer... what can you do]. Amsterdam: De Nederlandse Kankerbestrijding/KWF.

Dutch Cancer Society (1997). Jaarverslag Nederlandse Kankerbestrijding 1996 [Annual report 1996]. Amsterdam: De Nederlandse Kankerbestrijding/KWF.

Dutch Central Bureau for Statistics (1994). Statistisch jaarboek [Annual statistical report]. Den Haag/Heerlen: CBS.

Dutch Central Bureau for Statistics (1995). Statistisch jaarboek [Annual statistical report]. Den Haag/Heerlen: CBS.

Dutch Foundation on Smoking and Health (1995). Jaarverslag 1994. [Annual report 1994]. Den Haag: Stichting Volksgezondheid en Roken.

Dutch Foundation on Smoking and Health (1996). Jaarverslag 1995. [Annual report 1995]. Den Haag: Stichting Volksgezondheid en Roken.

Dutch Nutrition Council [Voedingsraad] (1986). Richtlijnen Goede Voeding [Guidelines for a healthy diet]. Voeding, 47, 159-181.

Dutch Nutrition Council [Voedingsraad] (1991). Nader advies inzake richtlijnen m.b.t. de vetconsumptie uit het advies Richtlijnen Goede Voeding 1986 [Further advice on the dietary recommendation for fat consumption from 1986]. Den Haag: Voedingsraad.

Eagly, A.H., \& Chaiken, S. (1993). The psychology of attitudes. Fort Worth (TX): Hartcourt.

Eardley, A., \& Elkind, A. (1990). A pilot study of attending for breast cancer screening. Social Science and Medicine, 30, 693-699.

Eardley, A., Elkind, A.K., Spencer, B. et al. (1985). Attendance for cervical screening: Whose problem? Social Science and Medicine, 20, 955-962.

Elkind, A., Haran, D., Eardley, A., \& Spencer, B. (1987). Computer-managed cervical cytology screening: A pilot study of non-attenders. Public Health, 101, 253-266.

Elwood, J.M., \& Gallagher, R.P. (1993). Sun exposure and the epidemiology of melanoma. In R.P. Gallagher \& J.M. Elwood, Epidemiological aspects of cutaneous malignant melanoma. Boston: Kluwer Academic Publisher.

European Community Commission (1990). Notities over Europa: Europa tegen Kanker [Reports on 
Europe: Europe against Cancer]. Brussels: Bureau for Official Publications of the EC.

Evans, M.G. (1991). The problem of analyzing multiplicative composites: Interactions revisited. American Psychologist, 46, 6-15.

Evans, R.D., Kopf, A.W., Lew, R.A., Rigel, D.S., Bart, R.S., et al. (1988). Risk factors for the development of malignant melanoma: Review of case control studies. Joumal of Dermatologic Surgery and Oncology, 14, 393-406.

Falbo, T., \& Becker, H.A. (1980). The Fishbein model: Triumphs, problems, and prospects. In T.K. Burch (ed.), Demographic behavior, interdisciplinary perspectives on decision-making (pp. 125-140). Boulder (CO): Westview Press.

Feldman, S.G., Carter, A.C., Nicatier, A.D., \& Hostar, S.T. (1981). Breast self-examination: Relationship to stage at breast cancer at diagnosis. Cancer, 47, 2740-2745.

Fink, D.G. (1991). Guidelines for the cancer related checkup: Recommendations and rationale. Atlanta: American Cancer Society.

Fishbein, M., \& Stasson, M. (1990). The role of desires, self-predictions, and percieved behavioral control in the prediction of training sessions attendance. Journal of Appied Social Psychology, 20, 173-198.

Fishbein, M., \& Ajzen, I. (1975). Belief, attitude, intention and behavior: An introduction to theory and research. Reading (MA): Addison-Wesley.

Fishera, S.D., \& Frank, D.I. (1994). The Health Belief Model as a predictor of mammography screening. Health Values, 18, 3-9.

Flay, B.R., \& Petraitis, J. (1994). The theory of triadic influence: A new theory of health behaviour with implications for preventive interventions. Advanced Medical Sociology, 4, 19-44.

Fleiss, J. (1981) Statistical methods for rates and proportions. New York: John Wiley.

Foster, R.S., \& Costanza, M.C. (1984). Breast self-examination practices and breast cancer survival. Cancer, 53, 999-1005.

Fredricks, A.R., \& Dossett, D.L. (1983). Attitude-behavior relations: A comparison of the Fishbein-Ajzen and Bentler-Speckart models. Joumal of Personality and Social Psychology, 40, 226-238.

Freidenreich, C.M., \& Rohan, T.E. (1995a). A review of physical activity and breast cancer. Epidemiology, 6, 311-317.

Freidenreich, C.M., \& Rohan, T.E. (1995b). Physical activity and risk of breast cancer. European Journal of Cancer Prevention, 4, 145-151.

Friedman, L.C., Nelson, D.V., Webb, J.A., Hoffman, L.P., \& Baer, P.E. (1994). Dispositional optimism, self-efficacy, and health beliefs as predictors of breast self-examination. American Journal of Preventive Medicine, 10, 130-135.

Garretsen, H.F.L. (1986). Alcohol gebruik en -problemen in Nederland [Alcohol use and problems in the Netherlands]. In H.F.L Garetsen, J. Van Hattum \& W. Hekkens (eds.), Voeding en alcobol [Nutrition and alcohol]. Alphen aan den Rijn/Brussel: Samson Stafleu.

Gerster, H. (1991). Potential role of beta-carotene in the prevention of cardiovascular disease. International Joumal of Vitamin and Nutrition Research, 61, 277-291.

Gezondheidsraad (1994). Commissie Risico's UV straling (publ nr 1994/05). Den Haag: Gezondheidsraad.

Glanz, K., \& Eriksen, M.P. (1993). Individual and community models for dietary behavior change. Journal of Nutrition Education, 25, 80-86.

Glanz, K., \& Mullis, R.M. (1988). Environmental interventions to promote healthy eating: A review of models, programs, and evidence. Health Education Quarterly, 15, 394-415.

Glanz, K., Patterson, R.E., Kristal, A.R., DiClemente, C.C., Heimendinger, J., Linnan, L., \& McLerran, D.F. (1994). Stages of change in adopting healthy diets: Fat, fiber, and correlates of nutrient intake. Health Education Quarterly, 21, 499-519.

Glanz, K., Resch, N., Lerman, C., \& Rimer, B. (1996). Differences in factors influencing mammography use among black and white employed female Health Maintenance 
Organization members. Ethnicity \& Health, 1, 217-230.

Godin, G. (1993). The theories of reasoned action and planned behavior: Overview of findings, emerging research problems and usefulness for exercise promotion. Joumal of Applied Sports Psychology, 5, 141-157.

Godin, G., Desharnais, R., Valois, P., \& Bradet, R. (1995). Combining behavioral and motivational dimensions to indentify and characterize the stages in the process of adherence to exercise. Psychology and Health, 10, 333-344.

Godin, G., \& Kok, G.J. (1996). The theory of planned behavior: A review of its implications to health-related behaviors. American Journal of Health Promotion, 11, 87-98.

Godin, G., \& Shepard, R.J. (1990). Use of attitude-behaviour models in exercise promorion. Sports Medicine, 10, 103-121.

Goldbohm, R.A., Van den Brandt, P.A., Brandts, H.A.M., Van 't Veer, P., Al, M., Sturmans, F., \& Hermus, R.J.J. (1994). Validation of a dietary questionnaire used in a large-scale prospective cohort study on diet and cancer. European Journal of Clinical Nutrition, 48, 253-265.

Gorsuch, R.L., \& Ortberg, J. (1983). Moral obligation and attitudes: Their relation to behavioral intentions. Journal of Personality and Social Behavior, 44, 1025-1028.

Green, L.W., \& Kreuter, M.W. (1991). Health promotion planning: An educational and environmental approach. Mountain View: Mayfield.

Greene, G.W., Rossi, S.R., Richards-Reed, G., Willey, C., \& Prochaska, J.O. (1994). Stages of change for reducing dietary fat to $30 \%$ of energy or less. Journal of the American Dietetic Association, 94, 1105-1110.

Greenstein, M., Miller, R.H., \& Weldon, D.E. (1979). Attitudinal and normative beliefs as antecedents of female occuparional choice. Personality and Social Psychology Bulletin, 5, 356362.

Grube, J.W., Morgan, M., \& McGee, S.T. (1986). Atritudes and normative beliefs as predictors of smoking intentions and behaviours: A test of three models. Britisch Journal of Social Psychology, 25, 81-93.

Hallal, J.C. (1982). The relationship of health beliefs, health locus of control, and self-concept to the practice of breast self-examination of adult women. Nursing Research, 31, 137-142.

Harris, S.S., Caspersen, C.J., De Friese, G.N., \& Estes, E.H. (1989). Physical activity counseling for healthy adults as a primary preventive intervention in the clinical setting. Journal of the American Medical Association, 261, 3590-3598.

Havas, S., Heimendinger, J., Reynolds, K., Baranowski, T., Nicklas, T.A., Bishop, D., Buller, D., Sorensen, G., Beresford, S.A.A., Cowan, A., \& Damron, D. (1994). 5 a day for better health: A new research initiative. Joumal of the American Dietetic Association, 94, 32-36.

Hayward, R., Shapiro, M., Freeman, H.E., \& Corey, C.R. (1988). Who gets screened for cervical and breast cancer? Results from a new national survey. Archives of International Medicines, $149,1177-1181$.

Hertog, M.G.L., Feskens, E.J.M., Hollman, P.C.H., Katan, M.B., \& Kromhout, D. (1993). Dietary antioxidant flavonoids and risk of coronary heart disease: The Zutphen Elderly Study. The Lancet, 342, 1007-1011.

Hewstone, M., \& Young, L. (1988). Expectancy-value models of attitude: Measurement and combination of evaluations and beliefs. Joumal of Applied Social Psychology, 18, 985-971.

Hill, D., White, V., Marks, R., Theobald, T., Borland, R., \& Roy, C. (1992). Melanoma prevention: Behavioral and nonbehavioral factors in sunburn among an Australian urban population. Preventive Medicine, 21, 654-669.

Hobbs, P., Smith, A., George, W., \& Selwood, R. (1980). Acceptors and rejectors of an invitation to undergo breast screening compared with those who referred themselves. Joumal of Epidemiology and Community Health, 34, 19-22.

Hoffman, G.L., \& Husted, J. (1994). Exercise and breast cancer: Review and critical analysis of the 
literature. Canadian Journal of Applied Physiology, 19, 237-52.

Howe, H.L. (1992). Repeat mammography among women over 50 years of age. American Joumal of Preventive Medicine, 8, 182-185.

Hulshof, K.F.A.M., Löwik, M.R.H., Kistemaker, C., Hermus, R.J.J, Ten Hoor, F., \& Ockhuizen, Th. (1993). Comparison of dietary intake data with guidelines: Some porential pitfalls. European Journal of Clinical Nutrition, 45, 441-450.

Hulshof, K.F.A.M., Löwik, M.R.H., \& Kistemaker, C. (1994). Voeding na vijf jaar opnieuw gepeild [A new surveillance of the Durch diet, after five years]. Voeding, 55, 28-32.

Janis, I.L., \& Mann, L. (1977). Decision making: $A$ psychological analysis of conflict, choice and commitment. New York: Free press.

Janz, N.K., \& Becker, M.H. (1984). The Health Belief Model: A decade later. Health Education Quarterly, 11, 1-47.

Jepson, C., \& Rimer, B.K. (1993). Determinants of mammography intentions among prior screeners and nonscreeners. Journal of Applied Social Psychology, 23, 40-51.

Joossens, L., Naet, C., Howie, C., \&. Muldoon, A. (1994). Tobacco and bealth in the European Union: An overview. Brussels: European Bureau for Action on Smoking Prevention.

Keesling, B., \& Friedman, H.S. (1987). Psychological factors in sunbathing and sunscreen use. Health Psychology, 6, 477-493.

Kelder, H. (1994). De toestand van de ozonlaag, heden en verleden [The ozon-layer, past and present]. Presentatie op het UV symposium "Gezond in de zon", 7 juni 1994. Bilthoven: RIVM.

Kelsey, J.L., \& Gammon, M.D. (1988). Epidemiology of breast cancer. Epidemiological Review, 12, 228-231.

King, J. (1987). Women's attitudes towards cervical smears. Update, 34, 160-168.

Knibbe, R.A., \& Swinkels, H. (1992). Alcoholgebruik in Nederland: Een analyse van gegevens uit de CBS-gezondheidsenquete 1989 [Alcohol consumption in the Netherlands: An analysis of the data from the CBS health questionnaire 1989]. Tijdscbrift voor Alcohol, Drugs en andere Psychotrope Stoffen, 18, 124-138.

Kok, G. (1985). Een model van gedragsverandering door voorlichting [A model for behavioral change through public education]. Nederlands Tijdschrift voor de Psychologie, 40, 71-76.

Kok, G.J., Den Boer, D., De Vries, H., Gerards, F., Hospers, H., \& Mudde, A., (1992). Selfefficacy and atribution theory in health education. In R. Schwarzer (ed.), Self-efficacy: thought control of action (pp. 245-262). Washington, DC: Hemisphere Publishing.

KPN [Royal Dutch Post and Telephone Company]. Jaarverslag 1995 [Annual report 1995]. Groningen: KPN, 1996.

Kramisch-Campbell, M., DeVellis, B.M., Strecher, V.J., Ammerman, A.S., DeVellis, R.F., \& Sandler, R.S. (1994). Improving dietary behavior: The effectiveness of tailored messages in primary care settings. American Joumal of Public Health, 84, 783-792.

Krebs-Smith, S.M., Heimendinger, J., Patterson, B.H., Subar, A.F., Kessler, R., \& Pivaonka, E. (1995). Psychosocial factors associated with fruit and vegetabe consumption. American Journal of Healtb Promotion, 10, 98-104.

Kris-Etherthon, P.M., Volz-Clarke, P., Clark, K., \& Dattilo, A.M. (eds.) (1990). Cardiovasculair desease: Nutrition for prevention and treatment. The American Dietetic Association.

Lechner L. (1991). Determinanten van opkomstgedrag bij bet bevolkingsonderzoek naar borstkanker [Determinants of participation in a national breast cancer screening program]. Maastricht: University of Limburg.

Lechner, L., \& Brug, J. (1997). Consumption of fruit and vegetables: How to motivate the population to change their behavior. Cancer letters, 114, 335-336.

Lechner, L., Brug, J., \& De Vries, H. (1997). Misconception of fruit and vegetable consumption: Interpretation and consequences. Journal of Nutrition Education, 29, 313-320.

Lechner, L., Brug, J., De Vries, H., Van Assema, P., \& Mudde, A. (1998). Stages of change for 
fruit, vegetable, and fat intake: Consequences of misconception. Health Education Research, (in press).

Lechner, I, \& De Vries, H. (1994). Determinanten van deelname aan bedrijfsfitness. Tijdscbrift Sociale Gezondheidszorg, 72, 21-27.

Lechner, L., \& De Vries, H. (1995a). Starting participation in an employee fitness program: Attitudes, social influence and self-efficacy. Preventive Medicine, 24, 627-633.

Lechner, L., \& De Vries, H. (1995b). Participation in an employee fitness program: Determinants of high adherence, low adherence and dropout. Joumal of Occupational and Environmental Medicine, 37, 429-436.

Lechner, L., \& De Vries, H. (1995c). Participatie binnen een bedrijfsfitnessprogramma: Determinanten van deelname en uitval. Gedrag \& Gezondheid, 23, 59-69.

Lechner, L., \& De Vries H. (1996). Nederlanders in de zon: 1994 - 1995 [The Dutch in the sun: 19941995]. Maastricht: University of Limburg.

Lechner, L., \& De Vries, H. (1997). Nederlanders in de zon: Risicogedrag en determinanten [Sunbathing among the Dutch: risk behaviour and determinants of sunscreen use]. Tijdschrift voor Sociale Gezondheidszorg, 2, 61-69.

Lechner, L., De Vries, H., Adriaansen, S., \& Drabbels, L. (1997). Effects of an employee fitness program on reduced absenteeism. Joumal of Occupational and Environmental Medicine, 9, 827-831.

Lechner, L., De Vries, H., \& Brug, J. (1994). Evaluatie Europese Week tegen Kanker 1994: Groente en fruit [Evaluation of the European Week against Cancer 1994: Fruit and vegetables]. Maastricht: University of Limburg.

Lechner, L., De Vries, H., \& Offermans, N. (1997). Participation in a breast cancer screening program: Influence of past behavior and determinants on future screening participation. Preventive Medicine, 26, 473-482.

Lipmann, M.E., Lichter, A.S., \& Danforth, D. (1988). Diagnosis and management of breast cancer. Philadelphia: Saunders Company.

Liska, A.E. (1984). A critical examination of the casual structure of the Fishbein/Ajzen atritudebehavior model. Social Psychology Quarterly, 47, 61-74.

Longnecker, M.P., Berlin, J.A., Orza, M.J., \& Chalmers, T.C. (1988). A meta-analyses of alcohol consumption in relation to risk of breast cancer. Joumal of the American Medical Association, 260, 652-656.

Lutz, R.J. (1975). Changing brand attitudes through modification of cognitive structure. Journal of Consumer Research, 1, 49-59.

Lynch, W.D., Golaszewski, T.J., Cleary, A.F., Snow, D., \& Vickory, D.M. (1990). Impact of a facility-based corporate fitness program on the number of absences from work due to illness. Journal of Occupational Medicine, 32, 9-12.

MacFarlane, G.J., \& Lowenfels, A.B. (1994). Physical activity and colon cancer. European Joumal of Cancer Prevention, 3, 393-398.

Mackenbach, J.P.(1988). Mortality and medical care. Thesis. Rotterdam: Erasmus University.

MacKie, R.M., Osterlind, A., \& Ruiter, D., (1991). Report on consensus meeting of the EORTC Melanoma Group on educational needs for primary and secondary prevention of melanoma in Europe. Results of a workshop of the EEC Europe against Cancer programme, Innsbruck, 1991.

MacKie, R.M., \& Rycroft, M.J. (1982). Severe sunburn and subsequent risk of primary cutaneous malignant melanoma in Scotland. British Joumal of Cancer, 46, 955-960.

Maclean, U., Sinfield, S., Klein, B., \& Harnden, B. (1984). Women who decline breast screening. Joumal of Epidemiology and Community Health, 38, 278-283.

Madden, T.J., Ellen, P.S., \& Ajzen, I. (1992). A comparison of the theory of planned behavior and the theory of reasoned action. Personality and Social Psychology Bulletin, 18, 3-9.

Manstead, A.S.R., \& Parker, D. (1995). Evaluating and extending the theory of planned behaviour. 
In W. Stroebe, \& M.Hewsrone (eds.), European Review of Social Psychology, 6, 69-95.

Marcus, B.H., Banspach, S.W., Lefebre, R.C., Rossi, J.S., Carleton, R.A., \& Abrams, D.H. (1992).

Using the stages of change model to increase the adoption of physical activity among community participants. American Joumal of Health Promotion, 6, 424-429.

Marcus, B.H., \& Owen, N. (1992). Motivational readiness, self-efficacy and descision-making for exercise. Journal of Applied Social Psychology, 22, 3-16.

Marcus, B.H. Rakowski, W., \& Rossi, J.S. (1992). Assessing motivational readiness and decision making for exercise. Health Psychology, 11, 257-261.

Marcus, B.H., Selby, V.C., Niaura, R.S., \& Rossi, J.S. (1992). Self-efficacy and the stages of exercise behavior change. Research Quarterly for Exercise and Sport, 63, 60-66.

Marks, R., \& Hill, D. (eds.) (1992). The public health appraoch to melanoma control: Prevention and early detection. Geneva: International Union Against Cancer.

McAuley, E. (1993). Self-efficacy and the maintenance of exercise participation in older adults. Journal of Behavioral Medicine, 16, 103-113.

McCarthy, W.H., \& Shaw, H.M. (1989). Skin cancer in Australia. Medical Journal of Australia, 150, 469-470.

McDermot, F. (1991). Risk-factors in breast cancer. Australian Family Physician, 10, 1455-1460.

$\mathrm{McD}$ onald, J. (1982). Moderate amounts of alcoholic beverages and clinical nutrition. Jourmal of Nutrition Education, 14, 58-60.

McGuire, W.J. (1985). Attitudes and attitude change. In G. Lindzey, \& E. Aronson (eds.), Handbook of Social Psychology Volume II, (pp. 233-246) New York: Lawrence Erlbaum Associates.

Mellenbergh, G.J., Molendijk, L., De Haan, W., \& Ter Horst, G. (1990). The sum of products variable reconsidered. Methodika, 4, 37-46.

Mensink, R.P., Zock, P.I., \& Katan, M.B. (1994). Vet, vetzuren en coronaire hartziekten [Fat, fatty acids and coronary heart disease]. Hart bulletin, 25, 111-115.

Miniard, P.W., \& Cohen, J.B. (1981). An examination of the Fishbein-Ajzen behavioral-intentions model's concepts and measures. Joumal of Experimental Social Psychology, 17, 309-339.

Ministry of Welfare, Health and Cultural Affairs (1993). Feiten over alcohol [Facts about alcohol]. Rijswijk: Bureau Alcohol Voorlichtingsplan.

Nathoo, V. (1988). Investigation of non-responders at a cervical cancer screening clinic in Manchester. British Medical Journal, 296, 1041-1042.

National Cancer Institure (1980). National survey on breast cancer. A measure of progress in public understanding. (NIH Publication No.81-2306).

National Research Council (1989). Diet and bealth: Implication for reducing chronic disease risk. Washington, DC: National Academic Press.

Netemeyer, R.G., Burton, S., \& Johnston, M. (1991). A comparison of two models for the prediction of violitional and goal-directed behaviors: A confirmatory analyses approach. Social Psychology Quarterly, 54, 87-100.

Netherlands Bureau for Food and Nutrition Education (1993). Zo eet Nederland [This is how the Dutch eat]. Den Haag: VoVo.

Neve, R., Knibbe, R., \& Swinkels, H. (1994). Gaan drinkgewoonten van vrouwen steeds meer lijken op die van mannen? Tijdschrift voor Alcobol, Drugs en andere Psychotrope stoffen, 20, 65-77.

Nunnally, J.C. (1967). Psychometric theory. New York: McGraw-Hill.

Offermans, N. (1994). Het bevolkingsonderzoek naar borstkanker: Determinanten van opkomstgedrag eerste ronde en determinanten van intentie aan volgende screeningsrondes [The national breast cancer screening program: determinants of participation]. Maastricht: University of Limburg.

Oldridge, N.B. (1984). Adherence to adult exercise fitness programs. In J.D. Matarazzo (ed.), Bebavior health: $A$ bandbook of health enbancement and disease prevention. New York: Wi- 
ley, 467-487.

Ossendorp, S.J.M., Ypma, E.B., Van Leeuwen, F.E., \& Rookus, M.A. (1993). Vet en het risico op borstkanker [Fat and breast cancer risk]. Voeding, 54, 16-20.

Österlind, A., Tucker, M.A., Stone, B.J., \& Jensen, O.M. (1988). The Danish case-control study of cutaneous malignant melanoma II: Importance of UV light exposure. International Joumal of Cancer, 42, 319-324.

Owen, N., \& Lee, C. (1989). Development of behaviorally-based policy guidelines for the promotion of exercise. Journal of Public Health Policy, 10, 43-61.

Palm, B.T., \& Kant, A.C. (1994). Bevolkingsonderzoek baarmoederhalskanker. De invloed van de huisarts op deelname en follow-up. Eindrapportage van bet project "Bewaking deelname en follow-up screening cervixcarcinoom in de buisartsenpraktijk". Nijmegen: University of Nijmegen.

Palm, B.T., Kant, A.C., Van den Bosch, W.J.H.M., Vooijs, G.P., \& Van Weel, C. (1993). Preliminary results of a general practice based call system for cervical cancer screening in the Netherlands. British Journal of General Practice, 43, 503-506.

Parker, D., Manstead, A.S.R., \& Stradling, S.G. (1995). Extending the theory of planned behaviour: The role of personal norm. British Journal of Social Psychology, 34, 127-137.

Pate, R.R., Pratt, M., Blair, S.N., Haskell, W.L., Macera, C.A., Bouchard, C. et al., (1995). Physical activity and public health: A recommendation from the Centers for Disease Control and Prevention and the American College of Sports Medicine. Journal of the American Medical Association, 273, 402-407.

Patterson, B.H., Block, G., Rosenberger, W.F., Pee, D., \& Kahle, L.L. (1990). Fruit and vegetables in the American diet: Data from the NHANES II Survey. American Joumal of Public Health, 80, 1443-1449.

Peay, M.Y. (1980). Changes in attitudes and beliefs in two-person interaction situations. European Journal of Social Psychology, 10, 3670-3677.

Peeters, M., Kok, G.J., \& Oostveen, T. (1989). Beweegredenen: een pilotstudie naar determinanten en effektiviteit van sporten onder werktijd. Maastricht: University of Limburg.

Peeters, M., Oostveen, T., \& Kok G.J. (1991). Sociaal-psychologische determinanten van sporten onder werktijd [Social-psychological determinants of exercising at work]. Gedrag en Gezondheid, 19, 302-314.

Peeters, P.H.M., Bijnen, F.C.H, Pols, M.A., Kemmeren, J.M., Collette, H.J.A., \& Mosterd, W.L. (1993). Lichamelijke (in)activiteit. In Rijksinstituut voor Volksgezondheid en Milieuhygiëne, Volksgezondheid Toekomst Verkenning: De gezondheidstoestand van de Nederlandse bevolking in de periode $1950-2010$ (pp. 585-590). Den Haag: SDU.

Peto, R., Lopez, A.D., Boreham, J., Thun, M., \& Heath, C. (1992). Mortality from tobacco in develloped countries: Indirect estimation from national vital statistics. The Lancet, 339, 1267-1278.

Poppe, E. (1991). Motieven voor het bedrijuen van bedrijfsfitness [Motives for participating at an employee fitness program]. Nijmegen: University of Nijmegen.

Potter, J.D. (1995). Risk factors for colon neoplasia: Epidemiology and biology. European Joumal of Cancer, 31, 1033-1038.

Powell, K.E., Caspersen, C.J., Koplan, J.P., \& Ford, E.S. (1989). Physical activity and chronic diseases. American Joumal of Clinical Nutrition, 49, 999-1006.

Powell, K.E., Thompson, P.D., Casperson, C.J., \& Kendrick, J.S. (1987). Physical activity and the incidence of coronary heart disease. Annual Review of Public Health, 8, 253-287.

Prochaska, J.O., Velicer, W.F., Rossi, J.S., Goldstein, M.G., Marcus, B.H., Rakowski, W., et al. (1994). Stages of change and decisional balance for 12 problem behaviors. Health Psychology, $13,39-46$.

Prochaska, J.O., \& DiClemente, C.C. (1983). Stages and processes of self change of smoking: Toward an integrative model of change. Journal of Consulting and Clinical Psychology, 51, 
390-395.

Prochaska, J.O., Velicer, W.F., DiClemente, C.C., Guadagnoli, E., \& Rossi, J.S. (1991). Patterns of change: Dynamic typology applied to smoking cessation. Multivariate Bebavior Research, 26, 83-107.

Randall, D.M., \& Wolff, J.A. (1994). The time interval in the intention-behaviour relationship: Meta-analysis. British Joumal of Social Psychology, 33, 405-418.

Rakowski, W., Dube, C.E., Marcus, B.H., Prochaska, J.O., Velicer, W.F., \& Abrams, D.B. (1992). Assessing elements of women's decisions about mammography. Health Psychology, 11, 111 118.

Rakowski, W., Fulton, J.P., \& Feldman, J.P. (1993). Women's decision making about mammography: a replication of the relationship between stages of adoption and decisional balance. Health Psychology, 12, 209-214.

Rakowski, W., Rimer, B.K., \& Bryant, S.A. (1993). Integrating behavior and intention for the study of mammography: Data from the 1990 supplement to the national health interview survey. Public Health Report, 108, 605-624.

Reno, R.R., Cialdini, R.B., \& Kallgren, C.A. (1993). The transsituational influence of social norms. Journal of Personality and Social Psychology, 64, 104-112.

Richard, R., Van der Pligt, J., \& De Vries, N. (1995). Anticipated affective reactions and prevention of AIDS. British Journal of Social Psychology, 34, 9-21.

Rimer, B., Kasper Keintz, M., Kessler, H., Engstrom, P., \& Rosan, J. (1989). Why women resist screening mammography: Patient-related barriers. Radiology, 172, 243-246.

Rimer, B.K. (1994). Interventions to increase breast screening. Cancer, Supplement, 74, 323-327.

Rimer, B.K., Trock, B., Engstrom, P.F., Lerman, C., \& King, E. (1991). Why do women get regular mammograms. American Joumal of Preventive Medicine, 7, 69-74.

RIVM. Milieurapportage 1993 II: Integrale rapportage aantasting ozonlaag en blootstelling $U V$. [Integral report on affect of the ozon-layer and UV-exposure.] Bilthoven: RVM, 1993.

Rogers, R.W. (1983). Cognitive and physiological processess in fear appeals and attitude change: A revised theory of protection motivation. In J.T. Cacioppo \& P.E. Petty (eds.), Social psychophysiology: A sourcebook (pp. 153-176). New York: Guilford Press.

Rutledge, D., Hartman, W., Kinman, P., \& Winfield, A. (1988). Exploration of factors affecting mammography behaviors. Preventive Medicine, 17, 412-422.

Ruwaard, D., \& Kramers, P.G.N. (1993). Volksgezondheid Toekomst Verkenning: De gezondbeids. toestand van de Nederlandse bevolking in de periode 1950-2010 [Public health status and forecasts: The health status of the Dutch population over the period 1950-2010]. RIVM. Den Haag: SDU.

Ruwaard, D., \& Kramers, P.G.N. (1997). Volksgezondheid Toekomst Verkenning 1997: De som der delen [Public health status and forecasts: Summing up the different parts]. RIVM. Den Haag: Elsevier/De Tijdstroom.

Sallis, J.F., Haskell, W.L., Fortmann, S.P., Vranizan, K.M., Taylor, C.B., \& Solomon, D.S. (1986). Predictors of adoption and maintenance of physical activity in a community sample. Preventive Medicine, 15, 331-341.

Sallis, J.F., Hovell, M.F., Hofstetter, C.R., Faucher, P., \& Elder, J.P. (1989). A multivariate study of determinants of vigorious exercise in a community sample. Preventive Medicine, 18, 2034.

Saltzer, E.B. (1981). Cognitive moderators of the relationship between behavioural intentions and behaviour. Journal of Personality and Social Psychology, 41, 260-271.

Scaf-Klomp, W., \& Van den Heuvel W. (1990). Participatie in bevolkingsonderzoek op borstkanker: Een literatuuronderzoek [Participation in a breast cancer screening program: a review] Groningen: University of Groningen.

Schmitz, S., Garbe, C., Tebbe, B., \& Orfanus, C.E. (1994). Langwellige ultraviolette Strahlung (UVA) und Hautkrebs [UVA-radiation and skin cancer]. Hautartz, 45, 517-525. 
Schwartz, S.H., \& Tessler, R.C. (1972). A test of a model for reducing measured attitude-behavior discrepancies. Joumal of Personality and Social Pyychology, 24, 225-236.

Schwarzer, R. (ed.) (1992). Self-efficacy, thought control of action. Washington: Hemisphere Publishing Corporation.

Shannon, B., Bagby, R., Wang, M.Q., \& Trenker, L. (1990). Self-efficacy: A contributor to the explanation of eating behavior. Health Education Research, 5, 395-407.

Shapiro, S., Venet, W., Strax, P., Venet, L., \& Roeser, R. (1982). Ten- to fourteen-year effect of screening on breast cancer mortality. Journal of the National Cancer Institute, 69, 349-355.

Sheeshka, J.D., Woolcott, D.M., \& MacKinnen, N.J. (1993). Social cognitive theory as a framework to explain intentions to practice healthy eating behaviors. Journal of Applied Social Psychology, 23, 1547-1573.

Shepard, R.J. (1996). Exercise and cancer: Linkages with obesity? Critical Review of Food Science and Nutrition, 36, 321-339.

Shepard, R.J., \& Shek, P.N. (1995). Cancer, immune function, and physical activity. Canadian Journal of Applied Physiology, 20, 1-25.

Sheppard, B., Hartwick, J., \& Warshaw, P. (1988). The theory of reasoned action: A meta-analyses of past research with recommendations for modifications and future research. Joumal of Consumer Research, 15, 325-343.

Shrapnel, W.S., Calvert, G.D., Nestel, P.J., \& Trustwell, A.S. (1992). Diet and coronary heart disease. The Medical Joumal of Australia, 156, 9s-16s.

Skinner, C.S., Strecher, V.J., \& Hospers, H. (1994). Physicians' recommendations for mammography: Do tailored messages make a difference? American Journal of Public Health, 84, 43-49.

Sparks, P., Hedderly, D., \& Shepherd, R. (1991). Expectancy-value models of attitudes: A note on the relationship between theory and methodology. European Journal of Social Psychology, 21, 261-271.

SPSS Inc. (1988). SPSS-X User's guide. Chicago: SPSS Inc.

Stafleu, A., De Graaf, C., \& Van Staveren, W.A. (1991). A review of selected studies assessing social-psychological determinants of fat and cholesterol intake. Food Quality and Preference, 3, 183-200.

Stiggelbout, A.M., Van Leeuwen, F.E., \& Daleisio, O.B. (1989). Kanker, Signaleringsrapport. Rijswijk: Stuurgroep Toekomstscenario's Gezondheidszorg.

Strax, P. (1984). Mass screening for control of breast cancer. Cancer, 53, 655-670.

Surgeon General (1988). Report on Nutrition and Health. US Department of Health and Human Services. DHHS (PHS) Publication N0 88-502010.

Sutton, S., Bickler, G., Sancho-Aldridge, J., \& Saida, G. (1994). Prospective study of predictors of attendance for breast screening in inner London. Journal of Epidemiology and Community Health, 48, 65-73.

Svenoe, T., Falk, E.S., \& Henriksen, K. (1995). Irradiances and health risks associated with the use of UV lamps and sunbeds. Review of European Science and Medicine Farmacology, 17, 53-62.

Swanborn, P.G. (1995). De Fishbein/Ajzen-theorie in de kritiek [The Fishbein/Ajzen model: Some critical remarks]. Nederlands Tijdscbrift voor de Psychologie, 51, 35-43.

Swerdlow, A.J., English, J.S., MacKie, R.M., O'Dohorty, C.J., Hunter, J.A., Clark, J., \& Hole, D.J. (1988). Fluorescent lights, ultraviolet lamps, and risk of cutaneous melanoma. British Medical Joumal, 297, 647-650.

Tabar, L., Fagerberg, G., Duffy, S, et al. (1985). Reduction in mortality from breast cancer after mass screening with mammography. The Lancet, 1, 829-832.

Te Wierik, E. (1991). Moderate and excessive drinking, problem drinking and alcoholism: Definitions. In D.G. Van der Heij \& G. Schaafsma (eds.), Biomedical and social aspects of alcobol use: $A$ review of the literature (pp. 5-13). Wageningen: Pudoc.

Triandis, H.C. (1977). Interpersonal Behavior. Monterey, CA: Brooks/Cole. 
Triandis, H.C. (1980). Values, attitudes and interpersonal behavior. In H.E. Howe \& M.M. Page (eds.), Nebraska Symposium on Motivation, 1979 (Vol. 27, pp. 195-259). Lincoln: University of Nebraska press.

Tsai, S.P., Braun, W.B., \& Bernacki, E.J. (1987). Relationship of employee turnover to exercise adherence in a corporate fitness program. Journal of Occupational Medicine, 29, 572-575.

US Department of Agriculture and Health and Human Services (1990). Nutrition and your health: Dietary guidelines for Americans. Home and Garden Bulletin, 232.

US Department of Agriculture (1992). USDA's Food Guide Pyramid. Home and Garden Bulletin, 249.

US Department of Health and Human Services (1983). The bealtb consequences of smoking: Cardiovascular disease. $A$ report of the Surgeon General (DHHS publication No. 84-50204). Washington, DC: U.S. Government Printing Office.

US Department of Health and Human Services (1984). The bealth consequences of smoking: Chronic obstructive lung disease. A report of the Surgeon General (DHHS publication No. 84-50205). Washington, DC: U.S. Government Printing Office.

Valiquette, C.A.M., Valois, P., Desharnais, R., \& Godin, G. (1988). An item-analytic investigation of the Fishbein and Ajzen multiplicative scale: The problem of a simultaneous negative evaluation of belief and outcome. Psychological Reports, 63, 723-728.

Valois, P., Desharnais, R., \& Godin, G. (1993). Psychometric properties of a perceived behavioral control multiplicative scale developed according to Ajzen's theory of planned behavior. Psychological Reports, 72, 1079-1083.

Van Assema, P., Brug, J., \& Kok, G. (1996). Misconceptie van de consumptie van vet, groente en fruit [Misconception of consumption of fat, fruit and vegetables]. Maastricht: University of Limburg.

Van Assema, P., Brug, J., Kok, G., \& Brants, H. (1992). The reliability and validity of a Dutch questionnaire on fat consumption as a means to rank subjects according to individual fat intake. European Journal of Cancer Prevention, 1, 375-380.

Van Assema, P., Pieterse, M., Kok, G., Eriksen, M., \& De Vries, H. (1993). The determinants of four cancer-related risk behaviours. Health Education Research, 8, 461-472.

Van Assema, P., Steenbakkers, M., Kok, G., Eriksen, M., \& De Vries, H. (1994). Results of the Dutch community project 'Healthy Bergeyk'. Preventive Medicine, 23, 394-401.

Van de Graaf, Y., Klinkhamer, P.J.J.M., \& Vooijs, G.P. (1986). Effects of population screening for cancer of the uterine cervix in Nijmegen, the Netherlands. Preventive Medicine, 15, 582590.

Van de Graaf, Y., Vooijs, G.P., \& Zielhuis, G.A. (1988). Population screening for cervical cancer in the region of Nijmegen, the Netherlands. Gyneacolical Oncology, 30, 388-397.

Van den Brandt, P.A., Van 't Veer, P., Goldbohm, R.A., Dorant, E., Volovics, A., Hermus, R.J., \& Sturmans, F.(1993). A prospective cohort study on dietary fat and the risk of post menopausal breast cancer. Cancer Research, 53, 75-82.

Van den Putte, B. (1993). On the theory of reasoned action [dissertation]. Amsterdam, the Netherlands: University of Amsterdam.

Van den Putte, B., Saris, W., \& Hoogstraten, J. (1995). Measurement with multiple indicators and psychophysical scaling in the context of Fishbein and Ajzen's theory of reasoned action. Quality \& Quantity, 29, 207-222.

Van der Pligt, J., \& Richard, R. (1993). Changing adolescent's sexual behaviour: Perceived risk, self-efficacy and anticipated regret. Patient Education and Counseling, 23, 187-196.

Van der Sanden, G.A.C., Van Barneveld, T.A., Daleisio, O.B., \& Van Leeuwen, F.E. (1994). Kanker Signaleringsrapport 4; 1994 [Cancer registry report 4 1994]. Amsterdam: Nederlands Kanker Instituut.

Van Loveren, H. (1994). UV-effecten op het immuumsysteem [UV-effect on the immuun system]. Presentation on the UV symposium "Gezond in de zon"[Healthy in the sun], June 7, 1994. 
Bilthoven: RIVM.

Van Veen, W.A. (1992). Borstkankerscreening in het buitenland [Breast cancer screening programs outside the Netherlands]. Borstbeeld, 4, 9-15.

Velicer, W.F., DiClemente, C.C., Prochaska, J.O., \& Brandenburg, N. (1985). Decisional balance measure for assessing and prediction smoking status. Journal of Personality and Social Psychology, 48, 1279-1289.

Vernon, S., Laville, E., \& Jackson, G. (1990). Participation in breast screening programmes: A review. Social Science and Medicine, 30, 1107-1118.

Verschuur, R., \& Kemper, H.C.G. (1983). Dagelijkse lichamelijke activiteiten en risicoindicatoren voor hart- en vaatziekten [Daily physical activity and risk factors for cardiovascular disease]. Geneeskunde en Sport, 16, 128-134.

Visser, O., Coebergh, J.W.W., \& Schouten, L.J. (1996). Netherands Cancer Registry 1993: Incidence of cancer in the Netherlands. Utrecht: Comprehencive Cancer Centres.

Walter, S.D., Marret, L.D., From, L., Hertzman, C., Shannon, H.S., \& Roy, P. (1990). The association of cutaneous malignant melanoma with the use of sunbeds and sunlamps. American Journal of Epidemiology, 131, 232-243.

Wardle, J., Steptoe, A., Burckhardt, R., Vögele, C., Vila, J., \& Zarczynski, Z. (1994). Testicular self-examination: Attiudes and practices among young men in Europe. Preventive Medicine, 23, 206-210.

Wardle, J., Steptoe, A., Smith, H., Groll-Knapp, E., Koller, M., Smith, D., \& Brodziak, A. (1995). Breast self-examination: attitudes and practices among young women in Europe. European Journal of Cancer prevention, 4, 61-68.

Weinstein, N.D. (1988). The precaution adoption process. Health Psychology, 7, 355-386.

Weinstein, N.D., \& Sandman, P.M. (1992). A model of the precaution adoption process: Evidence from home radon testing. Health Psychology, 11, 170-180.

Weisburger, J.H. (1991). Nutritional approach to cancer prevention with emphasis on vitamins, antioxidants and carotenoids. American Joumal of Clinical Nutrition, 53, 226-237.

Westerdahl, J., Olsson, H., Masback, A., Ingvar, C., Jonsson, N., Brandt, L., Jonsson, P.E., \& Moller, T. (1994). Use of sunbeds or sunlamps and malignant melanoma in Southern Sweden. American Joumal of Epidemiology, 140, 691-699.

Willemsen, M.C., \& De Vries, H. (1996). Saying "no" to environmental tobacco smoke: Determinants of assertiveness among nonsmoking employees. Preventive Medicine, 25, 575 582.

Willemsen, M.C., De Vries, H., Van Breukelen, G., \& Oldenburg, B. (1996). Determinants of intention to quit smoking among Dutch employees: The influence of the social environment. Preventive Medicine, 25, 195-202.

Willet, W.C., Hunter, D.J., Stampfer, M.J., Colditz, G., Manson, J.E., Spiegelman, D., Rosner, B., Hennekens, C.H., \& Speizer, F.E. (1992). Dietary fat and fiber in relation to the risk of breast cancer. Journal of the American Medical Association, 268, 2037-2044.

Zuckerman, M., \& Reis, H. (1978). Comparison of three models for predicting altruistic behavior. Joumal of Personality and Social Psychology, 36, 498-510. 


\section{Summary}

Cancer and cardiovascular diseases (CVD) are together accountable for more than half of all mortality within the Netherlands. In recent decades, increasingly more emphasis has been placed on primary and secondary prevention of the major health diseases of cancer and CVD. There are several lifestyle health behaviors that can contribute to preventing getting cancer or CVD, or that can contribute to detecting these diseases at an earlier stage. To encourage health-related behaviors and to reduce risk-behaviors it is important to develop interventions based on empirical data on determinants of the behaviors concerned. Thus, behavioral change can be brought about by changing the behavioral determinants of the particular behavior. The main goal of this thesis was to study recent developments and possible modifications of the Attitude - Social influence - self-Efficacy (ASE) model, in order to discover the social psychological determinants of behaviors related to cancer and CVD.

Chapter 1 provides an overview of the possible lifestyle behaviors related to cancer and CVD. For primary prevention the most important lifestyle risk behaviors are smoking, lack of exercise, an unhealthy diet, a high alcohol consumption, and excessive UV-exposure; for secondary prevention they are not participating in cancer screening programs or not performing self-detecting techniques (such as, breast and testis self-examination). The first chapter shows that for some of these behaviors (exercise, nutrition, alcohol consumption and self-detecting techniques) it is difficult to distinguish between healthy and unhealthy behavior. According to the guidelines in the literature, around $40 \%$ of the Dutch adult population can be considered as physically inactive. Furthermore, about $35 \%$ of the Dutch adult population smoke, and the large majority of the adult population (more than 70\%) eat too much (saturated) fat and not enough fruit and vegetables. Moreover, around $10 \%$ of the Dutch adult population has an excessive alcohol intake, and over half of the Dutch adult population is sometimes excessively exposed to UV-radiation. With regard to secondary prevention, self-detection techniques for cancer are not practiced by many people and are not performed according to the guidelines. In addition, and participation in cancer screening programs declines with every new scree- 
ning round. This large prevalence of risk behaviors provides many challenges for health education and promotion interventions. However, for these interventions to be successful, they have to be well-planned and based on a thorough insight into the important determinants of these risk behaviors.

The second chapter reviews the literature on models that were developed to study social psychological determinants of behavior, such as the ASE model and the Theory of Planned Behavior. An overview of the different constructs of these models, such as intentions, attitudes, social influence, and self-efficacy is presented. For each construct, an overview is presented of its background, operationalization and different applications. Besides the basic constructs, potential new additions are discussed, such as the role of personal norms within the attitude construct, the inclusion of past behavior in the ASE model, the integration of the Stages of Change concept within the ASE model (the ASE-stages model), and the possible consequences of misconception of one's own behavior for the ASE model and the ASEstages model.

In the third chapter, the integrated ASE-stages model is applied as a model for explaining starting to exercise in an employee fitness program. The integrated model appears to be a valuable model for explaining participation in exercise programs. Subjects in the action stage, followed by subjects in preparation stage, are most convinced of the benefits of participation in an employee fitness program and of their own skills to exercise in problem situations. Contemplators have lower scores on these determinants than preparators but higher scores than precontemplators. Participants in the fitness program (action stage) experience the most social support from their environment to participate in the fitness program.

Chapter 4 describes an application of the integrated ASE-stages model to a longitudinal study on maintenance and dropout of exercising in an employee fitness program. The ASE determinants prove to be relevant predictors of exercise adherence and dropout. Dropouts have much lower scores on attitude and self-efficacymeasures than maintainers. Furthermore, besides assessing self-efficacy in different problem situations, another aspect of self-efficacy is operationalized by asking subjects how often they encounter problem situations in which exercising is difficult. Chapter 4 shows that this direct way of measuring self-efficacy has a unique 
contribution to the explanation of exercise adherence.

In the fifth chapter, an alternative method is tested to measure attitudes. According to the Theory of Reasoned Action, attitudes are operationalized as a multiplicative function, in which different beliefs are multiplied by the evaluation of these beliefs. The traditional multiplicative measure of attitudes has some methodological and statistical weaknesses. Chapter 5 tests whether the attitude can be assessed by adding up the different belief items to one total scale. The evaluations of the beliefs are then omitted from the attitude measure. The results show that omitting the evaluations from the attitude concept does not lead to a loss of predictive power of attitudes in the explanation of the intention. Moreover, the analyses show that the multiplicative construct of attitudes (beliefs * evaluation) correlates more with beliefs than with the evaluations. It is concluded that if possible outcomes or beliefs are clearly operationalized as either positive or negative outcomes, the evaluation concept can be omitted from the attitude concept without loosing vital information.

Chapter 6 reports on the prevalence of misconceptions in the Dutch adult population concerning their own fruit and vegetable consumption. This study reports that a large proportion of the Dutch population do not comply with the guidelines with regard to their daily fruit and vegetable intake. Furthermore, this study shows that a large proportion of the people who do not eat enough fruit and vegetables, overestimate their own fruit and vegetable consumption. This lack of awareness of their own behavior has consequences for the relation between behavior and the ASE determinants. These determinants appear to be more strongly related to the subjective estimation people make of their own fruit and vegetable intake, than to their actual fruit and vegetable intake. It is concluded that making people aware of their own consumption and of the misconceptions they have of their own behavior, should be a first intervention target, before stimulating behavioral change by use of attitude and self-efficacy information.

Chapter 7 reports on the consequences of people's misconception of their own food intake (vegetables, fruit and fat) for the application of the Stages of Change concept. Since the traditional Stages of Change concept uses the estimation of people's own behavior as a starting point, problems occur when this concept is 
applied to behaviors in which subjects do not have an accurate perception of their own actual behavior. According to the traditional stages of change, subjects are placed in the action or maintenance stage when they think they eat enough vegetables. However, some of these subjects should be placed in the precontemplation stage (subjects whose actual vegetable intake is insufficient, and who have no intention of changing their behavior). Chapter 7 uses an alternative method to classify subjects into Stages of Change, in which people's subjective estimation of their own behavior is validated with their actual behavior. Results show that the application of both Stages of Change concepts result in very different distributions of respondents over the stages of change.

Chapter 8 describes a longitudinal study on the determinants of participation in a breast cancer screening program. Besides the traditional ASE components, several additional determinants are included in the model. Within the attitude construct, besides possible perceived consequences of breast cancer screening, two new concepts are included: anticipated regret of not participating in the screening, and the moral obligation that women experience to participate in the screening. Both concepts appear to be important predictors of (intention of) future screening participation. Furthermore, the influence of participation in the previous screening program (past behavior) was studied. Results show that there is an interaction-effect between the ASE determinants and previous participation: participants of the previous screening round differ from nonparticipants on the determinants that predict their intention to participate in the next screening round. Both past behavior as well as the new attitude concepts prove to be valuable additions to the ASE model.

Chapter 9 gives the main conclusions of the different studies of this thesis, and translates these results into implications for the ASE model. Furthermore, this chapter provides suggestions for further research. 


\section{Samenvatting}

Kanker en hart- en vaatziekten zijn samen verantwoordelijk voor meer dan de helft van alle sterfgevallen in Nederland. In recente jaren is steeds duidelijker gebleken dat primaire en secundaire preventie van kanker belangrijke manieren vormen voor het voorkomen of vroegtijdig ontdekken van kanker en hart- en vaatziekten. Er zijn verschillende gedragingen die kunnen bijdragen aan het voorkomen of vroegtijdig opsporen van deze chronische ziekten. Om gezondheidsgedragingen te stimuleren en gezondheidsrisico-gedragingen te beperken is het belangrijk dat er interventies worden ontwikkeld die gebaseerd zijn op een gedegen inzicht in de determinanten van deze verschillende gedragingen, zodat via het veranderen van deze determinanten van gedrag zo mogelijk ook de gedragingen zelf kunnen veranderen. Dit proefschrift heeft tot doel deze sociaal psychologische determinanten te onderzoeken van de gedragingen die gerelateerd zijn aan kanker en hart-en vaatziekten. Hiervoor wordt gebruik gemaakt van het Attitude - Sociale invloed - eigen Effectiviteit (ASE) model. Dit proefschrift exploreert enkele toepassingen van dit model en zoekt naar mogelijke aanpassingen of uitbreidingen voor het ASE model.

Hoofdstuk 1 geeft een analyse weer van de mogelijke leefstijlgedragingen die gerelateerd zijn aan kanker en hart- en vaatziekten. De belangrijkste leefstijlgedragingen bestaan uit roken, te weinig bewegen, ongezonde voeding, te hoge alcohol consumptie en overmatige UV-blootstelling voor de primaire preventie en het niet participeren in screeningsprogramma's of het niet doen van zelf-onderzoek voor de secundaire preventie. Het eerste hoofdstuk laat zien dat het voor een deel van deze gedragingen (zoals bewegen, voeding, alcoholconsumptie en zelfonderzoek technieken) moeilijk is om precies de scheidslijn aan te brengen tussen gezond en ongezond gedrag. Wanneer we de richtlijnen uit de literatuur volgen, blijkt dat in Nederland zo'n 40\% van de volwassen bevolking als fysiek inactief kan worden beschouwd. Verder rookt ongeveer $35 \%$ van de bevolking en eet de grote meerderheid van de bevolking (meer dan $70 \%$ ) te veel (verzadigd) vet en te weinig groente en fruit. Bovendien kan zo'n $10 \%$ van de volwassen Nederlandse bevolking beschouwd worden als overmatige alcohol drinkers en zijn grote delen van de Nederlandse bevolking wel eens overmatig blootgesteld aan UV-straling. 
Met betrekking tot de secundaire preventie laat de literatuur zien dat zelfontdekkingstechnieken (zoals borst- of zaadbalzelfonderzoek) door slechts weinigen uit de doelgroep (correct) worden toegepast en dat participatie in bevolkingsonderzoeken voor vroege opsporing met iedere nieuwe ronde verder afneemt. Deze hoge prevalentie van risico-factoren onderstreept het belang van primaire en secundaire preventie en laat bovendien zien hoe belangrijk het is om inzage te krijgen in de determinanten van deze gedragingen.

Hoofdstuk 2 geeft een overzicht van de literatuur over modellen, zoals het ASE model en de theorie van beredeneerd gedrag (Theory of Planned Behavior), die tot doel hebben motivationele determinanten van gedragingen te onderzoeken. Er wordt een overzicht gegeven van de verschillende basiscomponenten van deze modellen, zoals intenties, attitudes, sociale invloed en eigen-effectiviteit. Per concept wordt een overzicht gegeven van betekenis, operationalisaties en toepassingen. Naast de basisconcepten worden mogelijke nieuwe toepassingen besproken, zoals de inclusie van morele plicht en geanticipeerde spijt binnen het attitude concept, de inclusie van eerder gedrag in het model, het integreren van het stages of change concept binnen het ASE model (het ASE-stages model), en het verwerken van misconceptie van het eigen gedrag in het ASE-stages model

In het derde hoofdstuk wordt het ASE-stages model toegepast als verklaringsmodel voor het al dan niet starten bij een bedrijfsfitness programma. Het ASE-stages model blijkt goed toepasbaar te zijn op fitnessdeelname. Respondenten die gaan starten met bedrijfsfitness zijn het meest overtuigd van de voordelen van deelname, en van hun vaardigheden om in moeilijke situaties toch te gaan sporten, gevolgd door de respondenten die in de preparatiefase zitten. De respondenten in contemplatie scoren weer lager op deze determinanten, maar weer hoger dan respondenten uit de precontemplatiefase. De deelnemers aan fitness (actiefase) ondervinden de meeste ondersteuning uit hun omgeving om deel nemen aan het firness programma.

Het vierde hoofdstuk past het ASE-stages model toe op een longitudinale studie naar het volhouden of uitvallen bij deelname aan een bedrijfsfitness programma. In dit hoofdstuk blijkt dat de ASE determinanten belangrijke verklarende variabelen vormen voor het blijvend volhouden of uitvallen bij een bedrijfsfitnessprogramma. Uitvallers scoren veel lager op de attitude- en eigen- 
effectiviteitsmetingen dan blijvende deelnemers. Dit hoofdstuk toetst bovendien de waarde van een aanvullende operationalisatie van eigen-effectiviteit, waarin aan respondenten wordt gevraagd hoe vaak men in situaties komt waarin het moeilijk is om aan het fitness programma deel te nemen. Hoofdstuk 4 laat zien dat deze tweede methode om eigen-effectiviteit te meten een relevante bijdrage levert aan de verklaring van het deelname-gedrag.

In het vijfde hoofdstuk wordt een alternatieve methode getoets voor het meten van attitudes. Volgens de theorie van beredeneerd gedrag worden attitudes geoperationaliseerd via een multiplicatieve functie, waarbij verschillende beliefs worden vermenigvuldigd met de evaluatie van deze beliefs. Aan deze multiplicatieve meting kleven enkele methodologische en statistische nadelen. In deze studie wordt daarom getoetst of de attitude niet ook gemeten kan worden door alleen de verschillende beliefs op te tellen tot een totale schaal. De evaluaties van de beliefs worden dan buiten beschouwing gelaten. De resultaten laten zien dat het weglaten van de evaluaties uit het attitude concept niet tot verlies van voorspellend vermogen van intentie leidt. Bovendien laten de analyses zien dat het multiplicatieve construct van attitudes (belief * evaluatie), vooral samenhangt met de beliefs en veel minder met de evaluaties. Er wordt geconcludeerd dat evaluaties bij de meting van de attitude weggelaten kunnen worden wanneer de beliefs als duidelijk positief, dan wel negatief worden geformuleerd.

Hoofdstuk 6 geeft inzicht in de mate waarin er bij het algemeen publiek misvattingen bestaan omtrent hun eigen consumptie van groente en fruit. De studie laat zien dat grote delen van de bevolking niet voldoen aan de richtlijnen van de dagelijkse inname van groente en fruit. Verder laat de studie zien dat een groot deel van de mensen die onvoldoende groente en fruit eten, van zichzelf denken dat ze wel een voldoende of hoge inname van groente en fruit hebben. Dit gebrek aan bewustzijn van het eigen gedrag heeft ook gevolgen voor de relatie tussen het gedrag en de ASE determinanten. Deze determinanten blijken veel sterker gerelateerd te zijn met de subjectieve inschatting die mensen maken van hun eigen groente en fruit inname, dan met hun daadwerkelijke inname van groente en fruit. Geconcludeerd wordt dat alvorens mensen door middel van attitude en eigen effectiviteit informatie tot gedragsverandering kunnen worden gestimuleerd, ze eerst bewust moeten worden gemaakt van hun eigen consumptie en van 
misvattingen omtrent hun eigen gedrag.

Hoofdstuk 7 laat zien dat de misconceptie die mensen hebben over hun eigen voedsel inname (groente, fruit en vet), grote gevolgen heeft voor de toepassing van het stages of change concept. Omdat het traditionele stages of change concept uitgaat van de inschatting die mensen maken van hun eigen gedrag, ontstaan er problemen wanneer dit concept wordt toegepast op gedragingen waarin misconceptie van gedrag veel voorkomt. Zo worden mensen die onterecht denken dat ze voldoende groente eten in de action of maintenance stage geplaatst, terwijl ze eigenlijk in de precontemplatie. fase geplaatst zouden moeten worden (zij eten onvoldoende groente en hebben geen intentie om hun gedrag te veranderen). Voor gedragingen waarin veel misconceptie voorkomt, toetst de studie een alternatief stages concept, waarin de subjectieve eigen inschatting van respondenten wordt gevalideerd aan het daadwerkelijke gedrag. Uit de resultaten blijkt dat toepassing van beide stages of change concepten resulteert in geheel andere verdelingen van respondenten over de stages of change.

Hoofdstuk 8 beschrijft een longitudinale studie naar de determinanten van deelname aan het bevolkingsonderzoek naar borstkanker. Naast de traditionele ASE concepten, worden aanvullende nieuwe determinanten meegenomen in de studie. Binnen de attitude worden er naast de mogelijke gevolgen van screening (beliefs) twee nieuwe concepten ondergebracht: geanticipeerde spijtgevoelens over niet deelnemen aan de screening, en morele plichtgevoelens die vrouwen mogelijk ervaren omtrent hun deelname aan de screening. Beide concepten blijken belangrijke determinanten te zijn van (intentie tot) herhaalde deelname. Daarnaast wordt de rol van deelname aan de vorige screeningsronde onderzocht (past behavior). Er blijkt een interactie-effect te zijn tussen de ASE determinanten en de deelname aan de vorige screeningsronde: deelnemers aan de vorige screening kennen andere determinanten van (intentie tot) deelname aan de volgende screening dan niet-deelnemers aan de vorige screening. Zowel eerder gedrag alsook de nieuwe attitude concepten blijken zinvolle aanvullingen te vormen voor het ASE model.

Het laatste Hoofdstuk 9 geeft de belangrijkste conclusies weer van de verschillende studies en vertaalt de resultaten van de verschillende studies naar gevolgen voor het ASE model. Daarnaast worden er aanbevelingen gedaan voor toekomstig onderzoek. 


\section{Acknowledgments}

During my work on this dissertation I often asked myself what were my reasons for doing this dissertation. Looking back I realize that there were many reasons. First, I was convinced that finishing this thesis would have many positive consequences for me: although the work during the thesis was sometimes quit difficult, I knew that in the long run finishing this thesis would bring me much satisfaction. Furthermore, I expected to be very sorry if I would not be able to finish the dissertation. Also, I was convinced that I was able to finish this thesis, although in some situations I had my doubts.

But most of all, I experienced a lot of positive support to finish my research. For this, I would like to thank many people: my advisors (Hein de Vries, Gerjo Kok), research assistants (Jolanda, Jascha), roommates (Marc, Ron), and my other colleagues on the Department of Health Education and Promotion. Outside of the Department, I would like to thank the Dutch Cancer Society, both for their financial support, as well as for the pleasant cooperation with Karel van Koppen and Cora Honing. Finally, I would like to thank some other organizations (MEMIC, Netherlands Heart Foundation, High Five, InterView), for their cooperation and support during my research.

Lilian Lechner,

Maastricht, 1998 


\section{Curriculum Vitae}

Lilian Lechner was born in Roermond on October 4, 1967. In 1987, she received her VWO diploma at the Rijksscholengemeenschap in Roermond. In that same year she started studying Health Sciences at the Maastricht University. In 1991, she graduated, specializing in Health Education. The first half year after graduating, she worked as a health educator at the Public Health Department in Helmond. In 1992, she started to work at the Department of Health Education and Promotion at the University of Maastricht on the evaluation of an employee fitness program. This project was financed by the Netherlands Heart Foundation. In 1993 she started as a research associate at the Department of Health Education and Promotion, on the project "Public and patient education from the Dutch Cancer Society". During this project, that was financially supported by the Dutch Cancer Society, she conducted most of the studies described in this thesis. Since January 1998 she has been working as a post-doc at the Department of Health Education and Promotion. In this function, that is financed by the Dutch Cancer Society, she does research to advice and evaluate on health education projects of the Dutch Cancer Society. 